Illinois State University

ISU ReD: Research and eData

Theses and Dissertations

$10-14-2015$

\title{
Fan the Flames of Discontent: Contemporary Labor Literature and Social Movements
}

Ericka Rae Wills

Illinois State University, willsericka@gmail.com

Follow this and additional works at: https://ir.library.illinoisstate.edu/etd

Part of the English Language and Literature Commons

\section{Recommended Citation}

Wills, Ericka Rae, "Fan the Flames of Discontent: Contemporary Labor Literature and Social Movements" (2015). Theses and Dissertations. 480.

https://ir.library.illinoisstate.edu/etd/480

This Dissertation is brought to you for free and open access by ISU ReD: Research and eData. It has been accepted for inclusion in Theses and Dissertations by an authorized administrator of ISU ReD: Research and eData. For more information, please contact ISUReD@ilstu.edu. 


\title{
FAN THE FLAMES OF DISCONTENT: CONTEMPORARY LABOR LITERATURE AND SOCIAL MOVEMENTS
}

\author{
Ericka R. Wills
}

\section{Pages}

Fan the Flames of Discontent: Contemporary Labor Literature and Social Movements balances a literary approach to textual analysis with socially grounded reflections on diverse worker organizations. Chapters analyze Leslie Marmon Silko's Almanac of the Dead, Helena Maria Viramontes's Under the Feet of Jesus, and Thomas Pynchon's Against the Day alongside worker-writers' texts and testimonies, such as Fran Leeper Buss and María Elena Lucas's Forged under the Sun / Forjada bajo el sol and The Heat: Steelworker Lives and Legends, a collection of United Steelworkers' Institute for Career Development writings. In each of five chapters, this dissertation respectively discusses how literature can enact an inclusive definition of labor, amplify effaced labor voices, popularize workers' counter-histories of labor conflict, provide an imaginative space for envisioning global social movements, and contribute to university students' and union workers' labor education. Each chapter in this dissertation grounds analyses of literary texts with discussion of parallel contemporary events and social movements. Specifically, thanatopolitical manipulations in Silko's Almanac of the Dead are analyzed alongside the ongoing biopolitical expulsion and social rebellion occurring in Cananea, 
Mexico. Viramontes's Under the Feet of Jesus and Buss and Lucas's Forged under the Sun / Forjada bajo el sol are contextualized through community-based farmworkers' organizations that combat injustice by promoting public awareness and fostering collective representation. Pynchon's narrativization of the Colorado Coalfield War in Against the Day is related to workers' and communities' living memory of the Ludlow Massacre in present-day southern Colorado. Silko's, Viramontes's, and Pynchon's literary visions of global counter-hegemonic social movements are analyzed in relation to contemporary United States labor organization and cross-border solidarity programs. Finally, considering multiple texts, including The Heat: Steelworker Lives and Legends, a collection of rank-and-file union member's create writings, this dissertation provides examples of how to use literature to further university students' and union workers' labor education.

KEYWORDS: Biopower, Labor Literature, Labor Union, Pynchon, Silko, Viramontes 
FAN THE FLAMES OF DISCONTENT: CONTEMPORARY LABOR

LITERATURE AND SOCIAL MOVEMENTS

ERICKA R. WILLS

A Dissertation Submitted in Partial

Fulfillment of the Requirements

for the Degree of

DOCTOR OF PHILOSOPHY

Department of English

ILLINOIS STATE UNIVERSITY

2015 
(C) 2015 Ericka R. Wills 
FAN THE FLAMES OF DISCONTENT: CONTEMPORARY LABOR LITERATURE AND SOCIAL MOVEMENTS

ERICKA R. WILLS

COMMITTEE MEMBERS:

Christopher Breu, Chair

Robert McLaughlin

Gina Hunter 


\section{ACKNOWLEDGMENTS}

Above all, to my grandpa, Willard LaMar Tipsord, who went to work and died too young. To Bob LaVenture, Mike Matejka, and Bob Bruno for teaching me what "one day longer" really means. And to my dissertation committee, Chris Breu, Bob McLaughlin, and Gina Hunter, for always supporting me.

E. R. W. 


\section{CONTENTS}

Page

ACKNOWLEDGMENTS $\quad$ i

CONTENTS $\quad$ ii

CHAPTER

I. INTRODUCTION: WHY FAN THE FLAMES OF DISCONTENT? 1

Blurring Boundaries 3

Cultural Studies, Working-Class Studies, American Studies, and the study of labor literature $\quad 6$

$\begin{array}{ll}\text { Experiential Elements } & 14\end{array}$

Thought and Action: Theoretical Framework and Practice 16

$\begin{array}{ll}\text { Chapter Previews } & 22\end{array}$

Chapter I Endnotes 25

II. "SQUEEZING EVERY LAST DROP OF BLOOD AND PROFIT": NEOLIBERAL BIOPOLITICS IN SILKO'S ALMANAC OF

THE DEAD

Almanac's Political Economy of Life and Death 30

"Marx had been right about a great many things:"

Vampire Capitalism and Bio-Materials, Inc. 43

Neoliberal Thanatopolitics and Biomaterial

TechnoService Complex, Inc. 45

Necro-Economics and Value of Lumpenproletariat 52

"A conjunction would occur; everywhere at once, spontaneously":

Rising Resistance Networks $\quad 58$

A Town Called "Revolutionary Cananea" $\quad 64$

$\begin{array}{ll}\text { Chapter II Endnotes } & 78\end{array}$ 
III. “MY STORY IS NOT UNIQUE": LISTENING TO FARMWOKERS' VOICES IN VIRAMONTES'S UNDER THE FEET OF JESUS AND

LUCAS'S FORGED UNDER THE SUN / FORJADA BAJO EL SOL

"Listen to my silence": What voice? Whose voice? Why voice?

"[A] woman named Star": Constructing Farmworkers' Voices

through Spanish/English Language Use

100

"This is a crime:" Narratives Recounting and Surmounting Linguistic Barriers and Institutional Marginalization

"You wetback don't understand": Collective Democratic Voice and Structural Reformation

Coalition of Immokalee Workers: "[W]orkers are demanding a voice in the industry"

Chapter III Endnotes

VI. A "MIXTURE OF NOSTALGIA AND AMNESIA": REMEMBERING THE LUDLOW MASSACRE IN PYNCHON'S AGAINST THE DAY

"Against the grain": Constructing Historical Memories

A "mixture of amnesia and nostalgia": Remembering/Forgetting Labor Conflict in Constructed Histories

"Hundreds, by now thousands, of narratives, all equally valid": An Intertextual Analysis of the Ludlow Massacre

"And if gold don't work, sooner or later they get around to lead": Versions of Violence

History In-flux: The Living Memory of Ludlow in

Contemporary Southern Colorado

201

Chapter IV Endnotes

V. REMAPPING GLOBAL LABOR SOLIDARITY: THE TRANSNATIONAL IMAGINGATION OF VIRAMONTES, PYNCHON, AND SILKO

"Militancy today is a positive, constructive, and innovative activity:" Theory for Action

"Oil was made from their bones:" Transnational and

Transtemporal Labor in Under the Feet of Jesus

"A vast unseen commonwealth:" Globalizing Struggle in Against the Day

The Geography of Counter-Hegemonic Resistance in Almanac of the Dead

The Evolution of a Global Labor Movement

A Call for U.S. Labor Law Reform

Building a Multitude through Labor Coalitions and Strategic Alliances 
Labor Organizing as a Global Social Movement 288

Chapter V Endnotes $\quad 294$

VI. TEACHING ABOUT LABOR THROUGH UNION WORKERUNIVERSITY STUDENT DIALOGUES

Considering University Students' Initial Knowledge of Labor

Topics and Perceptions of Unions

Classroom Approaches to Teaching about Labor through

Union Worker-University Student Dialogues 315

Student Writing in Preparation for Dialogues 316

Reading Workers' Stories and Participating in Written Dialogues 319

Engaging in Face-to-Face Dialogues 322

Maintaining the Union Worker-University Student Connection 327

Reflections

329

Chapter VI Endnotes $\quad 339$

$\begin{array}{ll}\text { REFERENCES } & 343\end{array}$

APPENDIX A: $\quad$ Historical Texts, Contemporary Learning:

A CHAT Approach to Labor Education 


\section{CHAPTER I}

\section{INTRODUCTION: WHY FAN THE FLAMES OF DISCONTENT?}

If the workers take a notion,

They can stop all speeding trains;

Every ship upon the ocean

They can tie with mighty chains.

Every wheel in the creation,

Every mine and every mill,

Fleets and armies of the nation,

Will at their command stand still.

- Joe Hill

Sung in collective voice at protests, while organizing, and on the picket line since the early of the twentieth century, Joe Hill's "Workers of the World, Awaken!" resounds a call for global labor justice that continues to reverberate to this day. The potential and power of global workers' movements echo in other songs included in the International Workers of the World's Little Red Songbook: To Fan the Flames of Discontent. The widely circulated booklet, first published in 1909 and released in updated editions to the present, seizes the power of artistic word, lyrics, and narrative to mobilize workers' collective agency. 
Borrowing and building on a rich tradition of using the arts in labor organizing, Fan the Flames of Discontent: Contemporary Labor Literature and Social Movements embraces the power of creative texts to support labor culture and inform responses to workers' struggles. This dissertation recognizes the role that artistic production plays in cultural formation, affirming the potential agency of texts to shape wider social consciousness. One of my central arguments in this dissertation is that literature not only catalyzes cultural and intellectual labor; it also has the potential to influence material actions and social movements by circulating inclusive definitions of labor, obscured workers' voices, effaced accounts of history, and counter-hegemonic visions of transnational organizations. Elaborating each of these functions in subsequent chapters, Fan the Flames of Discontent balances a literary approach to textual analysis with socially grounded reflections on intersecting contemporary and historical workers' movements.

This dissertation discusses three United States novels from the last 25 years which have been widely studied by scholars but are not primarily classified as labor texts: Leslie Marmon Silko's Almanac of the Dead, Thomas Pynchon's Against the Day, and Helena Maria Viramontes's Under the Feet of Jesus. When analyzing issues of labor in literature, scholarship frequently focuses on nineteenth-century Industrial Revolution texts and works from the early twentieth-century golden age of proletariat literature (i.e. Cindy Weinstein; Laura Hapke; Claudia Durst Johnson; H. Gustav Klaus). However, Silko’s, Pynchon's, and Viramontes's more recent novels are no less deserving of analysis as labor literature. Through narratives of material/immaterial production, institutionalized thanatopolitics, and global counter-hegemonic movements, these novels 
unmask dialectic labor exploitation and worker organization that characterizes current transnational capitalism. Reading these novels alongside worker-writers texts and testimonies, such as María Elena Lucas's Forged under the Sun / Forjada bajo el sol and The Heat: Steelworker Lives and Legends, a collection of United Steelworkers' Institute for Career Development writings, this dissertation offers multiple trajectories for conceptualizing, studying, and teaching labor literature.

\section{Blurring Boundaries}

Approaching Silko's, Pynchon's, and Viramontes's relatively recent novels as labor literature expands exclusive definitions that delineate this genre as emerging primarily from established union movements (Coles and Zandy). While many of my observations about contemporary workers' struggles are grounded in my own experience with unions, this dissertation conceptualizes organized labor as one component of larger social movements that advocate for more equitable distribution of wealth, respect for multiple types of labor, safe living and working conditions, an end to child and forced labor, and other issues that transcend national geospatial and political boundaries. To be effective, labor movements must be social movements, as exemplified by farmworkers' community-based coalitions and women's workplace action groups.

Therefore, to engage with multifaceted labor-centered social movements, Fan the Flames of Discontent implements an inclusive definition of labor and designation of the working-class. From this standpoint, Silko's, Pynchon's, and Viramontes's texts may be investigated as labor literature that addresses transtemporal and transspatial commonalities of existing and emerging social movements that resist the effacement of workers' labors, bodies, perspectives, voices, and agency. By not only providing literary 
scholarship, but also grounding observations in applicable social movements and offering pedagogical application in university and union settings, the form and content of this dissertation seeks to deconstruct false binaries between intellectual/physical labor, theoretical/practical approaches, and academic/popular culture. Acknowledging, as Harry Braverman asserts, "the separation of hand and brain is the most decisive single step taken in the division of labor taken by the capitalist mode of production," structural change demands looking beyond restrictive binaries that underpin capitalist economic production and social organization (87). Reading canonical literature in mining union halls, listening to Steelworkers' stories in university classrooms, and recognizing the beautifully tangled threads of historicism, cultural studies, literary analysis, social advocacy, political economy, and other strands of praxis is a powerful initiative for deconstructing the institutional and psychological binary between hand and brain.

However, one risk in composing Fan the Flames of Discontent as a transdisciplinary work, which disrupts traditional conceptions of labor, class, and literature, is that no singular approach may locate itself at the center of this process. Perhaps this occurrence is partially inherent to English Studies as a discipline that is itself an assemblage of literature, linguistics, composition, rhetoric, cultural studies, creative writing, publishing, and other specializations. To embrace the diversity of English Studies, this dissertation, to borrow Gilles Deleuze and Felix Guattari's terms, the endeavor developed rhizomatically, splitting, growing, and flowering in multiple directions with various, non-hierarchical points for diverse audiences to enter and exit the text. Deleuze and Guattari posit that a rhizome "ceaselessly establishes connections between semiotic chains, organizations of power, and circumstances relative to the arts, 
sciences, and social struggles" (A Thousand Plateaus 6). This dissertation focuses on a few of those connections between power, art, and social struggle as chapters maintain thematic interconnections of labor literature and social struggle, while individually emerging as independent nodes of inquiry engaged with particular theoretical and disciplinary traditions.

Chapters are designed to be of interest to a relatively diverse and inclusive audience, such as labor historians, union activists, border anthologists, pedagogues, worker-writers, university and labor educators, and social activists, to name a few. I believe that when each group filters their own specialization into an interpretation of the text, interesting possibilities emerge as different aspects are foregrounded. Chapters not only analyze particular literary texts but also address each of these broader questions respectively: How can narratives of inclusive class and labor distinctions inform current workers' movements? When might conceptualizing the notion of voice in a way that grinds against literary, rhetorical, and popular conceptions produce spaces of political and cultural agency for underrepresented populations? What happens when the reading of fictional texts ignites new interpretations of scholarly and first-hand accounts of labor history? How might a reading that emphasizes contemporary social movements suggest practical applications for a novel's vision of transnational social organizations? How might dialogues between university and union students shape personal perspectives and inform pedagogical practices? As each of these queries offer new ways to read this dissertation, it remains rhizomal-open to new lines of flight, growing through ruptures, and embracing multiplicities. 


\section{Cultural Studies, Working-Class Studies, American Studies, and the study of labor literature}

Almanac of the Dead, Against the Day, and Under the Feet of Jesus not only narrate labor and social injustices; they also function as a "call for action" to reform labor conditions, political economies, and other inequitable structures (Christopher and Whitson 72). In conceptualizing literature as a tool for such transformations, scholars must be aware of how this approach might run counter to certain currents in the contemporary university. According to Paul Lauder, the "American academy has become little more than a training ground for consumption...academic institutions are, in many respects, training students to be comfortable and compliant inhabitants of a selfish order. But it is still a terrain worth struggling over" (487). Scholarship that links literature and activism is part of this struggle against a conception of higher education that marginalizes the post-Enlightenment mission of the humanities as it faces attacks on legitimacy and suffers massive budget cuts. ${ }^{1}$

Moreover, by focusing on labor literature and contemporary social movements, this dissertation works against economic and institutional oversight that effaces workers in global capitalism and shifts a portion of material production processes to so-called peripheral territories less visible to privileged populations. As Michael Denning notes, for many members of ostensibly post-industrial nations, "most work remains invisible: we have all seen more different places of consumption than places of production: The Gap in the mall, not the garment sweatshop; the Honda showroom, not the auto factory; Perdue chickens in the supermarket, not the chicken processing plants" (92). Perhaps, this should not come as a surprise. As Marx recognizes, capitalism fundamentally obscures the 
means of production insofar as a commodity "actually conceals, instead of disclosing the social character of private labor, and the social relations between the individual producers" (Capital: Vol 1 324). Manufacturing and distribution processes have become virtually invisible to many Americans, as over the past few decades numerous United States production operations have shifted off-shores and out of view (Hardt and Negri, Empire 297). Under these conditions, the global nature of contemporary capitalist commodity chains conceals from individuals the transnational labor embedded in the clothing, electronics, food, and other everyday products we consume.

In overlaying textual analysis, accounts of contemporary worker movements, and pedagogical models, this dissertation's content and form advocates the continued relevance of literary studies for illuminating, understanding, envisioning, and enacting conceptual and material changes to exploitive economic and institutional structures that may be obscured in many facets of contemporary U.S. society. This aim draws on foundational inquiries in cultural, working-class, and American studies, while engaging the tensions and delineations among these fields. For instance, in addressing the cultural dimensions of the popular and scholarly effacement of labor, Denning advocates the elaboration and application of a labor theory of culture that may "take us beyond the noisy sphere of the market in the analysis of mass culture, reminding us that the apparent confrontation between cultural commodities and cultural consumers obscures the laborers in the culture industry" (94). While Denning proposes a necessary corrective to the trajectory of cultural studies scholarship, his appeal does not go far enough. Not only are aspects of cultural production important to recognize, but we must also attend to the material dimensions of labor. Too often, these material aspects-including the bodies of 
laborers, working and living conditions, and the resistance situated within this contextremain invisible in our literary scholarship, as in global capitalist culture. To more fully address the interconnected material and cultural labors represented in texts and performed by texts, it is essential for these aspects to inform a labor reading of contemporary literature.

In pursuit of this objective, Fan the Flames of Discontent offers targeted labor readings that collectively address the literary treatment of work, workers, and labor organizations as well as parallel contemporary social movements. To provide an inclusive analysis, this dissertation proceeds from a definition of labor that seeks to expand traditional modernist conceptions of work that previously acknowledged "only such labour that has a value recognized by others-labour which commands salaries or wages" (Bauman 5). For instance, Chapter 2's analysis of the neoliberal biomedical complex in Almanac of the Dead applies Bauman's “emancipation of work from market-centered calculations and the constraints they impose" in order to value paid and unpaid labor in the text (97). ${ }^{2}$ This reading rejects what Marx delineates as the division between useful proletariat workers and those he defines in The Communist Manifesto as the "dangerous class', [lumpenproletariat] the social scum, that passively rotting mass thrown off by the lowest layers of the old society" (65). Rather, as Hardt and Negri point out, waged labor represents only a portion of the labor economy and, additionally, the "poor, the unemployed, the unwaged, the homeless, and so forth... are in fact included in social production" (Multitude 129). These unrecognized workers, traditionally associated with the lumpenproletariat, "are in fact active in social production even when they do not have a waged position" (Multitude 131). This more inclusive definition of labor-which, for 
instance, incorporates bioproducers in Almanac of the Dead-allows a variety of labor to be recognized as such and analyzed within a production framework.

Expanding traditional conceptions of labor consequently problematizes divisive notions of social class. No longer can industrial, manual, intellectual, affective, and other dimensions of work be hierarchically organized by ascending wealth, prestige, or other notions that strategically divide collective class interests. Rather, more inclusive analysis demands respect for particular subgroups' material and cultural distinctiveness. Given that each of the novels is set partly in the U.S. (while also challenging national borders) they confront the restrictive stereotypes and misconceptions that perpetuate the myth that the United States is primarily middle-class. Fan the Flames of Discontent investigates literary and cultural landscapes that offer visions of more inclusive egalitarian social and economic organizations constructed around the tensions between those who own the means of production and those who do not. Micheal Zwieg's asserts:

Most people in the United States are working class: men and women, skilled and unskilled, blue-, white-, and pink-collar, in all industries and from all nationalities and races; people who have little control over the pace and content of their work, who are no one's boss, who answer to the discipline and needs of their employers on the job. They form a class because they share a relationship with another class, the capitalist class, those who exercise power by controlling the operations of the businesses that employ the working class. (99) 
Reflective of Zwieg's categorization, notions of class must be understood around loci of economic and political power that transects gender, ethnic, sexual, occupational and other identities.

John Russo and Sherry Lee Linkon explain that "new working-class studies" reflect the "common interests as well as the divisions between the most commonly imagined versions of the working class-industrial, blue-collar workers-and the workers in the 'new economy' whose work and personal lives seem, at first glance, to place them solidly in the middle class" (11). In addition, those laborers who have traditionally fallen "below" working-class positioning in hierarchical constructions-the lumpenproletariat, homeless, unemployed, or unwaged (often women and children)-must be more thoroughly accounted for in inclusive egalitarian social and economic organizations.

This dissertation recognizes that physical work and immaterial labor, as well as the hybridity of these forms, in material, intellectual, and cultural production are components in a more complex understanding of class identity and social movements. Nicholas Coles and Janet Zandy clarify, "Working-class identity is, of course, much more than a matter of one's economic position; it is also a lived experience, a set of relationships, expectations, legacies, and entitlements (or lack of them). Literature illuminates those experiences and relationships, revealing how class as a shaping force is inseparable from other markers of identity" (xx). On one hand, the literature discussed in this dissertation suggests the cultural, social, economic, and geographical diversity of workers' experiences-represented by Silko's homeless, Viramontes's farmworkers, and Pynchon's miners. On the other hand, these texts jointly illustrate the commonality of capitalist exploitation that unites manufacturing, agricultural, mining, and other 
production industries with work that exists beyond the parameters of wage-earning employment and includes, for instance, the physical, intellectual, emotional, and biological labors of so-called unemployed individuals like housewives, children, or the homeless.

The texts in this dissertation bring into focus the hidden worlds of work-material, immaterial, or hybrid-effaced by historical mechanisms of capitalism as well as modern technologies of neoliberal globalization. While chapters focus on novels by U.S. authors, this should not suggest an unmediated reproduction of prior U.S.-centric approaches to American studies. Rather, this dissertation explores the ways that particular U.S. authors disrupt hierarchical categorizations of social, production, and geopolitical spaces by transcending boundaries, providing counter-hegemonic narratives, and privileging underrepresented voices that may dislodge the U.S. as a central, exceptional point of reference. For instance, Chapter 5 analyzes Silko’s Hundred Years Map as a visual representation of de-centered, subaltern transnational power relations. At the heart of this approach lies the concept of long-emerging, uneven processes of globalization, as articulated in Immanuel Wallerstein's global systems theory and more geographically localized in Anibal Quijano and Immanuel Wallerstein's elaboration of Americanity as a geo-social, imperial concept that merges hierarchical notions of power, ethnicity, and, arguably, labor. Quijano and Wallerstein elaborate that as an inclusive concept encompassing not only the United States but the greater Western Hemisphere, Americanity delineated the "social boundaries corresponding to the division of labour. And it justified multiple forms of labor control, invented as part of Americanity: slavery for the Black Africans, various forms of coerced cash-crop (repartimiento, mita, peonage) for the Native Americans, 
indentured labor (engagés) for the European working class” (550-51). Slavery, coerced labor, and indentured work linger as residual reminders of Americanity. Chapter 3 approaches the plight of farmworkers in Viramontes's Under the Feet of Jesus as one indication of Americanity's persistent "labor control" that correlates "social boundaries corresponding to the [hegemonic] division of labor." Specifically, this chapter notes how ethnicity, nationality, employment sector, language proficiency, and documentation status contributes to the marginalization of many Latino farmworkers' linguistic and democratic voices in the broader U.S. public sphere.

Recognizing, on one hand, the marginalization of particular populations within nation-states and, on the other hand, center-less social and economic organizations that transcend sovereignty demands reconsidering problematic binary terms such as first world/third world counties, core/peripheral nations, or the Global North/Global South. Fan the Flames of Discontent illustrates zones of development where these hierarchical spaces exist within and against traditionally defined national-state boundaries. Identifying uneven development characterized by vast economic and material inequity within nationstates, as well as similarities between social struggles and working or living conditions that transcend geo-political boundaries, might allow for the elaboration of commonalities between seemingly disparate populations similarly affected by global capitalist power relations.

As Michael Hardt and Antonio Negri recognize, "One of the most powerful operations of the modern imperialist power structures was to drive wedges among the masses of the globe... Segments of the proletariat in the dominant countries were even led to believe that their interests were tied exclusively to their national identity and 
imperial destiny" (Empire 42). This dissertation explores how literary narratives, such as Pynchon's Against the Day and Silko's Almanac of the Dead, envision global networks that connect diverse local populations who are working towards similar goals of social empowerment and economic justice. Specifically, Hardt and Negri believe that in order for workers to be successful in changing the condition of labor, they needed to unite beyond national boundaries, as Pynchon's and Silko's texts illustrate. To (re)establish conceptions of commonality between workers, Hardt and Negri assert, "International solidarity had to be recognized not as an act of charity or altruism for the good of others, a noble sacrifice for another national working class, but rather as proper to and inseparable from each national proletariat's own desire and struggle for liberation" (Empire 49-50). As the struggle to organize international workers continues, literature provides a fictional space for imagining, defining, elaborating, and communicating different visions of labor solidarity that might move beyond national allegiances and rearticulate global space for counter-hegemonic empowerment.

Grounded in the material underpinnings of labor, Silko's, Viramontes's, and Pynchon's novels employ what Coles and Zandy identify as "a common language of the body at work, showing how workers face occupational hazards and physical risks that mark the body and the text...Through its focus on physical labor, this writing presents worlds of work that are usually hidden or not deemed appropriate subjects from literary expression" (xxii). The thanatopolitics Silko exposes in transnational biomaterials markets, the abuse of child labor Viramontes details in the fields, and the exploitation of workers for unfettered capitalist wealth Pynchon critiques in the coalfields each expose laborers' bodies as marked and marred by a system in which they are simultaneously 
essential for production and dispossessed from accumulation. However, these texts, like historical and contemporary workers themselves, seek to alter these uneven contours of power.

\section{Experiential Elements}

"Seen as a body of work, working-class literature documents the rift between America's inclusive promise and its exclusionary (for some) historical reality without losing sight of repair and redemption," assert Coles and Zandy (xxi). Such literature not only illustrates "occupational hazards and physical risks," but also serves as a mode of resistance through which "voices emerge despite efforts to silence them through strikebreaking, militias, red-baiting, corporate dominance, and political unwillingness to name the class" (xxii). Shaped by this and other factors such as ethnicity, language, and gender, this dissertation concentrates on what José David Saldivar calls "the small voices of those positioned within a 'subordinated particularity' and in the difficulty in representing...the subaltern in our discourses (academic, literary, and testimonial)" (Trans-Americanity xviii). It is an academically perilous venture that must be mindful of group's identity politics, theoretical notions of voice, and other contested scholarly terrain. Yet, this dissertation advocates exploring, in Salvidar's terms, how the "unspeakable" vision "might be meaningfully communicated" (Trans-Americanity xix). This ambition links scholarship and activism which George Lipsitz notes "compels us to think of American studies not just in terms of academic inquiry and arguments, but also in terms of social movements, spaces, and institutions" (443).

In the subtext of the following chapters unfolds my journey as a labor activist. This dissertation began, as many do, in the library, at my office, and in my graduate 
school courses. Over time the project was shaped by the classes that I taught in university and union settings, and in those spaces the connections between scholarship and contemporary lived experiences became undeniable. It felt increasingly irresponsible to dissociate my intellectual work from the underlying material conditions and social movements that inform it. When I set out to do archival research and scholarly interviews at the Ludlow Memorial and in Pueblo, Colorado, I never expected to end up inside an EVRAZ steel mill days after a workplace fatality, nor could I image how that experience would so profoundly shape the course of this project. As I walked through the steel mill, the thermometer in the seamless pipe building hit 130 degrees. Workers in the mill pointed out sites of near-death encounters along the line and showed scars as if they were documents of provenance.

As I talked with workers across North America, I increasingly understood that the literature I was studying both reflected a version of their lived experience and engaged with the foundational economic, social, and political systems that shape their daily lives. Over the next three years I met with paper workers in the Northwest, negotiated wages, benefits, and working conditions alongside miners in the Southwest, joined global female workers for International Women's Day in the Northeast, and marched with farmworkers on a 200-mile trek across the Southeast. When county sheriffs detained the farmworker marchers for hours along the roadside, with men, women, the elderly, and children (including my own) waiting in the Florida sun, I perceived at least a glimpse of the ongoing struggle for worker rights and social equality. I followed that vision to contract negotiations between Grupo Mexico/ASARCO and United Steelworkers-represented miners in Arizona and further south to sites of the company and Mexican Federales' 
armed strike-breaking in Cananea, Mexico. Through these travels, I couldn't help but think about the concepts of voice, equality, and justice not only as contested terrain in the intellectual tradition of the university but also as grounded struggle in the lived experience of working people.

It is a challenge to briefly articulate how deeply this work has affected me. I have come to recognize that working with the labor movement is a way of life. To adopt Bob Bruno's concept from Justified by Work, it is an unexpected calling. I have had to develop confidence in myself and my work in order to boldly face the ongoing struggles of social movements in classrooms and in communities. I find strength in recognizing that I am the female legacy of generations of male family members who believed in the power of collective action. Collective representation, safe working conditions, workers' compensation, and workplace democracy are not merely abstract rights to me. Rather, they are life-and-death realities embodied in the scars, burns, damaged hearing, partial vision, missing fingers, and worn-out joints of those who gather around my table at family dinners. Then there are those who will never again join the family celebrations, such as my grandfather who died of asbestosis/mesothelioma resulting from his work at United Asbestos and Rubber Company. Unfortunately, my story is not unique.

\section{Thought and Action: Theoretical Framework and Practice}

In 2013, twelve people a day left for work in the United States and never came home (OSHA). When you take into account the fatalities from occupational diseases one hundred and fifty people die everyday from hazardous working conditions (AFL-CIO, Death on the Job 1,5). The number of global workplace fatalities may be exponentially higher. These deaths are often preventable and rarely memorialized. Most occur in 
manual labor professions and suggest the persistent material underpinnings of a neoliberal global society that extracts maximum profit from not only ostensibly immaterial human capital, but also workers' physical bodies and potential labor power. Academic scholarship's privileging of immaterial production, as reinforced by postmodernism's emphasis on the virtual, simulacrum, and signification, too often effaces the persistent material grounding and consequences of contemporary global capitalism. Materiality is relatively evident in the manual labor and physical commodities of industrial, agricultural, and mining processes, which continue to be foundational to the economic stability of ostensibly post-industrial nations. However, forms of materiality also persist in biological and affective labors, such as biomedical production or caring for others, which are traditionally associated with women, children, and other historically marginalized populations. Even forms of electronic production existing in virtual space are ultimately tied to industrial, agricultural, mining, and other material production processes, just as global neoliberal capitalism is still tethered to the foundations of primitive accumulation, or, as David Harvey terms it, accumulation by dispossession. In other words, higher prestige jobs in finance, technology, or other sites of immaterial production located primarily in privileged zones of development are dependent upon the material labors of exploited bodies in less-privileged and more obscured zones of the globe. For instance, Silko illustrates how the innovative research and practice of transplant medicine in Almanac of the Dead is predicated on the lethal exploitation of biological products from dispossessed populations. The speculative capitalists' investments in Pynchon's Against the Day ultimately depend upon the infrastructure of mining, smelting, transportation, and construction that allows for rising office buildings, 
sprawling railroads, and stockpiles of military equipment. In one of the most vivid scenes in Viramontes's Under the Feet of Jesus, a child farmworker, Estrella, realizes that her often unwaged manual labor in fruit and vegetable fields (not to mention her affective labors in the home) provides the basic material substance for life to exist. Estrella symbolically "remembered the tar pits. Energy money, the fossilized bones of energy matter. How bones made oil and oil made gasoline. The oil was made from their bones, and it was their bones that kept the nurses car from not halting on some highway, kept her on her way to Daisyfield to pick up her boys at six... Their bones. Why couldn't the nurse see that?" (148).

Through long processes of globalization that play out both regionally as in Quijano and Wallerstein's Americanity, and locally in structures of power have evolved to extract increased human capital from bodies while obscuring the labor process, why can't we see the oil is made from bones? In Michel Foucault's work on prisons, schools, and hospitals, he exposes how the exercise of biopower inextricably links material bodies to institutional and political spaces by regulating human life through not only corporal and disciplinary manipulation of the individual but also more efficient classification and regulation of populations. Drawing on Foucault's concept of biopower, Roberto Esposito, Giorgio Agamben, and Achille Mbembe illustrate that biopolitical control over life ultimately rests on thanatopolitical or necropolitical control over who may live and who must die. These theorists posit that contemporary neoliberal global capitalism acts not only through the inclusive regulation of physical and political bodies in populations, but also through particular groups' selective exclusion purportedly for the health and welfare of society. Thus, the nation may be, in Benedict Anderson's terms, an imagined 
community, but it is one in which labor, violence, and other material processes underpin the logic of in/exclusion by which such communities are maintained.

Silko’s, Viramontes's, and Pynchon's texts illustrate how notions of labor control delineated by race, ethnicity, and nationality rest on the concept of biopolitically regulated in/exclusion. A liberal democracy strives for individual voice with collective cohesion; yet, in pursuit of this unity, certain populations are strategically marginalized or excluded from full participation in the nation state, such as Viramontes's migrant farmworkers, Pychon's stateless anarchists, or Silko's transient homeless. Under the logic of thanatopolitics, these populations are excluded from safeguards that protect the larger society. In concrete terms, Viramontes' farmworkers are segregated from specific federal minimum wage and child labor laws; Pynchon's miners' struggle for collective representation and enforced workplace safety standards; and Silko's homeless are effaced by impoverished, transient living conditions and unwaged biological labor. Such institutionalized exclusivity creates what Agamben terms a "state of exception" in which the sovereign sphere suspends its laws in order to act in disregard to what is legally acceptable within the disciplinary structure (27-8). This obscured existence not only marginalizes undocumented farmworkers in Viramontes's novel but also nation-state citizens in Pynchon's and Silko's texts, all of whom are sacrificed to symbolic, institutional, structural and corporeal violence that mar the body and mute the voice.

Recognizing the persistent materiality of a fundamental corporality that eludes dematerialization can not only help illustrate how biopolitical control functions; this focus can also expose passive and active sites of resistance. Material limits to natural resources and laboring bodies shape the future of global capitalism. While economic 
restructuring and technological advances characterize privileged zones of development, immaterial production never completely incorporates or displaces the material processes on which it ultimately rests. Recognizing such occurrences, this dissertation posits an articulation of biopolitics that maintains a portion of the material and corporal that can never be subsumed under governmentality. Turning Foucault on his head, Esposito, Agamben and Mbembe illustrated that we live in an era where life is not only productively managed by forms of economic and political control that work through disciplinary and corporal manipulations of populations, but society is also destructively undercut by the systematic sacrifice of particular groups. The "inclusive exclusion" of sacrificed populations suggests sites of vulnerability where a system depends upon the very groups in seeks to exclude. Recognizing that individuals and populations must not be conceptualized as passive sites of inscription, this dissertation explores how contemporary neoliberal biopolitics' dependence upon inclusively excluded populations gives these groups the potential to exert significant bottom-up influence over the system.

Silko's, Viramontes's, and Pynchon's texts illustrate visions for more egalitarian social and political arrangements that emerge not by the obliteration of existing power structures but through the counter-hegemonic appropriation and rearticulation of these systems. This method functions by subverting what Deleuze and Guattari identify as the de- and re-territorializing logic of capitalism, whereby the process of deterritorialization undoes previously existing power structures and reterritorialization introduces new power structures (Anti-Oedipus 257). Instead of being erased, the previous power structure is overcoded $^{3}$ by a new logic: "The old inscription remains, but is bricked" (Anti-Oedipus 196). To borrow Laura Shackelford's terms, modes of resistance may write in reverse the 
logic of global capitalism, "[s]ubjecting global capitalist networks to its own networking logic" (par. 3). Hardt and Negri recognize that this process signifies a positive contribution by what they term contemporary capitalist Empire: "[W]e insist on asserting that the construction of Empire is a step forward...today we can see that Empire does away with the cruel regimes of modern power and also increases the potential for liberation" (Empire 43-4). While capitalist neoliberal globalization has opened new unfettered and exploitive transnational consumptive and production markets, the global channels established by Empire also hold the radical potential for rearticulation as routes by which transnational labor populations can mobilize for resistance.

Such counter-hegemonic rearticulations of power structures are illustrated by Almanac of the Dead's revolutionaries who subvert black market biomaterials trade routes between Tucson, Mexico and South America to smuggle arms for resistance. Under the Feet of Jesus offers a vision of labor empowerment seen through the eyes of a young girl who recognizes that the health and welfare of a society depends upon the labor she provides. Against the Day presents global anarchist groups who circulate in the transnational space of global capital with relative disregard to national boundaries. Each of these instances suggests ways in which characters are not only acted upon by systems of power but also resist and rearticulate these structures.

While these examples are drawn from literary texts, in an increasingly socially and economically disparate globalized society, realizations of how biopolitics may be rearticulated as a productive force are neither purely fictional nor academic arguments. As George Lipsitz recognizes: 
Scholars who work through social movement institutions as well as academic institutions, who refuse to separate social identities into mutually exclusive realms, who understand the always international dimensions of U.S. culture and the connections linking low-wage labor and racialization to sexism and citizenship, and who embrace the ways in which new eras demand both new forms of cultural expression and new methods of cultural criticism, will be prepared for the demands of the future in a way that does honor to our past without getting trapped by its contradictions and shortcomings (458).

In the chapters that follow, literary analysis, discussions of contemporary social movements, personal observations, and classroom praxis offer multiple points of entry into discussions on the production of a more equitable global society.

\section{Chapter Previews}

Chapter 2 explores how literature can enact an inclusive definition of labor that emphasizes the connections between biological, manual, intellectual, affective, and other types of work. Reading Leslie Marmon Silko's Almanac of the Dead as a novel that exposes uneven biopolitical manipulations of certain bodies and populations, this chapter illustrates how diverse types of labor are commonly linked through shared exploitation. As Almanac counters markets of abuse with networks of resistance, this chapter concludes by considering the contemporary biopolitical expulsion and social rebellion occurring in Cananea, Mexico. 
Chapter 3 considers how literature may amplify effaced labor voices, experiences, and struggles. This chapter reads considers Helena Maria Viramontes's novel Under the Feet of Jesus alongside María Elena Lucas's worker testimony Forged under the Sun / Forjada bajo el sol as a method for grounding fictionalized narratives in concrete historical and cultural contexts. As these texts detail the effacement of farmworkers' linguistic voices and subjugation of their democratic voices, it becomes clear these occurrences link to widespread labor exploitation and systematic institutional exclusion. Therefore, this chapter concludes by considering how farmworkers' labor organizations, such as Coalition of Immokalee Workers, combat injustice by promoting public awareness and fostering collective representation.

Chapter 4 illustrates how literature can popularize workers' counter-histories of labor conflict. Thomas Pynchon's Against the Day offers depictions of the Colorado Coalfield War and Ludlow Massacre from workers' perspectives, emphasizing the persistent struggle between capital and labor. Because violence against workers and labor resistance movements is not a historical anomaly resulting from exceptional circumstances but, rather, is symptomatic of the uneven distribution of power and resulting counter-hegemonic movements that continue in contemporary transnational capitalism, this chapter concludes by looking at the living memory of the Ludlow Massacre in present-day southern Colorado.

Chapter 5 demonstrates how literature can provide an imaginative space for creating and manipulating organizations of power that transcend nation-state boundaries and engage current global capitalism on transnational levels. After looking at the interconnected images of transnational solidarity in Silko's, Viramontes's, and Pynchon's 
novels, this chapter concludes by discussing how these visions might inform global labor movements.

Chapter 6 offers a pedagogical model for facilitating union worker-university student dialogues on labor issues. Taking students' opinions about organized labor into consideration when designing university classroom activities and approaches, this chapter overviews how a dialoguing process was developed to encourage university and union participants to articulate their viewpoints, engage in reciprocal written and verbal exchanges, and reflect on others' perceptions in order to enhance their own labor perspectives.

While Chapter 6 focuses primarily on praxis in the university classroom, the appendix that follows the chapter offers labor educators a short, corresponding example of cultural-historical activity theory (CHAT) in a union education setting. As this dissertation balances academic scholarship and contemporary on-the-ground practice in each of its first four chapters on labor literature, the final chapter and appendix of this dissertation also offer both university and union approaches to pedagogy. 


\section{Chapter I Endnotes}

1. "The academia we know or thought we knew or imagined, the academia grounded in the liberal arts and professional autonomy, is already at an end through the mechanisms of capitalist power as represented for us by the modern, transnational corporation," asserts Eric Cheyfitz: "[U]nless we change the corporate dynamic of America to one of redistribution of all kinds of capital, we cannot change the institutional arrangements of the university, which is, after all, no more than a corporation among corporations, albeit one that contains a certain kind of countercorporation discourse" $(534,524)$.

2. Braverman's critique of categories of "productive" and "unproductive" labor also provides an important corrective to both traditional capitalist and Marxist concepts of value.

3. Deleuze and Guattari define overcoding as "the operation that constitutes the essence of the State, and that measures both its continuity and its break with the previous formations" (Anti-Oedipus 199). 


\section{CHAPTER II}

\section{“SQUEEZING EVERY LAST DROP OF BLOOD AND PROFIT”: NEOLIBERAL BIOPOLITICS IN SILKO'S ALMANAC OF THE DEAD ${ }^{1}$}

In 1906, Mexican miners at a large copper mine in Cananea, Sonora, began a battle for equal rights, self-determination, and dignity that continues to this day. Over 5,000 Mexican miners and their families demanded that the mining operation, owned by United States "Colonel” William Cornell Greene, pay Mexican miners the same wages as Anglo workers, enforce an eight-hour work day, ban child labor, base promotions on merit, maintain safe working conditions, and fulfill other requirements. ${ }^{23}$ When Mexican miners, their families, and allies marched for these rights, U.S. management and employees viciously quelled what they considered a political uprising. According to a 1906 New York Times article, Greene characterized the conflict as "[t]rouble incited by Socialist organization [sic] that has been formed here by malcontents opposed to Diaz Government" (“Armed Americans at Greene's Mine”). ${ }^{4}$ In the chaos that ensued, not only were Mexican troops called in to suppress the labor dispute, but also United States militia from Arizona crossed into the sovereign nation to protect U.S. corporate interests abroad.

Situated predominantly in the geographic and symbolic borderland of northern Mexico and the southwestern United States, Leslie Marmon Silko's novel Almanac of the Dead depicts a long history of passages, invasions, exploitation, and resistance in this region. Along with representing the historically foreign-owned mines in Sonora, Mexico, 
Almanac also portrays the incursion of uranium mining on sacred tribal lands in the United States, suggesting how forces of corporate greed, governmental corruption, and ecological degradation similarly shape political economies, environments, and daily lives on both sides of the border. To counter these images of exploitation, Almanac offers histories of grassroots opposition movements situated within mine tunnels used for arms storage outside of Tucson, Yaqui uprisings in Sonora, labor strikes in northern Arizona copper mines, and other points that have the potential to converge into transnational revolution. Almanac emphasizes that the historical development of the border region exemplifies not only a trajectory of foreign appropriation of Native lands, private accumulation by dispossession, and physical or wage enslavement but also progressive social movements, organized labor resistance, and strategic counter-hegemonic alliances. Like the lines of flight radiating from Tucson's off-centered hub on Almanac's Five Hundred Year Map, this region is shaped by the transnational movements and sitespecific consequences of foreign investment, population migration, and resistance networks that are both ancient and contemporary. ${ }^{5}$ For Silko, each conflict is part of a longer history of struggle extending from European invasion of the Americans into a potentially different, more egalitarian future.

The precedence for such change is deeply rooted in the transnational border region, where shifting geopolitical boundaries (the Treaty of Guadalupe Hidalgo and the Gadsden Purchase) and cyclical migrations (ancient Toltec, traditional Yaqui, contemporary farmworkers, and others) alter political, economic, and social climates. ${ }^{6}$ Located only 25 miles south of the U.S./Mexico border, Cananea exemplifies these sitespecific transformations. In 1906, workers in Cananea did not immediately achieve the 
changes they demanded; however, their actions triggered wide-spread social unrest and rebellion that culminated in the Mexican Revolution of 1910. Commonly referred to as the spark that started the Revolution, the Cananea labor dispute inspired collective resistance that eventually led to the miners' original demands for enforced maximum hours, equal pay, safe working conditions, and other labor rights as guaranteed for all workers-not just the miners-in the new Mexican Constitution of 1917.

As Silko illustrates in Almanac, struggles against global business, worker exploitation, ethnic persecution, ecological disaster, and population displacement are part of a continuing, interconnected fight in which people "must reckon with the past because within it lay seeds of the present and future. They must reckon with the past because within it lay this present moment and also the future moment" (Almanac 311). Today, the battle for fundamental rights and dignity again rages in Cananea. The dispute is historically familiar, as thousands of miners, families, and members of surrounding communities have again gathered to demand social change and corporate responsibility in the face of multinational mining conglomerate Grupo México’s labor, environmental, and, ostensibly, human rights violations. However, the political and economic terrain has shifted over the last century, intensifying the scope and degree of labor exploitation and specific populations' exclusion from basic protections. Napoleón Gómez Urruta, President and General Secretary of the National Union of Mine, Metal, and Steel Workers (colloquially referred to as Los Mineros), details this situation in his 2013 book Collapse of Dignity: The Story of a Mining Tragedy and the Fight Against Greed and Corruption in Mexico: 
The situation that we miners experienced in recent years has not just been another attack against a group of workers; it has been an all-out war against free and democratic trade unionism of the people, an assault without precedent in our country...The brutality with which these attacks against Mexican miners and steel workers was orchestrated reflects how unbridled capitalism works against the fundamental rights of workers and the most neglected social classes. Above all, it is clear that exploitative systems have no principles, no ethics of any kind, not even the vision to realize that when the situation reverses in favor of the neglected and the oppressed, the reaction is much more violent. (151)

It is within this context-where the historical expansion and intensification of human, economic, and environmental exploitation is met by escalating opposition movements-that this chapter explores two contrasting images in Silko's Alamance of the Dead. Primarily, this chapter investigates the multifaceted modes by which neoliberal biopolitics shapes Silko's novel and contemporary workers' lived experiences. This chapter dissects Almanac's Bio-Materials, Inc.-an international blood, organ, and tissue conglomerate-as a quintessential image of contemporary biopolitics' unfettered capitalist exploitation of workers and homicidal maximization of profit. As Silko's Bio-Materials, Inc. is predicated on the global market for innovative techno-scientific procedures that literally divide and reify the bioproducer's body, the corporation exemplifies political economies and private capitalists' interdependent exercise of biopower. However, increased governmental and corporate intervention in particular populations, institutions, 
and individual bodies does not occur without conflict. Mindful of how Almanac consistently counters markets of exploitation with networks of resistance, this chapter secondarily analyzes the Army of the Homeless's opposition to Bio-Materials, Inc. as one node in a larger counter-hegemonic revolution. Finally, this chapter ties these literary images to the real-life biopolitical expulsion and social rebellion occurring today in Cananea, Mexico.

This type of labor reading is an active process of constructing meaning. Such a reading can facilitate an inclusive definition of labor that accentuates the connections between biological, manual, intellectual, affective, and other types of work. It is a notion of labor that recognizes not only the abuses against individual workers but also the extending repercussions that labor exploitation has on families, communities, and entire populations and environments that are sacrificed for increased capitalist accumulation. By recognizing that diverse modes of work are underpinned by common materiality, (ultimately resting on the connected labors of the mind and body) and linked through a global political economy, transnational markets of exploitation can be rearticulated as worldwide networks of resistance. As such, conflict is central to an inclusive conception of work in which the balance of capital/labor power relations continually depends upon the proliferation of social movements that oppose the growth of unfettered, exploitive, and noxious economic and political systems.

\section{Almanac's Political Economy of Life and Death}

Almanac is a history of power: a journey through Native cultures, conquests and slaughter, colonization, corporal sovereignty, the disciplinary state, wage enslavement, and privatized biopower-with aspects of each fluid phase persisting in what follows. 
Silko’s Bio-Materials, Inc. demonstrates contemporary power structures that are individualizing (targeting the unique organs of a specific human body) and massifying (exploiting undifferentiated members of particular populations). Yet within this model of global neoliberal biopolitics, the logic of colonial racism and sovereign violence endures and evolves. Bio-Materials, Inc. preys not only on the local homeless populations near its headquarters in Tucson, Arizona, but also expands nationally and internationally targeting striking U.S. mine workers, victims of political unrest in Mexico, and, more generally, the globally expelled, marginalized, poor, and victimized. In its exploitive pursuit for maximum profit, Bio-Materials, Inc. provides a fictionalized archetype of reallife modes of contemporary neoliberal corporatism that structure local workplaces, global markets, transnational migrations, geopolitical conflicts, and infinite sites of our emerging history.

To understand how Bio-Materials, Inc.'s homicidal maximization of profit aligns with the persistently corporal, stratifying, and violent logic of global neoliberal biopolitics, we must first explore what Foucault might term a brief genealogy of this concept. Such an analysis must emphasize the functional symbiosis of tightly intertwined contemporary politics and economics; as Hardt and Negri point out, in "Empire and its regime of biopower, economic production and political constitution tend increasingly to coincide" (Empire 41). Recognizing the inequality, exploitation, and, ultimately, death that result from this particular political and economic convergence, we may find, in terms that will become increasingly relevant, this genealogy more analogous to a social biopsy.

Giorgio Agamben points out that along with other shifts in the late $18^{\text {th }}$ and early $19^{\text {th }}$ centuries, the "triumph of capitalism would not have been possible... without the 
disciplinary control achieved by the new bio-power, which, through a series of appropriate technologies, so to speak created the 'docile bodies' that it needed" (3). To create the docile workforce necessary for capitalism's expansion, Foucault identifies that "disciplines of the body and the regulations of the population constituted the two poles around which the organizations of power over life was deployed" (History of Sexuality 139). The first of these processes, the "anatomo-politics of the human body," was intimately intertwined with the emergence and growth of industrial capitalism, which conceptualized the worker-as-machine, able to achieve mechanical precision of gesture and maximum speed through increased conditioning and obedience. The second, complimentary technique of biopower involved the "species body, the body imbued with the mechanics of life and serving as the basis of the biological processes: propagation, births and mortality, the level of health, life expectancy and longevity" (History of Sexuality 139).

To create docile laboring bodies and manage populations of workers, politics took as its task the administration of life. This emerging biopolitics functioned as a normative, institutional, and legislative power that controlled and manipulated specific populations' mobility, birthrate, health, education, and mortality through calculated interventions on the body, home, family, sexuality, workplace, and other sites. For instance, throughout the $18^{\text {th }}$ and $19^{\text {th }}$ centuries, aspects of life previously existing in the home-space, such as hygiene or exercise, became reconceptualized as medical problems that biopolitics "integrated into the social space in its entirety" (Foucault, Birth of the Clinic 20). To deal with illness meant not just treating the individual, but understanding sickness and death on the level of population management in order to avoid illness that "shortened the 
working week, wasted energy, and cost money, both because they led to a fall in production and because treating them was expensive" (Foucault, Society Must be Defended 244). Understood as threats to capitalist production and economic stability, natural processes such as health and disease became political concerns.

To elaborate the economic underpinnings of biopolitics, Paulo Virno explains, "[B]io-politics can be traced back, without hesitation, to the mode of being of the laborpower. The practical importance taken on by potential as potential (the fact that it is bought and sold as such), as well as its inseparability from the immediate corporal existence of the worker, is the real foundation of bio-politics" (271-72). ${ }^{7}$ Understood in this way, at the core of biopolitics is a recognition of and investment in persistent materiality-a realization that before labor-power is reified as a commodity, it is embodied and subject to biological, environmental, and social conditions. By manipulating these conditions through, for instance, "segregation and social hierarchization" to guarantee the “domination and effects of hegemony," modern biopower and biopolitics structures a set of relations that produces and reproduces the docile worker (Foucault, History of Sexuality 141). In such a stratified biopolitical society, the worker is conceptualized not merely as providing the managed labor power necessary for capitalist accumulation but also maintaining the undisputed obedience natural to and necessary for the greater health and safety of the entire population. Thus, biopolitics strives to create docile, predictable workers over whom the exercise of power is not limited to actions in the workplace but normalized into every aspect of life.

Silko illuminates the dark social and economic underside of a medicalized biopolitical society that functions, in Esposito's terms, with an “absolute implication 
between biology and right" (Immunitas 138). In Almanac, Serlo, an advocate of eugenics, creates an economic market for disposing of unwanted populations by infecting them with particular diseases: "Hepatitis B was a disease of the poor, the nonwhite, the addicted, and the homosexual, but hepatitis B was curable. HIV had no cure. Members of the research team bragged that they had created the first 'designer virus' specifically for targeted groups. The filthy would die. The clean would live" (548). Almanac's corporate and military leaders, such as Menardo and General J, mirror this pathologization of socioeconomic, sexual, and ethnic groups. Because Menardo and General J viewed Indians as neither docile nor obedient workers who threaten economic and social stability: "Indians however were the worst workers-slow, sloppy, and destructive of tools and machinery. Indians were a waste of time and money. No refugee camps for them-the best policy was quick annihilation on the spot, far, far from satellite TV cameras" (495). When specific populations are understood as putting the rest of society at risk or lacking appropriate labor-power potential, Serlo, Menardo, and General J believe those groups are best eliminated for the greater good. Through such characters, Almanac illustrates how Esposito's “absolute implication between biology and right" is tempered by Hannah Arendt's realization that "crimes against human rights, which have become a specialty of totalitarian regimes, can always be justified by the pretext that right is equivalent to being good or useful for the whole in distinction to its parts" ("The Perplexities of the Rights of Man” 91). In other words, as human life is integrated into the core of politics, and, viseversa, politics into the management of biological life, those bodies deemed unproductive, useful, or dangerous to the dominant political economy are at risk of elimination. 
Drawing on Arendt's work, Roberto Esposito's immunity paradigm more fully elaborates the biological basis for population management tactics that target particular bodies' health, reproduction, and death. Esposito explains how the relationship between politics and life depends upon bodies being preserved through political immunity, which, like its biological counterpart, identifies, delineates, isolates, and eliminates internal, as well as external, hazards: "Whether an individual life or the life of the species is involved, life itself is what politics is called upon to make safe, precisely by immunizing it from the dangers of extinction threatening it" (Immunitas 112). As biopolitics links survival to preemptive defense against potential risk, violence becomes conceptualized as necessary for general health and well-being. War, mass destruction, even institutionalized domestic state violence occurs "in the name of the survival itself of populations that are involved. But it is precisely what reinforces the tragic aporia of a death that is necessary to preserve life, of a life nourished by the death of others" (Bios 39). ${ }^{9}$ Reversing bios's emphasis on life, Esposito terms the calculated elimination of life thanatopolitics.

Because calculated deaths are understood as necessary to protect particular lives, biopolitics cannot be understood only by the life that it positively defends but also, on the flipside, by recognizing and embracing the life that it negates. When power "makes live" through selective segregation, it is not life that is at the center of power but the persisting permanence of death, held strategically at bay. In other words, the primary function of biopolitics is not, as Esposito might posit, to protect society through immunizing the population but rather to eradicate the "carriers," those historically-specific groups whose very existence poses a threat to the safety and security of the society or the political economy. These are the populations that Silko exposes in Almanac-the homeless, 
indigenous, prisoners, poor, and others who are overlooked, concealed, and too often exterminated at predetermined rates (more quickly by capital punishment and military/police violence or more slowly by starvation, disease, and detainment). These othered populations are conceptually aligned with "the zone of indistinction and continuous transition between man and beast"-the site of bare life that Agamben terms the "homo sacer" (109). The homo sacer is defined by contradictions. Bare life is the target of murderous violence, yet rhetoricized as a threat. It is stripped of political status, yet central to a "state of exception" in which the law that defines the sovereign is confirmed and suspended. ${ }^{10}$

Today, the homo sacer may well be found among the migrants, ethnic outcasts, forced laborers, indigenous, or amid an ever-expanding category of peoples rhetoricized as depraved and diseased, draining social safety nets, or putting society at risk. ${ }^{11}$ As Esposito recognizes, this distinction is always historically specific:

[W] hat is healthy is only defined through contrast by the 'decision' about what is diseased-the origin, development and outcome of the illness. If, for example, the ultimate evil is identified in the threat of insurrections and rioting, the health of the State will be viewed as residing in an order guaranteed by the control of the head over the other parts of the body. If, on the contrary, what we fear instead is the tyranny of a despotic ruler, the salvation of the body politic will be located in a balanced equilibrium between its different members. (Immunitas 121-22)

Silko illustrates the fluidity with which historically specific criteria dictate shifts in 
protected and threatened populations: "Alleys and vacant lots across Florida and the Southwest were littered with human refuse from the Midwest and Northeast-cast-off white men, former wage earners from mills and factories. Remnant labor-union ideas made older workers dangerous in times of national unrest" (461). Along with outsourcing that left these former mill and factory workers excluded from the post-industrial U.S. economy, their political ideas also affiliate them with expelled populations conceptualized as superfluous, dangerous, or diseased.

The expansion of exclusion into populations of formerly protected laborers is possible partly because of the increasing fusion of economics, politics, and life. As Agamben explains, in biopolitics "life and politics-originally divided, and linked together by means of the no-man's-land of the state of exception that is inhabited by bare lifebegin to become one, all life becomes sacred and all politics becomes the exception" (148). In other words, in a biopolitical society, the potential for sacred and bare life is integrated into each body, meaning not only that every person is potentially protected, but also that every person is potentially at risk.

Recognizing the way in which colonial and post-colonial political economies depend upon the delineation of unprotected populations, Achille Mbembe argues that biopower is exemplified not, as Foucault states, by "that domain of life over which power has taken control," but rather through the power to "divide people into those who must live and those who must die" (11-12). Mbembe advances the notion of necropower and necropolitics to more fully account for the "various ways in which, in our contemporary world, weapons are deployed in the interest of maximum destruction of persons and the creation of death-worlds, new and unique forms of social existence in which vast 
populations are subjected to conditions of life conferring upon them the status of living dead" (40). In Almanac, these living dead are a diverse mixture of indigenous peoples, former slaves, cast-off industrial workers, unemployed strikers, and, too often, "isolated and lonely, despised outcasts of the earth" (513). Together, the living dead in Almanac are guided by ghosts: the ghosts of burning Eskimo children in the Arctic; Lakota ghost armies; ghosts of slaughtered Yaqui women and babies; the ghost of Marx whispering wisdom. Yet, the dead and ghosted are never rendered powerless in their purgatory state; rather, the dispossessed "seemed not to fear death much because they already talked to spirits of the dead anyway" (590). They seem to embrace the fact that death is not an unfortunate consequence of an immunized biopolitical economy; it is rather the singular process upon which all other maneuvers of power rest.

Expanding Mbembe's theory from a post/colonial context, Saskia Sassen asserts that today these death-worlds are formed by "complex modes of expulsion" that result in dismal material conditions for "the countless displaced people warehoused in formal and informal refugee camps, the minoritized groups in rich countries who are warehoused in prisons, and the able-bodied unemployed men and women warehoused in ghettos and slums" (Expulsions 3). In contrast to the immunity paradigm's emphasis on biopolitics' inclusive protection of populations, Sassen highlights contemporary power's increasing exclusion of peoples: "One familiar example in the West that is both complex and extreme is the expelling of low-income workers and the unemployed from government social welfare and health programs as well as from corporate insurance and unemployment support" (Expulsions 1). Like Almanac's homeless and unemployed in Tucson, an increasing populations of war veterans, former industrial workers, and 
families are also expelled from social protections. What these political, economic, and social expulsions produce "at ground level is more akin to a kind of economic version of ethnic cleansing in which elements considered troublesome are dealt with by simply eliminating them" (Sassen, Expulsions 36). Such economic ethnic cleansing racializes populations, not only based on skin color, physical features, or heredity, but also on historically-specific cultural, political, and economic characteristics, such as social class, religion, culture, political beliefs, and even employability, labor capacity, consumer potential, and net worth. ${ }^{12}$

This is not to say that racism based on physical features does not exist, it is rather to recognize a broader more incipient type of racialization which orders and others groups according to their relative position in the stable functioning of the state and economic markets. In economic terms, Immanuel Wallerstein suggests that such "[r]acism operationally has taken the form of what might be called the 'ethnicization' of the work force, by which I mean that at all times there has existed an occupational-reward hierarchy that has tended to be correlated with some so-called social criteria" ("The Ideological Tensions of Capitalism" 33). ${ }^{13}$ Almanac identifies how racialization persists and evolves with concrete historical circumstances, such as shifts from agrarian to industrial economies in which groups who were once "needed in the gold mines and plantations that were worthless without slave labor" eventually become wage-slaves "who worked like slaves but got even less than slaves had in the old days" $(407,116)$. Wallerstein elaborates that "if one wants to maximize the accumulation of capital, it is necessary simultaneously to minimize the cost of production (hence the costs of labourpower) and minimize the costs of political disruption (hence minimize-not eliminate, 
because one cannot eliminate - the protests of the labour force). Racism is the magic formula that reconciles these objectives" ("The Ideological Tensions of Capitalism” 33). For Mbembe, the construction of race has more sinister applications, where in "the economy of biopower, the function of racism is to regulate the distribution of death and to make possible the murderous factions of the state" (166). Silko demonstrates that not only on the plantations and in the mines but also with the biomaterials industry, arms and drug trade, and other sectors, racism provides justification for the economic exploitation and slaughter of Indians, blacks, 'the white-trash 'gringos,' the pigtailed biker gangs, or the filthy Mexicans. Human sewage all of them" (434).

At the core of this racialized economy are decisions that differentiate biopower from necropower-decisions about whether to invest in life or accelerate death. In Agamben's words this is the "fundamental biopolitical structure of modernity-the decision on the value (or nonvalue) of life" (137). Therefore, with necropower and thanatopolitic's investment in death, we must recognizes the logic of an nerco-economics by which "the market, understood as the very form of human universality as life, must necessarily, at certain precise moments, 'let die'” (Montag 204). Warren Montag asserts that "alongside the figure of the Homo sacer, the one who may be killed with impunity, is another figure, one whose death is no doubt less spectacular than the first and is the object of no memorial or commemoration, he who with impunity may be allowed to die, slowly or quickly, in the name of the rationality and equilibrium of the market" $(213) .{ }^{14}$ Silko offers countless historical images of these economic homines sacri: African slaves on plantations, forced indigenous laborers in mines, laid-off industrial wage-slaves, bioproducers victimized by wage-theft. These laborers die, not as a result of the "invisible 
hand" of the market, but by the discernable actions undertaken by employers and politicians. $^{15}$

Montag stops short of identifying how, while necro-economics may be of concern to the nation-state, it is increasingly practiced through the concrete procedures and actions of private corporations. Almanac illustrates how the state of exception, state of siege, and, ultimately, ability to inflict death, no longer resides solely in the sovereign but perhaps something akin to an assemblage of individual, state, and corporate actors that rheotricize an enemy and thrive on crisis. ${ }^{16}$ For instance, Almanac's Universal Insurance provides privatized "highly trained, well-armed security forces for land, sea, and air" available to support economic stability: "Wherever revolution, mutiny, uprising, or guerrilla war might strike, Universal Insurance would be there to offer complete protection to clients. No need to depend on poorly equipped government forces" (435, 292). Private companies, such as Universal Insurance, profit on the political and social stratification and unrest that neoliberal biopolitics creates.

When politics revolves not around the state, but around corporations, the privatization of death is not just a biopolitical reality, it is a neoliberal imperative. ${ }^{17}$ In $A$ Brief History of Neoliberalism, David Harvey analyzes neoliberalism as a "political project to re-establish the conditions for capital accumulation and to restore the power of economic elites" (19). This assertion distinguishes two important components of neoliberalism. First, in Harvey's words, neoliberalism is “a theory of political economic practices that proposes that human well-being can best be advanced by liberating individual entrepreneurial freedoms and skills within an institutional framework characterized by strong private property rights, free markets, and free trade" 
(Neoliberalism 2). Neoliberalism promotes minimal government regulation and intervention outside of creating new markets, often through privatizing municipal/state services (like Universal Insurance demonstrates), public resources, and personal information. As Silko illustrates with Trigg's biomaterials trade and Serlo's genetic cloning, increasingly invasive modes of biopolitical medicalization privatize unique genetic information and specific human tissues to establish a new profitable sector that "extend[s] the rationality of the market" into areas previously "not exclusively or not primarily economic" ("The Birth of Biopolitics" 79).

Secondly, in part as a result of privatizing publically held wealth, personal information, and public services, neoliberalism has "not only restored power to a narrowly defined capitalist class. They have also produced immense concentrations of corporate power in energy, the media, pharmaceuticals, transportation, and even retailing" (Neoliberalism 38). To facilitate this obscene concentration of wealth, neoliberal politics has “entailed much 'creative destruction', not only of prior institutional frameworks and powers (even challenging traditional forms of state sovereignty) but also of divisions of labour, social relations, welfare provisions, technological mixes, ways of life and thought, reproductive activities, attachments to the land and habits of the heart" (Neoliberalism 3). Almanac details how Bio-Materials, Inc.'s concentration of profits depends partially on such "creative destruction:" "Trigg was buying downtown block by shabby block...blood-plasma donor centers busted neighborhoods and drove prices down without moving in blacks or Mexicans. With property prices down, Trigg came and cleaned up, buying most property at forty cents on the dollar" (Almanac 379). 
Additionally, working within the structure of contemporary neoliberal biopolitics, Trigg discovers more modes by which to expand markets and concentrate profit.

\section{"Marx had been right about a great many things:" Vampire Capitalism and Bio-Materials, Inc. $^{18}$}

In Capital: Volume 1, Marx writes, "Capital is dead labour, that vampire-like, only lives by sucking living labour, and lives the more, the more labour it sucks. The time during which the labourer works, is the time during which the capitalist consumes the labour-power he has purchased of him" (257). In other words, through the work of laborers, 'dead' capital is brought to 'life' as a commodity. Capital's 'life' is maintained through the vampiric destruction of the laborer, sucking the energy, time, skill, and vitality out of workers. Marx elaborates in Grundrisse that capital suspends its own death through continually reproducing itself as money and commodities, and "capital obtains this ability only by constantly sucking in living labor as its soul, vampire-like" (646).

Silko's vision of Bio-Materials, Inc. creates a terrifyingly literal interpretation of this process of vampire capitalism. Bio-Material Inc., established and directed by wheelchair-bound Trigg, depends on bodily materials, such as blood, tissue, and organs, harvested from laborers and introduced as 'living' capital on the global market. The problem with such capitalist markets, as Nancy Scheper-Hughes explains in "The Ends of the Body: Commodity Fetishism and the Global Traffic in Organs," is that they "reduce everything-including human beings, their labor, and their reproductive capacity-to the status of commodities that can be bought, sold, traded, and stolen. Nowhere is this more dramatically illustrated than in the market for human organs and tissues" (62). In this extreme instance, not only abstract or potential labor but also material bodies are reified. 
Laborers who have internally produced the brain, blood, kidneys, or other biomaterials literally have the life extracted from them by vampire capitalists who desire to sell these bodily commodities with maximum surplus value or, in other words, little or no financial compensation for the producers.

Trigg's interest in blood-plasma provides an ironic, contemporary twist to his literal and figurative actions as a vampire capitalist. The blood-donors in Almanac, who sell their bodily fluids to a division of Bio-Materials, Inc. called Blood Plasma International, are literally selling their bodies to capitalism as both raw material and marketable commodity. When Blood Plasma International was first established, Trigg recruited the homeless and poor as donors who would accept meager financial compensation for their blood. In time, his intolerance of black, Latino, and homeless donors whom he considered "human debris" caused him to provide only drugs and sexual acts as compensation for their plasma. Trigg refused to recognize or reimburse the value of the labor put into the production of extracted biomaterial, in essence, refusing to recognize the laborer as such, creating and validating a space for unpaid labor. Yet, as a vampire capitalist who, to paraphrase Marx, only lives by sucking in living labor as its soul, Trigg hungered for ever increasing production and profit.

As Bio-Materials, Inc. expanded from blood-plasma into the growing market for "fresh" human organs, the thanatopolitical underpinning of biopolitics become visible. Trigg's “"plasma donors' were slowly bled to death, pint by pint. A few who had attempted to get away had lost too much blood to put up much fight even against a man in a wheelchair. Of course the man in the wheelchair had a .45 automatic" (444). To harvest all viable organs, Trigg slowly slaughtered his victim, who was "unaware he was 
being murdered" (444). During this this deliberate death, Trigg performed a final vampiric act as he gave the donor "a blow job while his blood filled the pint bags," sucking the victim's "swollen cock in his mouth" as the donor "go[es] out taking head from him" (444). This terminal act exemplifies Marx's assertion that "in fact the vampire will not lose its hold on him 'so long as there is a muscle, a nerve, a drop of blood to be exploited"' (Capital: Volume 1330). It is the epitome of biopolitical control, an instance in which economic, political, and social power has so completely permeated the individual bodies of excluded populations that the thanatopolitical extermination of these groups (such as the poor, revolutionaries, strikers, people of color) appears rational, even pleasurable, for the social good.

\section{Neoliberal Thanatopolitics and Biomaterial TechnoService Complex, Inc.}

Biomaterial production is about the materiality of our most basic, involuntary type of human labor: the production of life through the tissue, blood, organs, and other matter of the body. It embodies Arendt's explanation that "[1]abor is the activity which corresponds to the biological process of the human body, whose spontaneous growth metabolism, and eventual decay are bound to the vital necessities produced and fed into the life process by labor. The human condition of labor is life itself" ("Selections from The Human Condition"103). Bio-Materials, Inc. exploits this fundamental labor with techno-scientific innovations that transform flesh into globally marketable commodities. Through homicidal manipulations of biomaterial producers, nonconsensual extraction of blood and organs, and commodification of flesh for the global market, Almanac lays bare a global biopolitical economy that exploits producers, reifies workers, and commodifies human labor on the most literal and fundamental level. The novel illustrates how 
biopolitics and the immunity paradigm can serve as a rationale for the violent expulsion of particular ethnic communities, impoverished peoples, political radicals, dissident groups, or, as Haraway recognizes, any historically specific population conceptualized as putting society at risk. Silko extends this logic of biopolitics, invested simultaneously in manipulating populations and distributing flesh, to its obscured thanatopolitical underpinnings, making clear the way in which the extension of life for a privileged few depends upon the unheeded death of many.

In this way, the growth of the biomedical industry through the tools of biopolitical/thanatopolitical control and necro-economics cannot be divorced from the minimally regulated global neoliberal markets through which it functions, as well as the more place-specific ramifications of labor reification and body commodification. In Biomedicalization: Technoscience, Health, and Illness in the U.S., Adele E. Clark, Laura Mamo, Jennifer Ruth Fosket, Jennifer R. Fishman, and Janet K. Shim offer the Biomaterial TechnoService Complex, Inc. as a model for understanding the shifts from medicalization to biomedicalization: "This concept emphasizes the corporatized and privatized (rather than state-funded) research, products, and services made possible by technoscientific innovations that further biomedicalization. The corporations and related institutions that constitute this complex are increasingly multinational and are rapidly globalizing" (57). Clarke et al. recognize this phenomenon in neoliberal terms, where "health itself and proper management of chronic illnesses are becoming individual moral responsibilities to be fulfilled through improved access to knowledge, self-surveillance, prevention, risk assessment, and consumption of appropriate self-help and biomedical goods and services" (48). They explain that in contemporary biopolitics the management 
of life extends all the way to the molecular level-where health is then patented, packaged, and marketed to the global elite. ${ }^{19}$

Through privatized corporate medical markets, Trigg financially prospers not only from the sale of health as a generic marketable concept but also from the trade of specific bodily materials necessary to maintain or reestablish life. To expand Bio-Materials, Inc. and Blood Plasma International's investment in the Biomaterial TechnoService Complex, Inc., Trigg seeks a commercial partnership with his lovers and incidental business partner, Leah Blue. Like Trigg's Bio-Materials, Inc., which parasitically sucks the life out of labor, Leah Blue's Blue Water real-estate developments vampirically drains all attainable water out of the desert environment. Together, the vampire capitalists dream of combining their business expertise to develop the "first luxury community designed for the handicapped and the addicted" (Almanac 382). Reflecting the Biomedical TechnoService Complex Inc.'s model of expanding privatized corporate healthcare, they hope to create the largest medical "conglomerate in southern Arizona," in which they will "[c]over all the squares. Touch all the bases. Own a hospital, an ambulance service, and a mortuary as well" (381). ${ }^{20}$

In a tight concentration of speculation and profit, “Trigg wanted Leah’s Blue Water group to finance and build his detox and addiction treatment hospital. In return, Leah's Blue Water Investment Corporation would receive stock in the blood plasma business" (382). Under this scheme, Trigg and Leah would profit from fused neoliberal ownership and management, yet shoulder little of the risk. ${ }^{21}$ If employees "went nuts" from working for them, “[W]hose fault was it? 'Independent contractor' like the rest of them, that was what Trigg had always had his attorney tell the police and the prosecutors" 
(394). In cases of legal trouble, they could "shift liability for the error to Bio-Materials, Inc.” or, as Leah Blue points out, declare "bankruptcy and form a new corporation" (751). The duo could smoothly reestablish business-as-usual using one of Trigg's "manila folder" corporations-from "Alpha-Hemo-Science Limited" to "Biological Industries" to "Bio Mart"-which were registered but had not conducted business (402). ${ }^{22}$

Trigg and Leah Blue's medical conglomerate is constructed on the foundational assumption that, like other modes of neoliberal biopolitics, biomedicalization's management of bodies has uneven effects on varied populations, in this case, stratifying groups into donor and recipient classes on a global level. According to Clarke el al., "Even as techno-scientific interventions extend their reach into ever more spaces, many people are completely bypassed, others impacted unevenly, and while some protest excessive biomedical intervention into their lives, others lack basic care" $(61){ }^{23}$ While biomedicalization labels health a "moral obligation," it is underpinned by an imbalanced conception of whose health should be protected and at whose expense. According to Scheper-Hughes, "To a great many of those living on the fringes of the new global disorder, the scramble for 'fresh' organs and tissue increases their profound sense of ontological insecurity in a world that values their bodies as a reservoir of spare parts" (63). With privileged populations opting for elective and cosmetic procedures, often at the expense of disadvantaged peoples who lack rudimentary medical care, the polarization of medicine parallels and perpetuates established economic, ethnic, and geographical divisions.

Like other biopolitical institutions which, as Foucault explains, implement "segregation and social hierarchization" to guarantee "relations of domination and effects 
of hegemony," Clarke et al. recognize that "biomedicalization carries within itself the ideological, social, and cultural infrastructures that support and maintain racial and class inequalities" (Foucault, History of Sexuality 141; Clarke et al. 29). Through what Clarke et al. terms biomedicalization's "exclusionary disciplining," a new type of biomedical homo sacer is established by "exclusionary actions of medicine that erect barriers to access to medical institutions and resources that target and affect particular individuals and segments of populations" (61).

Bio-Materials, Inc. is fundamentally invested in the effects and perpetuation of such social inequalities and medical stratification. Marginalized groups are targeted as donor populations, a term perhaps too strongly connotative of choice and free will to accurately represent what Trigg views as "human debris" expendable for biomaterial extraction to extend the life of wealthy, privileged few (444). As Sarah Blacker elaborates, "[B]iopolitics makes the rich live through the indoctrination of the belief that extending life through organ transplantation is not an elective decision but an unquestioned path of action, and lets the poor die through the creation of conditions for life that drive poverty-stricken organ-possessors to sell their means to biological life" (par. 6). In stark contrast to Esposito's immunized populations, these donors are characterized by their association with danger and risk, conceptualized as a population best sacrificed for the good and wellbeing of society, particularly when the death of undesirables results in extending the lives of more worthy peoples.

Thus, firmly bound to the immunity paradigm's biopolitical rationale is its racialized, thanapolitical double and necro-economic core. According to Ann Folwell Stanford, Trigg's racial and economic prejudices support "getting rid of certain (radically 
unstable) categories of people...and, in so doing, creating the means to save those worth saving (with organ transplantation)" (32). Trigg uses racism as, in Wallerstein's words, the "magic formula" to create maximum accumulation of capital with minimum production costs or political disruption. By seducing disadvantaged potential donors to his bio-bank with the promise of financial compensation, yet providing no reimbursement for the victim's biomaterials, Trigg is able to simultaneously eliminate undesirables and maximize profit. In Mbembe's terms, it is racism for the economic distribution of death. Trigg's actions are fueled by "paranoi[a] about Mexicans and blacks" who "could drift up from the bottom of the cesspool;" yet his intolerance is not only based on skin color, heredity, or ethnicity, but also on cultural, political, and economic characteristics. (387). Trigg demonstrates what David Campbell and Adam Sitze term "biopoitical racism," which works "in populations without any explicit reference to 'race' whatsoever...It doesn't seek to exclude certain populations from the institutions of civil and political life; it explains why, despite so many painstaking attempts at inclusion, certain populations nevertheless seem permanently incapable of achieving flourishing lives within those institutions" (19). Trigg pathologizes exploited bio-producers as "human debris" who are unable to be integrated into the protection of the immunized biopolitical population and must be expelled. It is, in a very neoliberal way, victim blaming (Harvey, Neoliberalism 76).

Though rapidly expanding multinationals, the Biomaterial TechnoService Complex, Inc. globally reproduces hegemonic divisions produced by other capitalist markets as "the circulation of organs flows from South to North, from poorer to more affluent bodies, from black and brown bodies to white ones" (Scheper-Hughes 70). Trigg 
and Leah Blue's plans for a strategically situated medical conglomerate in southern Arizona are reinforced by the fact that "if civil war broke out in Mexico, there would be no shortages of donor organs in Tucson" (Almanac 663). As Trigg purchases conflict victims, particularly from places where it is the "state's right to claim dead bodies for organs and tissues harvesting," he further monetarily and ideologically supports a political economy invested in interrelated military force, neoliberal market expansions, and labor exploitation (Scheper-Hughes 63). Trigg and Leah seek to reproduce the cycle of vampire capitalism where their own sociopolitical and economic power is bolster by the exploitation and commodification of effaced bioproducers. ${ }^{24}$

Under these conditions develops a "new form of 'apartheid medicine' that privileges one class of patients, organ recipients, over another class of unrecognized 'patients,' organ donors, about whom almost nothing is known” (Scheper-Hughes 68). Not only is "almost nothing" known about the organ donors, Trigg's experience suggests that the market demands that biomaterials be conceptualized as commodified objects, non-representative of the life they once sustained and the labor that produced them. Trigg claims that he "had found no market for dark cadaver skin," but the organs he extracts from these bodies, which retained no racialized evidence of the human that produced them, are "lean and strong" preferred commodities (404). This process of commodification detaches organs from their place and body of origin masking the violent production relations that procured them. As such, the biomedical industry not only propagates a stratified system that supports "life nourished by the deaths of others," as Esposito recognizes (Bios 39). Additionally, the deaths sustain an economic system in 
which the donors "with impunity may be allowed to die, slowly or quickly, in the name of the rationality and equilibrium of the market," as Montag points out (213).

\section{Necro-Economics and Value of Lumpenproletariat}

With its focus on material bodies, recognition of biopolitical exploitation, and problematization of traditional notions of work, Silko's Bio-Materials, Inc. serves as a corrective to strands of intellectual debate and social awareness that privilege contemporary immaterial labor in developed nations while marginalizing discussions of already obscured material production around the globe. This is not to say that material/immaterial labors are distinct categories. Rather the opposite it true; Silko’s discussion of the biomaterials trade is intriguing because it resists distinct categorization. Part material product and part immaterial labor, the commodification of biomaterials exposes the false binary between these modes of production while drawing into sharp focus the ways in which neoliberal biopolitics exerts increasingly invasive and uneven power over general and particular bodies. Although blood, organs, and tissues are physically produced by natural, involuntary processes, the biomaterial industry introduces these body parts into a global commodity market established by accumulation by dispossession and supported through a system of worker exploitation, wage theft, forced labor, and, ultimately, control over live and death. Thus, the image of BioMaterials, Inc. demands that we address the material underpinnings of all interrelated labor, as well as the political economy that reproduce and reinforce our uneven and unsustainable global production and consumption system.

The origin of the commodities Trigg harvests is strategically obscured through an anonymous, global market in which evidence of biomaterials' violent extraction and the 
social implications of these practices are seemingly erased. However, Almanac endeavors to, in Marx's terms, "decipher the hieroglyphic, to get behind the secret" of the social, economic, and political processes embedded in commodified biomaterials (Capital Vol. 1 85). Populations such as Tucson's homeless bio-producers or the unelaborated group of Mexican organ suppliers may not appear to be laborers in a traditional Marxist or modernist sense of the word. In fact, these donor groups are more closely aligned with Marx's lumpenproletariat, defined in the Communist Manifesto as the "'dangerous class', [lumpenproletariat] the social scum, that passively rotting mass thrown off by the lowest layers of the old society" (65). Trigg's donor population can be associated with, as Zygmunt Bauman elaborates in Work, Consumerism, and the New Poor, an "underclass" that strategically evokes an image of "people without role, making no useful contribution to the lives of the rest, and in principle beyond redemption" (66). Certainly, Trigg identifies his donors as "human debris," "Hoboes or wetbacks," and, in part, this inability to see donors as contributing members of society provides Trigg with justification for his lethal exploitation (Almanac 444, 663). According to Bauman, people tend to see "no good reason" for the underclass's existence "and may imagine themselves to be much better off if they were not around" (66). Ann Brigham writes that for Trigg, the homeless and unemployed "form society's waste because, until he puts their bodies to use, they represent society's nonproducers" (309). Because Trigg conceptualized donors as reified things which only have value once he homicidally markets their commodified bodies, he is able to boast of the homeless and oppressed individuals he kills: "Nobody ever notices they are gone. The ones I get" (444). 
Silko provides an ironic, literal interpretation of Marx's statement that advanced accumulation was "impossible without disposable human material" where a "surpluspopulation...furnishes to capital an inexhaustible reservoir of disposable labour-power" (Capital: Volume 1 705). Bio-Materials, Inc. demonstrates a shift from what Virno identifies as the management of life to control the potential labor-power necessary for capitalist production and towards the management of death when laborers' flesh is the commodity in demand. Trigg's actions are symptomatic of, in Blacker's words, "the way power is working under capitalism to maximize production in which body parts themselves are transformed into capital. The human body becomes divisible and destructible; the productive value of the body no longer lies in its potential for labour, but instead in its components" (par. 3). While in modernist industrial societies, surplus populations were necessary to compose a reserve workforce to ensure continued production, in today's consumer societies the need for an internal reserve workforce has diminished in certain privileged nations. As Randy Martin describes in Financialization of Daily Life, in a these societies "populations are not a surplus held in reserve for burgeoning industrial employment, but expendable masses who may or may not fit with the developmental scheme of a particular nation" (154). If future workers are ever needed, the capitalist may look outside sovereign boundaries to find new populations of workers, to pay lower wages and provide fewer benefits. ${ }^{25}$ Therefore, Trigg literally disposes of this so-called surplus population in the United States in order to harvest their internal commodities without allowing them consent or providing financial compensation for the value of their labor. When "fresh" organs are needed, he looks to conflict-ridden Mexico and other countries to provide new sources of bio-production. ${ }^{26}$ 
Since many of the biomaterial donors are under/unemployed, it may be tempting to view them as outside the definition of laborers. However, the conceptual linkage between work and wage is a double-edged sword. On one hand, this association excludes un- or under-compensated labor from traditional conceptions of work. ${ }^{27}$ It obscures the process by which the maximization of profit at one privileged location is often predicated on exploitation, destruction, and, ultimately, death at another location. On the other hand, strategically de-linking labor from wage is already too often employed to rationalize an array of exploitation. As David Harvey elaborates, a new wave of primitive accumulation, what he terms accumulation by dispossession, surges in neoliberal capitalism as natural products-such as cultural knowledge, physical environments, or genetic information-are commodified and privatized with maximum profit by providing meager, if any, compensation to producers. ${ }^{28}$

The uneven correlation between work and wage (the creation of surplus value) forms the fundamental foundation for exploitation in a capitalist system. However, profit is also maximized by implementing narrow conceptions of labor that exclude and consequently unwage large sectors of production. Hardt and Negri point out that waged labor represents only a portion of the labor economy, and that "the poor, the unemployed, and the underemployed in our societies are in fact active in social production even when they do not have a waged position" (Multitude 131). Tethering definitions of labor to wage structures has disproportionate implications for women, people of color, and other marginalized populations who more often perform domestic duties, affective labor, and other under/uncompensated work in official and unofficial capacities. As Bridget O'Meara elaborates in the context of Almanac, "the 'symbolic association' of the poor 
and people of color with 'waste' has been used to justify and reinforce intensified economic and ecological exploitation of politically disenfranchised communities worldwide" (O’Meara 71). These are the very populations that Trigg preys upon.

Labeled as society's nonproducers, Trigg sees the only potential value for the lumpenprolitariat or underclass in terms of their "biocapital," or the "capacities of certain things-such as organs and tissues-to produce surplus value" (Clarke et al. 8). Surplus value increases when " $[\mathrm{t}]$ issues may be taken from us for 'free' in our interactions with biomedicine (such as tests), regardless of our preferences and regardless of their 'biovalue"' (Clarke et al. 10). Corporations such as Bio-Materials, Inc. maximize profit and negate the workers' share of biovalue by "extracting and removing such [biomaterial] resources from their sites of origin without adequate, if any, compensation" (Clarke et al. 9). The populations that Trigg preys on-the homeless, conflict victims, and indigenous peoples-are particularly vulnerable to this type of accumulation by biological dispossession due to the "stratification of biomedicalization by race, class, and citizenship," where underprivileged populations are disproportionately conceptualized as donor groups.

Almanac explains, "Marx had recited the crimes of slaughter and slavery committed by the European colonials who had been sent by their capitalist slave-masters to secure the raw materials of capitalism-human flesh and blood" (315). Trigg's unwaged exploitation of bio-producers is a sort of neoliberal slavery, where it is not the laborers' potential for work but rather their divisible, reified bodies that produce maximum surplus bio-value. Looking across national borders to procure new populations of unpaid producers, Bio-Materials, Inc.'s business model parallels what Gayatri Spivak describes 
as global organizations interest "in the rural and indigenous subaltern as sources of traderelated intellectual property...Marxist theory best describes the manner in which such 'intellectual property' is made the basis of exploitation in the arenas of biopiracy" ("The New Subaltern” 232). What Clarke et al. identifies as "biopiracy for corporate appropriation" occurs as "the subaltern body as bios or subaltern knowledge" becomes the object of accumulation by dispossession (Clarke et al. 381, Spivak, "The New Subaltern" 231). Under such conditions, Spivak asserts that the "'the agent of production' here is no longer the working class as produced by industrial or post-industrial capitalism" but rather subaltern victims of biopiracy ("The New Subaltern" 231-2).

Rather than being on the margins of capitalist production, as victims of biopiracy, Almanac's bio-producers are at the core neoliberalism's accumulation by dispossession. Trigg's ability to introduce homicidally harvested bioproducts into the global market with apparent ease is symptomatic of what Clarke et al. recognize as a persistently troubling "political economic facet of biomedicalization [concerning] whether and how 'tissue' circulating in the global tissue economy is paid for before being transformed into products bought, sold, and used in biomedicine" (9). Within such a political economy, Bio-Materials, Inc.-with its genocide of unimmunized labor populations-is not an exception to the rule of capitalist profit but rather exemplifies the fundamental premise that increased revenue at one site is too often bound to exploitation and dispossession at another site.

These realizations expose revolutionary possibilities. According to Hardt and Negri, "[D]istinctions too have often been used to exclude women, the unemployed, and the poor from central political roles, entrusting the revolutionary project to the men (with 
calloused hands from the factories) who were thought to be the primary producers" (Multitude 135). The inclusion of traditionally excluded groups, such as the homeless bioproducers, provides a "threat to destabilize the global hierarchies and divisions on which global capitalist power depends" (Multitude 137). In other words, identifying under-recognized and under-compensated laborers not only provides an initial step in reducing their exploitation, it also acknowledges groups which have too often been excluded from workers' movements. For instance, recognizing the homeless, (often) unemployed donors in Almanac as laborers resists the type of othering that has excluded these groups from traditional definitions of workers or proletariats and suppressed them to the excluded, lower-ranks of the underclass or (traditionally-defined) lumpenproletariat. By identifying these groups as laborers, the commodification and dehumanization that occurs to organ donors can be conceptualized as extreme instances of these processes that also impact groups of traditionally-defined workers. This is a fundamental step in the type of revolution Silko envisions, as well as contemporary global alliances we see emerging today.

\section{"A conjunction would occur; everywhere at once, spontaneously":}

\section{Rising Resistance Networks ${ }^{29}$}

Almanac demonstrates a definition of labor that is both inclusive and expansive, exposing how biopolitical economies shape workers through modes of power that transcend divisive paid|unpaid, productive|unproductive, material|immaterial, first world|third world binaries. This is not only theoretically and rhetorically significant for how we frame contemporary conceptions of work, but also pragmatically essential for the type of revolutionary project Almanac illustrates. The novel's various interconnected 
economies of exploitation-biomaterials, human trafficking, arms trade, pornography, torture films, mineral extraction-are never completely conceptualized in negative terms that enclose workers in a system of abuse, destruction, and powerlessness. Rather these violent political economics are elaborated as having the inherent potential for revolutionary rearticulation.

Transnational capitalist networks-in which the accumulation of profit at one site depends upon the exploitation of workers, cultures, and environments at other locationsmight be functionally inverted to mobilize innumerable points of global resistance against contemporary biopolitical neoliberalism. In a fundamental counter-hegemonic shift, Almanac's producer (or biomaterial laborer) who is traditionally concealed in the process of global capitalism becomes the focus of inquiry, while the consumer (or biomaterial recipient) becomes unelaborated and masked by the global markets. Through depicting the populations directly impacted by Trigg's Bio-Materials, Inc., Almanac resists the abstracting tendencies of global capitalism, instead exposing the market's material underpinnings, humanizing biomaterial workers, and demanding accountability for the industry's biopiracy.

Almanac predominantly elaborates the Tucson population of bio-workers through the perspectives of Rambo-Roy and Clinton, two homeless war veterans who work as night watchmen at Trigg's Bio-Materials, Inc. While Trigg originally hired Roy to "hand out leaflets to homeless people," following this recruitment, "Roy had warned the men about the habit of selling their plasma or whole blood. He promised very soon there would be alternatives that would provide shelter and food without the sale of blood" (394, 403). Roy and Clinton personally experience the structural marginalization and 
systemic violence that left the homeless with few economic options other than selling their flesh and blood in order to survive. Yet in spite of their marginalized social and economic positions, the pair of homeless vets recognize the potential for change and the role they must play in catalyzing it. Roy "had seen for himself women and children hungry, and sleeping on the streets. This was not democracy. Police beating homeless old men was not the United States of America. Something had to be done, and Rambo and his army would do it" (393). Clinton too recognizes that all "around them, all their lives they had witnessed their people's suffering and genocide; it only took a few, the merest handful of such people, to lay the groundwork for the changes" (742). Together, RamboRoy and Clinton become architects of transformation, planning "to mobilize and rally [the] army of homeless to accuse the blood and biomaterials industry of mass murder" (445). Appropriating the resources of capital to use against the dominant class, RamboRoy and Clinton establish their own "headquarters" in the basement of the Bio-Materials, Inc.; occupy Tucson's vacant vacation homes; and gather "gasoline credit cards, Tucson bank-machine cards, bank statements" from seasonal mansions' unchecked mailboxes $(410,408-9)$

The Army of the Homeless originated, in part, to combat the atrocities of Trigg's Bio-Material's Inc. However, as the movement expands, solidarity forms not only around bio-workers' common employment but also the shared exploitation, abuse, and expulsion facing by an expanding sector of society. Rambo-Roy and Clinton observe, "In the beginning, the homeless had mostly been white men who wintered in Tucson then fled the heat; but now the big arroyo sheltered families, and the women and children did not leave when the heat came" (616). The displaced women, people of color, and recent 
immigrants who arrive in Tucson join the Army of the Homeless's ranks beside the white men. They all similarly suffer, in Sassen words, the "complex modes of expulsion" that result in "the able-bodied unemployed men and women warehoused in ghettos and slums" (Expulsions 3). In these spaces, Almanac exposes the inscription of biopolitical racism marking the material bodies put at risk.

For the diverse homeless in Tucson, this common categorization forms the core of resistance networks that solidify around shared experiences as bodies bound by wageslavery, expelled by biomedical "exclusionary disciplining," and endangered through biopolitical unimmunization. Almanac explains that "[b]lack women, Hispanic women, white women, homeless with starving children; they all said they'd rather fight. They'd rather burn down the city, take a police bullet, and die quick, because that way they died fighting, they died warriors, not slaves" (747-748). Under a regime of biopolitical racism, Almanac illustrates how the poor, homeless, whites, blacks, Latinos, and others are similarly exploited through a system of neoliberal slavery in which profit is accumulated by marketing their divisible bodies, native knowledge, and cultural production. As Clinton realizes, "One kind of slavery had often been traded for another slavery as bad or worse. Slaves of past centuries had shelter and food. Yet today in the United States, socalled 'free' men, women, and children slept under cardboard on the street" (412)

Diverse local-level revolts, such as the Army of the Homeless, serve as the building-blocks of an inclusive global counter-hegemonic movement which combats similar modes of biopolitical wage-enslavement, land and pay theft, and expulsion from protected immunization in the political economy. As Shackelford recognizes, "Joining forces with an army of the homeless, with Vietnam veterans, and with ecoterrorists, the 
Native American and other indigenous characters in the novel comprise key nodes in what is explicitly envisioned as a broader subaltern network of resistance to the structural inequities of global capitalism" (par. 38). This network of the globally dispossessed includes not only post-colonial or indigenous peoples, but also an ever-expanding segment of the unimmunized first world, such as former industrial workers, the homeless, and the incarcerated. Working against neoliberalism's dissolution of social solidarities, the movement builds unity around the common thanatoplitical atrocities that bind bodies who, in whole or parts, are exploited and abused for profit (Harvey, Neoliberalism 23).

Bio-Materials, Inc. personifies the obscene relationship between fragmented material bodies and profit in capitalist political economies. However, the neoliberal accumulation by dispossession that destroys marginalized bioworkers also underpins notions of human capital that impact relatively privileged immaterial laborers. The biopolitical production of controlled bodies for biological work or for intellectual and effectual labor is shaped by a common regime of power. By building solidarity among those diverse, interconnected modes of labor exploited for capitalist profit, Almanac's network of resistance defies exclusive categorization as an indigenous or third/fourth world movement. Rather, as Almanac states, “All were welcome. It was only necessary to walk with the people and let go of all the greed and the selfishness in one's heart" (710).

At the conclusion of Almanac, a growing mass of "unarmed and unguarded" people from the metaphoric Global South-those nations or continents generally labeled as third/fourth world, as well as exploited regions of the first world- approach the U.S./Mexican border from the geographical South (735). Led by the twin brothers, El Feo and Techo, "nicknamed Wacah because he tamed big wacahs or macaws," the diverse 
followers "came from all directions, and many claimed they had been summoned in dreams...People from tribes farther south, peasants without land, mestizos, the homeless from the cities and even a busload of Europeans, had come to hear the spirit macaws speak through Wacah" $(468,709)$. Symbolizing a grassroots movement that gains power from its base, "The spirit macaws promised spiritual strength and satisfaction to all who marched north. North was the direction of Death, but they must not be afraid. The number of the landless and the homeless and those who joined them had grown steadily" (590).

This bottom-up resistance comes not only from the metaphorical and geographical South but also from beneath the earth. The Barefoot Hopi, a de facto spokesperson for the opposition movement, explains, "They were waiting for the right moment-for certain conjunctions between the spirit forces of wind, fire, water, and mountain with the spirit forces of the people, the living and the dead" (618-9). Almanac offers a terrifying vision of techno-scientific innovations and increasingly invasive biopolitical economies in which nature-the earth and its inhabitants-are ripped open, cut apart, commodified, marketed, and consumed. Yet, this mode of power leads not only the destruction of an exploited planet and its peoples, but also to the eventual devastation of the oppressors themselves. Echoing the Barefoot Hopi, Angelina, a leader from the South, explains to the indigenous followers, “The ancestors' spirits speak in dreams. We wait. We simply wait for the earth's natural forces already set loose, the exploding, fierce energy of all the dead slaves and dead ancestors haunting the Americas. We prepare, and we wait for the tidal wave of history to sweep us along" (518). Almanac illustrates this moment where the dispossessed characters and the abused Earth reach a tipping-point. Solidarity is built 
between diverse peoples and the planet, all exploited by capitalism's quest for maximum profit produced by abusing, exploiting, and killing populations and environments. However, this mode of power is not only destructive; the networks of oppression it establishes holds the potential to be radically reconceptualized in a resistance network joining the earth and peoples, creating unexpected alliances between the Army of the Homeless, Green Vengeance Eco-Warriors, followers of the Twin Brothers, and others. As the Barefoot Hopi reads, "'Rejoice! We are no longer solitary beings alone and cut off. Now we are one with the earth, our mother; we are at one with the river. Now we have returned to our source, the energy of the universe. Rejoice!'” (733).

\section{A Town Called "Revolutionary Cananea"}

Almanac reminds readers that the history of the Americans-from European invasion to the present -is fueled by mutual exploitation of peoples and environments. Native populations and imported African slaves became bare life, central to the production of mineral wealth that financed European conquest in the Americas, yet situated outside of legal protections and suffering direct abuse from concurrent states and corporations. Sent into the earth to excavate wealth for white Europeans, "Indians had seen generations of themselves ground into bloody pulp under the steel wheels of ore cars in crumbling tunnels of gold mines" (Almanac 312). Mining corporations tore open the mountains and polluted the waters-"the earth had been blasted open and brutally exploited"-with little regard for the environment or the people that inhabited it (Almanac 718). Yet, Almanac illustrates that both the exploited earth and the abused populations persistently rise in resistance.

Yoeme, a Yaqui elder, explains to her young twin granddaughters that their 
European maternal grandfather and white father had both died for their crimes against the earth and its peoples: "Against the spirits, the white man was impotent. 'You girls will see someday. Look what happened to your grandfather. Those mine shafts into the earth turned against him, and his bones broke to mush" (581). Yoeme teaches the girls about a sort of cyclical spiritual and environmental retribution where their grandfather, who exploited the earth and slaves in the "crumbling tunnels" of his mines, himself dies "broke to mush." The girl's father, a mining engineer sent to the southern Sonora mines from the company headquarters in Cananea, suffers a similar fate. Suggesting the everevolving, unpredictable nature of the earth and the limits to rational techno-scientific innovations, Almanac explains, "The rumors and reports had arrived in Canenea [sic] that while the mining engineer could still name the formations and the ore-bearing stones and rocks, and could recite all of the known combinations for that particular area, his calculations on the maps for known deposits and veins had been wrong; he had directed the miners to nothing" (120). The twin's grandmother explains this occurrence as punishment for their father's exploitation of the earth: "Yoeme said the veins of silver had dried up because their father, the mining engineer himself, had dried up. Years of dry winds and effects of the sunlight on milky-white skin had been devastating. Suddenly the man had dried up inside, and although he still walked and talked and reasoned like a man, inside he was crackled, full of the dry molts of insects" (120).

Today, in the contemporary mines of Cananea, Mexico, the local inhabitants and environment have reached a tipping-point where, similar to the vision expressed in Almanac, the biopolitically unimmunized or neoliberal homines sacri are joining forces to demand human dignity and environmental justice. It is unsurprising that Silko chose 
the mines of Sonora, and particularly Cananea, to signify, on one hand, corporate greed, wage slavery, and environmental degradation, and, on the other hand, persistent resistance movements, cross-border solidarity, and strategic alliances. I have been to Cananea several times to support the union miners and their families, people whose daily lives are shaped by neoliberism's “creative destruction” of organized labor, biopolitics' expulsions from medical protections, and military forces' allegiance to private corporations. Yet the town's nickname of "Revolutionary Cananea" is well earned, and through dedication to their labor union, transnational worker solidarity, and strategic community alliances the residents provide a model of grass-roots social rebellion. ${ }^{30}$

For miles before you reach the outskirts of the isolated mining town you can see an unnatural gash in the side of a mountain crawling with barely perceivable specks of activity. Mounds of white dust-mining slag finer than talcum powder-swirl up into the air like puffs of smoke then slowly drift down on the community. Situated at the base of the carved out mountain, the town of Cananea always appears to face imminent engulfment by the enormous open-pit Buenavista copper mine, the largest in Mexico and one of the biggest in the world.

As the oldest copper mine in North America, Cananea's past reads like Angelita's “crimes against the people's history" in Almanac of the Dead (525); Cananea chronicles political economic shifts from the mid-1600's, when the mine was established, to the present. In the early 1900s, when Cananea's Mexican miners resisted foreign exploitation of the workforce, community, and mine, the labor dispute signaled growing unrest that would culminate in the Mexican Revolution. Yet by the end of the century, Cananea was again a model of human and environmental exploitation, demonstrating the failure of 
neoliberal privatization to raise the standard of living and labor dignity for the majority of the population. Although the mine was incrementally nationalized throughout the 1970 s, with the neoliberal turn of the late 1980s and international trade agreements of the 1990s, the mine was privatized, undervalued, and sold. The mine was purchased at a fraction of its value by mining conglomerate Grupo México. The company's largest shareholders, the Larreas, are one of the richest and most politically-connected families in Mexico with a fortune boosted by investments in the countries' privatized railroad, ports, and mineral extraction operations. During the 1990s and 2000s, Cananea's productivity continued to soar, with Grupo México's four copper mines accounting for 90\% of all the copper produced in Mexico (Bacon, The Children of NAFTA 242). Yet during this boom, Grupo México continued to reduce the size of the workforce in Cananea and neglect health and safety infrastructure investments in the mines. Between 2008 and 2013 a staggering two hundred workers were killed in accidents at Grupo México's mines and plants (Gómez 151). Facing these intolerable circumstances, in 2007 , one hundred and one years after the pivotal pre-Revolution labor conflict, the miners in Cananea went out on strike and were again on the front lines of global industrial/labor conflict.

When Los Mineros Section 65, the miners' local union in Cananea, went out on strike, it was not to negotiate for more money, increased benefits, or better work hours. Rather it was to demand, in a very literal way, their right to life. Los Mineros asserted that since taking over the mine, Grupo México had refused to abide by health and safety laws or the union's collective bargaining agreement. This not only put mineworkers at risk but also endangered the entire community, as water sources were polluted from mine leakage and super fine particles of mine dust became air-born toxins that caused fatal 
respiratory diseases such as silicosis. Workers were also concerned about safety conditions following a 2006 explosion at another Grupo México operation, the Pasta de Conchos mine in Coahuila, Mexico, in which sixty-five miners died as a result of company neglect-a gas leak that workers had complained about but was ignored by the company. A National Commission on Human Rights report from that year found that Grupo México and the Mexican labor ministry had clear knowledge of dangerous conditions at Pasta de Conchos before the explosion, yet chose to do nothing to remedy the problems (Gómez 141). A few days after the explosion at Pasta de Conchos, Grupo México abandoned any rescue operation, refused to retrieve sixty-three bodies for proper burial, and sealed the mineshaft with concrete. Workers in Cananea were well aware that they could suffer a similar fate. A 2007 report by the Maquildora Health \& Safety Support Network detailed two hundred and twenty serious health and safety infractions at the Cananea operations (Gómez 199-200). Corroded metal walkways; missing guardrails, protective panels, and grate covers; and an inoperable dust ventilation system meant that every day a worker left for the mine in Cananea, he might never return home again. ${ }^{31}$ Along with miners' knowledge of Grupo México’s health and safety violations, they also realized the threats they could face during a labor dispute. In 2006, Grupo México fired 1,200 striking miners at the Nacozari mine and used federal troops to bring in replacement workers, a move which devastated the economic security of the mining community. ${ }^{32}$ When Los Mineros members went on strike at a steel mill in Lázaro Cárdenas in 2006, two strikers were killed and over one hundred more were wounded by gunfire from federal troops deployed to suppress the union. After Napoleón Gómez Urrutia, President and General Secretary of Los Mineros, publicly called the tragedy at 
Pasta de Conchos an instance of "industrial homicide," he and his family faced death threats, criminal charges, property seizure, frozen bank accounts, assassination plots, political persecution and, eventually, forced exile. Only recently, after an eight-year legal battle, have all charges against Gómez been dismissed. During this time, Los Mineros executive committee member Juan Montúfar Linares spent two years, two months, and twenty days in a Mexican prison before all accusations of wrongdoing were found by a Mexican court to have been baseless. In spite of the political persecution of leadership and the violence against workers at Pasta de Conchos, Nacozari, and Lázaro Cárdenas, Los Mineros members were left no option other than to strike against the life-and-death issues that Grupo México was unwilling to remedy.

When the miners in Cananea went out on strike, they not only stood up for themselves and their community. They also stood against one of the largest mining corporations in the worlds, one of the wealthiest families in the country, and a contingency of Mexican politicians who supported the neoliberal trends of privatization, on-demand employment, dissolution of worker collectivity, and reduced corporate regulations. Gómez explains that the "all-out war against the free and democratic trade unionism of the people...reflects the ambitions and appetites of unlimited power, the insensitivity of some groups who, by following globalization and international organization theories in addition to their own interests, seek to destroy the autonomy and freedom of workers and trade unionism itself" (151). To combat a neoliberal system in which the Mexican "populace struggles under the weight of a government that manages the nation's riches for a few," at Cananea and other sites, Los Mineros wages a "fight for human rights and dignity" (Gómez 24, xxii). 
During these battles, solidarity has strengthened between Los Mineros and the United Steelworkers, who represent Grupo México mine and smelter workers in the United States. With only around fifty miles separating the Grupo México mines in Cananea and near Tucson, it is not uncommon for families to have miners working on both sides of the border. Much like the vision of transnational solidarity that Silko offers in Almanac, Cananea has a long history of international worker alliances, starting with the 1906 strike that was supported by unions in the United States, including the Industrial Workers of the World. Throughout the 1990s and 2000s, Los Mineros and United Steelworker members traveled across the border to help each other during strikes or labor disputes at Grupo México mines in each country. In 2005, Los Mineros and the United Steelworkers signed a strategic alliance agreement and, in 2011, expanded the initial partnership into an enhanced solidarity agreement that includes plans for an eventual union merger. When Gómez and his family faced death threats in Mexico, the USW helped him get to the United States and eventually reach sanctuary in Canada. When miners went on strike in Cananea, backed by Los Mineros and the United Steelworkers, they had the support of the two largest copper mining unions in North America. They would need it.

In response to the strike in Cananea-a dispute primarily catalyzed by miners' health and safety concerns-Grupo México further flexed its biopolitical control over workers and the community. After previously closing the worker's health clinic, in 2008 Grupo México defunded the only remaining medical facility available in the community, the Ronquillo Hospital. With the next nearest hospital several hours away in Hermosillo, Sonora, Cananea's men, women, and children, many of whom were suffering diseases 
from working at or living near the mine, were left without medical care. Not only had their bodies been put at risk by the mine pollutants and safety violations, but now the population of Cananea faced more direct forms of biopolitical expulsion. Medical care was eliminated; electrical outages plagued the town; water supplies were intermittently shut down; natural gas was cut; and, in an almost inexplicable move to target young children, the schools were closed (Gómez 274).

However, the most direct corporal suppression of the strike to-date occurred at dusk on June 6, 2010. Approximately 4,000 heavily armed federal and state troops invaded Cananea, serving as strike breakers on behalf of Grupo México. As families gathered for safety in the union hall, troops shot tear gas into the building and barricaded the doors. Manny Armenta, a representative from the United Steelworkers assisting Los Mineros, snuck women and children out a back staircase fearing that the union hall would soon go up in flames. With helicopters, guns, tear gas, and riot gear, federal troops seized the mine that day and ushered in replacement workers who currently live in barracks on the mine property and work twelve hours a day for a mere $\$ 85$ a week (Bacon, "Miners and Farmers Challenge Mexico’s Copper Giant”). Today, five years later, 2,000 military personnel continue to have a presence in the community and mine, which now resembles an armed prison camp enclosed by barbwire and surveilled by troops atop guard towers. Yet, facing imminent threats from armed troops, expulsion from public services, and economic insecurity, 850 of the original 1,200 miners in Cananea currently continue the strike (Martinez in Bacon, The Right to Stay Home 130-134). ${ }^{33}$

Recently Grupo México’s continued disregard for health, safety, and environmental regulations impacted the wider community and ecology, from south of 
Cananea extending north into the United States. In August 2014, around eleven million gallons of toxic copper sulfate acid concentrate containing arsenic, lead, cadmium, aluminum, iron, and manganese spilled from the mine reservoir in Cananea into the Bacanuchi River. From there the toxins flowed into the Yaqui and Sonora Rivers and, in a dark twist of fate, the north-flowing San Pedro River that runs past Grupo México’s mine in Cananea, Mexico to Grupo México’s mine near Kearny, Arizona in the United States. The following month heavy rains caused polluted water to breech damns, further contaminating surrounding areas.

As the polluted water seeped into homesteads' wells, livestock water supplies, and agricultural irrigation systems, many people in the region were left displaced, destitute, and diseased. The groups who suffered as a result of Grupo México’s willful neglect are, in Esposito's terms, a population already unimmunized from the exploitive political economy. Many are cut off from channels of alternate employment, social mobility, and access to information technologies. The river communities were not alerted to the environmental emergency until days after the spill, and they have found it difficult to get reliable information (Bacon, "Miners and Farmers Challenge Mexico’s Copper Giant"). The Arizona Star reported that although Mexico's "state newspapers are writing about the spill and its aftermath," some of those affected "rarely [have] the 10 pesos, less than $\$ 1$ to buy one" (Trevizo). In the short term, farmer's crops and livestock have been killed; rural people have no clean drinking water; and residents exposed to the water have developed rashes and open sores (Trevizo). The long-term effects of heavy metal pollutants on the land, water, and residents' rates of fatal diseases may not be fully known for years. 
These events were on my mind as I rode south to Cananea-me in the backseat with Manny Armenta driving the car and in the passenger seat, Bob LaVenture, United Steelworker director of the western eleven U.S. states. Crossing the border with Armenta is always a bit nerve-wracking. While working with Los Mineros in 2008, Armenta was arrested by Mexican border patrol, locked in a prison cell, and his union files, personal belongings, and automobile were confiscated (neither the papers, his cash, nor the car were ever returned). ${ }^{34}$ Along with Armenta, in 2007, LaVenture had been part of the United Steelworkers' contingency in New Mexico that helped Gómez cross the border when he and his family's lives were in danger in Mexico. Since those occurrences, LaVenture and Armenta's support of Los Mineros has only grown and, at that time of our trip to Cananea, both were in year-long negotiations with Grupo México for renewed contracts at the company's U.S. mines and smelters. I too had sat at the negotiating table across from Grupo México and facilitated United Steelworkers and Los Mineros crossborder solidarity training programs with wrongly-imprisoned Juan Linares. Now I was heading into the heart of the battle with Grupo México.

On this visit I was less concerned with driving down the narrow, winding streets to the Los Mineros union hall or peering through the chain-link fence at the dusty mine that had fascinated me on previous trips. I knew that today the action was concentrated on the outskirts of town around a towering cylindrical water tank. The previous day, armed with rocks and fists, a group of striking miners, local townspeople, and displaced farmers and ranchers had ousted armed troops serving as mine security and taken control of the Buenavista mine's pump water transfer station. Nearly 2,000 men, women, and children poured into the facility, pitched tents, made campfires, and refused to leave until Grupo 
México met and discussed their demands. By occupying the station, which provides the water necessary to operate the mine, the protesters had shut down $80 \%$ of the Buenavista operation. $^{35}$

Whatever fears I may have had during the drive to Cananea faded as I opened the car door at the pump station and was welcomed with handshakes and hugs. A large ring of people encircled LaVenture, Armenta, and me, talking quickly and pointing out areas of the recently established headquarters. ${ }^{36}$ I surveyed the inside of the pump station, locking eyes with a miner clad in olive green fatigues who smiled broadly and threw his fist up in an international gesture of solidarity. Men in cowboy hats and boots huddled around campfires trying to keep warm on this chilly spring day. Women welcomed me into a makeshift outdoor kitchen where they cooked tortillas over an upside-down kettle atop hot ashes. Families showed me the temporary shelters they had constructed out of tarps, rope, and cardboard. For many, this was now their only home. We were guided to a microphone connected to a speaker perched atop a green Chevy Suburban. Speaking to the hundreds of displaced people gathered around, Armenta proclaimed, "The government and Grupo México are making history-but backwards. They are taking away the right to strike and the right to industrial safety!" The crowd erupted in cheers. ${ }^{37}$

This alliance between diverse groups-miners, farmers, community members, and river area residence-was forged from Grupo México’s empty promises. Like Los Mineros, who found that Grupo México refused to recognize the collective bargaining agreement between the company and the union, residents and farmers from the polluted river region discovered that, although Grupo México set up a fund to pay for damages, they received no money and struggled to fulfill their families' basic needs of clean water, 
safe food, and sanitary housing. However there, in the middle of the Sonoran desert, recently homeless families, unemployed striking miners, and newly landless farmers asked how they could help me; what could they do so that I could share the story of what was happening in Cananea. I was reminded of what Angelita explains to the indigenous peoples in Almanac: 'In the repetition of the workers' stories lay great power; workers must never forget the stories of other workers... stories, or 'history,' accumulated momentum and power. No factory inspector's 'official report' could whitewash the tears, blood, and sweat that glistened from the simple words of the narratives" (520). Now the people of Cananea were teaching me that same lesson.

I have heard Napoleón Gómez tells his stories in a voice tempered by humility and punctuated by flashes of passion and brilliance. As the son of a Mexican miner, the everyday struggles of working peoples are never far from Gómez's mind. Yet, as an Oxford-educated economist who was director of the Mexican Mint for twelve years, Gómez is also well aware of what neoliberalism has done to his country and his union. He can speak with authority about the "many gains that Mexican companies have experienced under the neoliberal economic model, with its appropriation by individuals of public resources" (149). Then he can share the painful memory of meeting with widows and children after the Pasta de Conchos explosion and of his own son, who "got out of class one day soon after the Pasta de Conchos tragedy and found a note and a bullet on his windshield that threatened the same thing: If I didn't shut my mouth about the government and Grupo México's lies and abuses, my family would pay with their lives" (97). Yet, Napoleón refuses to be silenced.

Perhaps part of Almanac's power comes from the fact that it is not merely an 
imagined vision, but rather a narrative of our contemporary neoliberal biopolitical economy. When human welfare is undermined by corporate welfare ideological decision about the political economy can have devastating material effects on human bodies. Laborers, families, and communities are confronted with a toxic mixture of unsafe working conditions like in Pasta de Conchos, wide-spread economic expulsion like in Nacozari, direct physical violence like in Lázaro Cárdenas, and environmental devastation like in Cananea. As Gómez explains, "We have faced appallingly unsafe work sites, physical abuse at the hands of police and government forces, threats of violence and job loss-and we have lost lives. Yet we continue on in our fight against the politicians and industrialists who want us to simply vanish, allowing them to continue at their game of squeezing every last drop of blood and profit from Mexico’s workers and natural resources" (xxii). It is vampire capitalism on full display, companies out for every last drop of blood and profit.

At the end of Almanac, the appearance of an ancient stone serpent-rising from the radioactive mine tailings that defile scared tribal land-signals the converging forces of ecological and human resistance. The prophecy that foretells the serpent's emergence states: "One day a story will arrive at your town. It will come from far away, from the southwest or southeast-people won't agree. The story may arrive with a stranger or perhaps with the parrot trader. But when you hear this story, you will know it is the signal for you and the others to prepare" (135-36). In Cananea I heard such as story. I saw the obscene underbelly of neoliberal capitalism-biopolitics in all its necrotic glory-preying upon the unemployed, homeless, sick, elderly, and children. These are the faces of the necro-economic homines sacri, sacrificed for financial markets and the concentrated 
accumulation of capital. Yet it is here among the disenfranchised-whose work, homes, and health have been taken-that people have joined together in a global network of resistance. From both sides of the border, diverse men, women, and children come together to remember the past, demand a better present, and build a different future. While at the conclusion of Almanac the opposition networks begin to mobilize, in Cananea, Mexico, they have already arrived. 


\section{Chapter II Endnotes}

1. Gómez, xxii.

2. This general history of Cananea is influenced by In the Shadow of the Mexican Revolution: Contemporary Mexican History, 1910-1989 by Héctor Aguilar Camín and Lorenzo Meyer; The Mexican Revolution, Volume 2: Counter-Revolution and Reconstruction by Alan Knight; and Mexico's Revolution Then and Now by James D. Cockcroft.

3. The origins of Greene's title of "Colonel” are somewhat dubious. In "Colonel William C. Greene and the Cananea Copper Bubble," Marvin D. Bernstein explains that Greene received the title after leading a band of men up a hill during a conflict with Native Americans. Others assert that he was given an unofficial title "either from leading a posse pursuing Apaches or from his financial activities in New York” (Ascarza).

4. Along with other atrocities, the Diaz government massacred, enslaved, or deported to the mines Yaqui living in Sonora.

5. See Chapter 5 for more on Almanac's temporality and resistance networks.

6 See Chapter 5 for a longer discussion of this history.

7. Virno asks: "[W]hy is life, as such, managed and controlled? The answer is absolutely clear: because it acts as the substratum of a mere faculty, labor-power, which has taken on the consistency of a commodity" (272). With a focus on creating docile laboring bodies and managing populations of workers, capitalism is directly invested in the emergence of biopolitics. Virno focuses on capacity or potential for work, emphasizing the fact that maintaining the capability of labor-power means that the "living 
body which is a concern of the administrative apparatus of the State, is the tangible sign of a yet unrealized potential, the semblance of labor not yet objectified; as Marx says eloquently, of 'labor as subjectivity"' (271).

8. This processes of medicalization-where humans increasing become defined and managed by diagnoses, treatments, and preventative measures-sets a procedural precedence with widespread ramifications. Roberto Esposito notes:

The resulting limitless process of medicalization thus extended well beyond the health sector in a growing interplay between the biological, legal, and political. It is well represented by the semantic passage from the sovereign language of the law to the biopolitical language of norms: while law still subjected life to an order that presupposed it, norms are based on an absolute implication between biology and right. (Immunitas 138)

In this way, medicalization functioned not only through laws that governed conduct, ordered space, and institutionalized health, but also more efficiently through internalized norms which self-regulated individuals' bodies and behaviors.

9. Generally, Esposito expresses biopolitics in positive terms, for instance, insisting that the "purpose of biopolitics is not to distinguish life along a line which scarifies one part of it to the violent domination of the other-although that possibility can never be completely ruled out-but on the contrary, to save it, protect it, develop it as a whole" (Immunitas 139). However, not only through its elaborations, but also through its strategic silences, the immunity paradigm raises interesting concerns: From whom is 
society immunized? In other words, who unimmunized? Does society only provide selective immunization from death? Is death-massacres, genocide, police violence, execution, industrial homicide-an exception to the rule of biopolitics, or is death at the very core of how biopolitics functions? Does biopolitcs make live only through what it makes die? Do biopolitical societies protect the life of some at the expense of others? Or, increasingly, are the lives of a few protected by the sacrifice of many? While this chapter addresses some of these issues, I believe that these questions form a basis for continued research.

10. For Agamben, in contrast to Esposito, the link between biological life and politics is not unique to our contemporary state: "the production of the biopolitical body is the original activity of sovereign power" (6). What differs, according to Agamben, is that the bare life that marked the margins of sovereign power has become the center of biopolitical power, where "the exception everywhere becomes the rule" (9). In the state of exception, "Bare life remains included in politics in the form of the exception, that is as something that is included solely through an exclusion" (11). For Agamben, the modern state marks the proliferations of the state of exception: "[T] he sovereign who, insofar as he decides on the state of exception, has the power to decide which life may be killed without the commission of homicide, in the age of biopolitics this power becomes emancipated from the state of exception and transformed into the power to decide the point at which life ceases to be politically relevant" (142). This scholarship recognizes that a shifting threshold between decisions over between life and death is intrinsic to modern biopolitics: "If there is a line in every modern state marking the point at which 
the decision on life becomes a decision on death, and biopolitics can turn into thanatopolitics, this line no longer appears today as a stable border dividing two clearly distinct zones" (Agamben 122).

11. Esposito recognizes that the categorized of so-called diseased or degenerate populations expands based on historically-specific criteria:

The ascription of the degenerate type to an ever vaster number of social categories-alcoholics, syphilitics, homosexuals, prostitutes, the obese, even to the urban proletariat itself-reinstates the sign of this uncontrollable exchange between biological norm and juridical-political norm. What appears as the social result of a determinate biological configuration is in reality the biopolitical representation of a prior political decision. (Bios 119-120).

12. Sassen asserts that at certain points in advanced capitalism an increasing number of people lose value both as producers and consumers, including those bourgeoisie who were previously "immune" to economic fluctuations:

We can characterize the relationship of advanced to traditional capitalism in our current period as one marked by extraction and destruction, not unlike the relationship of traditional capitalism to precapitalist economies. At its most extreme this can mean the immiseration and exclusion of growing numbers of people who cease being of value as workers and consumers. But today it can also mean that economic actors once crucial 
to the development of capitalism, such as petty bourgeoisies and traditional national bourgeoisies, cease being of value to the larger system. (Expulsions 10)

Here we might pause to consider: How do we account for this trend towards the individualized potential for bare life or sacred life more often being realized through the expulsion of populations? Is the notion that violence stems from sovereign power persisting in an era of biopolitics an adequate way to account for current exclusions? Or does this conception imply that violence, like other residuals, may fade away, leaving a society focused on life rather than implicated in death? I think to make this latter assumption would allow the concept of biopolitical violence to too easily remain interrogated, left in the pauses and silence of scholarship. In addition, we must recognize that since low-wage workers in the United States are disproportionately women and people of color, it is difficult to delink expulsion based on income from expulsion based on gender and skin-color.

13. Agamben recognizes that "when natural life is wholly included in the polis [politics]-and this much has, by now, already happened-these thresholds pass, as we will see, beyond the dark boundaries separating life from death in order to identify a new living man, a new sacred man" (131). At this border between life and death we might turn back to Foucault to discover how the new sacred man is realized through defining its contradiction, a new Homo Sacer, a population of bare life: "How can the power of death, the function of death, be exercised in a population centered upon biopower? It is, I think at this point that racism intervenes." (Society Must be Defended 254). This racialization is 
a complex process where residual colonial discourses, gender stereotypes, economic hierarchies, and other politically-charged codes are inscribed (and over-inscribed) on the body.

14. Re-reading Adam Smith's theory of economic markets, Montag explains the explicit links between market stability and calculated death:

Smith postulates an equilibrium or harmony productive of life that is paradoxically created and maintained by the power of the negative, of death; that the allowing of death is necessary to the production of the life of the universal. Smith's economics is a necro-economics. The market reduces and rations life; it not only allows death, it demands that death be allowed by the sovereign power, as well as by those who suffer it. (210)

15. As Sassen recognizes, "People as consumers and workers play a diminished role in the profits of a range of economic sectors. For instance, from the perspective of today's capitalism, the natural resources of much of Africa, Latin America, and central Asia are more important than the people on those lands as workers or consumers" (Expulsions 10). For both of these (intersecting) populations, regardless of their primary role as labor or consumer, their expulsion needs to be strategically slowed down during times of maximum production and consumption in traditional capitalism, and their expulsion sped up when a surplus population and dwindling resources calls for social safety nets in an advanced capitalist society. 
16. Reminiscent of Naomi Klein's concept of "disaster capitalism” in The Shock Doctrine modern power is executed through the relations between state institutions, international economies, and private corporations that draw profits from natural or manufactured emergencies. As Harvey elaborates:

$[\mathrm{C}]$ orporations have profiteered from with-holding the benefits of their technologies (such as AIDS drugs) from the public sphere, as well as from the calamities of war (as in the case of Halliburton), famine, and environmental disaster. It raises the worry as to whether or not many of these calamities or near calamities (arms races and the need to confront both real and imagined enemies) have been secretly engineered for corporate advantage. (Neoliberalism 38)

17. Foucault recognizes that contemporary biopolitically defined populations cannot "be disassociated from the framework of political rationality" known as "liberalism" or, in the United States, "American neoliberalism" ("Birth of Biopolitics" $73,78)$.

18. "Marx had been right about a great many things" (Silko 290).

19. Clarke et al. situate their work predominantly in the trends of medicalization/biomedicalization that occurred in the United States after WWII.

20. Trigg and Leah Blue's business strategy reflects the trend that in neoliberal biomedicalization the "centralization of facilities, healthcare services, and corporate 
healthcare coverage has been on the rise through the merger and acquisition of hospital facilities, insurers, physician groups, and pharmaceutical companies" (Clarke et al. 59).

21. Clarke et al. explain, "Trends in corporatization and commodification are embodied in the moves by private corporate entities to appropriate increasing areas of the health-care sector under private management and/or ownership," (58) For more on fused neoliberal ownership and management see Harvey, Neoliberalism 32.

22. The international interdependence of Bio-Materials, Inc. and the Blue Water group with other technological and social networks, such as "a brisk trade exists between the U.S. and South America, where videos of live torture, abortions, fetal dissections, experiments, and surgical operations are made and sold," connects the biomaterial extraction process (which can be recorded and peddled) with an entire interdependent economy of body commodification (Stanford 30). For example, Trigg's interest in biomaterials both thematically and economically connects him to Serlo's experiments in South America where bioproducts are necessary for attempts to breed a "genetically superior" master-race conceived through in-vitro fertilization (561). Both Trigg and Serlo are invested in the concept of themselves as members and saviors of an elite race, who shall exploit the global subaltern in order to maintain the global hegemony. Echoing Trigg's sentiments that he would "do the world a favor" by draining undesirables of their biomaterials, Serlo notes that some people "are only fit as organ donors. That is the only useful function left for common rabble"” (560).

23. Clarke et al. describe the profitable markets that have emerged around populations' stratified access to medical services: 
[B]iomedicalization is stratified, ranging from the selective corporatization of 'boutique' biomedical services and commodities directed towards elite markets, to the increasingly exclusionary gatekeeping made possible by new technologies of risk and surveillance, to the stratification of rationalized medical care. (83)

24. Trigg reproduces the cycle of vampire capitalism where his exploitation and commodification of disenfranchised labor and their bio-products allows him to further maintain his own sociopolitical power, as well as validating the larger neoliberal, biomedical economy-all at the expense of the exploited, unrecognized subaltern who serve as the international labor for the biomaterials market. For Trigg, this is connected to his own self-serving dream of curing himself:

Trigg was becoming acquainted with human organ transplant research teams at the university hospital. Someday Trigg would walk again with the aid of their electronic-impulse hookups to his legs and skull. He wanted to help research teams obtain the fresh biomaterials they needed. (389).

25. With a decreasing portion of the population in so-called developed countries employed as industrial laborers, and less need for a reserve work force, national policies evolved to reflect this new situation. Bauman posits that neoliberalism emerged at a time where "[g]iven the present-day tendency to measure the effects of business by the shareand-dividends value rather than the volume of product, as well as the rapidly falling role of labour in production and the global dimensions of companies' freedoms, the 
investment in welfare provision does not seem all that profitable after all" (53). Sassen points out economic restructuring often "involves keeping the increasingly privatized and corporatized economy going by getting rid of excessive social contract-related expenditures. Debt repayment and austerity programs are disciplining mechanisms that serve this larger project of protecting a particular type of economy" (Expulsions 41).

26. Bauman explains that when additional labor are needed, companies often look for workers "abroad" in "less demanding places" (54).

27. Bauman argues that to combat traditional modernist definitions of labor that recognized "only such labour that has a value recognized by others-labour which commands salaries or wages," we must seek the "emancipation of work from marketcentred calculations and the constraints they impose" in order to value other types of labor and laborers $(5,97)$.

28. With particular relevance to the biomaterial trade, David Harvey points out that neoliberal commodification and accumulation by dispossession often "amount[s] to putting a price on things that were never actually produced as commodities" (Neoliberalism 166).

\section{Almanac 617.}

30. Much of the news and scholarship on Los Mineros is published in Spanish; however, when possible, I have tried to provide English resources. For more information on Los Mineros and Cananea, I recommend Bacon's books and on-line articles, as well as Gómez's book and on-line articles and speeches. 
31. See the United Association for Labor Education (UALE) report "Crossing the Border to Cananea: High Stakes and Teachable Moments for North American Workers" for more information on of health and safety conditions.

32. In this conflict one striker died, twenty were tortured, and many more were beaten (Gómez 203-4).

33. For a more detailed account of the troop invasion and events at the Los Mineros union hall in Cananea, see Bacon's The Right to Stay Home and "Tear Gas in Cananea."

34. For more on this see Bacon's The Right to Stay Home 98-99.

35. See Bacon’s “Miners and Farmers Challenge Mexico’s Copper Giant.”

36. This trip is referenced in the United Steelworkers' article "United Steelworkers Stand with Los Mineros in the Struggle Against Grupo Mexico" and Amelia Escobar's "Yaquis y Padres ABC se unen a movement contra Grupo México." 37. An account of this is also available in Bacon's "Miners and Farmers Challenge Mexico’s Copper Giant.” 


\section{CHAPTER III}

“MY STORY IS NOT UNIQUE”: LISTENING TO FARMWOKERS' VOICES IN VIRAMONTES'S UNDER THE FEET OF JESUS AND LUCAS'S

FORGED UNDER THE SUN / FORJADA BAJO EL SOL ${ }^{1}$

Listen to my silence.

It is soundless and empty.

It is vast and deeply profound.

Oh God, my silence is so loud, that it wakes my nights

and it makes me break down

without sleep.

Listen to my silence,

It moves like the presence

of grief around me

and denies me the right

to speak.

- María Elena Lucas in Forged under the Sun / Forjada bajo el sol 260

Through her poetic lyrics, migrant farmworker and labor organizer María Elena Lucas resists the muting of her bold voice. She challenges us to interrogate spaces of silence and discover the voices of those workers who are denied the "right to speak." 
Lucas's poems, plays, personal accounts, and other texts transmit tales of her painful and remarkable life; yet she insists, "You know, my story is not unique. I don't think it's really unusual" (70).

Most people in the United States rarely hear the stories of farmworkers like Lucas. While many enjoy the literal fruits of farmworkers' labors, the voices of these agricultural workers are structurally obscured from the consumer's consciousness. ${ }^{2}$ Factors such as language barriers, arduous labor, abject poverty, voting obstructions, and marginalized residency status prevent many agricultural laborers from voicing their experiences in the larger public sphere. This effacement results in consumers seeing shiny apples and juicy peaches materialize in markets without recognizing the human cost embedded in these foods.

Over the last sixty years, organizations such as the United Farm Workers (UFW), Farm Labor Organizing Committee (FLOC), Coalition of Immokalee Workers (CIW), and other community and religious groups have fought to give farmworkers a voice in all aspects of their lives, including working conditions, living standards, and government. Yet, the battle for farmworker dignity and justice takes place not only on the picket line and in courtrooms. As Lucas exemplifies, it also occurs through sharing workers' stories, educating the public, and advocating for change. To these ends, literature serves as a transformational force for transmitting and amplifying effaced labor voices to a wider public audience.

Both professional authors and worker-writers create texts that give voice to farmworkers' struggles and offer counter-narratives that challenge the xenophobic rhetoric of prevalent anti-immigrant discourse. Helena Maria Viramontes's literature is 
recognized as "giving a voice to Americans whom many readers have not heard" (Welch, Elkins, and Cook in Dulfano 647). This is particularly true of her novel Under the Feet of Jesus, which shares the struggles of a migrant farmworker family in California in the second half of the twentieth century. Under the Feet of Jesus conveys characters' workplace, educational, and healthcare experiences by rhetorically integrating bilingual language use with overarching narratives that signify the structural and institutional marginalization of farmworkers' voices. To more fully explore the socio-cultural context of farmworkers' effacement, Under the Feet of Jesus may be read alongside Forged under the Sun / Forjada bajo el sol, as a complementary narrative that gives a personal voice to the legacy of workplace abuse and institutional marginalization. In her bilingual, multi-genre memoir, Forged under the Sun / Forjada bajo el sol, Lucas testifies to the inextricable links between language, labor, narrative, agency, and activism. The text's editor, Fran Leeper Buss, explains that by "using the language and symbol systems of her heritage, María Elena constructed a new history for her people, recorded in her diaries, plays, songs, and poems" (30).

As Forged under the Sun / Forjada bajo el sol passionately shares the struggles and triumphs of farmworkers, it epitomizes John Beverley's criterion that the "situation of the narration in testimonio has to involve an urgency to communicate, a problem of repression, poverty, subalternity, imprisonment, struggle for survival, implicated in the act of narration itself' (32). Lucas's account gives voice to the experiences of many farmworkers. Because, in Lucas's works, her "story is not unique," in her testimony she "does not conceive of him/herself as extraordinary but instead as an allegory of the many, the people" (Lucas in Buss 70; Gugelberger and Kearney 8). Therefore, we can 
understand testimonies like Lucas's not only as a singular narrative but, more broadly, as a political act that represents collective experience. As Marc Zimmerman explains, "By virtue of its collective representativeness, testimonio is, overtly or not, an intertextual dialogue of voices, reproducing but also creatively reordering historical events in a way which impresses as representative and true and which projects a vision of life and society in need of transformation" (12). Referencing Under the Feet of Jesus, Anne Shea notes that placing a "novel alongside testimonies is not to eradicate the differences between the terms of their production and reception but to see them both as articulations that respond to a shared set of social conditions" (137). In such a fashion, Forged under the Sun / Forjada bajo el sol offers a concrete historical context for understanding the "shared set of social conditions" portrayed in Under the Feet of Jesus. Under the Feet of Jesus and Forged under the Sun / Forjada bajo el sol represent different types of authorship-from researched professional fiction to experiential worker testimony-and demonstrate the temporal, geographical, and cultural range of farmworkers' struggles. ${ }^{3}$ Yet, together, these texts illustrate and enact efforts to strengthen the agency of farm laborers' collective voice in workplaces, communities, schools, and other aspects of public life in the United States.

Under the Feet of Jesus and Forged under the Sun / Forjada bajo el sol transmit, as Janet Zandy describes, “working-class experience, history, knowledge, language, values (with all their contradictions and complexities) out and into the world" (86). By circulating farmworker topics in a larger public sphere, the authors serve as "conduits, mediators, pipelines for those (usually) silenced multiple voices" (Zandy 86). Read together, these works speak as intertextual counter-narratives that surmount barriers to 
farmworkers' voices and amplify a cry for social, economic, political, and environmental justice. Therefore, the purpose of this chapter is not only to offer scholarship that contributes a thoughtful analysis of Under the Feet of Jesus and Forged under the Sun / Forjada bajo el sol's engagements with farmworkers' effaced linguistic and democratic voice. More importantly, these texts must be approached on their own intended terms: as tools that communicate a call for action to transform the inadequacies of existing geopolitical, social, and economic structures in meeting the multifaceted needs of agricultural laborers. ${ }^{4}$

To such ends, this chapter analyzes how Under the Feet of Jesus and Forged under the Sun / Forjada bajo el sol recount and surmount the complex ways in which farmworkers' linguistic and democratic voices are functionally, institutionally, and structurally marginalized in the United States. This inquiry builds from an initial literary interpretation to an expanded social and geopolitical analysis. Expanding in scope, this chapter considers: first, the particular rhetorical construction of farmworkers' fictionalized linguistic voices; second, the linguistic and institutional marginalization of farmworker children in schools; and, third, the institutional and structural effacement of farmworkers' democratic voice in the workplace and contemporary political economy. Because Under the Feet of Jesus and Forged under the Sun / Forjada bajo el sol not only communicate circumstances but also call for interventions, this chapter moves towards a theorization of the present in which the effacement of farmworkers multifaceted voices can be conceptualized and combatted through concrete, contemporary on-the-ground practices. 


\section{"Listen to my silence": What voice? Whose voice? Why voice?"}

Voice is one of the most fraught categories of inquiry in English studies, and perhaps the humanities as a whole. However, this does not mean that we should shy away from investigations in which the subjective concept of voice intersects with the physical realities faced by working people, like farm laborers, in concrete settings such as workplaces, schools, and medical facilities. Heterogeneous, multidisciplinary theory is necessary to further our understanding of how and why certain voices are marginalized within U.S. society, as a whole, and academia, specifically. However, scholarship must also engage with the material consequences of this marginalization, as well as the potential on-the-ground implications of popularizing labor voices that are commonly obscured within the U.S. public sphere. In pursuit of this latter line of inquiry, voice is a central theme-and a central problem-in this chapter. As such, this chapter is positioned within the space of divergence between scholarly theory and on-the-ground practice, or, as Étienne Balibar recognizes, within the "latent conflict between the idea of representation (interpretation, contemplation) and that of activity (labour, practice, transformation, change)" (The Philosophy of Marx 25). Mindful of the potential on-theground material implications of particular representations and theoretical paradigms, this chapter resists approaches that undercut the agency of voice before marginalized populations, like farmworkers, have had the chance to be actively heard in the larger public, political, and academic spheres.

Melanie Sperling, Deborah Appleman, Keith Gilyard, and Sarah Freedman note that within literary studies, "[T]he term voice is used frequently and freely both to stand for and to accompany such language and literacy concepts as writing style, authorship, 
language register, rhetorical stance, written and spoken prosody, the self in text and in discourse, and scores of others" (70). ${ }^{6}$ While such invocations of voice are commonplace when discussing literary texts, this chapter adopts a slightly different approach. This chapter specifically engages voice as a linguistic and democratic concept that has concrete material consequences for particular populations of laborers. ${ }^{7}$ In Under the Feet of Jesus, Viramontes is not reproducing a specific migrant farmworker's spoken voice; rather, she is self-consciously constructing a collective voice through which the linguistic and cultural diversity-as well as the exploitation and effacement-of farmworker populations might resonate in the wider public sphere. Similarly, as a worker testimony, Forged under the Sun / Forjada bajo el sol transmits the "collective representativeness" of an "intertextual dialogue of voices" (Zimmerman 12). Together, Under the Feet of Jesus and Forged under the Sun / Forjada bajo el sol are, in Judith Butler and Athena Athanasiou's terms, "articulating a voice of the people from the singularity of the story and the obduracy of the body, a voice at once individual and social" (175) Proceeding from this realization, the chapter frequently employs the generalized term voice to denote the unification of diverse individual perspectives into a collective call to action, as reflected in AFL-CIO president Richard Trumka's eloquent assertion that the labor "movement gives voice to the hopes, values, and interests of working people every day" (Trumka). This use of the singular term does not dismiss the contradictions and complexities of individual voices; rather it emphasizes embracing elements of commonality to mobilize mass movements. ${ }^{8}$

Through Under the Feet of Jesus and Forged under the Sun / Forjada bajo el sol the authors communicate fictional and first-hand narratives of farmworkers' labor 
exploitation, educational exclusion, physical injury, and language discrimination to a public audience, potentially expanding the base for collective action. The authors rhetorically manipulate language[s] as an abstracting symbol system through which to educate the public about concrete material and psychological violence against farmworkers and amplify a call for action. In Dispossession: The Performative in the Political, Judith Butler and Athena Athanasiou consider this complex interplay between language, narrative, corporeality, and action:

What happens then to the language of representation when it encounters the challenge of conveying broken human corporeality into the body of the text? What happens to the language of representation when it encounters the marked corporeality-at once all too represented and radically unrepresentable-of contemporary regimes of "horrorism"? How does ineffability organize the nameable? It seems to me that our critical task might entail tracing the problematic of the articulation between what cannot be said and what should be said, an articulation without guaranteed purity... This is perhaps about imagining and putting forth the necessary possibility of shifting or disrupting this limitation, even though there can be no question of fully overcoming it and even though (or because?) language always fails us. In the context of proliferating contemporary forms of injurability, we are called, politically and intellectually, to name these occasions and come to grips with them. (Butler and Athanasiou 13233) 
Butler and Athanasiou point out that communicating the stories and experiences of effaced populations is of primary importance, in spite of the implicit inadequacy of language to fully do so-"what cannot be said and what should be said, an articulation without guaranteed purity" (133). While Viramontes and Lucas's texts are implicitly limited by the very nature of language and personal perspective, they are nonetheless vital for communicating the "proliferating contemporary forms of injurability" as a "politically and intellectually" grounded public call for action. In particular, as Under the Feet of Jesus and Forged under the Sun / Forjada bajo el sol illustrate the functional effacement of farmworkers linguistic and democratic voice (in schools that discriminate against Spanish speaking children; health clinics where English is a prerequisite for treatment; and workplaces where laborers have no collective, democratic say over their own working conditions and the employer's violations), it becomes clear that these sites are symptomatic of a more insidious institutional marginalization in which labor exploitation, educational exclusion, and other instances of marginalization similarly stem from overarching structural dispossession.

Recognizing that dispossessed populations are "narrativized by the law, political economy, and ideology of the West....curiously sewn together into a transparency by denegations, [which belong] to the exploiters' side of the international division of labor," Spivak famously asks: "On the other side of the international division of labor from socialized capital, inside and outside the circuit of the epistemic violence of imperialist law and education supplementing an earlier economic text, can the subaltern speak?" $(280,283)$. For Spivak, assuring that the subaltern, on the exploited side of the 
international division of labor, achieve voice requires more than just an adjustment to the politics of representation or aesthetics. It necessitates the active reformation or revolutionary reconstruction of hegemonic power structures. "Who the hell wants to museumize or protect subalternity?" Spivak declares: "You don't give the subaltern voice. You work for the bloody subaltern, you work against subalternity" (Spivak in de Kock 46).

Spivak's fiery statement compels us to consider the links between literature, material conditions, social movements, and counter-hegemonic change. She does not simply call for an intellectual adjustment to the representation of voices or subject construction; rather, she advocates activity that fundamentally rearticulates lived power relations. This designation highlights how, when theory critiques power structures without taking into account the situated material realities faced by existing marginalized populations, "the site of cultural difference can become the mere phantom of a dire disciplinary struggle in which it has no space or power," as Homi Bhabha points out (46). Under these avoidable conditions, the "Other text is forever the exegetical horizon of difference, never the active agency of articulation... The Other loses its power to signify, to negate, to initiate its historical desire, to establish its own institutional and oppositional discourse" (Bhabha 46). By engaging two types of authorship, professional fiction and first-hand testimony, within a context of contemporary farmworker issues linking literary and theoretical inquiry to on-the-ground social movements, this chapter attempts to address these texts as active oppositional discourses articulating a powerful call for collective action. 
In support of farmworkers' own voices, those of us whose voices are privileged in the United States can mobilize our advantage to the benefit of others. To not only "give the subaltern voice," but to "work against subalternity" by shifting the fundamental power dynamics of economic and geopolitical systems that construct, profit, and prosper on dispossessed populations, requires mass mobilizations and collective calls for change. No lone, individual voice can catalyze a paradigm shift; however, the collective (negotiated, conflicting, imperfect) voice of the masses has the ability to create systemic alterations to lived power relations. As Butler and Athanasiou recognize, for marginalized populations such as farmworkers, the "struggle then to regain 'standing' and 'voice' becomes one that cannot be done alone, requiring as it does collective support, if not a social movement" (77) As this chapter moves from considering a specific literary construction to an overarching structural configuration, it straddles the dangerous Balibarian conflict between the idea of representation and of activity, only to come down firmly on the side of action. As Cesar Chavez urged, the public can "add your voice to our demands of decency" for farmworkers (Jensen and Hammerback 134). Currently, the Coalition of Immokalee Workers and Fair Food Program "harnesses the power of consumer demand to give farmworkers a voice in the decisions that affect their lives, and to eliminate the longstanding abuses that have plagued agriculture for generations" ("Fair Food Program"). It is my sincere hope that this chapter will contribute to this mission. 


\section{“[A] woman named Star": Constructing Farmworkers' Voices through Spanish/English Language Use ${ }^{9}$}

"It's difficult to get used to living in the United States. If you can't speak English, then your voice is worthless. Even if you're educated, you have to work in the fields. You're never your own boss, and the mayordomos mistreat and humiliate you. You have to learn to accept it because that's the only way to survive" (Cuj in Rothenberg 48). Migrant farmworker Demetrio Cuj's statement highlights the extent to which issues of linguistic and democratic voice are fundamental in the struggle for farmworkers' rights. His experience illustrates how both language proficiency and structural obscuration can make workers feel that their voices are "worthless," as even "educated" workers may not have access to the linguistic or institutional agency to combat mistreatment and humiliation in the fields. Additionally, Cuj's statement suggests that the material conditions of daily life-meeting basic needs to "survive"-remain the paramount concern of many farmworkers. ${ }^{10}$

As a fictional text (grounded in existing cultural and historical contexts), Under the Feet of Jesus implements the artistic, rhetorical use of use of English and Spanish to convey, legitimize, and empower the linguistic experiences of farmworkers. Under the Feet of Jesus offers a glimpse of the language diversity of migrant farmworkers, some of whom are monolingual Spanish speakers, some of whom are proficient in English, some of whom are bilingual, some of whom speak other languages. By not only voicing the perspectives of farmworkers to a larger U.S. audience, but by doing so in a way that recognizes the linguistic heterogeneity of this population, Under the Feet of Jesus 
demonstrates the important relationships between language, cultural identity, and the struggle for farmworkers' rights. ${ }^{11}$

When asked about her language use in Under the Feet of Jesus, Viramontes defended "the relevance of Spanish to be truthful to my characters. I really, really have to be truthful to how they speak. It's my responsibility to capture it in an honest and open way" (Viramontes in Flys-Junquera 227). While a growing number of farmworkers speak an indigenous dialect as their first language, statistics still support the applicability of Viramontes's Spanish use to capture farmworkers' speech, as the vast majority of farmworkers are from Mexico and speak Spanish as their primary language (McCauley et al.). The 2012 National Agricultural Workers Survey conducted by the United States Department of Labor found that 70 percent of farmworkers select Spanish as their dominant language, while 57 percent of all farmworkers speaking little or no English (U.S. DOL). Yet, Viramontes's statement also suggests something beyond what this quantifiable data demonstrates. It marks how language use is intimately connected with personal and cultural identities.

As Gloria Anzaldúla explains (and enacts) in her seminal text Borderlands/La Frontera, "Ethnic identity is twin skin to linguistic identity-I am my language" (81). In this context, Under the Feet of Jesus illustrates how, in the border space that José David Saldívar depicts as a "paradigm of crossings, intercultural exchanges, circulations, resistances, and negotiations," farmworkers' identities are shaped by the interaction between multiple languages and cultures (Border Matters ix). While maintaining the importance of linguistic identity, according to Kamala Platt, Anzaldúla promotes transcending cultural or language divides in order to connect "members of a historically 
disempowered community with members of a dominant group as a means of dismantling domination" (48). Similarly, Viramontes creates a text that bridges cultural, linguistic, and experiential differences to share a story of migrant farmworkers with members of the wider public sphere as a means of raising awareness and potentially "dismantling domination" related to the linguistic, institutional, and structural effacement of many farmworkers.

In order to create a text with resonance in the public sphere, overarching language issues-such as the domains of Spanish and English use, the conditions under which bilingual characters choose one language over another, and the implications of language proficiency or choice-seem to be of more concern to Viramontes than replicating actual regional or cultural speech patterns. As evidence of this, Under the Feet of Jesus does not use quotation marks, and the reader only has access to conversations that are filtered through different characters' perspectives. According to Jeehyun Lim, the reader receives characters" "internal translation" rather than actual speech acts (232). While Viramontes claims to have created dialogue that is "truthful" to how her characters speak, this does not mean that she is reflecting exact speech as articulated by a character. Instead, she creates a text that emphasizes the interplay between Spanish and English as the languages rub against each other in the border space.

Under these conditions, it would be ill-advised to look too specifically at Spanish use on a grammatical level; rather, it is most productive to examine the overarching social and physical contexts where Spanish is used in the novel in order to connect these linguistic occurrences with institutional and structural critiques. While some literary critics refer to Under the Feet of Jesus's Spanish use as code-switching, I propose that 
code-meshing is a more applicable concept for a socially-grounded literary analysis. ${ }^{12}$ In contrast to code-switching, which is popularly described as the unthinking or instinctive shuttling between languages, code-meshing creates a space of agency by identifying the active and purposeful integration of languages for intended rhetorical and ideological effect. Sara Michael-Luna and Suresh Canagarajah point out that in code-meshing, the "dominant discourse is mastered, resisted, and rewritten strategically through integration of local, vernacular discourse within established discourse" $(58) .{ }^{13}$

While Spanish use in Under the Feet of Jesus may be sparse, by investigating the context in the novel where Spanish is used, one may better understand how code-meshing is adopted as a compositional technique that rhetorically signifies a monolingual Spanish speaker's experience or a bilingual speaker's language choice within particular hegemonically power-latent contexts. ${ }^{14}$ This method pushes against the boundaries of disciplinary-specific literary or linguistic inquiry in order to emphasize the links between textual inquiry and contemporary farmworker movements (in other words, Balibar's conflict between the idea of representation and of activity). Because Under the Feet of Jesus is not only a literary work-but also a social text-this focus on the domains in which farmworkers face institutional and structural effacement of their linguistic and democratic voice ultimately underscores the need for concerted action in particular spaces.

Specifically, instead of offering an English-only text that glosses the language variation among mono- and bi-lingual Spanish speakers, Under the Feet of Jesus's use of code-meshing signifies: first, the contexts where speakers might typically conduct a conversation exclusively in Spanish; second, where bilingual speakers are faced with making decisions about which language to choose; and third, the cultural and material 
impacts of language proficiency and choice within particular domains and institutions. While none of these individual assertions should surprise linguists, taken as a whole, this literary code-meshing strategy signifies the culturally-grounded mobilization of fiction to assemble and circulate a collection of farmworkers' voices as a method for catalyzing social action that combats the material consequences of farmworkers' economic exploitation, institutional marginalization, and structural effacement.

In the novel, as in some farmworkers families, older members are monolingual Spanish speakers and the children have greater bilingual Spanish/English proficiency. Accordingly, representations of dialogue spoken by the mother, Petra, and father-figure, Perfecto, contain more Spanish than the younger characters' speech. For instance, when 13-year-old Estrella states, "Come to bed, Mama," her mother, Petra, replies "Yo no quisiera separarme de tu lado" (41). Since the mother is a monolingual Spanish speaker, in real life such an exchange would have happened in Spanish. Yet, communicating the younger character's dialogue in English not only makes the text more accessible to English-only readers, code-meshing additionally rhetorically marks linguistic differences between older and younger characters in the novel. In general, scholarship on the domains of Spanish and English use for bilingual Hispanic speakers conducted by François Grosjean, Rosaura Sanchez, Fernando Peñalosa, and others suggest that the private domain of the home is predominately associated with Spanish use. Research shows that even bilingual parents and grandparents often choose to speak Spanish in the home with their children.

In contrast to the Spanish and English use in exchanges between older and younger characters (such as Estrella and her mother) and conversations in the home, 
exchanges among bilingual teenage characters are presented almost exclusively in English. When young characters refer to Estrella, even her name is frequently communicated in English, as "Star." A few notable exceptions are that bilingual children and teenagers often use Spanish when they tease each other, express strong emotions, and engage in parenting roles. For instance, anxious that they might get caught stealing fruit to sell, Gumecindo yells to Alejo, “¡Mano, pronto!” (38). Additionally, when Estrella is in a mother-role, taking care of her younger siblings, constructions of her speech include increased Spanish use. This code-meshing creates dialogue that mirrors Estrella's own mother's language use and additionally suggests how Spanish may associated with acts of parenting in the home. ${ }^{15}$ Far beyond Scott A. Beck and Dolores E. Rangel's assessment that Under the Feet of Jesus is "spiced with bits of Spanish," Spanish and English codemeshing rhetorically emphasizes the conditions under which bilingual speakers typically use each language (16). ${ }^{16}$ This literary variation not only signifies patterns of language practices but also suggests the links between language, labor, and culture.

One of the most Spanish-heavy scenes in the novel occurs when Gumecindo is speaking to a group of piscadores. Gumecindo, who is a teenager and has been to public school in Texas, presumably has some degree of bilingual proficiency. Because almost all of his dialogue until this point in the novel is presented in English, it stands in stark contrast that Gumecindo's speech with the other piscadores is delivered almost exclusively in Spanish. This has several implications: First, Gumecindo's extended Spanish use again emphasizes the fact that most farmworkers identify Spanish as their first langauge; however, some farm laborers, particularly children, may be bilingual. The fact that the dialogue between a central character in the novel, Gumecindo, and this 
unnamed, undifferentiated group of piscadores is primarily represented in Spanish additionally suggests the author's purposeful, rhetorical use of code-meshing to "be truthful" to the voice of farmworkers within this predominately English text.

Secondly, this scene suggests the types of communication barriers faced by monolingual Spanish speaking (or non-English speaking) farmworkers in the U.S. Specifically, when a piscador looking for Gumecindo's cousin asks "Y tu primo?," Gumecindo's reply, "Taking a leak," is written and presumably spoken in English. The piscador’s response, “¿Cómo?,” is followed by the English narration, "He seemed not to understand.” The piscador eventually asks "Qué es eso, take un leak?" to which Gumecindo’s reply, portrayed in Spanish, is “EEn serio?” (63-64). If this were a record of real-world speech, linguists might characterize Gumecindo's movement between Spanish and English as code-switching. However, by focusing on how the novel enacts codemeshing as a compositional strategy, the dialogue stays "truthful" to how characters speak while additionally highlighting the ways in which the transfer of information is complicated by the esoteric nature of colloquialisms, like "taking a leak." While the content of this example may seem insignificant (or perhaps very significant given the fact that farmworkers have no federally guaranteed access to sanitary facilities in the field ${ }^{17}$ ), as this chapter will later investigate, these types of language barriers can influence farmworkers' access to wider public spheres and agency within them. Specifically, codemeshing in this scene rhetorically emphasizes how, on one hand, limited English proficiency can inhibit understanding or participation for the monolingual Spanishspeaking piscador. However, on the other hand, bilingual language proficiency allows Gumecindo access to multiple codes to choose from when expressing himself. 
Third, we can consider how the reader's experience might also be affected by his or her proficiency in Spanish and/or English. Inverting the linguistic confusion of the monolingual Spanish-speaking piscadores, it is the monolingual English reader who may find this Spanish text ambiguous. One result of this, as Lourdes Torres explains, is to "subvert the commodification of Spanish and gratify the bilingual, bicultural reader" (78). The rhetorical impact of Spanish use in this section serves to, as definitions of codemeshing state, "resist identities and redefine discourses" (Michael-Luna and Canagarajah 58). Framed in this way, bilingual ability is empowering, both for Gumecindo who can adjust his language use based on the participants in a conversation, as well as for the bilingual Spanish/English reader who has greater access to this section of text. Conversely, the potentially obscured meaning of this text for the English-only reader illustrates the use of code-meshing to rhetorically emphasize the obscuring of farmworkers' voices that occurs in the larger U.S. culture.

Recognizing, as Geneva Smitherman notes, that language is inextricably embedded within organizations of power, one can additionally consider the rhetorical use of code-meshing to articulate counter-narratives that voice farmworkers' perspectives or experiences, which are commonly obscured from the wider U.S. society. Under the Feet of Jesus conveys fictional voices of migrant farm laborers, a population that may feel their own voices silenced or devalued for a variety of reasons, including the degree to which limited English proficiency can preclude full participation in the wider publicsphere. As Cuj notes, limited English proficiency can stand as an initial, seemingly insurmountable obstacle for some farmworkers who feel their voices are obscured in the workplace and United States as a whole. Through its predominately English composition 
with the purposeful integration of untranslated Spanish words or phrases, the very language of the Under the Feet of Jesus confronts these linguistic power paradigms by illustrating the concrete circumstances in which language proficiency impacts characters' access to and agency in occupational, home, and public spaces.

Due in part to the way in which capitalist production fundamentally obscures the labor embedded in commodities, for many U.S. consumers, the laborers who harvest our food are under-recognized, as nondescript as the conspicuously unnamed piscadores in this scene. Often the public never hears their stories, their voices, or their messages, as language barriers and institutionalized social, political, and economic structures, obscure their experiences from public view. However, as Buss identifies, farmworkers' texts like Lucas's "give names to the nameless so they can be known" (27). Using Spanish and English, Viramontes's and Lucas's works circulate farmworkers' counter-hegemonic narratives that recount and surmount institutional and structural marginalization in the larger public sphere.

\section{“This is a crime:" Narratives Recounting and Surmounting Linguistic Barriers and Institutional Marginalization ${ }^{18}$}

Under the Feet of Jesus is not only "truthful" to many farmworkers' monolingual Spanish or bilingual Spanish/English voices; the novel is also "truthful" to the ways in which farmworkers' language proficiency may link with institutional marginalization in particular spaces. Specifically, Under the Feet of Jesus illustrates how the effacement of Estrella's linguistic voice at school is symptomatic of the insidious institutional marginalization that migrant farmworker children have historically faced in schools that are unprepared, underfunded, or unwilling to developing educational programs that meet 
the unique needs of children who are likely to move between schools or in and out of school depending on harvest schedule and crop locations (Dunbar and Kravitz). ${ }^{19}$ While particular programs currently offer educational assistance to migrant farmworker children, a 2000 Human Rights Watch report entitled "Fingers to the Bone: United States Failure to Protect Child Farmworkers" states, "Nationally, the dropout rate for farmworker youth is 45 percent. Reflecting this legacy of under-education, a full 80 percent of adult migrant farmworkers function at a 5th-grade literacy level or less" (48). These statistics provide a grim perspective on the contemporary state of migrant farmworker education and suggest the persistence of structural barriers to migrant farmworker children similar to those Lucas and Viramontes illustrate in schools with "English-speaking teachers, strange curricula, and conflicting rules" (Arceo, Kusserow, and Wright 224). ${ }^{20}$

Both Under the Feet of Jesus and Forged under the Sun / Forjada bajo el sol narrate the emotional and material impacts that ethnic, social, and linguistic prejudices have when institutionalized in educational systems. In her introduction to Forged under the Sun / Forjada bajo el sol, Buss recalls revealing this to Lucas:

I had found evidence that during her childhood it was public policy in [her home of] South Texas to make sure that so-called Mexican children did not attend school past the age of ten or twelve. In fact, school systems exchanged suggestions for circumventing attendance laws. They worked out techniques to ensure they received tax credits for the Mexican children in their districts while guaranteeing that none of those children would 
achieve a sufficient education to equip them for work beyond the fields. Public humiliation and separate seating were common tactics. María Elena looked incredulous as I told her what I had read. "You mean it wasn't just because of my parents or an accident or because I was poor that I didn't get school? You mean they actually planned it that way?" I nodded, and she cried. To read no poetry, to teach no history, to give no books to such a child: This is cruelty; this is a crime. (3)

Under these circumstances, the very fact that Lucas achieved an education and published Forged under the Sun / Forjada bajo el sol stands as a counter-hegemonic narrative in opposition to farmworkers' multifaceted educational marginalization. Buss notes that "Lucas, who always had a thirst for knowledge and who loved to write and paint, was angered by the realization that her lack of education was not only the result of the poverty her family suffered but of official policy as well" (134). ${ }^{21}$

Lucas's experiences suggest how, on one hand, Under the Feet of Jesus and Forged under the Sun / Forjada bajo el sol reflect Bourdieu's assertion that educational systems reproduce class divisions by providing individuals with varying access to cultural knowledge and credentials based on social class position. Bourdieu characterizes school as "one of the fundamental agencies of the maintenance of the social order" that acts as "an institutionalized classifier which is itself an objectified system of classification reproducing the hierarchies of the social world" (Distinction 387). In other words, educational institutions naturalize historical and culturally specific power 
relations. School policies may reproduce social class exclusions and institutionalize stratified access to training, jobs, and economic security. ${ }^{22}$

Yet, on the other hand, Viramontes and Lucas suggest points for individual and collective resistance outside of Bourdieu's purview. ${ }^{23}$ Brought from the realm of theory into the gritty context of agricultural labor, Viramontes's fiction and Lucas's testimony serve as counter-narratives that illustrate farmworkers' surmounting institutional marginalization and exposing hegemonic power structures. Together Viramontes's novel and Lucas's testimony offer what Shea calls "narratives that articulate forms of oppositional knowledge and identity" (123). Under the Feet of Jesus and Forged under the Sun / Forjada bajo el sol depict how schooling systems serve, as Bourdieu asserts, for institutionalized social and economic classification; however, the texts also contribute oppositional narratives of farmworker children who overcome obstacles such as exclusion from legal protections, constant mobility, poor housing, economic pressures, and limited English proficiency to get an education in hopes of a better future (Arceo, Kusserow, and Wright 222). These texts function as alternate accounts that can disrupt hegemonic narratives of the lazy, uneducated farmworker, who is obstinately content as a monolingual Spanish speaker. By giving voice to farmworkers' struggles, Under the Feet of Jesus and Forged under the Sun / Forjada bajo el sol can "disrupt the hegemonic narratives of immigration and fracture the romanticized images of farm workers found on raisin boxes and in the nightly news" (Shea 137). These texts suggest methods for overcoming linguistic barriers and communicate the means by which institutional spaces may be circumvented or rearticulated to create opportunities for farmworkers to develop their language, literacy, and educational goals. 
Reflecting the socio-historical context that impacted Lucas's formal education (or lack thereof), Under the Feet of Jesus narrates how Estrella's pleas for knowledge fell silent in the classroom: "Estrella hated when things were kept from her. The teachers in the schools did the same, never giving her the information she wanted. Estrella would ask over and over, So what is this, and point to the diagonal lines written in chalk on the blackboard with a dirty fingernail” (24). Although school may have stirred Estrella's interest in literacy, the classroom did not provide the structure or curriculum to foster her language learning or burgeoning social voice. During the sporadic times Estrella was able to attend school, she faced an "alphabet she could not decipher" and words that were "foreign and meaningless...chalky lines on the blackboard" (24-25). While Estrella worked to understand the unfamiliar words and classroom customs, this struggle was augmented by teachers "more concerned about the dirt under her fingernails" than her fostering her intellectual ability (24). Reminiscent of Lucas, who remembers being "sent home because a little girl said I was stinking," in Under the Feet of Jesus, Estrella's teacher, Mrs. Horn, "asked how come her mama never gave her a bath...And for the first time, Estrella realized words could become as excruciating as rusted nails piercing the heels of her bare feet" (Lucas in Buss 85, Viramontes 25). Estrella recalls how some schools viewed her presence in the classroom as a temporary problem, and much like Lucas's educational experiences with "us real poor kids in the back," teachers said "good luck to her when the pisca was over, reserving the desks in the back of the classroom for the next batch of migrant children" (Lucas in Buss 84, Viramontes 25). Estrella's journey towards literacy is not only complicated by her evident linguistic struggles as a Spanish speaking student in an English-only classroom. ${ }^{24}$ This outward occurrence is 
symptomatic of the institutional marginalization of farmworker children in schools where, as Lucas discovered, official policy and planning has historically excluded this population.

Reading Under the Feet of Jesus beside Forged under the Sun / Forjada bajo el sol highlights the circumstances under which language proficiency and institutional barriers must be mutually considered to account for the historical marginalization of farmworker children in educational institutions. Specifically, Estrella's voice is at least doubly obscured in the classroom: Immediately, she faces challenges as a not-yet-literate child from a Spanish speaking household who is suddenly subsumed in an English-only educational system. ${ }^{25}$ Concurrently, like Lucas, Estrella is socially stigmatized by teachers who quarantine her in the back of the classroom and fuss over her physical appearance rather than focusing on her intellectual potential. ${ }^{26}$ These teachers demonstrate to Estrella that hurtful language can be used as a destructive weapon. Therefore, it is not in school, but in her nearly bookless home (having only her folded catechism chapbook) that with a supportive guide Estrella finally recognizes the power of language as a constructive tool.

Inverting the abstraction of language, Viramontes suggests that the familiar cultural and material surrounding of the home provides Estrella with a supportive environment in which to more fully understand and engage the power of language. With the help of her father-figure Perfecto Flores, Estrella learns how his carpentry tools, like language, can "build, bury, tear down, rearrange and repair" (26). She curiously links the "curlicue of a pry bar" with the shape of "script $A$ 's," and soon Estrella "lifted the pry bar in her hand, felt the coolness of iron and power of function, weighed the significance 
it awarded her, and soon she came to understand how essential it was to know these things. That was when she began to read" $(24,26)$. Overcoming marginalization in the classroom, sporadic enrollment in school, and grueling fieldwork schedules, in a literal and figurative tool-mediated learning process, Estrella achieves literacy in the safe, familiar surroundings of her home. ${ }^{27}$

While Estrella surmounts numerous obstacles in order to learn English, Under the Feet of Jesus does not simply conceptualize the acquisition of language power-bilingual proficiency or English literacy-as an end, but additionally as a means by which voice is developed to mobilize action and catalyze structural change. The repeating image of a physical tool-a solid, metal pry bar-symbolizes Estrella's conflicted engagement with literacy and institutional silencing. While the pry bar initially symbolizes a tool that aids Estrella's emerging English literacy, it reappears as a potential weapon in a moment of fear and confusion. Estrella "rummaged though Perfecto's tools until she found the thick pry bar" to protect herself from the enveloping feeling that "[s]omeone's trying to get me" (61). Pertra helps Estrella conceptualize the invisible institutional threat in linguistic terms, associating the fear with "La Migra." Only after the threat is named in Spanish and Petra identifies English language as a defensive tool that can be used for "telling La Migra you've lived here all your life," does Estrella at last lay "the crowbar across her lap" (62). Believing that the agency of her spoken voice (and her birth certificate under the altar of Jesus Christ) gives her power beyond physical aggression, Estrella is able to set the weapon aside.

The crowbar appears again at a moment when Estrella transitions from knowing how language describes and defends to recognizing how language can be used as an 
aggressive tool against institutional silencing. Unable to get help for Alejo at a health clinic, "Estrella opened the back door, pulled open the hidden trunk door, grabbed the crowbar which laid next to the red jack, heavy, iron cold, and walked back to the clinic" (148). With the "crowbar locked in her two fists," Estrella demands that the nurse "[g]ive us back our money" (149). The pry bar, like Estrella's own voice, is both a creative tool and a destructive weapon. Facing the nurse, pry bar in hand, Estrella must make a decision between trusting the potential power of her spoken voice or relying on the physical force of violence. Estrella asserts the agency of her voice, yet she frustratingly recognizes its institutional marginalization and structural effacement: "You talk and talk and talk to them and they ignore you. But you pick up a crowbar and break the pictures of their children, and all of a sudden they listen real fast" $(151) .^{28}$

Speaking to Estrella after the conflict, Alejo posits the ambiguous question: "Can't you see, they want us to act like that?" (153). Alejo recognizes that Estrella is at a crossroads. She knows that her individual voice is institutionally and structurally obscured. Yet, he warns her that violent reactions will not achieve meaningful social transformation but rather validate institutionalized prejudice and stereotypes. At this moment, although Estrella realizes her individual voice is powerless, she has not discovered how her democratic voice as part of a collective movement may function as an effective agent for change.

“You wetback don't understand": Collective Democratic Voice and Structural Reformation ${ }^{29}$

Along with written texts, such as Under the Feet of Jesus and Forged under the Sun / Forjada bajo el sol, other artistic forms communicate farmworkers' struggles and 
organizing efforts, such as UFW's historically popular Teatro Campesino and CIW's informative, music-rich contemporary labor actions. ${ }^{30}$ In Illegal People: How Globalization Creates Migration and Criminalizes Immigrants, David Bacon recounts how one "'teatro began to work toward forming the union.' They even began singing a song, 'La Frasesita,' about learning to read” (Juan Carrillo in Bacon 126):

I went to study English

because I felt I had to, so I could defend myself from an angry Anglo.

There where I worked

they tried to cheat me because of the damn English

I didn't know how to speak.

That white man told me

in his angry English words:

You wetback don't understand

what you are supposed to do.

You wetback don't understand

what you are supposed to do.

(Bacon, Illegal People 126) 
On one hand, these lyrics suggest ways in which farmworkers' effaced linguistic voice is reciprocally related to their institutional marginalization. On the other hand, Bacon emphasizes the way that this theatro experience was used to organize farmworkers whose collective democratic voice can combat linguistic, institutional, and structural marginalization. Workers' shared experiences and modes of performance (visual arts, literary texts, theater skits) not only, in Spivak's words, “give the subaltern voice," but more importantly are tools for catalyzing social movements that work "against subalternity" (Spivak in de Kock 46).

A social movement based on non-violent intercession against farmworker exploitation must simultaneously function on at least two crucial levels: alleviating injustices experienced on-the-ground and shifting the power relations that create these stratified conditions. To accomplish transformation on both levels, farmworkers must achieve a strong collective democratic voice in their workplaces and in the countries where they labor. Under the Feet of Jesus and Forged under the Sun / Forjada bajo el sol respectively provide fictional and first-hand descriptions of why such democratic voice is necessary and how it may be achieved. Specifically, Lucas's testimony provides a concrete context for exploring how scenes in Viramontes's novel intersect with realworld issues of effaced collective democratic voice. ${ }^{31}$

Working in the fields provides a necessary livelihood for Alejo, a fifteen-year-old migrant farmworker in Under the Feet of Jesus. But it is not a way of life he resigns himself to continuing: "Every time he awoke to the pisca, he thought only of his last day here and his first day in high school" (52). However, before Alejo has a chance to return to his grandmother's home in Texas, he suffers acute pesticide poisoning. As he is 
pilfering peaches to sell for desperately needed additional income, a crop dusting airplane begins to spray chemicals on the orchard a week ahead of schedule. Alejo "had not guessed the biplane was so close until its gray shadow crossed over him...the poison rolled down his face in deep sticky streaks....Air clogged in his lungs and he thought he was just holding his breath, until he tried exhaling but couldn't which meant he couldn't breathe" (76-77). As the poison weakens Alejo’s body, he "could no longer stand upright without feeling faint, his body weak from bouts of diarrhea and vomiting" (93). With only $\$ 9.07$ available, the farmworker family caring for Alejo worries that they cannot afford the medical care he needs and still pay for essentials like groceries and gasoline. Alejo's situation is all too common for young farmworkers. ${ }^{32}$ As an Oxfam America report entitled, "Like Machines in the Fields: Workers without Rights in American Agriculture" describes:

The protections provided by the law against the hazards faced by students working in shopping malls are stronger than the protections offered to children working in agriculture where toxic pesticides, heavy machinery and other hazards are commonplace. In addition, agricultural employers' ability to employ low-cost child labor (often "off the books") helps to perpetuate adult farmworkers' low rates of pay, which in turn prevents farmworkers from earning enough to afford child care or eliminate the need for their children's income from agricultural work. (Oxfam 40)

As the report suggests, child farmworkers suffer in a cycle of exploitation where low rates of pay and diminished health, safety, and child labor regulations perpetuate the need 
for families to send their children to the fields to earn essential additional income. As Under the Feet of Jesus illustrates, Alejo is in the peach orchard stealing fruit and receives delayed medical treatment because of the lack of safe working conditions and increased economic exploitation of farmworkers. ${ }^{33}$ This dire situation is compounded by lax agricultural labor laws and many farmworkers lack of collective democratic representation.

A collective democratic voice in the workplace can help farmworkers reform unsafe conditions, wage theft, child labor, and other injustices, such as those illustrated in Under the Feet of Jesus. However, powerful strategic legal barriers in the United States preclude agricultural workers from having a legally protected democratic voice in their workplace. Farmworkers are omitted from key federal labor legislation, including the National Labor Relations Act/Wagner Act (NLRA) and key provisions of the Fair Labor Standards Act (FLSA) which regulate minimum wage, maximum hours, working conditions, and child labor standards. Exclusion from these federal laws allows producers to pay agricultural workers on lower wage scale than non-agricultural laborers and employ children at a younger age than in other industries. "Children typically described going to work full-time outside of school at age 11 or 12 . Even very young workers, ages $7,8,9$, are not difficult to find working in the fields, however," states Human Rights Watch (Fields of Peril 19). As Alejo's narrative suggests, child farmworkers are often grossly undercompensated for their backbreaking labor, yet they have no legallyprotected collective voice by which they-or their parents-can bargain over wages, hours, and working conditions. 
In particular, because of contemporary farmworkers' exclusion from NLRA, they do not have a federally protected right to organize and bargain collectively with a democratic voice. ${ }^{34}$ As Under the Feet of Jesus illustrates, without a union, worker's center, or community-based labor organization, farmworkers have limited mechanisms by which to pressure employers to abide by laws and protect workers' health and safety. Furthermore, lacking workplace-based support systems, injured or ill laborers may be unaware of available medical treatment options and reporting standards. Through labor organizations, in Alejo's case workers might have more powerfully demanded they be notified of chemical applications and fields be sprayed on a pre-determined schedule. If accidents occur, a response protocol-established and enforced by a legally-binding negotiated contract between the company and worker organization-may have prevented delayed medical care such as Alejo experienced. Overall, without a legally protected democratic voice through which to collectively bargain with employers, unorganized farmworkers have little control over their working conditions, hours, and pay. In addition, without the support of a union, workers' center, or community-based labor organization, farmworkers may have trouble initiating and substantiating claims of unjust termination, sexual harassment, workplace injuries, or discriminatory practices.

In Forged under the Sun / Forjada bajo el sol Lucas's experiences provide a poignant personal context for understanding the type of hazards, injuries, and injustices described in Viramontes's fictional text, as well as the benefit for farmworkers that have collective democratic representation in the workplace. After laboring as a seasonal farmworkers throughout her childhood, adolescence, and early adult years, Lucas 
experienced what she terms a "sacred call to action," leading to her work as a community and labor organizer (Lucas in Buss 181). Lucas recalls:

[W]hen I was out in the fields organizing I saw a crop-duster airplane heading at all the people, then it began spraying right directly over them...I started screaming and hollering and shouting, "Hey don't do that! They're not animals!”...I started hollering at several people, "Hey, don’t let the guy spray you! It's dangerous." And one guy said, "But what can we do? They don't listen to us." (227)

Similar to Estrella's frustrated plea at the lack of medical care accessible for Alejo"[y]ou talk and talk and talk to them and they ignore you"-Lucas's recollection exemplifies how, without a legally guaranteed democratic voice for collective bargaining, farmworkers are structurally (and sometimes literally) silenced in the workplace, unable to adequately individually combat health, safety, and other violations (Viramontes 151).

A few years after this organizing experience, Lucas herself was severely poisoned and permanently disabled after a crop-duster began spraying chemicals over an open car that she was driving, "blanketing her with pesticides... and for the next three days she fought to live... a few weeks later, she still struggled with breathing difficulties and chest pain, loss of memory, and sudden periods of intense confusion" (2). Lucas benefited from having a labor union and support network to help her during this difficult ordeal, but she realizes that not all farmworkers enjoy these benefits: 
Whoever had been sprayed, it would have been very difficult for that person, unless that person was is contact with an organization like the UFW [United Farm Workers], which can help...Lots of people, when they get sprayed, they just do or don't die, without any help, and I know people that can never work again. Nobody worries too much when they think it's just a bunch of wetbacks. (248)

Much like Estrella and her family discover at the health clinic after Alejo's poisoning, Lucas points out that non-unionized farmworkers are disadvantaged on multiple levels when accidents occur, lacking information, structural assistance, medical care, and, often, public compassion. Moreover, without democratic collective representation they lack the bargaining power to change working conditions and prevent such injuries from reoccurring.

Lucas realizes that the workplace hazards and violence that farm laborers suffer result partially from legal exclusions that preclude farmworkers from protected organizing for a collective democratic voice by which to bargain over wages, hours, and working conditions. "I read the National Labor Relations Act that was passed in 1935," Lucas explains. "It stated that 'All people have the right to organize for collective bargaining except for the farmworkers,' All of a sudden, for the first time in my life, I realized what I really was, due to the law, a farmworkers in bondage, a legal slave as inconspicuous as an earth worm" (186). Lucas recognizes that by restricting this basic right to speak out against workplace injustice with a collective democratic voice, farmworkers, and particularly undocumented workers and laborers on temporary visas, 
are singled out for a type of modern slavery where they are intimidated, abused, and, too often, exterminated. This reciprocal linkage among labor abuse, legal exclusion, and effacement of democratic voice suggests the extent to which issues of structural expulsion and material exploitation must be jointly considered in addressing farmworker issues.

In addition to lacking a legally protected collective voice in the workplace, undocumented farmworkers and those in the United States on temporary work visas also lack a democratic voice in the electoral politics of the countries where they labor. The United States agricultural economy depends on the labor of foreign-born farmworkers, with over 78 percent of farmworkers crossing the U.S. border to work (U.S. DOL 2012 National Agricultural Workers Survey). However, “[i]mmigration and labor law work together to create a legal space which excludes the voices of guestworkers," Shea explains in her essay on Under the Feet of Jesus: "Through the exclusion of the farmworkers' narratives, the law becomes a univocal script written by lawmakers and employers, and serving their interests" (127). ${ }^{35}$ As David Bacon similarly iterates, when immigration and trade are discussed, “Those who live with globalization's consequences are not at the table, and their voices are generally excluded" (Illegal People viii). In part because the vast majority of farmworkers are prohibited from voting in U.S. politics, their voices are underrepresented in the national and international policies that affect them.

"Historically, agricultural workers in the U.S. have been imported from other countries with vulnerable populations, have always been a disenfranchised group of workers, and have in general never had the right to vote" (Farmworker Ministries "Farm Workers \& Immigration”). Echoing the United States government's Barcero Program 
that imported 4.5 million Mexican contract farmworkers from the 1940s-1960s, the current H2-A guestworker system classifies foreign-born laborers as non-citizens and non-immigrants. This means that legal workers receive neither the benefits of citizens nor the rights of immigrants, including voting rights and certain legal protections and benifits in the United States. According to Bacon, "Current H2-A and H2-B programs give people a work visa, but the rights of workers in these programs are not respected. Often they aren't paid legal wages, they live in terrible conditions in substandard housing, and they have no right to organize or make demands on their employers" (The Right to Stay Home 88). Moreoever, obtaining an H2-A visa is a time-consuming, bureaucratic, and costly process, with no guarantee that applicant will actually receive one of the few temporary visas issued. In 2014, approximately 2.4 million season farmworkers labored in the United States-hundreds of thousands of whom where children-yet the U.S. government authorized only 89,274 H2-A temporary agricultural worker visas (Farmworker Justice "Immigration Reform and Farmworkers"; U.S. Department of State Bureau of Consular Affairs). ${ }^{36}$ As a result of a broken immigration and guest worker system, in 2014 the majority of seasonal farmworkers in the United States lacked authorized immigration status (Farmworker Justice, Making an Impact 4). ${ }^{37}$

As Bacon explains, the current U.S. guest worker programs and immigration policy produces "throwaway workers, whose labor gets used but who have no benefits" (The Right to Stay Home 88). In Under the Feet of Jesus, seventy-three-year-old Perfecto Flores poignantly feels this reality: "He had given this country his all....this land that used his bones for kindling...this land that never once in the thirty years he lived and worked, never once said thank you" (155). Perfecto recognizes the exploitation of his 
body in the United States, and longs for the life he had to leave behind in Mexico:

"Perfecto desired to return home. To his real home, not the bungalow." (78-9). It "was essential to get home before home became so distant, he wouldn't be able to remember his way back" (83). However, the Mexico that Perfecto left may be just that, a fading distant memory, now transformed by the national and international trade policies and structural adjustments that have fueled immigration to the United States. Perfecto's narrative in Under the Feet of Jesus suggests how immigration policies must be understood as one component in a larger structural problem in which neoliberal adjustments to political economies have cause wide-spread population displacement. Under the Feet of Jesus elaborates the sense of ontological insecurity this snare of national and international laws, policies, and treaties creates for farmworkers: "Perfecto lived a travesty of laws. He knew nothing of their source but it seemed his very existence contradicted the laws of others, so that everything he did like eat and sleep and work and love was prohibited" (83). Perfecto's sentiment personalizes a systemic problem.

Exemplifying Butler and Athanasiou's assertion that one "form that injustice takes is the systematic dispossession of peoples through, for example, forced migration, unemployment, homelessness, occupation, and conquest," many migrant farmworkers are doubly marginalized by national immigration policies and international trade policies which do not reflect their interests, desires, or democratic voice (xi). ${ }^{38}$ Like Perfecto, who sorrowfully yearns for a past life, Lucas shares the grief and pain that migrates with many farmworkers: "[T]he people came. The came "cause they were starving in Mexico. And because it was so bad in Central America, too. It's the only way the people saw for their kids. Families got separated and went through such anguish. Sometimes mothers almost 
felt like committing suicide, they got so desperate. Lots died along the way. And they lived in constant fear" (Lucas in Buss 199). Too often these migrant workers-displaced by economic and trade policies in their home counties and exploited by immigration and labor laws in the United States-find themselves structurally muted, at the loosing end of transnational geopolitical and economic policies. ${ }^{39}$

As Bacon recognizes, treaties such as the North American Free Trade Agreement and coinciding economic reforms "didn’t just eliminate earlier programs for finding markets for the products grown by farming families...It eliminated food sovereignty and self-sufficiency as a goal of economic development. In its place it substituted development based on exports, a policy that, in the countryside, favored large landholders producing for export over small ones producing for a national market" (The Right to Stay Home 59). As Mexico's land reforms ended and small farmers were unable to compete in a marketplace skewed towards large, transnational producers, rural populations in Mexico were left with few economic options other than to look for jobs north of the border. While resulting national immigration issues are fundamentally intertwined with international trade politics, Bacon explains that in "the United States, the political problems of trade and immigration are discussed in isolation from each other, as though Congress, in passing a trade bill, will not have to deal with the displaced people created by the legislation the next time it takes up immigration reform" (Illegal People vii). This situation is magnified when temporary and undocumented workers employed in a country lack a democratic political voice in the decisions that impact them.

Pushed north towards the United States by stratifying international trade policies, speaking little or no English, historically marginalized in educational and health care 
institutions, and denied a democratic voice in their workplace and the country where they labor, migrants must create alternate forms of collective representation to amplify their voice. Viramontes and Lucas adopt established literary forms, such as the novel and testimony, to communicate an assemblage of farmworkers counter-hegemonic voices that engage with and in domains of linguistics, institutional, and structural marginalization. In doing so, Viramontes's literary vision and Lucas' first-hand experiences illustrate how overarching power structures influence-but do not dictate-the agency of specific populations' voices. Dissident voices can disrupt the hegemonic formations that subjugate them by advocating reform, or, potentially, egalitarian rearticulation of uneven power distributions. Expanding these efforts, a collaboration of academic theory and social movements-“"the idea of representation (interpretation, contemplation) and of activity (labour, practice, transformation, change)"- may suggest sites and modes for targeted counter-hegemonic intervention (Balibar, The Philosophy of Marx 25).

\section{Coalition of Immokalee Workers: "[W]orkers are demanding a voice in the industry}

In 2013, my first-grade son, Wylie, and I went to Florida for Spring Break. While debaucherous college students flocked to the state's infamous party beaches, Wylie and I headed inland toward flat, sun-scorched Florida farmland. On a particularly warm morning, we joined the Coalition of Immokalee Workers (CIW), a community-based farmworker organization, on their two-hundred-mile march from Immokalee, Florida, to Publix grocery stores' corporate headquarters in Lakeland, Florida. The event was designed to raise public awareness about CIW's campaign to gain Publix's support for the organization's Fair Food Agreement, a program that brings farmworkers, growers, 
food retailers, and consumers together in support of fair pay and humane labor conditions for laborers who harvest fruits and vegetables.

At first my son was hesitant to join the mass of strangers. Wylie quietly observed the new situation, slowly joining in call-and-response labor songs. Gaining more confidence with each step, Wylie was soon enjoying the festive mood of the march. He ran ahead, waving in his hand a yellow flag that read, "A New Day for Farmworkers" in bold, red letters. Then suddenly, as he neared the front of the parade of people, multiple police vehicles pulled in front of our long line of marchers. Uniformed officers ordered the peaceful, permitted marchers off of the shoulder of the road and into a steep ditch bordered by railroad tracks. As a seven-year-old encountering the police for the first time, Wylie was immediately confused. We joined the men, women, children, and elderly marchers detained in the Florida heat and humidity with no shelter or shade. Remembering a famous scene from the film Salt of the Earth, which Wylie and I had watched together, he asked if the police would tear gas our line. He was becoming increasingly afraid. Then something amazing happened.

On the grassy strip between the highway and the railroad, the farmworkers and activists formed a long oval. We grabbed sticks, buckets, an old guitar, and a megaphone; then we began to sing and dance. I saw Wylie's fear melt away as the music and laughter defiantly filled the muggy air. He found a group of young boys whose families were farmworkers and CIW activists, and, although Wylie spoke no Spanish and many of the boys spoke limited English, their game of tag required little explanation. Sticks became swords and the CIW flags became treasured trophies as the little boys ran and played, giving little notice to the police patrolling the parameter of the group. 
That day, and those that followed on the march, left a lasting impression on my son and me. When Wylie returned home to Illinois, he created a poster of snapshots to show his first-grade class and brought a children's book about Cesar Chavez that his teacher could read aloud. For Wylie, farmworkers were no longer the two-dimensional characters illustrated in picture books. They were his friends, and the people he had met; they suffered the poverty and the injustice that, in a moment, he had indelibly experienced.

The more social, economic, and political issues feel personal, the more difficult it can be to negotiate between the urgency of on-the-ground intervention and the long-term consequence of contextualizing and theorizing occurrences, such as the functional silencing, institutional marginalization, and structural effacement of farmworkers. Lucas Benitez (one of many leaders in CIW, which practices the slogan "we are all leaders") explains that every day in Immokalee, Florida, "thousands of people wake up at 4:00 in the morning to beg for a day's work in the central parking lot in town.... No company has a fixed workforce. There are only the changing faces of Immokalee workers picking, planting, and pulling plastic every day" (Benitez in Bacon "Interview with Lucas Benitez"). Mirroring these material conditions, Butler and Athanasiou contend, "We have to be able to think about the arbitrary and violent rhythms of being instrumentalized as disposable labor: never knowing the future, being subjected to arbitrary hirings and firings, having one's labor intensively utilized and exploited and then enduring stretches of time, sometimes indefinite, in which one has no idea when work might come again" (148). We must not only "be able to think about" these processes, as Butler and Athanasiou posit, but also offer considered intervention into circumstances such as those 
Benitez describes. Long-term structural change must be accompanied by efforts to more immediately alleviate material suffering.

According to the United States Occupational Safety \& Health Administration, in 2011, the fatality rate for farmworkers was seven times higher than the fatality rate for all other workers in private industries. From 2003 to 2011, 5,816 farmworkers in the United States died from work-related injuries, and this number does not take into account the potentially thousands more people who died from long-term exposure to carcinogenic agricultural chemicals or other occupational diseases (Occupational Safety \& Health Administration). ${ }^{41}$ In spite of these statistics, Immokalee does not have a hospital, and residents (who often do not own vehicles) have to travel twenty miles or more to the nearest hospitals in Naples, Fort Myers, or Lehigh, Florida. In addition to lacking medical facilities, Immokalee's educational and childcare recourses are limited. In 2011, only 125 children, from six weeks to five years old, were in preschool childcare with another 350 on the waiting list (Giagnoni 11). Underscoring interconnected issues of linguistic and educational marginalization, "[e]ighty percent [of children in Immokalee] don't speak English at home, and approximately 65 percent of the children drop out before finishing high school" (Giagnoni 11). To make matters worse, in Immokalee, children and families also endure in a town with a violent crime rates six times the nation's average (Estabrook 75).

Facing omission from federal laws protecting labor organizing, suppression of democratic voice in national and international policies, exploitation in the fields, marginalization in underserviced health and educational institutions, and other instances of exclusion, many farmworkers live in what Agamben terms a "state of exception." 
Farmworkers are regulated as an "inclusively excluded" population, at the core of agricultural production yet banished to the peripheries of nation-state and global protections. Considering this reality, the structural and the material, the theory and practice, must be considered together and linked through simultaneous, collective, concerted action for immediate and long-term change.

"It was always a question of work, and work depended on the harvest, the car running, their health, the conditions of the road, how long the money held out, and the weather, which meant they could depend on nothing," states Viramontes (4). As Under the Feet of Jesus poignantly illustrates for many farmworkers who cannot depend on steady work, social safety nets, or basic protections in the nation-state where they labor, “dispossession is a condition painfully imposed by the normative and normalizing violence that determines the terms of subjectivity, survival, and livability" (Butler and Athanasiou 2). Farmworkers often suffer multiple dimensions of violent dispossession, from the push of trade agreements and structural adjustment that leave populations displaced and struggling for "survival" in their home countries to the pull of potential intermittent employment in the United States where reduced regulations and increased exploitation defines the limits of "livability."

Benitez explains, "In some ways, [Immokalee is] more a labor reserve than a town, an unincorporated area where the population nearly doubles to 30,000 people during harvest season" (Benitez in Bacon "Interview with Lucas Benitez"). Immokalee farmworkers are biopolitically managed as a reserve workforce and as individual laboring bodies strictly regulated by "normative and normalizing violence" that includes containment in migrant housing, pre-dawn/post-dusk bus schedules that transport workers 
to the fields, and calculated physical movements that increase harvest efficiency. Each day, workers gather in the parking lot of a shuttered convenience store known as the "Pantry," hoping to be chosen for work. Out of necessity, laborers often seek housing close to these pick-up areas. As Barry Estabrook explains in Tomatoland: How Modern Industrial Agriculture Destroyed Our Most Alluring Fruit, “[M]any workers lack vehicles and must live within walking distance of the downtown pick-up areas where crew leaders' buses stop each morning and evening" (105). With housing close to pick-up areas in high demand, Estabrook states that there is "easy money to be made renting shacks to migrant workers at Manhattan prices" (104). In Fields of Resistance: The Struggle of Florida's Farmworkers for Justice, Silvia Giagnoni elaborates, "Whereas wages have remained the same since the late seventies, the cost of living has risen, and rent, especially, has soared in Immokalee. Rent for a dilapidated apartment close to the Pantry can be up to $\$ 850 "$ (Giagnoni 14 ). With Immokalee's average per capita adult income around $\$ 8,500$, exorbitant rent often necessitates that multiple families share small living quarters (Giagnoni 11). Together, these material constrains-lack of a vehicle, exorbitant rent costs, low pay, and other factors-introduce a functional parameter delineating where farmworkers in Immokalee can reasonably live. Reflecting Mbembe's notions that Foucault's concept of biopower is connected to "two other concepts: the state of exception and the state of siege," farmworkers are held not only in a state of exception that symbolically binds the populations through their central production labor and marginal legal protections, but also a state of siege that functionally encloses them within limited proximities to farm fields and available transportation sites (16). 
In extreme cases such biopolitical manipulation of farmworkers crosses the threshhold to physical enslavement. Benitez states:

As surprising as it may seem, we still have debt bondage in the fields of Florida. During the past five years we have taken before the Department of Justice documentation of three slavery operations existing here in our midst. One southwest Florida operation held over 400 people in bondage, forcing them to work 10-12 hour days, six days a week, for as little as \$20. They were watched by armed guards in both the fields and camps. (Benitez in Bacon “Interview with Lucas Benitez”)

CIW organizer Geraldo Reyes explains that farmworker slavery exists on a continuum, from physical captivity to neoliberal indebtedness: "Most people hope to come here and send money home and perhaps make enough to return there someday,' Reyes said. 'But when you get here, it's all you can do to keep yourself alive with rent, transportation, and food. Poverty and misery are the perfect recipe for slavery."' (Reyes in Estabrook 100). Estabrook paraphrases Reyes's description of this situation:

[Reyes] explained, slavery is an inherent part of an economic system built on the ruthless exploitation of its workers. In this grim continuum, there is not much difference between an actual slave and a man who, say, has put his family's property in Mexico up as collateral for a loan from an unscrupulous crew boss to get across the border to Florida and who must work indefinitely just to pay off that loan. A tiny step beyond that along 
the continuum is the worker who may not be indebted to his boss but has to pay him inflated rates for lodging, transportation, and food. (97-98)

Reyes's elaboration of a continuum of farmworker enslavement seems all the more tenable when one realizes that in Immokalee, "farmworkers are paid by piece rate and they need to be fast: in order to earn $\$ 50$ a day, they must pick four thousand pounds of tomatoes" (Giagnoni 14). In other words, a piece rate system with stagnant wages keeps even the most able-bodied, hard-working farm labors in a cycle of poverty. ${ }^{42}$ Faced with inflated rent, limited transportation, wage theft, physical enslavement, and other issues, to paraphrase Under the Feet of Jesus, farmworkers may feel they can depend on nothing.

Benitez's and Reyes's accounts illustrate concrete materialization of the "normative and normalizing violence that determines the terms of subjectivity, survival, and livability" for farmworkers (Butler and Athanasiou 2). While neoliberal biopolitics generally regulates individuals and populations increasingly through normative procedure, migrant farmworkers and other dispossessed populations suffer both calculated disciplinary control and corporeal manipulation of their bodies and population. Although Foucault points out that one consequence "of biopower was the growing importance assumed by the action of the norm, at the expense of the juridical system of the law," through national labor, immigration, economic and trade policies, farmworkers still feel the sword of the sovereign (History of Sexuality 144).

David Bacon explains, "Political violence not only takes place during demonstrations and strikes, but has been used in the political system itself. It can force people into migration when even poverty itself doesn't”' (The Right to Stay Home 72). As 
Bacon details, the push of displacement (often due to international trade agreements and structural adjustments) and the pull of potential work in the agricultural fields in the United States (marked by multifaceted risk and limited protection) entails a sort of political violence. In particular, documented immigrant workers, undocumented laborers, and those here on temporary H2A visas may feel particularly vulnerable to U.S. law enforcement. Giagnoni points out that undocumented immigrants are "discouraged from collaborating with the police especially after $287(\mathrm{~g})$ agreements have extended the power to local police to enforce immigration law by cross-designating officers. Latino legal residents also may not report crimes since they fear harassment or retaliation against their families and communities that host undocumented individuals" (40). As Giagnoni recognizes, this ontological insecurity often results in immigrant workers being hesitant to report employers' labor violations and abuses. With farmworkers' persisting linguistic, institutional, and structural marginalization in the United States, Estabrook echoes that in a "strange country where they understand neither the language nor the law, workers [who suffer abuse and enslavement] are reluctant to come forward. In their homelands, cops are often thugs in uniform, so they have good reason to fear police. Without green cards, they face arrest and deportation" (Estabrook 80).

Together such instances of normalized and juridico-institutional violence against farmworkers reflect Mbembe assertion that "the state of exception and the relation of enmity have become the normative basis of the right to kill. In such instances, power (and not necessarily state power) continuously refers and appeals to exception, emergency, and a fictionalized notion of the enemy" (16). In particular, symbolic violence, such as 
normalized anti-immigrant discourse, can underpin corporeal violence. Giagnoni explains:

Low-income Latino immigrants, who make up most of today's farmworking population, are all too often demonized in public discourses. Labels like "illegal aliens" or "illegal immigrants" have the effect of dehumanizing real people who might not have citizen rights yet, but surely deserve to be respected as human beings and recognized, if anything, for their economic contribution to the wealth of the nation. They are often mistreated and robbed, and, increasingly, victims of hate crimes and racial profiling. (2)

While farmworkers may deserve respect, concrete mistreatment, such as wage theft, exposure to toxic agricultural chemicals, substandard living conditions, limited access to health care, and other similar occurrences, have tangible consequences for farmworkers.

In the United States, the average life expectancy is 78 years old, unless you are a farmworker. If you are a farmworker in one of the most prosperous nations in the world, you are expected to live to around 49 years old. Migrant farmworkers' labor power is central to the stability of the global food chain, until they are too old to do strenuous work, and their consumer power is limited by the poverty wages they have been paid. All of this makes a middle-aged farmworkers a superfluous liability in a capitalist economy. Those farmworkers not physically enslaved in the United States on persistent plantationlike properties still suffer a type of neoliberal slavery where their profitable, limited economic inclusion is tempered by overarching political exclusion. With historically 
limited access to social institutions such as hospitals and schools, as well as persistent structural marginalization from the halls of government, farmworkers are managed as biopolitically-regulated individual bodies and as a fluid, generalized population central to agricultural production during their years of peak physical performance and expendable after their labor power is used up. Such treatment of farmworkers in the United States suggests that in an economic system founded on extracting maximum profit, the controlled death of superfluous labor or under performing consumer populations must be central to any political project. This conceptualization inverts the emphasis, as in necropolitics, from power over life, to power to make die, recognizing farmworkers as necro-economic homines sacri. As Estrella realizes in Under the Feet of Jesus, "Is that what happens? Estrella thought, people just use you until you're all used up, then rip you into pieces when they're finished using you?" (75).

Recognizing and understanding these conditions is one component towards creating change; however, theorization must be paired with concerted activity. With multiple dimensions of farmworkers' (interconnected) linguistic and democratic voices marginalized in the U.S. public sphere, innovative methods of organizing, forming coalitions, and building power are necessary. In her essay on Forged under the Sun / Forjada bajo el sol, Platt recognizes that when "voting is not an option for an increasing number of disenfranchised peoples (including those who have been convicted of a felony, are immigrants without appropriate documentation, and those who are not provided with first-language voting facilities), alternative political options become increasingly important" (54 emphasis added). These options include UFW, FLOC, and CIW's crucial efforts to transmit farmworkers' voices through legislative channels while simultaneously 
mobilizing broad-based community support for immediate local and long-term structural change by circulating farmworker issues in the public domain.

According to André C. Drainville, "Coalition of Immokalee Workers (CIW) is arguably the most significant migrant workers' organization to have been born in the United States since the founding of the National Farmworkers Association (later named the United Farmworkers Association) in the early 1960s" (146). CIW directly targets the issues most important to farmworkers and their families by bringing the Immokalee community, the consumer public, growers, food manufacturers, and retailers together to create change. Specifically, CIW works to stop multi-faceted institutional and structural violence against farmworkers. They fight to improve farmworkers' wages, field safety standards, and growers' compliance with labor laws such as break and meal periods, providing access to clean drinking water, and offering restroom facilities. CIW creates and implements programs that protect workers from sexual harassment, enslavement, and other abuses. Workers are provided with free trainings (typically in their first language) that detail their rights and give them information on how to report abuses. In the community, CIW fights for decent, affordable housing, runs a local food bank, and coordinates educational opportunities for children and adults, including language training, preschool programs, and college scholarships.

Part of what makes CIW so successful is that the organization draws on activism techniques that the multinational workers bring from their home countries. This approach recognizes the diverse backgrounds of workers and creates connections that help members affirm their transnational experiences. In particularly, because CIW is a community-based organization not a traditional labor union (in part because of a lack of 
legal protections when organizing farmworkers due to their exclusion from the NLRA), the organization implement general strikes, secondary boycotts, hunger strikes, and other modes of activism which workers may bring from their home countries but that the NLRA and Taft-Hartley amendments ban traditional labor unions from practicing in the United States. Also, CIW adopts a more grassroots, bottom-up structure and approach to organization than many traditional labor unions. As Benitez describes:

We are rooted in the concept that we are worker-led. Each and every one of us is a leader, and we have to have ties, deep roots in the community. We use the method of popular education to tie us to all the different communities that exist in Immokalee. It's a method strongly rooted in Mexico, Guatemala, Central America, South America, the Caribbean, which is based on the need to raise consciousness. Though the workers from these regions who come to Immokalee are newly arrived, they recognize that these are the same methods of organization that existed in their country. They identify with them and see that, though their situation may have changed, they must become leaders in this new situation too. It may be a slow method in terms of raising consciousness, but it's a lasting one, and creates changes that will not disappear. It's been embraced by the grassroots and by the community....Though many of the workers cannot read, we use methods that are appropriate, such as movies, popular theater, and cartoons and drawings, which enable everyone to reflect upon their lives, upon their situation, and to understand more clearly what is 
happening around them. (Benitez in Bacon "Interview with Lucas Benitez).

Through these methods, CIW has had unprecedented success in organizing in the Florida tomato fields and creating a worker-centered structure that meets the unique needs and experiences of farmworkers.

CIW recognizes that to create lasting localized change in Immokalee (and other sites) requires structural intervention. Specifically, CIW taps into the power of consumers to create changes in the food chain. Pairing a worker-led movement with consumer support, CIW not only targets particular growers but also the global companies that purchase or contract agricultural produce. Through this approach, CIW has won agreements with Walmart, McDonald's, Taco Bell, Trader Joe's, Burger King, Chipotle Mexican Grill, Subway, Whole Foods Market, Fresh Market, Sodexo, Aramark, Bon Appetit Management Company, Ahold USA Compass Group, and Yum Brands. These companies have signed on to CIW's Fair Food Agreement which requires them to suspend purchases from growers who have failed to comply with the Fair Food premium-a small premium which growers pass on to workers (Penny a Pound more program)-and a Code of Conduct that includes zero-tolerance for sexual harassment, verbal abuse, and wage theft and other forms of exploitation. ${ }^{43}$ Through the member-led organization, CIW gives farmworkers a voice in some of the largest, most profitable corporations in the world, including Wal-Mart, McDonalds, and others. Unlike traditional labor unions, "A worker does not have to 'join' anything to benefit from the Fair Food Program. The instant a person steps into a tomato field, he or she is linked into a legally 
binding system that leads directly to the executive suites of the largest food companies in the world" (Estabrook 197).

CIW's success also depends on workers creating coalitions with other groups, including religious, student, human rights, and civil rights organizations. Above all the worker-led movement depends on public pressure that amplifies farmworkers message with a collective social voice. As Benitez summarizes:

[O]ur campaign for dialogue and a living wage-is one of the many examples from across the country where workers are demanding a voice in the industry and their supporters - students, clergy, and lay people, union leaders and everyday citizens-are standing with them in their fight....Our experience in 1995 [during the Taco Bell Campaign] left us more determined than ever to not just fight for higher wages, but for a new voice in the industry, for a new role where we are no longer only two hands to work but a mind and soul - a whole person to be respected and to be compensated as a person and not a beast of burden. And to do so, we knew that we would have to not only keep organizing in or own community but to enlist the support of the "outside community," people unfamiliar with the fields who, given the opportunity to learn of our situation would lend their support, lend their voice, to our fight. (Benitez in Thompson Jr. and Wiggins 277)

CIW calls on each of us, as consumers, voters, and human beings, to share in the fight for farmworker justice and decency. Douglas Molloy, the Chief Assistant U.S. Attorney in 
Fort Myers, Florida, who specializes in prosecuting slavery cases, states that Immokalee is "'ground zero for modern-day slavery"” (Molloy in Estabrook 75). Molloy explains that "any American who has eaten a winter tomato, either purchased at a supermarket or on top of a fast food salad, has eaten a fruit picked by the hand of a slave. 'That's not an assumption... That is a fact."” (Molloy in Estabrook 75).

Molloy's assertion highlights the ways in which each of us may be implicated in the perpetuation of contemporary slavery operations in the United States. However, it also suggests our possible agency in altering these circumstances. Like Viramontes's and Lucas's texts, which potentially expand the base for social action by amplifying farmworker issues in the wider public sphere, CIW recognizes that informed consumers may lend their voice to a public call for change. Like the labor songs sung in peaceful protest by CIW members and activists detained in the hot Florida sun, CIW calls on all of us to raise our collective voice in a demand for decency and justice for farmworkers. 


\section{Chapter III Endnotes}

1. Lucas in Buss, 70.

2. In this chapter, I frequently use the singular voice rather than the plural voices. This grammatical choice is not meant to dismiss the varied and unique perspectives and experiences of individual farmworkers. Rather, the singular form is adopted with respect to UFW, FLOC, CIW and other organizing agents who have fought to secure a collective voice through which individual farmworkers can address overarching issues such as working conditions, access to healthcare, educational opportunities, and other concerns.

3. For more on this topic see Chapter 5 of this dissertation.

4. As a non-Hispanic scholar not proficient in Spanish, I make no claim to personal experiential authority when addressing migrant farmworker issues or voices. To limit the scope of this chapter, only briefly, and with respectful caution, do I gesture towards the ways in which voice and language intersect with identity politics or the construction of the subject. I am primarily interested in how specific texts' language use and narratives engage with the politics of reform that drive historical and contemporary migrant farmworker labor movements. I am less focused on how literary voices may be critiqued within the academic politics of representation or aesthetics. Therefore, this chapter adopts the generalized term "voice"-and notes specific linguistic and democratic dimensions-to signify an assemblage of multiple perspectives influenced by discursive structures. As Foucault articulates, the "point of reference should not be to the great model of language (langue) and signs, but to that of war and battle. The history which 
bears and determines us has the form of a war rather than that of language: relations of power, not relations of meaning" (Power/Knowledge 114).

5. Lucas in Buss, 260.

6. The term discourse is almost as difficult to pin down as the notion of voice. This work implements an iteration of discourse informed by Foucault, Gramsci, and, to a lesser extent, Bourdieu. While this chapter engages with the study of linguistics in its application of code-meshing theory, it does not use the term discourse as it is applied in the field of linguistics.

7. To better understand the potential social action of literature that circulates labor voices, it is necessary not only to recognize how diversity may be maintained within these assemblages but also to contextualize them within the existing hegemonic powerdynamics that influence their creation and reception. Assemblage theory draws on Foucault's proposition that linguistic meaning and meaningful practice are interconnected and constructed (and reciprocally reconstructed) within historically-specific discourse. From this perspective, the obscuration of farmworkers' linguistic voices in specific domains can be understood as symptomatic of more insidious structural marginalization within particular discursive formations. Foucault's assertion that "nothing has any meaning outside of discourse" has been distorted to suggest entrapment within established power/knowledge systems (Archeology of Knowledge 32). However, his scholarship characteristically focuses on moments where fissures and fractures in the present anticipate potential paradigm shifts. Accordingly, discourse can be used, as 
theorists such as Ernesto Laclau and Chantal Mouffe recognize, "to emphasize the fact that every social configuration is meaningful' (100).

Literary expressions of migrant farmworkers' voices must not be misinterpreted as representing or creating a seamless whole, but rather recognized as envisioning the linkage of diverse perspectives and experiences in a collective articulation. Assemblage theory provides one paradigm for understanding how individual perspectives might be integrated into a collective voice (in contexts ranging from literary texts to collective bargaining) while still maintaining the heterogeneity of components. Drawing on Deleuze and Guattari’s scholarship, Manuel De Landa illustrates how historically-contingent, consistently-fluctuating collections of heterogeneous components organize societies on increasingly complex levels. He explains that "interacting persons yield institutional organizations; interacting organizations yield cities; interacting cities organize the space in which nations states emerge and so on" (De Landa in De Landa, Protevi, and Thanem 71). Such assemblages function as a whole, even as they retain the individuality of their parts.

Thus, in nonlinear assemblages (in contrast to hierarchical totalities), components can move from one system to another and perform different roles. In one instance, the notion that voice can be transmitted through an assemblage of diverse perspectives provides a theoretic apparatus for understanding how literary texts communicate an amalgamation of distinct voices on multiple strata. In another instance, this paradigm holds promise for the contemporary labor movement, which must confront global capital 
with transnational labor solidarity movements that demonstrate a united front while simultaneously reflecting the unique needs of varied constituents.

8. By first recognizing that the effacement of farmworkers' voice has material consequences and, second, arguing that circulating farmworker texts in the public sphere might combat this marginalization, this chapter fundamentally links the concept of voice with potential agency. This association does not disregard the critiques of voice posited by structuralists, poststructuralists, postmodernists, and other factions; rather, it suggests the limits of such theories for addressing marginalized, multi-linguistic, transnational populations that function in disregard to dominant geographical, political, social, and spacio-temporal logic. Certainly, I dispute phenomenological and positivist notions of voice as a signifier for some pre-existing truth or reality. However, I am suspicious of theories that uniformly silence the revisionary and revolutionary agency of individual and, particularly, collective voice. Accordingly, this chapter recognizes that literature can link heterogeneous individual perspectives and experiences into a collective assemblage of voice that counter-hegemonically mobilizes the power of texts to circulate farmworker issues in a public sphere.

This realization demands that scholars consider: To what extent do structuralist, poststructuralist, and postmodern theories reciprocally reinforce the dominant language/power cycle by enacting the very discursive practices that they critique? By employing privileged academic discourse as a means to refute the agency of voice, to what degree do these approaches functionally silence subjects who may already have been marginalized or objectified within dominate discourses? Instead of segregating 
theory and practice, how might new discursive structures emerge from existing power dynamics?

9. Viramontes, 46.

10. It is within this context of effaced democratic and linguistic voice, institutional marginalization, and daily survival that Viramontes mobilizes the power of literature by implementing rhetorical and narrative strategies for surmounting material and structural barriers to migrant farmworkers' voices and amplifying these stories in the larger public sphere. In her essay on language use in Chicano/a literature, Lourdes Torres states, "Through strategies that range from very infrequent and transparent use of Spanish to prose that requires a bilingual reader, Latino/a authors negotiate their relationships to homelands, languages, and transnational identifications. The strategies they use lend themselves to multiple readings and differing levels of accessibility" (76). Balancing the need to communicate farmworkers' stories to a predominately English-speaking audience and the desire to accurately portray farmworkers and their culture, Lucas and Viramontes adopt multiple linguistic strategies for integrating English and Spanish into their texts. Lucas provides the original Spanish text and her own English translations for many of the creative pieces included in Forged under the Sun / Forjada bajo el sol. In contrast, Under the Feet of Jesus is composed primarily in English with frequent passages of untranslated Spanish. While Forged under the Sun / Forjada bajo el sol offers opportunities to discuss the negotiations between languages and processes of translation, this chapter will focus the creative linguistic aspects of Viramontes's novel. 
11. Drawing on Geneva Smitherman's observation that "language power is a function not of one's dialect but of larger linguistic structures skillfully and effectively employed," this chapter investigates how Under the Feet of Jesus addresses notions of language power through the rhetorical use of Spanish and English to construct and communicate migrant farmworkers' voices (60). Because issues of linguistic voice are, as Smitherman notes, inextricably embedded within organizations of power, Viramontes's rhetorical language choice in specific settings of the novel suggests the domains and institutions in which migrant farmworkers' linguistic voices may be particularly marginalized. This technique not only exposes the linguistic hegemony of these domains, but also targets discursive spaces-[re]produced in language and practice--where collective democratic action might transform current power distributions.

12. A scientific approach to analyzing code-switching is evident in the touchstone work of Carol Myers-Scotton.

13. Michael-Luna and Canagarajah assert that code-meshing can be "used as a strategy to resist identities and redefine discourses" (58, emphasis added). One can debate whether code-meshing and code-switching signify two distinct linguistic processes. However, as a tool for looking at language use in literary texts, codemeshing's focus on embracing linguistic variability to achieve particular rhetorical effects and redefine discourses lends itself more aptly to an investigation of language issues than does code-switching's rule-governed approach to analyzing actual speech acts as predictably patterned, non-variable phenomenon. 
14. In contrast to literary critics who dismiss Viramontes's language use as, in Beck and Rangel's words, "English spiced with bits of Spanish," the concept of codemeshing may be adopted to inform an analysis of the rhetorical, ideological, structural, and potentially material impacts of Viramontes's treatment of language (16). Because Under the Feet of Jesus's Spanish/English composition reflects the linguistic reality of many migrant agricultural workers in the Mexican/U.S. borderlands, the rhetorical use of code-meshing voices the monolingual Spanish or bilingual Spanish/English identities and experiences of many farmworkers.

15. For more on language use and parenting see Alejandra Okie Holt and Sister Evelyn Mattern’s “Making Home: Culture, Ethnicity, and Religion among Farmworkers in the Southeastern United States."

16. Additionally, the purposeful integration of increased Spanish in older character's speech often signifies limited English or monolingual Spanish proficiency, and marks the linguistic differences between many of the older and younger individuals.

17. One of the many extreme examples of how this exclusion impacts farmworkers and their children is elaborated in Forged under the Sun / Forjada bajo el sol. To combat this inhumane treatment in Illinois, Lucas worked towards getting the state of Illinois to pass the Field Sanitation Act, which provided some workers working with specific types of crops to have access to drinking water and bathroom facilities.

18. Buss, 3.

19. While this chapter limits its discussion of education, migrant farmworker children face a multitude of other challenges, including: excessive hours, earning less 
than minimum wage (often piece rates), increased risk for sexual abuse of girls, exposure to toxic agricultural chemical, repetitive actions that can disfigure developing bodies, dangerous machinery and equipment, work in extreme conditions or temps tries, lack of sanitation facilities, and other factors. These topic are all equally worthy of further research.

20. Advocacy and government groups, such as the Department of Education's Office of Migrant Education and Head Start Programs, work to improve migrant farmworkers' access to education. These organizations recognize, "Research indicates the neurological connections formed by life experiences in the brains of babies and young children during the early childhood years (especially the first three years) are critical to later learning and school success," (National Migrant and Seasonal Head Start Collaboration Office 12). National Migrant and Seasonal Head Start Collaboration Office assert that "[1]ow-income children-especially those of migrant farmworkers-are assaulted by a variety of environmental, social and economic factors which impede this much needed optimal growth and development in the early years," (11). Specifically, they emphasize how issues of language proficiently and educational success are interconnected: "English-language fluency serves as a strong predictor of later school performance and early care and education programs have the potential to begin to address the needs of English language learners helping to close the school readiness gap" (6). However, migrant farmworkers express that many young children do not have access to these programs or safe, affordable childcare: "II bring the kids here because I can't pay a babysitter,' said a woman caring for her four-, six-, and seven-year-old grandchildren. 
'It's dangerous. They could get bitten by an animal. Run over by a machine.' Childcare would cost her $\$ 15$ per child per day, she said, but she earns only $\$ 45$ to $\$ 50$ a day hoeing cotton" (HRW, Fields of Peril 22-23). As children get older, lax regulations on child agricultural labor, the itinerant nature of seasonal work, economic pressures, cultural norms, language barriers, and other factors result in young farmworkers often bypassing education in order to work in the fields.

In spite the challenges they face, the testimonies of contemporary migrant farmworker children illustrate that, much like Estrella and Lucas, many of these young people are commitment to getting an education. Teenage migrant farmworker, Guadalupe Renya, writes:

I always ask my parents why they don’t think of getting a year around job, instead of all the hassle of their current migrant job; their reply every time in that they don't have an education. I want to further my education so that I'll have a great career, one that won't put me in harms way, or kept me from my family, the way I grow up. I'm not trying to forget my migrant background, but I want to change the future, I want to break the cycle. (PBS)

Numerous farmworkers recognize that getting a formal education and learning English may mean that when children grow up they will have employment opportunities outside the fields. As Julisa Velarde recalls, her mother said that if her children “don't want to end up like her [a migrant farmworker], we better go to school and get good 
grades....[she] has always told me to learn English" (Rothberg 24). Yet in order to attain an education, these children must grapple with a discursive system in which they continue to be linguistically and institutionally marginalized. Norma Flores, explains, "The summers are filled with scorching suns overhear and fruitful fields below. As you stand in the middle of the field and look around you, your mind is swarmed with millions of reasons why to pursue a college education" (PBS). These poignant testimonies underscore what is at stake-the material conditions and human lives-in efforts to redefine discourse on linguistic levels, such as Viramontes's code-meshing suggests, and through narrative practices, such as Under the Feet of Jesus and Forged under the Sun / Forjada bajo el sol exemplify.

21. Throughout her autobiographical oral history, Lucas recalls not only the way that this "crime" affected her life, but also how she surmounted these challenges. The material conditions of life as a migrant farmworker child stood as an initial barrier to Lucas achieving an education: "[S]chool was hard 'cause I'd always be taken out to work the fields three months before school was out, and I remember going to school three months late all the time. Sometimes I'd have to go to school barefooted and at times it was very cold and I didn’t have a sweater, just a shirt and pants” (84). Similar to Estrella's duties as a farmworker and mother-figure in Under the Feet of Jesus, Lucas's educational opportunities were significantly limited because her family’s economic situation demanded Lucas's waged employment and unwaged household labor to help the family meagerly meet their basic material needs. Lucas explains that these economic concerns served as one basis for rigidly defined family and community gender roles that 
undervalued females' formal education. Lucas states, "Daddy thought our [school] work was valuable time taken from them, from our chores. Any time that I spent doing anything else, I wasn't contributing to the household, to the babysitting, so I'd hide my work" (87). She details, "One time [Daddy] found me with a book. And, boy, he really grabbed me by the hair and hit me and said, 'I never again want to see you with another book.' So I can't remember ever having books to read" (86). In order to enter the classroom, Lucas had to first surmount these daily challenges. Yet, once in school, she faced institutionalized ethnic and economic prejudices that further hindered her learning.

Lucas's social position as a poor migrant farmworker marginalized her within the classroom space. She recalls how "the teacher put us real poor kids in the back...She didn't even try to teach me. I did go through some of those books with Dick and Jane and Sally, and I wasn't the only one that sat at the back of the room" (84-5). Migrant farmworker children were not only physically segregated in the classroom but also socially ostracized by both teachers and peers: "I was sent home because a little girl said I was stinking. I know I bathed that morning because I remember, and they made such a big thing about it at school. I was embarrassed. Lydia, the girl who accused me, was one of those little girls who would wear beautiful coats with pretty socks and shiny shoes and their hair all nicely done" (85).

22. In this way, educational structures support discursive practices that, as Bourdieu defines, seek the "recognition of legitimacy through the misrecognition of arbitrariness" ("Structures, Habitus, Power" 163). 
23. Migrant farmworkers do not resign to oppression, as the deterministic tone of Bourdieu or other theorists might suggest. Bourdieu's concludes "the dominated have only two options: loyalty to self and the group (always liable to relapse into shame), or the individual effort to assimilate the dominant ideal" (Distinction 386). Bourdieu asserts that "adapting to the dominated position implies a form of acceptance of domination" (Distinction 386), yet this scenario neglects to recognize the ways in which so-called "dominated classes" circumvent and rearticulate power structures. This may include organizing through community groups, labor unions, or other support systems, as well as incorporating the arts into these movements as a means through which struggles can be communicated and potential victories explored.

24. For more on issues of educating migrant farmworker children see Paul E. Green's "The Undocumented: Educating the Children of Migrant Workers in America."

25. In interviews, Viramontes suggests English-only education can negatively impact Spanish-speaking children's identities:

I was telling you about my growing up the first five years of my life speaking nothing but Spanish, and then going into the educational school system and finding out that Spanish was completely unacceptable there. Because it was unacceptable, it was almost as if anything that was attached to the language was a negative thing. So, I can understand to a certain extent why children grow up feeling that they want to hide their parents or the language or whatever, in order to be accepted into the larger dominant culture. (Viramontes in Flys-Junquera 225) 
26. In the introduction to Forged under the Sun / Forjada bajo el sol Buss speaks of the challenges of cleanliness in migrant camps with no running water.

27. See Appendix 1 for more information on the pedagogy of tool-mediate learning in Cultural-Historical Activity Theory.

28. For more on language barriers to farmworker healthcare see Deborah Martinez, Elizabeth A. Leone, and Jennifer Sternbach de Medina's "Language as a Barrier to Health Care" in Spanish Language Use and Public Life in the USA.

29. Bacon, Illegal People 126.

30. Peter Sawchuk explains that "labor arts, at their best, combine production and consumption to socially transform capitalism by giving voice to working-class standpoints, including their gendered and racial dimensions" ("Labor Education and Labor Art" 58). Building on a tradition of labor arts in farmworker movements, Viramontes' fiction and Lucas's accounts gives amplified voice to the struggles of migrant agricultural workers, while advocating methods for social engagement and structural change. In Under the Feet of Jesus, "Viramontes not only critiques the prevailing discourses of criminality that serve to legitimize the exploitation of migrant labor," Shea recognizes, "but also offers tools for intervention into the current legal and representational practices that seek to define migrant workers through essentializing race and gender stereotypes" (124). Likewise, Lucas's literary narratives not only circulate her published works to a wider audience; her stories and dramatic performances have also been used as tools to organize and rally migrant farmworkers (297-314). Platt identifies that Lucas's literature and activism associate her with "a growing group of predominantly 
working-class people of color who are generating a rich body of socially engaged cultural poetics extending a tradition that has spoken out against colonialism, imperialist capitalism, and racism. Their grassroots community organizations are expanding previous environmental and social justice agendas" (48).

31. Through the perspectives of multiple characters, Under the Feet of Jesus elaborates dismal working and living conditions that many farmworkers feel unable to alter individually. Likewise, Lucas's parallel experiences provide a real-life context for better understanding how such workplace and social marginalization may be combated by labor unions that provide farmworkers with information, agency, and a democratic voice for bargaining collectively over hours, wages, and working conditions. Paralleling Lucas, who can "remember seeing my mother in the fields crying. She's be pregnant and dragging a bag of cotton," Under the Feet of Jesus elaborates that Estrella "was not more than four when she first accompanied the mother to the fields. The mother showed pregnant and wore large man's pants with the zipper down and a shirt to cover her drumtight belly....she hauled pounds and pounds of cotton by the pull of her pack" (Viramontes 51; Lucas in Buss 76). Lucas recalls that as I child when she and her siblings "were in the fields, we were told you had to stay working all of the time...We'd wet our hats and put them back on. It felt like your eyes would get real red and irritated, and the dust, it was uncomfortable" (76). Under the Feet of Jesus conveys this discomfort as Estrella joins her mother in the fields, well aware that grueling farm labor is not like the image portrayed to the public: "not like the picture on the red raisin boxes Estrella saw in the markets, not like the woman wearing a fluffy bonnet, holding out the grapes... The 
sun was white and it made Estrella's eyes sting like an onion, and the baskets of grapes resisted her muscles, pulling their magnetic weight back to the earth. The woman with the red bonnet did not know this" (49-50). Estrella's experience suggests the public effacement of farmworker's labor and living conditions, yet Under the Feet of Jesus communicated these conditions, that closely parallel Lucus's experiences.

32. For more information on farmworker health issues see Eric Hansen and Martin Donohoe's “Health Issues of Migrant and Seasonal Farmworkers”; David Lighthall's "The Poor Health of Farm Workers"; the Center for Disease Control and Preventions's farmworker program, http://www.cdc.gov/omhd/amh/farmworker.htm; and the National Center for Farmworker Health, http://www.ncfh.org.

33. For more on migrant farmworker health issues see Colin Austin's "The Struggle for Health in Times of Plenty."

34. Similarly, the Migrant and Seasonal Worker Protection Act (MSPA), which provides some rudimentary labor standards for farmworkers, does not grant them the right to join unions, ability to engage in collective bargaining, or offer protection when they are fired for attempting to do so.

35. The 2002 case, Hoffman Plastic Compounds, Inc. v. National Labor Relations Board, 535 U.S. 137, is one important case in which the Supreme Court held that an undocumented worker who was fired illegally for participating in a union organizing campaign could not collect back pay even though the company was found to have committed an unfair labor practice when it terminated him. 
36. Factor such as mobility, families with undocumented or underage workers, and fear of government authorities, make it difficult to know how many children are currently engaged in farm work; however, estimates state that at least hundreds of thousands of children work in agriculture (Human Rights Watch; National Migrant and Seasonal Head Start Collaboration Office; Oxfam). "“Age doesn't matter,' said Marta V., age 13, who had hoed cotton since age seven in Texas" (HRW, Fields of Peril 19).

Another young woman who had "worked in California starting at age 12 said that no one asked her age or for any papers" (HRW, Fields of Peril 22). HRW reports, "At one farm in Michigan and one in Texas, children alternately told us they had to be 11 or 12 to work: "Only the little ones they ask their age but 11 and up is ok," (Fields of Peril 2021).

37. In 2015, a "visa-processing freeze" exacerbated the "challenges U.S. agriculture already faces. Amid a shortage of legal workers, farmers have become vocal proponents of an immigration overhaul to legalize undocumented farmworkers who are already in the country" (Jordan).

38. Focusing specifically on how "forced migration, unemployment, homelessness, occupation, and conquest" effect migrant farmworkers, Bacon details the impact that so called free-trade policies have had on rural Mexican populations, some of whom end up finding work as temporary farm laborers in the United States:

Together with the economic reforms that accompanied it, [treaties such as NAFTA] didn't just eliminate earlier programs for finding markets for the products grown by farming families, like those for the tobacco and coffee 
farmers of Veracruz. It eliminated food sovereignty and self-sufficiency as a goal of economic development. In its place it substituted development based on exports, a policy that, in the countryside, favored large landholders producing for export over small ones producing for a national market. (Illegal People 59)

As Mexico's labor reforms ended and small farmers were unable to complete in a marketplace skewed towards large, transnational producers, rural populations in Mexico were left with few economic options other than to look for jobs north of the border. Increasingly, our global economy is dependent upon such displaced migrant workers, regulated by neoliberal principle that "immigrant policy and enforcement should direct immigrants to industries when their labor is needed and remove them when it's not" (Bacon, Illegal People 76).

39. This immigrant perspective is less circulated in U.S. popular culture. Instead, there is a dominant mythology established around why immigrants come to the United States-for jobs, education, generational advancement, the "American Dream"-and typically far less is discussed about the powers that force workers and families to leave their home countries and push them into a new nation.

40. Benitez in Thompson Jr. and Wiggins, 277.

41. Eastabrook offers the following account which helps contextualize some of the health risks and fatalities not accounted for in the OSHA statistics, including instances of miscarriages, still-births, and infants with fatal birth diffects which may be caused by pregnant mothers' exposure to agricultural toxins: 
A sign at the entry warned that the field had been sprayed by no fewer than thirty-one different chemicals during the growing season. Many of them were rated "highly toxic," and at least three, the herbicide metribuzin, the fungicide mancozeb, and the insecticide avermectin, are known to be "developmental and reproductive toxins," according to Pesticide Action Network. They are teratogenic, meaning they can cause birth defects. If they are used, the U.S. Environmental Protection Agency mandates "restricted-entry intervals" (REIs in the jargon of chemical agriculture), the time that must elapse between when pesticides are applied and you breathe it." Although regulations require that handlers of many of these pesticides use protective eyewear, chemical-resistant gloves, rubber aprons, and vapor respirators, the three pregnant women said they had not been warned of the possible dangers of being exposed to the chemicals. They wore no protective gear, unless you count their futile attempts to avoid inhalation by covering their mouths with bandanas. (Estabrook 3637)

More information on birth defects in children born to mothers who are farmworkers in Immokalee, Florida can be found in "Case Report: Three Farmworkers Who Gave Birth to Infants with Birth Defects Closely Grouped in Time and Place-Florida and North Carolina, 2004-2005” by Geoffrey M. Calvert, Walter A. Alarcon, Ann Chelminski, Mark S. Crowley, Rosanna Barrett, Adolfo Correa, Sheila Higgins, Hugo L. Leon, Jane Correia, Alan Becker, Ruth H. Allen, and Elizabeth Evans. 
42. Farmworkers pay is typically based on the number of full thirty-two pound buckets they harvest per day. However, field managers may refuse to give a farmworker credit for a bucket they believe is insufficiently full or send the worker back to further fill the bucket. "'It was a constant source of friction and humiliation for the workers,' said Benitez" (Estabrook 193). Estabrook elaborates, "It was also one of the problems that the CIW and growers had to work out. To do so, they met in the CIW offices with an empty cubeta, a pile of tomatoes, and a scale. By weighing out exactly thirty-two pounds, they agreed on precisely what a full cubeta should look like" (193).

43. For more on the Fair Food Program see http://www.fairfoodprogram.org. 


\section{CHAPTER IV}

\section{A “MIXTURE OF NOSTALGIA AND AMNESIA”: REMEMBERING}

THE LUDLOW MASSACRE IN PYNCHON'S

$$
\text { AGAINST THE DAY }
$$

Speaking to a United Mine Workers convention on April 30, 1914, labor activist Mother Jones described the bloody events that had unfolded in Ludlow, Colorado, only days before:

The horrors of it cannot be depicted by human pen, or penned into the history to come. When these children were piled up, sixteen that we know of, don't know how many more were roasted, whose bodies were never found, and those bodies were piled up one after another and carried to their last resting place, how many people in the United States grasped the horror of that thing? (Jones in Steel 132)

On the morning of April 20, 1914, the Colorado National Guard opened machine gun and rifle fire on a tent colony of striking coalminers and their families in Ludlow, Colorado. That afternoon soldiers swept the colony, looting tents, soaking them in kerosene, and setting them on fire. It was two days before the flames died down and the charred, lifeless bodies of the eleven children and two women were discovered in a hand-dug pit under a 
tent where they had sought refuge from the bullets. Termed the Ludlow Massacre, these atrocities brought national attention to the 1913-1914 Colorado Coalfield War and defined one of the most disgraceful chapters in the history of U.S. industrial/labor relations.

Echoing Mother Jones's question, I ask: Today, how many people in the United States grasp the horror of that thing? Mother Jones predicted that the atrocities of Ludlow "cannot be depicted by human pen, or penned into the history to come." However, in his ambitious novel Against the Day, Thomas Pynchon attempts to do just that as he privileges strikers' perspectives in his narrativization of the Ludlow Massacre. ${ }^{2}$ By depicting how Ludlow "strikers, and children and their mothers, and even troopers and camp guards, took bullets or fought flames, and fell in battle," Against the Day forces contemporary readers to confront how these horrors "happened, each casualty, one by one, in light that history would be blind to" (1016). By the end of the battle at Ludlow, twenty-four lives had been lost, including little Elvira Valdez, who at only three months old was the conflict's youngest victim. Despite these casualties, in "The Ludlow Massacre: Class, Warfare, and Historical Memory in Southern Colorado," Mark Walker recognizes, "You won't read about Ludlow in military history. In fact, you're rather unusual if you have read about it in any history. This is because the conflict was an industrial one, between corporations and a state government on one hand and striking workers and their families on the other" (67).

Labor literature can serve to circulate and popularize workers' counter-narratives of historical industrial /labor conflicts. Defying the "silencing of labor conflict in American public history" (Walker 67), Against the Day interjects its narrativization of the 
Ludlow Massacre into the public sphere, demanding that we acknowledge the brutal conflicts that pit striking workers and their families against collusive military and industrial forces. It is within this context that this chapter explores Against the Day's depictions of the Colorado Coalfield War and Ludlow Massacre as advancing counternarratives of labor conflict against popular notions of peaceful paternalistic industrialism and the mythic American West. In doing so, this chapter problematizes any notion of a static boundary between fact and fiction, reflecting Against the Day's own metafictional commentary on the constructed nature of history. Read alongside conflicting union, government, media, scholarly, and eyewitness versions of the events at Ludlow, Against the Day can be understood not only by what it $i s-$ a rich intertextual narrativization of worker struggle-but also by what it does-contributing labor counter-narratives to our historical memory. By tracing the complex relationships between union and company forces, Against the Day illustrates how violence against workers and labor resistance movements is not a historical anomaly resulting from isolated exceptional circumstances, but rather is symptomatic of the uneven distribution of power and resulting counterhegemonic movements that persist in contemporary transnational capitalism. Therefore, at the close of this chapter, this discussion is brought into a concrete, present-day context by exploring the living memory of the Ludlow Massacre in contemporary southern Colorado.

\section{“Against the grain": Constructing Historical Memories ${ }^{3}$}

Against the Day advances resistance on numerous fronts: against the unfettered accumulation of capitalist wealth; against unexamined moral condemnations of violent revolt; against monolithic, stable notions of History. In this engagement with counter- 
hegemonic politics and didactics, Against the Day may, to borrow Benjamin's term, "brush history against the grain" (257).

Perhaps this should not be surprising. In his essay "Setting Sail Against the Day: The Narrative World of Thomas Pynchon," Heinz Ickstadt reminds us that we should be used to 'Pynchon's double role as painstaking historian and bizarre fabulator, to his peculiar mix of genres, discourses, tones, and styles" (37). While this quality makes Pynchon's works simultaneously convincing and implausible, any historical narrativization ostensibly involves a bit of "fabulation.” Hayden White's work helped expose the ways in which historical knowledge is regularly communicated through narrative structures that frame information according to intended ideologies. This realization does not deny the value of historical scholarship or completely conflate it with fictional literature; rather, it emphasizes the fact that, as Barthes recognizes, both "historical" and "imaginary" narratives are constructed texts (The Rustle of Language). That being said, this chapter is less interested in perusing the question of what Against the Day is-a postmodern historiography, a "historiographic metafiction," or some other hybrid form (Hutcheon ix). For an inquiry on how Pynchon constructs his historical narrative in Against the Day, the reader may turn to scholarship by David Cowart, Brian McHale, Terry Reilly, or Lovorka Gruić Grmuša. Instead, this chapter is more concerned with exploring what Pynchon's novel may do. This line of inquiry requires recognition of individuals as active agents who assemble historical meaning through multiple sources, not only conventional history scholarship but also novels, movies, photographs, personal accounts, and other texts. 
Implementing the interdisciplinary approach of historical archeology, Walker explains that our conceptions of historical events are formed by the interplay between dominant and "submerged" accounts: "[T]hese sources or narratives are pulled together, interpreted, and made coherent through preexisting understandings and experiences. This coherent individual understanding of history, where personal experience and formal historical narratives are integrated into a practical historical consciousness, is historical memory" (Walker 71). As White and Barthes recognize in their critique of historiographic narratives, prevailing ideological frameworks influence individuals’ negotiations between multiple accounts. When historical narratives support dominant ideologies, "these pasts flourish, propagating through official commemorations and interpretations, school textbooks, and the mass media" (Walker 72). However, "stifled," potentially counter-hegemonic narratives "do not necessarily disappear. The past is remembered through many means_ - photo albums, family conversations, and local commemorations of histories that have been excluded or marginalized within official history" (Walker 72). Conceptualizing marginalized, multi-genre historical texts as persisting accounts that shape individuals' construction of coherent historical narratives allows us to read Against the Day as a novel that not only represents the past but also potentially shapes our historical memory of it.

This chapter draws on Fredric Jameson's notions of "historical amnesia" and "nostalgia for the present" to explore how Against the Day might contribute to a culturally influenced historical memory of the events at Ludlow, as well as the larger field of U.S. labor struggle, for populations who have no immediate, personal connection to this living local history in southern Colorado. Jameson adopts the term historical 
amnesia to characterize how "our entire contemporary social system has little by little begun to lose its capacity to retain its own past" ("Postmodernism and Consumer Society" 125). Jameson argues that in the period of late capitalism, history is [re]constructed through modes of nostalgic cultural production-films, movies, books, merchandise, etc.-Which may "reinvent a picture of the past in its lived totality" or "reawaken a sense of the past associated with those objects" ("Postmodernism and Consumer Society" 116). Because individuals draw on cultural productions as they construct historical meaning, this process can be co-opted through the introduction of particular images that represent a stylized version of the past. ${ }^{4}$

Drawing on Jameson's scholarship, Arjun Appadurai’s Modernity at Large elaborates how merchandisers employ "nostalgia for the present" as a method for promoting mass consumption among diverse age groups. Appadurai suggests that consumer culture possesses a particular "nostalgia without lived experiences or collective historical memory," which he terms "armchair nostalgia" (78). In one respect, "armchair nostalgia" suggests the degree to which corporations have colonized individual consciousness. Appadurai recognizes, "Rather than expecting the consumer to supply memories while the merchandiser supplies the lubricant of nostalgia, now the viewer need only bring the faculty of nostalgia to an image that will supply the memory of a loss he or she has never suffered" (78).

However, "armchair nostalgia" can also be employed for counter-hegemonic functions. Suppressed narratives may be introduced into the meaning-making process by way of images that are less "rose-colored" than many of those that Jameson and Appadurai address. While Pynchon's readers may not identify their own lived 
experiences or familiar versions of U.S. history in the representations of corporal capitallabor violence that Against the Day provides, perhaps all that readers need to supply is the faculty of nostalgia in order for these images of industrial warfare to affect their historical memory.

\section{A "mixture of amnesia and nostalgia": Remembering/Forgetting Labor Conflict in Constructed Histories ${ }^{5}$}

In Against the Day, the boys' book heroes, the Chums of Chance, had to "find exactly the mixture of nostalgia and amnesia to provide them a reasonable counterfeit of the Timeless," a suspended dimension in which they began to comprehend the constructed, manipulated nature of their existence (406). It is within this context of amnesia and nostalgia that we too can begin to understand Against the Day's role as an active node in the construction of historical narratives that problematize the boundaries of fact and fiction.

Indeed, from the novel's opening pages, in which readers meet the Chums on their airship, the Inconvenience, Against the Day unambiguously demands that readers confront their conceptions of History, and implicit notions of fact, fiction, and Truth. Reflecting readers' own potential bewilderment, a perplexed Lew Basnight inquires:

"But you boys - you're not storybook characters." He had a thought. "Are you?"

"No more than Wyatt Earp or Nellie Bly," Randolph supposed. "Although the longer a fellow's name has been in the magazines, the harder it is to tell fiction from non-fiction." (37) 
The reply does little to quell Basnight's confusion. Instead, Randolph's insight suggests how print media selectively presents information and, concurrently, writes a version of history into being. It is within this context that Against the Day inserts itself into the narrative process of assembling history.

Through its metafictional incorporation of the Chums of Chance, Against the Day challenges readers to ponder the extent to which narratives shape our cultural and historical consciousness. As Shelley Streeby notes in American Sensations, mass-market literature historically played a central role in creating and popularizing conceptions of an exceptional American West. Sensational literature set in the mythic western landscape often promoted the cowboys-and-Indians image that inspired Wild West shows, while various novels set in urban spaces popularized the notion of a utopian west with free land and unlimited opportunities (Streeby 5, 23). These images, widely disseminated through printed texts, figured prominently in, to borrow Benedict Anderson's terms, the "national imagination" of the United States, in which individuals saw themselves as members of an "imagined community" partially defined by the unique, mythic landscape of the American West.

Walker notes that in this "dominant mythology, the U.S. is a classless society-'we are all middle class.' Events that bear a resemblance to class warfare or that even point to the presence of class are not easily incorporated with this mythology" (74). As a result, "[g]iven the sorts of interests that tend to drive and dominate public history, the silencing of labor struggle is unsurprising" (Walker 74). Unsurprising, perhaps, but nonetheless notable. In light of the silencing of labor perspectives in U.S. public history and national 
mythology, we must not only consider what is included in popular representations of the American West but also attend to what is excluded.

In The Archeology of Collective Action, Dean Saitta recognizes that the “institutions of cultural production in southern Colorado privilege a particular set of memories that emphasize the area's place in romantic, mythic narratives of the Old West" and "through Hollywood mythologization, [this image] has attained considerable global appeal" (91). However, in these representations the "[h]istories of coal mining, company towns, and labor struggle--while not totally erased from this commemorative landscapeare decidedly marginal" (Saitta 91). If, as Jameson asserts, "we are condemned to seek History by way of our own pop images and simulacra of that history" (Postmodernism 25), then the exclusion of organized labor perspectives from prevalent commodified images of the American West threatens to erase these workers' narratives from our historical memory.

Against the Day breaks this silence. By emphasizing disparate material conditions and opposing social standpoints, the novel challenges the continued feasibility of a United States mythology that excludes the lives and labors of its workers. To borrow the words of Professor Vanderjuice in Against the Day, the novel is "Buffalo Bill's Wild West Show stood on its head" (53). Instead of describing the iconic Old West cattle drive, Pynchon exposes the gritty Chicago stockyards "where the Trail comes to its end at last" (53). He illuminates the wage slaves who populate this space: "fingerless slaughterhouse veterans, irregulars in the army of sorrow, prophesiers who had seen America as it might be in visions America's wardens could not tolerate" (51). Then, Pynchon juxtaposes this image with one of individuals economically privileged enough 
to feel disconnected from this type of manual labor: "an excursion group, in town for a tour among the killing-floors and sausage rooms, an instructive hour of throat-slashing, decapitation, skinning, gutting, and dismemberment" (53). These brazen, disproportionate images confront any equalizing notion that "we are all middle class."

Certainly the novel acknowledges the version of the mythic American West circulated in "a dime novel of Old Mexico, featuring gringo evildoers in exile," as well as the global appeal of this image, sought by members of the Japanese trade delegation who accost Merle Rideout in search of "the American West-it is a spiritual territory! In which we seek to study the secrets of your-national soul'" (293). However, this facade of the American West is never stable; instead, it crumbles to expose a more malevolent presence. To the Chums of Chance, the "fabled 'White City,' its great Ferris Wheel, alabaster temples of commerce and industry, sparkling lagoons, and the thousand more such wonders" was initially both "dream-like and real" $(3,36)$. Buffalo Bill's Wild West Show and the Colorado Silver Camp Exhibit at the Chicago World's Fair "possessed the exact degree of fictitiousness to permit the boys access and agency" (36). Yet, after closing day, this illusion collapsed: "the abandoned structures of the Fair would come to house the jobless and hungry who had always been there, even at the height of the season of miracle just concluded. The Colorado Silver Mining Camp, like the other former exhibits, was occupied now by drifters, squatters, mothers with nursing infants" (55-56). Paradoxically, this post-Fair image of poverty, misery, and struggle more accurately depicts life in Colorado's numerous mining camps.

In stark contrast to mythic images of a classless American West with unfettered opportunities, Against the Day's western landscape is characterized by anarchist Rev. 
Moss Gatlin as the "lost South" where "[i]nstead of the old plantation, this time it was likely to be a silver camp, and the Negro slaves turned out to be us. Owners found they could work us the same way, if anything with even less mercy" (92). ${ }^{6}$ The physical Western landscape is disfigured by towns "black with slag, up every alley all the way out into open country...towering in great poisoned mountains" (88-89). Likewise, the social landscape is marred by Cripple Creek, Coeur d'Alene, Leadville, Victor, and other sites of armed struggle between capital and labor that perpetuate and pull West the legacy of oppression and resistance from Haymarket, McCormick Reaperworks, Pullman, and Homestead. Lew Basnight found that "it got like practically every day out here saw another little Haymarket” (176). Such workers' movements were met with fierce repression, and once Basnight "got up into the embattled altitudes of the San Juans, he noticed out on the trail that besides the usual strikebreaking vigilantes there were now cavalry units of the Colorado National Guard, in uniform... More than once he ran into ragged groups of miners, some with deeply bruised or swelling faces, coatless, hatless, shoeless, being herded toward some borderline by mounted troopers" (178).

Within this terrain of wage slavery, environmental degradation, and violent military oppression, Against the Day articulates what Saitta terms a "critical, countermythic history" of the American West (92). The novel's counter-narratives speak to how remembering and forgetting, voice and silence shape our historical memory. Workers face "the structure of industrial Hells wrapped in public silence everyplace" (Pynchon 76). Yet, when laborers organize to have a collective voice concerning their working and living conditions, they soon recognize that armed company and government suppression of organized labor meant that "being in the Union you were good as dead 
anyway" (Pynchon 218). Under these repressive circumstances, only ghosts possess the freedom to speak with impunity. The dead refuse to be silenced: "They wanted his attention, them and the ones who'd died at the other places, the Coeur d'Alene, Cripple Creek, even back east at Homestead, points in between, all kept making themselves known" (362). The deceased roamed "this country harrowed by crimes in the name of gold, swept over by unquiet spirits from the Coeur d'Alene and Cripple and Telluride who came in the rain and the blinding northern and lightening-glazed mountain faces, came forlornly to stare, all those used and imperiled and run into exile" (218). ${ }^{7}$ No longer fettered by earthly constraints-including what Webb recognizes as the shackles of wage labor where "he never saw a minute that didn't belong to someone else"-only ghosts have the boundless time and freedom to speak (91).

Janet Zandy reminds us, however, that not only the lifeless haunt this earth. Breathing, working humans are also "ghosted," or turned into dead laborers. "Felt, but rarely seen, ghosts hover between presence and absence, invisibility and visibility, trailing the residue of life, of relationships, of labor performed, a history buried but not completely lost" (Zandy 94). In Against the Day, Vastroslav calls these "Industrial ghosts. Your world refuses them, so they haunt it, they walk, they chant, when needed they wake it from its slumbers" (873). These living ghosts hover between "visibility and invisibility" as unrecognized laborers performing vital work. ${ }^{8}$ They possess, in Zandy's words, a "history buried but not completely lost" (94). Both the ghosts of dead laborers and those of the unseen workers speak the exiled, marginalized voice of labor struggle. These ghosts refuse to let us forget; as Mother Jones said, the "poor children that were roasted to death at Ludlow, their voice is coming to you, and as I said, some day we will 
find that they did not die in vain. They died for a great cause, in a great battle" (Jones in Steel 139, emphasis added).

\section{"Hundreds, by now thousands, of narratives, all equally valid":}

\section{An Intertextual Analysis of the Ludlow Massacre ${ }^{9}$}

Today, the voices of those "poor children that were roasted to death at Ludlow" and the stories of literally countless other victims who died "for a great cause" during the Colorado Coalfield War are still ghosted by a history partially "buried but not completely lost” to the larger U.S. public (Jones in Steel 139; Zandy 94). Against the Day speaks from this obscured history by amplifying these ghosted perspectives. Therefore, Pynchon's version of the events at Ludlow cannot be fully appreciated without recognizing the context of contradicting accounts in which his narrative is situated.

The events that occurred near Ludlow, Colorado, on April 20, 1914, have long been the topic of personally and politically charged debate. Discussing Ludlow in Killing for Coal, historian Thomas G. Andrews notes, "Few major events in American history seem so shrouded in misconceptions, harbored not only by the general public but even by esteemed scholars" (271). Beginning immediately after the battle at Ludlow, a different type of struggle ensued in which national newspapers, union publications, military reports, personal testimonies, and other accounts clashed over the version of events that would be presented to the U.S. public and recorded in history books.

On one hand, eyewitness labor reports, such as Godfrey Irwin's account, detailed how "the miners ran about in the tent colony and women and children scuttled for safety in the pits which afterward trapped them. We watched from our rock shelter while the militia dragged up their machine guns and poured a murderous fire into the arroyo from a 
height by Water Tank Hill above the Ludlow depot. Then came the firing of the tents" (Irwin in Stein and Taft 22). On the other hand, John D. Rockefeller maintained, "There was no Ludlow massacre... While this loss of life is profoundly to be regretted, it is unjust in the extreme to lay it at the door of the defenders of law and property, who were in no slightest way responsible for it" (Rockefeller in Gitelman 23).

Within this matrix of irreconcilable perspectives and conflicting narratives, it seems that there are really two Ludlows: one is recorded by union and workers' accounts, while a second is constructed by military and company testimonies. In the vernacular of Against the Day, the historical events of April 20, 1914, at Ludlow have been doubly refracted, split into two distinct narratives progressing in different trajectories. These diverse accounts function bilocationally, creating "lateral world[s], set only infinitesimally to the side of the one we think we know" (Pynchon 230). The question that must be addressed is, as Professor Werfner asks in Against the Day, with "[h]undreds, by now thousands, of narratives, all equally valid-what can this mean?" (682). This notion of meaning is compelling (albeit fraught) because the concept meshes both intellectual and material processes. Specifically, constructing the meaning of Ludlow is not only an intellectual pursuit isolated in scholarly institutions but also a process grounded in the dynamic social relationships, physical labors, and material symbols that persist throughout contemporary southern Colorado. ${ }^{10}$

Some scholars have asserted that because of varied perspectives and other complications, it is "foolish to think that we can know with any certainly what actually occurred on April 20" (Andrews 271). I am less concerned with reconstructing some inevitably flawed description of the events of Ludlow and more interested in exploring 
how Pynchon's narrative of the massacre can be situated within these contradictory accounts. This process allows Against the Day's narrative of Ludlow not only to be understood as a contemporary revitalization of the massacre story, but also to be recognized as an account which demands that multiple types of violence-such as murder, social marginalization, and even historical erasure-be interrogated as tools wielded both for labor repression and workers' liberation. Recognizing these binaries, this chapter resists reductive moralistic proclamations such as Hume's (perhaps not exclusively rhetorical) judgment that Against the Day forwards a message that "the workers are good; the owners are bad. The more advanced the technology, the greater the oppression it imposes on the working class and the more damage it does to Earth. America is hopelessly enslaved to and complicit with the evil and moronic" (170). Such generalizations are dangerous insofar as they restrict our ability to historicize capitallabor conflicts by recognizing the agency of workers' collective counter-hegemonic movements.

Andrews asserts that perhaps "the biggest problem with the narrowly focused, polarizing memories of Ludlow inherited from the past is that they pluck a single day of killing from the stream of time, thus severing Ludlow from the vast and tangled web of events amid which it unfolded. In the process, they prevent us from understanding the larger contexts of imagination, power, and violence that caused the Colorado coalfield wars and molded their course" (9). Considering this perspective, the Ludlow Massacre must be conceptualized as one tragic climax in decades of capital-labor conflicts perpetuated by the profound ideological and material chasm which divided core groups. One on hand, faced with meager financial compensation for their work in Colorado mines 
that had the worst safety record in the country, many miners believed that organizing as a union was their best chance for obtaining a voice over their repressive living and working conditions (Martelle 19, 27-29; Andrews 147). On the other hand, most mine owners and managers asserted that miners were treated fairly and maintained that the union movement was imposed by a small, remote faction of labor agitators (Gitleman 25; Martelle 15,74$)$. In order to more fully contextualize and interpret how these contradictory perspectives shape(d) dissimilar accounts of Ludlow, it is important to recognize that decades of capital-labor conflicts and festering mistrust on both sides perpetuated the systematic company and government suppression of sustained workers' revolts.

Attentive to the duration and divisiveness of the miners' struggles, Pynchon carefully situates his narrativization of the Ludlow Massacre near the end of his vast novel, foregrounding the conditions that precipitated the event. From its opening pages, Against the Day underscores the international reverberations of the Haymarket bombing, which epitomizes the militaristic aspects of labor conflict as well as the unsubstantiated persecution/prosecution of dissident labor activists. Yet the novel not only alludes to infamous labor conflicts like the contentious Haymarket affair, Homestead battle, and Pullman and McCormick strikes, but also references perhaps lesser known Western U.S. labor disputes. This trans-temporal, inter-spatial range suggests the persistence of organized labor movements between core spaces like the eight-hour work day demonstration at Haymarket Square in Chicago and relatively peripheral territories where “another little Haymarket” occurred during conflicts such as the Cripple Creek battles for maximum hour legislation (176). ${ }^{11}$ 
The novel underscores how personal experiences with these site-specific Western labor conflicts galvanized characters as life-long union activists. Veikko emerged as a "veteran of the Cour d'Alene [sic] bullpens and the strike at Cripple Creek for an eighthour day" (82). This experience demonstrated to him that, as in his native Russia, the U.S. too had "army and police free as wolves to commit cruelties on behalf of the bosses" (83). Likewise, Webb's "trajectory toward the communion of toil which had claimed his life had begun right out in the middle of Cripple Creek" (85). And, eventually, after Webb's death, his son Reef is stirred by the ghosts of workers "who'd died at the other places, the Coeur d'Alene, Cripple Creek, even back east at Homestead, points in between" (362).

The novel's references to Coeur d'Alene, Cripple Creek, and other Western battles suggest ways in which, instead of presenting Ludlow as an isolated, anomalistic capital-labor conflict, Against the Day historicizes the continuum of union struggle and precedence of military repression that culminated in the massacre. ${ }^{12}$ Historically, Coeur d'Alene, with a notable confrontation in 1892 followed by a second in 1899, and Cripple Creek, with an initial conflict in 1894 and another in 1903, were pivotal labor battles that shaped union and company approaches to subsequent engagements. The temporal recurrence of labor disputes at these sites should rightfully suggest the degree to which violent confrontations between workers and management persisted in the American West from (at least) the second half of the nineteenth century. These earlier battles catalyzed the Western Federation of Miners (WFM) as a powerful union which "in the next decade developed into the most aggressive, violent, and revolutionary labor body in the United States and became, years later, the backbone of the I.W.W. or the wobbly movement," 
and eventually integrated into the International Union of Mine, Mill, Smelter Workers, which merged with the United Steelworkers in 1967 (Adamic 125). While the WFM played a central role in the 1903-1904 strike, over the next decade the United Mine Workers of America (UMWA) emerged as a central force in the 1913-1914 strike.

Strikes at Coeur d'Alene, Cripple Creek, and other locales, not only solidified labor unions' presence in the Western United States, but also shaped the course of action that complicit mine owners' associations, private detective agencies, vigilante groups, and state militia would take during subsequent labor conflicts. The 1903-1904 coalfield war set a precedent in which "[h] $\mathrm{h}$ arassment of strike leaders, evasion of due process, suppression of freedom of speech and the press, collusion in order to railroad local union officials into prison, suspension of the writ of habeas corpus, imposition of 'limited martial law'-all followed as the state, under the guise of upholding law and order, joined the campaign to wreck the WFM" (Suggs 392). Against the Day highlights a particular tactic for union suppression as it recounts how Viekko and other miners had "been picked up in a general sweep" by the state militia and "sealed in a side-door pullman and taken south on the Denver \& Rio Grande across the invisible border into New Mexico...told to stay out of Colorado unless they wanted to leave it next time in a box" (82-83).

Throughout this time, it was not uncommon for strikers to be imprisoned with thousands of fellow union sympathizers in "bull-pens" and even deported from the territory (Adamic 125). Andrews states that by June of the 1903-1904 dispute, "more than 180 strikers had been jailed, often without formal charges' [sic] having been filed. State troops subsequently forced 97 men, as well as Mother Jones, to leave the state. Some they dumped on the high plains of Kansas, others in the New Mexico desert" (242). 
By 1913, decades of labor conflict had inflicted deep psychological and physical scars upon the working population of southern Colorado. Mineworkers who had taken part in the 1903-1904 strike remembered how companies tried to suppress labor action by physically assaulting union leaders and their families, increasing mine guard forces, retaining private detective agencies to infiltrate unions, and, ultimately, calling in private military forces and the National Guard to act as strikebreakers ${ }^{13}$ (Andrews 243-44). Mining interests had found this intensive approach advantageous; therefore, only "[n]ine years later, with the United Mine Workers again bent on organizing the southern fields and rumors of a strike on every tongue, coal company executives trotted out the same formula that had served them so well in 1903-1904" (Andrews 244). Recognizing this cyclical history, Against the Day notes that the 1913-1914 dispute was "“[1]ike Cripple Creek all over again,' those who remembered pointed out. Back then, ten years ago, the scabs had been Slavs and Italians, some of whom had stayed on and joined the Union, and this time around they'd become the ones who were on strike" (1009).

When a strike was called in September 1913, a staggering $80-90 \%$ of coal miners in southern Colorado walked out (Andrews 247). Undeterred by coal companies' militant efforts to contain another dispute, these 10,000-12,000 strikers advanced seven basic demands:

\section{Union recognition;}

2. A $10 \%$ wage increase on tonnage rates and a day scale corresponding with Wyoming;

3. Enforcement of the eight-hour work day law; 
4. Payment for dead work (Miners were paid on the basis of the coal they mined. Dead work was unpaid work necessary to keep the mines running, such as laying track, timbering, etc.);

5. The right to elect their own union check-weighmen who could verify the weight of coal mined;

6. The right to trade at any store, and choose their own boarding places and doctors (At this time most miners lived in company towns in which most aspects of workers' and their families' lives were dictated by the company, from the books they could check out at the library to the products they could purchase with company scrip in company stores.);

7. Enforcement of the state mining laws and abolition of the company guard system.

Immediately after they went on strike, miners and their families were expelled from company housing, often forced to quickly gather whatever basic necessities they could carry as armed mine guards oversaw the eviction. One account recalls how " mine guards hastened to the little huts where the miners lived and threw their families and furniture into the street. Little children so ejected were hurt and several fights resulted"' (Andrews 247). Facing a frigid winter in the Colorado mountains with no permanent shelter or prospect of employment, some miners left the region. However, many others, dedicated to the union cause, set up makeshift tent towns on land leased by the United Mine Workers, and continued the strike.

Historians confirm Against the Day's estimate that by winter the "strike relief rolls numbered about twenty thousand men, women, and children," the largest number of 
whom were housed at a provisional tent colony near the Ludlow train depot (Pynchon 1008-09; Andrews 248). The novel provides an ostensibly historical description of the Ludlow colony with "maybe 150 tents and nine hundred people living in them, mostly families," which precisely reflects McGovern and Guttridge's scholarly estimate (Pynchon 1007; McGovern and Guttridge 213). Pynchon elaborates that the colony "had been there since late last September, when the strike began. Little by little, flooring got put in, latrines were dug, a phone line was run to the Union office in Trinidad. After some shooting in early October between mine guards and the people in the tents, both sides had begun to store up guns and ammunition" (Pynchon 1007). As Against the Day suggests, these tent colonies served dual purposes as family communities-complete with sports fields and food storage cellars-as well as armed union strongholds situated amid the military-occupied strike zones. Andrews elaborates that, on one hand, "colonies sometimes took on an almost utopian cast...they buttressed the growing sense of conviction that led migrants from radically different backgrounds to embrace a common identity and common interest in the success of the strike" (251-52). However, on the other hand, these tent "colonies functioned as military encampments as well as refugee camps and incubators of group identity. From the start, Ludlow was undoubtedly the most martial of the camps" (Andrews 252).

As the diverse strikers' collective resolve solidified in communities with astonishingly congruous roles as utopic colonies and military camps, Rockefeller and other mine owners recognized that the strike would persist and appealed to Colorado governor Elias M. Ammonds to send in the National Guard. Among the military leaders who oversaw the occupation of the strike zone was General John Chase, a coal company 
attorney who had led troops during the violent Cripple Creek dispute only a decade earlier. Against the Day emphasizes the bias of this leadership choice, stating that "the governor declared martial law, and soon nearly a thousand troops, infantry, cavalry, and support, under the command of a Colorado Fuel and Iron stooge named John Chase who styled himself ‘General,' had set up base camps” (1007).

Strikebreakers were shipped in, as the novel describes, "from as far away as Pittsburgh, Pa., though many of them were from Mexico, escorted by Guardsmen all the way from the border, promised everything, told nothing" (1009). Inverting the process by which union agitators, like Viekko in the novel, were involuntarily deported from strike zones, now new unwitting workers were shipped in to replenish the dwindling labor force. ${ }^{14}$ "Scores, if not hundreds, of workers were duped into taking free train tickets from the East to promised jobs in Colorado, not realizing they were signing up for indentured servitude in strike-breaking coal mines," explains Scott Martelle in his history Blood Passion: The Ludlow Massacre and Class War in the American West (147).

With the arrival of trainloads of scabs into a region occupied by the Colorado National Guard, violent confrontations between strikers and soldiers unsurprisingly escalated. Against the Day alleges, "Women were raped, kids teasing soldiers were grabbed and beaten. Any miner caught in the open was fair game for vagging, arrest, assault, and worse. In Trinidad, cavalry of the state militia charged a band of women who were marching in support of the strike. Several, some only girls, were slashed with sabers. Some went to jail” (1009). This passage alludes to a particularly violent confrontation in which a women's protest march in Trinidad (calling for the release of labor leader Mother Jones from a makeshift prison cell) resulted in General Chase 
leading his troops "racing their horses through the crowd and swinging gun butts and the flat side of their swords at anyone they could reach. The crowd responded in a riot, heaving rocks and epithets as they scattered, long dresses billowing as women ran from the rearing, twisting horses" (Martelle 154).

In the swelling tent towns outside of Trinidad, the atmosphere was similarly tense. The novel elaborates that amid growing apprehension, the National Guard "gun emplacements" were positioned on high ground near the Ludlow tent colony and "company searchlights set up on towers began sweeping the tents" (1008). Camps were patrolled by the "Death Special," which Against the Day describes as an "armored motorcar, with two Colt machine guns on it, mounted fore and aft, that the Baldwin-Felts 'detective' agency had come up with for penetrating, controlling, and thinning down the size of ill-disposed crowds" (1009). Strikers first faced the "Death Special" as it rapidly riddled the Forbes tent colony with over 600 bullets. In subsequent days, it was seen near Ludlow on at least one occasion (Martelle 96-97; McGovern and Guttridge 122-23). As accounts of the savage destruction of Forbes tent colony circulated at Ludlow, strikers feared that their community would suffer a similar fate (Martelle 160).

However, in the weeks leading up to the massacre a significant number of troops had been withdrawn from southern Colorado (Walker 68). By April 17 $7^{\text {th }}$, only two small detachments remained in the area near Ludlow-Lieutenant Karl Linderfelt's Company B and Company E, which instead of being composed of traditional Guardsmen, were predominately made up of mine guards and other former CF\&I employees. In Against the Day, Stray characterizes "fucking Linderfelt" as a ruthless soldier: "When they attack tonight, it'll be him out front yelling Charge. Linderfelt is the devil” (1013). Many miners 
in the region shared this growing animosity towards the troops, in part, because since early November, the "growing practice of mustering former sheriff”s deputies, mine guards, and detectives into the National Guard" created "a force of men boasting a checkered history as criminals, counterinsurgents, and union busters” (Andrews 257). Moreover, by this time, the troops were no longer paid by the government; instead, the Colorado Coalfield War was fought by state troops that were directly funded by private coal mining interests who had an indisputably vested stake in the outcome of the struggle. Andrews explains, “Working with Denver's largest bankers, Colorado Fuel and Iron and its allies arranged to foot the bill for the troops' food, fuel, and other supplies. In time, they even paid the guardsmen's salaries" (257). As Walter Fink's union account contentiously asserts, "Quarter was given none by these assassins. They had been hired at $\$ 3$ to $\$ 7$ a day to do this dastardly work of exterminating the strikers, and they were determined to do it well" (9).

After decades of violent confrontations between coal mining interests and striking workers, on April 20, 1914, near Ludlow, Colorado, the largest tent colony of striking men, women, and children stood adjacent to a CF\&I-funded military detachment of former mine guards and company employees. The well-armed soldiers along the ridge possessed the physical and financial high ground against strikers and their families, who had persevered without employment in their makeshift housing through severe winter blizzards. When fighting broke out, the scene must have embodied the ideological and material chasm that divided these groups.

Against the Day narrates that the "shooting had begun at first light, and soon grew general, and went on in spasms all day. The militia were up on Water Tank Hill with a 
couple of machine guns. Their riflemen were set in a line along a ridge up there. There were some strikers in a railroad cut to the east that had the Guardsmen sort of enfiladed, but the militia were also higher" (1013). As the fighting continued "nearly a thousand troops, infantry, cavalry, and support" converged on the union camp at Ludlow, where ensuing "gunfire was unremitting" and "tents were all being set on fire, one by one...strikers, and children and their mothers, and even troopers and camp guards, took bullets or fought flames, and fell in battle" (Pynchon 1016).

Pynchon's narration provides a vivid fictionalized scene that parallels Fink's lessread union account that "tents were riddled by bullets until they looked like so many fishing nets. Using the machine guns like the garden hose, the gunmen cut down everything that rose in their path of death as they swerved from one end of the colony to the other and back again" (9). Fink graphically records the death of women and children who "were burned and roasted" in their tents or, like 11-year-old Frankie Snyder who left his cellar to get water, "shot through the head and killed instantly" (Fink 11, 13).

To escape the gunfire, women and children had two choices: They could stay in the safety of the tents and descend into the earthen cellars, or they could try to dodge bullets in a dash for nearby low ground located at an arroyo and the well pump station. Out of the Depths, Barron B. Beshoar's biography of labor leader John R. Lawson, depicts "women, screaming at the top of their voices, clutching their little ones tightly as they huddled in the underground cellars while explosive bullets burst in the streets and tents" (173). Other women and children fled to the arroyo where they gathered "only partially clad as the firing had started before they were fully dressed" (Beshoar 174). In her autobiography Those Damn Foreigners, Ludlow survivor Mary Thomas O’Neal 
recalls, "We all ran as we were, some with babies on their backs, in whatever clothes we were wearing...not even thinking through the clouds of panic. We were terrified" (13334). "[W]ith a child clinging to each hand," O'Neal "ran toward the arroyo. The frightened screeches and screams of all the women and children dashing over the prickly prairie were deafening" (134). As they dashed for safety the "guards couldn't help but see us out there in the brush, going as fast as we could, and they kept shooting at our heels, I supposed to hurry us on" (135). O'Neal recalls that once they were huddled in the arroyo, the "sound of gunfire went on and on as we shivered and pondered our immediate future, wet, hungry and miserable, wondering about the men in the hills as they probably were wondering about their wives and children" (136).

These firsthand accounts are mirrored in Against the Day's narration of Stray, who "got used to the dirt kicking up in little bursts around her, the fading hum of spent ammo bouncing away....Sometimes she was almost sure the marksmen who had the high ground were playing with her" (1007). However, recognizing the gravity of the situation on the day of the massacre, Stray, Frank, and Jesse-much like the historical strikers at Ludlow-took "shelter with hundreds of others, at least for a few minutes, in the wide arroyo north of town, waiting for some letup in the shooting to get someplace safe. But the militia were trying to take the steel bridge over the arroyo, which would cut off any more escape to the westward" (1015).

From the arroyo, the refugees in the novel could see that "tents were all being set on fire, one by one, by the heroes of Linderfelt's Company B. An impure reddish light leapt and shifted in the sky and the troopers made sounds of animal triumph" (1016). Against the Day recounts that at nightfall a "small band of horsemen was galloping 
past....The bunch might've been state militia, Baldwins, sheriff's posse, Ku Klux Klan or any of the volunteer ranger groups. It was getting too dark out to tell. They were carrying torches" (1014-15). Some scholars are noncommittal concerning the origins of the tent fires at Ludlow, which the military maintained was caused by a single stray bullet overturning a solid-metal pipe stove. However, Martelle asserts that this version-in which "the fires were an accident the mob helped spread-has been etched into the historical perception of what happened, but it doesn't pass the smell test” (179). Numerous accounts state that remaining tents were torched the following day, after the miners had left the area. Thus, it "stretches credulity to believe that the heavy, free standing iron stoves used in the tents could be knocked over by a bullet... There can be little serious doubt that the Colorado National Guard started the fire and spread the flames on Monday night, finishing the job Tuesday morning” (Martelle 179-80).

Adamant declarations, disputes, and denials over the origin of the tent fires persist because the flames resulted in the most vividly gruesome and widely publicized image of the Ludlow Massacre-the charred bodies of two women and eleven children who perished while hiding from gunfire in a tent cellar. One can only speculate why Pynchon does not elaborate this grisly consequence of the arson. In the days that followed the battle at Ludlow, this image was the focus of conflicting, shocking, and exaggerated stories in newspapers across the country. On April 22, 1914, a New York Times headline read “45 DEAD, 20 HURT, SCORES MISSING, IN STRIKE WAR; Women and Children Roasted in Pits of Tent Colony as Flames Destroy It.” One emotionally-charged banner in the Toledo News-Bee proclaimed, "COLORADO STRIKE WAR DEADLY TO WOMEN AND CHILDREN; Innocents Are Slain in Monday’s Battle Between the 
Striking Miners and Colorado Coal Company's Guards." The same day, the Atlanta Constitution declared, "Women and Babes Killed By the Colorado Militia; Four Mothers and Thirteen Children Victims in Battle Between the Strikers and Soldiers. DEATH TOLL OF BATTLE WILL PROBABLY REACH 25, Alleged The Soldiers Used Machine Guns on the Tent Colony of Strikers. Women and Children Had No Chance to Escape."

The gravity of these initial headlines might have suggested that the Ludlow Massacre would forever endure in the public's historical memory. However, today one is most likely to learn about Ludlow by hunkering down in a library piecing together interspersed scholarship or by spending time in southern Colorado talking to the minority of workers who maintain the living legacy of the battle. This contemporary situation is, in part, the result of concerted efforts by coal companies-predominantly Rockefeller's CF\&I-to shape the version of history recorded and popularized after the massacre. Following the April $20^{\text {th }}$ battle, national headlines that recounted the deaths of women and children in Ludlow's "black hole" put Rockefeller and CF\&I on the defensive (McGovern and Guttridge 236). During the 1903-1904 labor conflict, which served as a blueprint for coal companies' approaches during the 1913-1914 strike, the press was heavily censored in an attempt to keep stories of dubious company and military actions in the Colorado coalfields from reaching the wider U.S. public. Concurrently, coal companies launched media campaigns to shape a positive public image (Andrews 242). A decade later, after Ludlow, Rockefeller amplified this approach to counter negative public sentiment with an aggressive campaign designed by public relations experts Ivy L. Lee and Mackenzie King. Together, they implemented a publicity program 
that began by mailing pro-CF\&I bulletins to influential public figures and ultimately culminated in Rockefeller's Industrial Representation Plan, arguably designed to pacify workers and thwart membership in outside unions such as the UMWA. Through this comprehensive public relations approach, CF\&I directly and indirectly shaped the story of the 1913-1914 Colorado Coalfield War recorded in government documents, testimonies, and scholarship (Gitelman 24-25).

In Legacy of the Ludlow Massacre, Gitelman contends “contemporaries and all subsequent writers on the subject (whether friendly or not) have assumed that Rockefeller's actions in the months and years following Ludlow were the acts of a penitent, motivated by deep feelings of contrition. It may now be said without equivocation that this was not so. He deplored the events at Ludlow but never ever acknowledged any responsibility for them" (23). In a memorandum prepared after Ludlow, Rockefeller contended, “There was no Ludlow Massacre...There were no women or children shot by the authorities of the State or representatives of the operators in connection with the Ludlow engagement... Not one." (Rockefeller in Gitelman 23). Rockefeller's sentiment was precisely echoed by Major Edward J. Boughton in testimony before the U.S. Commission of Industrial Relations, in which he went so far as to say, "There was no such thing as the Ludlow massacre. Nobody was massacred at Ludlow. Nobody was killed at Ludlow in the tent colony or burned, with the one exception of a small child by the name of Snyder, who during the day...had faced toward the arroyo for private purpose, and was shot in the forehead from the direction of the position of the tent colonist combatants" (Boughton 7:6367-6368). To spread this fallacious message after 
his congressional testimony, Boughton traveled on an extended speaking tour financed by Rockefeller (McGovern and Guttridge 284). ${ }^{15}$

Short of complete denial of the events at Ludlow, other accounts attempted to justify CF\&I and the military's role by portraying the strikers as aggressive, unruly zealots. In his official report, General John Chase asserts that the union strikers were intent on violence: "The canvas for the tents had hardly been raised before deeds of violence were reported from the vicinity of nearly every one of the colonies...For at least ten days prior to the calling out of the National Guard a condition of absolute terror prevailed in the mining camps and in the tent colonies" (Chase 8). Chase summarizes, "Anarchy reigned supreme" (9).

While these official denials and extenuations briefly illustrate the types of corporate and military documentation that Pynchon is writing against, perhaps the most troubling aspect of dubious CF\&I and military accounts is their persistence in latetwentieth-century scholarship. University of Colorado history professor H. Lee Scamehorn's two-volume history of CF\&I problematically discusses the 1913-1914 strike and Ludlow Massacre by drawing heavily on CF\&I annual reports and accounts from company president Jesse F. Welborn. These perspectives lead Scamehorn to reinforce embellished images of violent, lawless strikers, asserting, "In spite of the company guard system, anarchy prevailed throughout the region. Men who continued to work in defiance of the strike call were in constant peril. Nonunion employees were murdered in cold blood. No one was safe from attack" (43). This characterization of strikers leads Scamehorn to justify CF\&I's approach during the strike, explaining, "The operators insisted that they had no option but to counter by employing armed guards at 
various mines for the protection of workmen and property...Non-striking employees were, if unguarded, subject to abuse and violence. Anyone who sympathized with the mine operators was vulnerable to attack" (43). Following this logic, Scamehorn reiterates a position that exonerates CF\&I and the military from any culpability for the Ludlow Massacre: "Tents went up in flames before the troopers entered the area, and may have been set on fire by the strikers. As the conflagration spread, militiamen helped women and children to escape from the tents, even while under heavy fire from strikers entrenched on nearby high ground" (emphasis added 45-46). Scamehorn's 1992 publication raises significant concerns about the degree to which CF\&I reports continue to shape contemporary histories of the Colorado Coalfield War and Ludlow Massacre.

Perhaps even more disturbing is the fact that the majority of CF\&I documentation that might shed light upon company orders and actions during the 1913-1914 dispute has disappeared. One of the few surviving documents is a photocopy of CF\&I management's strike notes from the period, which is preserved at the Bessemer Historical Society in Pueblo, Colorado. This notebook shows that management kept detailed records of the names and actions of union activists, as well as maintaining a list of strikers and family members killed during the conflicts. Soon after a photocopy of the strike notes was donated to the museum, the original notebook in the possession of CF\&I mysteriously vanished. $^{16}$

With CF\&I's well-funded, systematic program to shift public opinion and shape historical records, the fact that union and strikers' accounts of the Ludlow Massacre endure to any degree is a testament to the persistence of "submerged" narratives. Reflecting workers' ghosted perspectives, Against the Day's account of the Ludlow 
massacre offers a corrective to government, military, and scholarly documentation that emphasizes union hostility, while attempting to erase military violence from historical records. In his essay on Against the Day, Yerkes asserts, “Although [Pynchon's] novels are not conventionally historical, they are deeply so insofar as they compel the reader to actively grapple with the past in terms of identity and difference, without providing any answers or solutions for problems of human existence that may in fact transcend history" (231). By narrating union strikers' perspectives on the Colorado Coalfield War, Against the Day challenges readers to "actively grapple" with the limitations and omissions in our popular historical construction of the American West. Certainly Pynchon is aware of the ways in which corporate and military interests shape the writing of history, as he states, that the horrors of Ludlow "happened, each casualty, one by one, in light that history would be blind to"; however (fortunately), Pynchon uses artistic license as he continues, "The only accounts would be the militia's" (1016). Ultimately, the novel's depiction of the Ludlow Massacre serves as a poignant reminder of the facts that Rockefeller desperately wanted the public to forget-not only striking miners, but also their wives and children, were victims of corporations' and the United States government's thanatopolitical use of force to domestically support strike-breaking efforts.

"And if gold don't work, sooner or later they get around to lead": Versions of Violence ${ }^{17}$

To understand the "meaning" of Ludlow, one must recognize the range of disciplinary and corporal violence enacted against workers under capitalism, as well as the aggressive methods by which workers try to revolutionize economic, political, and social systems. By narrating labor perspectives on the battle at Ludlow, Pynchon compels 
readers not only to reevaluate their historical memory of the American West, but also to interrogate narrow moralistic conceptions of violence. Considering the thousands of coal miners who died on the job, Andrews astutely points out:

[The] association between violence and the Wild West appear[s] curious, even negligent. After all, on-the-job accidents and workplace disasters claimed many more lives than range wars and gunfights ever would. The gruesome industrial violence that resulted when colliers unintentionally detonated the immense energies latent in the ancient coal seams where they labored has been almost entirely overlooked by novelists, filmmakers, and historians alike. (Andrews 123)

Against the Day provides a notable exception to Andrews's accurate generalization.

To more fully contextualize industrial violence-catalyzed not only by the environmental forces Andrews describes but more commonly by human agents-Against the Day portrays the naturalized brutalities routinely faced by manual laborers. As the quintessential Rockefeller-esque capitalist of the novel, Scarsdale Vibe, readily admits, we "send [workers] up onto the high iron and down into mines and sewers and killing floors, we set them beneath inhuman loads, we harvest from them their muscle and eyesight and health, leaving them in our kindness a few miserable years of broken gleanings" (1000). Elaborating the material consequences of this capitalist exploitation, Against the Day recounts the dehumanizing working and living conditions faced by mining families in southern Colorado, where it "was coal and not gold that men went down underground to risk their lives and health for" (996). Historically, men (and boys) 
in the mines labored in "lung-destroying jobs" under constant threat of aspirated coal dust, deadly odorless gas known as damp, explosions, cave-ins, fire, and other hazards (92). Against the Day portrays the palpable oppressiveness of these subterranean workplaces, where the "noise was hellish, and air wet and hot and stifling when it wasn't full of stone dust" (653). Yet, the terrestrial landscape provided only nominal repute.

Workers and their families faced social and economic marginalization due, in part, to infamously low wages, substandard housing, poor education, and other shortfalls of company towns. This reality affirmed Webb's notion that in corporate jargon, "CCompassion' means the population of starving, homeless, and dead is about to take another jump" (93). Many company towns were plagued by threats to health and safety posed by slag piles "towering in great poisoned mountains" and other industrial toxins such as those in Little Hellkite, where the amalgamator became "crazy as a bedbug 'th all them fumes and shit he breathes in all the time and twice on bullion day" $(88-89,291)$. Through these images, Against the Day testifies to the fact that symbolic violence, including institutionalized "[h] umiliation routines over short weight or docked hours" and "assignment to less hopeful, even dangerous rockfaces and tunnels," ultimately results in physical realities such as the abject poverty, deadly working conditions, and toxic living environments for workers and their families (92).

Underpinned by the multiple layers of exploitation and violence inherent to the production of capitalist wealth, conflict in Against the Day never materializes in purely disciplinary or ideological realms. Animosities between opposing camps are embodied in aggressive, corporal actions. Yet the novel resists the absolution of either side by shaping narratives around the antagonism between, on one hand, the laborers and unions and, on 
the other hand, the owners and the nation-state. Voicing the stance of so-called captains of industry, Vibe muses, "Should there be moral reservations in a class war, about targeting one's enemies? You have been in this game long enough to appreciate how mighty are the wings we shelter beneath. How immune we are kept to the efforts of these muckraking Reds" (332). Accordingly, Webb sagely recognizes that the forces who hinder worker empowerment will stop at nothing to suppress labor organization, and "if gold don't work, sooner or later they get around to lead" (105). Webb correspondingly adopts violent methods to revolutionize the class wealth system, however, not without weighing the material and ethical dimensions of this approach:

Lord knew that owners and mine managers deserved to be blown up, except that they had learned to keep extra protection around them-not that going after their property, like factories or mines, was that much better of an idea, for, given the nature of corporate greed, those places would usually be working three shifts, with the folks most likely to end up dying being miners, including children working as nippers and swampers-the same folks who die when the army comes charging in. (84-85)

This insight reiterates the novel's central engagement with the dialectic tensions of seemingly incompatible concepts such as sacrifice|selfishness, violence|peace, and innocence|guilt that weave inextricably throughout the text and resist reconciliation. In such a way, Against the Day problematizes the notion that capitalist production rests predominately on the disciplinary regulation of laborers; rather, the novel illustrates how, for certain populations, disciplinary control is simultaneously maintained|resisted by the 
omnipresent threat of corporal violence. The biopolitcal manipulation of individual workers and larger labor populations functions simultaneously on the material body and the structural group.

Webb recognizes that laboring populations are fully included in the process of creating value in a capitalist economy, pointing out that "'Labor produces all wealth,"” and contentiously continuing, "Wealth belongs to the producer thereof"” (93). Yet as Warren Montag elaborates in his concept of necro-economics, maintaining the equilibrium of capitalist markets too often depends on the strategic elimination of particular populations of producers. Therefore, although workers are fully embedded in the process of labor exploitation necessary to create capitalist surplus value, certain populations of laborers occupy a position of, to borrow Agamben's term, “exclusive inclusion." Workers' inclusion is vital to the production of wealth; however, specific groups are governed under an exclusive "state of exception" in which the nation-state may implement military action to regulate (or eliminate) this population. Hardt and Negri elaborate Agamben's concept by looking beyond the nation-state paradigm and recognizing that capitalist organizations, such as transnational corporations, operationally control global populations of laborers in a "permanent state of exception" under which collusive state and private forces may deploy "a powerful police function against the new barbarians and the rebellious slaves who threaten its order" (Empire 20). As Saskia Sassen describes, superfluous populations may be regulated through expulsions, reminiscent of Vieko's deportation from Colorado in Against the Day. As a testament to these concerted forces, Vibe readily admits, "Of course we use [workers]...we harness and sodomize them...We take what we can while we may" (1000). Through this process, 
the laborers in Against the Day become an iteration of Montag's necro-economic and Agamben's biopolitical homines sacri-the lives that can be taken with impunity by the nation-state's military forces and privileged private industrialists.

Against the Day's account of Ludlow-as well as the novel's historical references to Cripple Creek, Coeur d'Alene, and other labor conflicts-underscores the fact that industrialists not only depended on the National Guard to support strikebreaking efforts, but also aggressively employed "extra-legal police agents," like the novel's White City detective, Lew Basnite (Hunter 281). In other words, the type of privatized militarization associated with contemporary neoliberal corporations can be seen in early twentieth century strike breaking efforts. Louis Ademic's 1931 study Dynamite: The Story of Class Violence in America, elaborates that during the early twentieth century, private capitalist enterprises employed detective agencies who "sent thieves and murderers to the scenes of labor disputes, where the employers appointed them 'guards,' with duties to protect property and scabs, to shoot down and slug strike pickets" (97). Similarly, Robert Hunter's Violence and the Labor Movement-published the same year as the Ludlow Massacre-reports that "there are unquestionably numerous agencies in this country where one may employ thugs, thieves, incendiaries, dynamiters, perjurers, jury-fixers, manufactures of evidence, strike-breakers, and murderers....If one can afford it, one may have always at hand a body of highwaymen or a small private army" (282). In such a fashion, Against the Day's Scarsdale Vibe travels not with just "one or two other Pinks," but instead with armed bodyguards "newly arrived in town from strike-breaking duties" $(742,669)$. These corporate paramilitary groups in the novel embody the underpinning 
corporal violence executed to maintain workers in a "permanent state of exception" through concurrent government forces and private guards.

Against the Day illuminates the obscured spectrum of violence faced by workers, from naturalized violence in workplaces to organized nation-state and private military campaigns against strikers. However, one would be remiss to conceptualize workers in the novel as static recipients of disciplinary|corporal regulations, or to presume that by elaborating workers' hegemonic subordination, the text absolves laborers from the consequences of violent resistance movements. Such reductive readings would do a disservice to Pynchon's rich text, as well as the complexities of historical and contemporary worker empowerment movements. For instance, after the Ludlow Massacre, enraged strikers, their families, and sympathetic factions engaged in what has been termed the Ten Day War, an under-recognized period of widespread domestic warfare in southern Colorado. Considering this response to the Ludlow Massacre, Andrews asserts that in "making victimization the main story line of a struggle in which strikers actually inflicted more deaths than they suffered, historians have treated men, women, and children who demonstrated tremendous capacity for action as having been almost entirely acted upon" (15). Thus, what is at stake in representations of capital|labor relationships is not only our historical memory of industrial violence, but also the ways in which we conceptualize the collective agency of workers.

By conceiving of dynamite as the “American working man's equalizer, his agent of deliverance, if only he would dare to use it," the novel recognizes violence as a tool wielded with the aim of rearticulating oppressive power structures (87). In her essay on Against the Day, Kathryn Hume suggests, "Pynchon seems more politically aggressive 
here than in earlier novels, if only out of despair over a lack of effective peaceful alternatives" (168). While the beginning of this statement seems plausible, I am less convinced of what Hume elaborates as the "seriousness with which Pynchon appears to support political violence" (168). Such a reading risks reducing the novel's central dialectic engagement with peace|violence into a binary choice between endorsing one of two divergent methods. Certainly, Against the Day repeatedly illustrates how violence often underpins employers' disciplinary actions, as well as the flip side, in which corporal aggression is recognized as a potential weapon for workers' liberation. Yet far from entertaining what Benton terms as a "romanticization of terrorism," Against the Day acutely recognizes the potential collateral damage of "children working as nippers and swampers" who perish during industrial sabotage and the working "folks who die when the army comes charging in" to support corporate warfare (Benton 203, Pynchon 85). Contextualized within this wider terrain of violence, Webb is far from the celebrated labor martyr who Hume characterizes as "an austere labor saint at the intersection between religion and politics" (181). Instead, Webb represents the human cost of industrial violence, as he is haunted in life by a "terrible real ballooning of emptiness at the core of his body" and transformed at death into a restless ghosted spirit unable to disentangle his family from corporate blood money (95). Pynchon's rhetorical strategy of constructing Webb as a sympathetic dynamiter draws the reader into the dialectic tensions of sacrifice|selfishness, violence|peace, and innocence|guilt, which ultimately illustrates how cyclical industrial/labor corporal aggression generates no sustainable rearticulation of power in the novel. 
Against the Day unabashedly illuminates the context of capital-labor conflict in which pervading social, economic, political, and environmental marginalization leads young Jesse to believe that being an American means "do what they tell you and take what they give you and don't go on strike or their soldiers will shoot you down” (1076). While violence is one material reality of labor struggle, Against the Day recognizes that there are multiple ways to detonate structural change. Reef initially assumes his father, Webb's, legacy as the dynamiting agitator, the Kieselguhr Kid; yet, by the end of the novel, he demonstrates to his son a different method of provocateuring. Upon hearing Jesse's essay prompt "What It Means To Be An American," "Reef had that look on his face, the same look his own father used to get just before heading off for some dynamiterelated activities, 'Let's see that pencil a minute"' (1076). With the radical power of dynamite transmuted into the writing stick, Reef and the next Traverse generation, Jesse, illustrate the historical legacy of industrial arbitration that emerged in the wake of Ludlow's industrial/labor warfare.

\section{History In-flux: The Living Memory of Ludlow in \\ Contemporary Southern Colorado}

Speaking to an audience of mine owners and local vigilantes in Against the Day, Scarsdale Vibe predicts that images of industrial/labor warfare in the American West will slowly fade from historical memory:

When the scars of these battles have long faded, and the tailings are covered in bunchgrass and wildflowers, and the coming of the snow is no longer the year's curse but its promise, awaited eagerly for its influx of 
moneyed seekers after wintertime recreation, when the shining strands of telpherage have subdued every mountainside, and all is festival and wholesome sport and eugenically-chosen stock, who will be left anymore to remember the jabbering Union scum, the frozen corpses whose names, false in any case, have gone forever unrecorded? [W] ho will care that once men fought as if an eight-hour day, a few coins more at the end of the week, were everything, were worth the merciless wind beneath the shabby roof, the tears freezing on woman's face worn to dark Indian stupor before its time, the whining of children whose maws were never satisfied, whose future, those who survived, was always to toil for us, to fetch and feed and nurse, to ride the far fences of our properties, to stand watch between us and those who would intrude or question? (Pynchon 1001)

I want to conclude this chapter by pursuing Vibe's questions: Who will be left anymore to remember? Who will care that once men, women, and children fought?

To find an answer, I journeyed along a sparsely traveled country road outside of Trinidad, Colorado, to a marble monument that marks the spot where eleven children and two women were murdered. Backdropped by the Spanish Peaks and bisected by lone railroad tracks, this seemingly peaceful field might easily betray its bloody history as the site of the Ludlow Massacre. Yet the sculpted images of a vigilant miner and brooding woman with an infant clinging to her breast stand as an adamantine reminder of the hot lead and purposeful flames that left the lifeless bodies of striking union men, women, children, and infants among the smoldering remains of Ludlow tent colony. 
The Ludlow site is sacred ground for union miners and for the U.S. labor movement. I joined the men, women, and children who gather annually on this hallowed battlefield to remember those who died in this and other labor conflicts to secure union representation, enforced safety regulations, child labor legislation, maximum hour laws, and other rights and privileges that contemporary workers now enjoy. The yearly memorial can draw hundreds of participants, who openly welcomed me into the storytelling, songs, speeches, and camaraderie through which we remembered labor's past in order to better understand the present and look toward the future. Through these events, those who attend maintain Ludlow as a living history, invoking the lessons of Ludlow as they engage with current labor struggles as rank-and-file union members, labor leadership, supportive family, and community members. ${ }^{18}$

Standing on a platform in the shadow of the marble monument, Dr. Fawn Amber Montoya, Associate Professor of History at Colorado State University Pueblo, fought back tears as she shared her grandfather's recollections of working in the local mines and mill in Pueblo. "Why is Ludlow worth remembering?" she asked: "Because it's a story of the economy. It's a story of immigration, of labor, of energy, of culture, of history" (Montoya). Montoya and other speakers at the memorial emphasized the importance of connecting stories of Ludlow's past to the present and the future. "Have there been changes in the corporate attitude since Ludlow, or, better put today, is the middle class dying a slow death by a thousand cuts?" asked United Mine Workers District 22 Vice President Mike Dalpiaz. "No major person ever went to jail for the murders [of workers resulting from coal mine disasters]. That in-and-of itself is a crime and an incitement of how this country worked yesterday and today," proclaimed Dalpiaz. 
At the podium, Thomas Andrews, professor of history at the University of Colorado and author of Killing for Coal, echoed how remembering, retelling, and circulating the history of Ludlow links to our larger responsibility as democratic citizens: "The Ludlow Tent Colony was a place shaped by singing, by the sharing of poetry, by learning, by remembering the dead, by celebrating, by listening, by joining together. And so I think it is wonderful that is what we are doing here this morning" (Andrews). Andrews emphasized to the audience that "coming here and committing yourselves to engaging in this vital civic task of remembering the past...is one of the more of important acts of citizenship that we perform in this country" (Andrews).

Finally, keynote speaker Dan Kane, United Mine Workers of America International Secretary-Treasurer, took the podium and asked, "What is it that makes us support policies that kill working people and kill the working class?” (Kane). In response he proclaimed:

The message of Ludlow is this: We have to fight for what is right for tomorrow! You know what they were fighting for in Ludlow? Human recognition. What they wanted was a chance to sit down and bargain. It astonishing to me that there are people in this county that claim to be patriots, they claim to support democracy, but they take a hike on democracy the minute you enter the work place. That is wrong. That is absolutely wrong. (Kane)

Kane's statement emphasizes the relevance of Ludlow today-the debt that contemporary workers owe to those who fought and died for workplace democracy. Kane continued: 
If you don't remember anything else I said here today, I want you to remember this: Organized labor has raised the standards in this country for all workers. The reason we have a weekend is because of organized labor. The reason we have health care is organized labor. The reason we have pensions, unemployment compensation, workers' compensation, health and safety laws is because of organized labor. (Kane)

Those rights and achievements that all workers enjoy, union and non-union, are the living legacy of the sacrifices of countless labor activists, including the strikers at Ludlow, and it is the responsibility of engaged, democratic citizens to remember and continue their mission.

While some of those who spoke at the memorial have achieved success in union and academic career paths that keep the memory of Ludlow alive, Colorado native Betty Dotson-Rickle epitomizes the extent to which the Ludlow Massacre continues to influence local peoples' lives. As we spoke and corresponded, Dotson-Rickle graciously shared her stories, collection of newspaper articles, and personal insight on Ludlow. A relative of John Dodson, who donated the 40 acres where the Ludlow Monument now stands, Dotson-Rickle's family is deeply rooted in southern Colorado. Her mother, Irene was barely two years old when she lived through the Ludlow Massacre. Dotson-Rickle explains that because her mother was so young when she experienced the conflict, she may have been one of the last living survivors of the massacre before she passed away in 2003. The image of young Irene nestled among her family at Forbes Tent Colony-a small 
girl adorned with a big white bow atop flowing blond curls-is one of the most famous photographs from the 1913-1914 Colorado Coalfield War. These images, events, and recollections deeply shaped Dotson-Rickle and her mother. She explained, "Before her death, my mom made me promise that I would always attend this Ludlow Memorial. And I do so to honor my mother" (Dotson-Rickle).

The people who participate in the annual Ludlow Memorial embody Walker's assertion that "[1]abor struggle and the life of labor is prominent, if that is the word, among those events and sites that are silenced in the historical public sphere, being instead commemorated by labor unions and working people themselves" (74). Histories of the Colorado Coalfield Wars are not merely contained in bound books, but additionally remembered, revered, retold, and rewritten by contemporary mine and metal workers in southern Colorado, as well as laborers across the United States. This means that Ludlow must be understood as a history in-flux, shaped not only by documents, accounts, and contemporary scholarship, but also by the actions and words of current workers. Each time the memory of Ludlow is invoked, the story evolves as it is transmitted to a new audience in a specific cultural-historical moment. At local levels, these accounts may carry with them a notion of identity and ancestry, while on an overarching cultural level, labor perspectives might permeate the construction of our historical memory of Ludlow. North of Ludlow, in Pueblo, CO, union activists work to the keep the memory of the Colorado Coalfield War alive. After the passage of the Wagner Act in 1935, which banned company unions popularized under the CF\&I's industrial representation plan enacted after Ludlow, 20,000 workers at the CF\&I steel mill in Pueblo, Colorado, voted to join the newly formed United Steelworkers. Today's United Steelworkers in southern 
Colorado are the proud living legacy of decades of industrial/labor struggle, including the 1913-1914 Colorado Coalfield War. This historical continuum became acutely prominent in 1997 when USW Locals 2102 and 3267 at the Pueblo steel mill went out on strike to combat the unfair labor practices of Oregon Steel, which acquired CF\&I in the early 1990s. What ensued was the longest labor dispute in United Steelworkers' history, lasting from 1997-2004.

Chris Youngmark, current United Steelworkers District 12 Assistant to the Director, was the first person sent from the USW International to coordinate the field operations that would sustain the strike in Pueblo for seven years. He describes that "it was a little like going back to turn of the century sweatshops. The pay was better, but the company put productivity above everything else" (Youngmark). Joel Buchanan, a thirtyyear veteran of the Pueblo steel mill and current coordinator for USW District 12 Steelworkers Organization of Active Retirees (SOAR), agrees:

One of the main issues of the Pueblo dispute was that we, the workers, were being forced to work tremendous amounts of hours by a company from another region of the country, Oregon. We were given no respect and the company was trying to control our lives by forcing us to work anywhere from 80 to 100 hours a week and not allowing us to take time for family or other things in our lives: kids' graduations, family issues, and personal time. (Buchanan)

Like Buchanan, Youngmark recognizes that in the company's unfettered drive for profit, the workers suffered: "Forced overtime created unsafe working conditions. People had no 
choice but to work multiple twelve-hour shifts for weeks at a time. We had to fight to get workers bathroom breaks, meal times, medical leaves, and such” (Youngmark).

Not only the USW members, but also their wives, children, friends, and neighbors joined the fight. During the seven-year labor dispute, Oregon Steel found that it was under-prepared for the solidarity of the Steelworkers. In an interview, Oregon Steel's CEO, Joe Corvin stated, "I don't think we had any idea of the impact of decades of mistrust of management. The workforce carried it along. We never even considered it. They're still mad about the Ludlow Massacre. We never thought about that. That culture is still there....We underestimated the degree to which they felt that they own the mill" (Strom). While Corvin's statement seems relatively indifferent towards the brutality of the Ludlow Massacre, he nonetheless acknowledges the lasting impact that this event has had on the workers of southern Colorado.

The Steelworkers recognized that the labor dispute in Pueblo for enforcement of maximum hour legislations, safety regulations, and other rights was a continuation of the struggle that the Ludlow strikers had fought. Youngmark explains, "In our field program during the strike in Pueblo, we used a lot of Ludlow information and history of labor in the region to show how, in Pueblo, CF\&I was going backwards instead of forwards" (Youngmark). During the 1997-2004 labor dispute USW Locals 2102 and 3267 invoked this historical memory in numerous ways, setting up a "Camp Ludlow" outside Oregon Steel headquarters and including the names and ages of fallen strikers and family members. The Locals also marched at the annual Ludlow Memorial wearing shirts that read "One Day Longer...One Day Stronger" and carrying a banner with the names of massacre victims. According to Buchanan strikers in Pueblo felt connected to those 
workers, wives, and children who had died nearly a century before. For Buchanan, "Ludlow's history is important to me because a lot of it is my history. Ludlow history is a way to learn lessons on how we got to where we are now and to try and progress instead of regressing... To see firsthand how a few steelworkers from a small town can make such an impact was one of the most memorable events of my life" (Buchanan).

Eventually, the years of effort paid off. When the labor dispute was ultimately settled in 2004, the Pueblo Steelworkers received the largest back-pay settlement in the history of the National Labor Relations Board. Current USW District 12 Director Bob LaVenture explains that the labor dispute at Pueblo was pivotal because it "demonstrated the continued strength and solidarity of our working men and women. Workers in Colorado were again standing up against the unfair labor practices of big corporations like CF\&I. And we won" (LaVenture, "Pueblo Interview”). LaVenture reminds members that their labor struggles connect them, through the generations, in a fight for rights and dignity. Workers must remember the history of the Ludlow Massacre and Pueblo labor dispute because, LaVenture states, "By learning labor history we better understand the sacrifices of past workers, and recognize that it is our duty to continue to protect the rights that these workers have fought and died to achieve" (LaVenture, "Pueblo Interview").

Today, the ghosts of Ludlow-those whom Mother Jones channeled-continue to speak. Perhaps, like Webb's ghost in Against the Day, they "keep things hopping” (218). The voices resonate in the campaigns of USW Locals 2102 and 3267. They echo in speeches at the annual Ludlow Memorial. And, I will bashfully admit that when I opened 
the heavy cellar door which covers the Death Pit at Ludlow, the rusted hinges let out a high-pitched scream that I momentarily expected to accompany some ethereal apparition.

In a more tangible form, art, music, and literature have served as significant conduits for transmitting voices and stories of Ludlow. Before earning accolades for $A$ People's History of the United States, Howard Zinn wrote his master's thesis on the Ludlow Massacre. Zinn explains that it was not scholarship, but the lyrics of Woody Guthrie's song, "The Ludlow Massacre," that first made him aware of the tragedy at Ludlow (188). Upton Sinclair wrote King Coal to raise public awareness about the Colorado Coalfield Wars, and was arrested picketing John D. Rockefeller's offices in New York City. These and other artistic iterations of Ludlow serve as counter-narratives against the sanitized histories of industrial giants and exceptional Western progress that generally appear in the versions of United States history taught in schools. Schoolbooks too often deify captains-of-industry, such as Rockefeller and Carnegie, while effacing events such as Ludlow and Homestead or, more recently, Pueblo. In wider U.S. and global culture, the public frequently encounters Wild West images of cowboys and gunslingers. Less often, if ever, does the public see the striking miners and families who underpinned this Western economy.

Resisting these dominant narratives, Against the Day brings to the reader's consciousness the same issues that Ludlow spurred for the American public: Are capital and labor equal partners? If we are to live in true political and social democracy, mustn't our workplaces also be democratic? What is the human cost of monetary profit? What violence is inflicted on workers and how do they resist? These questions are no less urgent today than they were one hundred years ago. Pynchon's text subtly pushes the 
story of Ludlow into the twenty-first century in a way that is both fine-grained and as explosive as dynamite. 


\section{Chapter IV Endnotes}

1. Pynchon, 406.

2. In Against the Day, Frank and Stray “thought once they'd caught a quick glimpse of Mother Jones herself" at Ludlow, a lady with "her hell-with-it attitude"-a lady, which historical documents like Major Edward J. Boughton's report on Ludlow claimed "is undoubtedly a most dangerous factor in the peace problem" $(1004 ; 46)$.

3. Benjamin, 257.

4. Jameson's concepts of "historical amnesia" and "nostalgia for the present" are less applicable to the small population for whom Ludlow is a living memory. However, these concepts are extremely useful for interrogating how the vast majority of people construct their impression of "Wild West" history through commodities such as media, books, and even cowboy toys and games. In his presentation at the 2012 annual Ludlow Memorial, one of the preeminent Ludlow historians, Thomas Andrews, admitted that although he grew up in Colorado, he never learned about the history of industrial/labor conflict in the region:

[The Ludlow Massacre] is actually an event that I didn't even encounter until I was working on a graduate degree in U.S. history...this despite being a Colorado native and being a history buff more of less for life. When I was in grade school, and this is probably true of most Coloradoans of my generation, we didn't touch on Ludlow when we did Colorado history. The Colorado history we did was a glorification of Colorado's 
19th century heritage. The two main things I remember is playing the “Oregon Trail” simulation game on very early Apple computers and learning about the Colorado gold rush. (Andrews)

This realization underscores the importance of introducing labor's counter-narratives into education and creating discussion in the larger public sphere. Such concerted efforts work to counter the prevalent, sanitized, commodified "Oregon Trail"-computer-game-esque history of the American West. Although Jameson's concepts have been critiqued due, in part, to their linkage with postmodernism, they are nonetheless useful insofar as they provide conceptual tools for understanding how capitalist culture influences the formation of historical memory, as well as the ways groups can intercede in this process.

The labor movement's efforts to introduce workers' perspectives into presentations of history suggest modes of intervention into society's desire to reinvent its past, even as they suggest limits to Jameson's concepts of "historical amnesia" and "nostalgia for the present" by emphasizing points at which collective agency can be introduced to subvert the dominant capitalist, commodity-fetish-ridden process of historical memory formation.

5. Pynchon, 406.

6. This sentiment is reminiscent of Almanac's realization that groups who were once "needed in the gold mines and plantations that were worthless without slave labor" eventually become wage-slaves "who worked like slaves but got even less than slaves had in the old days" $(407,116)$. For more on Silko, see Chapter 2 of this dissertation. 
7. Silko's Almanac similarly echoes this idea of resistance movements guided by ghosts: "They were waiting for the right moment-for certain conjunctions between the spirit forces of wind, fire, water, and mountain with the spirit forces of the people, the living and the dead" (618-9). For more on Silko, see Chapter 2 of this dissertation.

8. Farmworkers in Viramontes's Under the Feet of Jesus and bio-producers in Silko's Almanac can also be understood as un/under-recognized laborers performing vital work.

9. Pynchon, 682.

10. Some scholars frame radical rebellion as a natural byproduct of the violence of capitalism. Adamic posits that radicals "were but the natural result of our industrial conditions, of the System...If they had never lived, their present positions-those of the millionaires and of the anarchists - would have been filled by other men" (83). Adamic suggests the stratification between haves and have-nots, "millionaires" and "anarchists," creates these violent conflicts in capitalism. Other historians focus on how violence is embedded in the functioning of the capitalist nation-state. In Community, Anarchy and Liberty, Michael Taylor explains that the "most basic function of the state is to ensure that internal social order is maintained (possibly so that extraction can continue smoothly to the benefit of a dominant class...)" (7). In addition, Taylor asserts that in order for the state to maintain the dominant social order, it exerts a monopoly over the use and distribution of violence. He posits, “Max Weber's well-known definition of states as 'human associations that successfully claim the monopoly of legitimate use of physical force within a given territory"' is useful in understanding the emergence of the state; yet, 
it is also essential to recognize that what "is left of the Weberian account is the notion of a concentration of force and the attempt by those in whose hands it is (incompletely) concentrated to determine who else shall be permitted to employ force and on what occasions" (5). Friedrich Engels's writings provide another perspective on how the violence of capitalism is structurally supported by the nation-state:

[The] State arose from the need to hold class antagonisms in check, but because it arose, at the same time, in the midst of the conflict of these classes, it is, as a rule, the state of the most powerful, economically dominant class, which, through the medium of the state, becomes also the politically dominant class, and thus acquires new means of holding down and exploiting the oppressed class. (753)

Thus, the realm of economic, political, social, and military interests becomes intrinsically intertwined.

11. See Chapter 5 for a discussion of how Pynchon globalizes this core/peripheral labor struggle.

12. From early on, the WFM was active in uniting many smaller union organizations in the American West, and by "1903 there was talk within the Western Federation of Miners about starting a movement to join the entire working class of the United States, indeed of the whole world, into one general revolutionary organization'One Big Union'-formed upon industrial rather than trade lines. It was a typically Western idea-big: the sky was the limit" (Adamic 157). At a secret conference in 
Chicago in 1905 to organize the "One Big Union," Western Federation of Miners president Bill Haywood stated “"Fellow workers!...The aims and objects of this organization shall be to put the working class in possession of the economic power, the means of life, in control of the machinery of production and distribution, without regard to capitalist masters" (Haywood quoted in Adamic 157). Certainly the realization of such a statement would entail not only a revolutionizing of the capitalist economic system but also an overhaul to the nation-state structures that supported it. Quickly the rhetoric of the emerging IWW became more militant, and, eventually, overtly anarchistic. The preamble to the first IWW Constitution states, "[T]he workers and the employers 'have nothing in common'...that 'there can be no peace so long as hunger and want are found among millions of working people and the few who make up the capitalist class have all the good things in life"' (Adamic 158). The Constitution recognized the type of structural and physical violence that was perpetuated by capitalist economic conditions and the compliant state structures. By 1908, a "direct action" group had established power in the IWW and the preamble to the Constitution was rewritten in even more revolutionary language, stating, "the struggle between capital and labor 'must go on until the workers of the world organize as a class, take possession of the earth and the machinery of production, and abolish the wage system"' (Adamic 160).

13. See Chapter 2 for a discussion of similar contemporary events in Mexico.

14. See Chapter 2 for a discussion of similar contemporary events in Mexico, where mining company Grupo Mexico has brought in replacement workers during the strike at Cananea's Buenavista copper mine. 
15. Official government accounts such as Major Edward J. Boughton's report of the National Guard's activities during the Ludlow strike and the U.S. House of Representatives "Report on the Colorado Strike Investigation" are rather vague about the type of violence that occurred in Ludlow. Under the section "Violence," the House report notes:

The most severe of these battles were called the Forbes, Berwind, Seventh Street in Walsenburg, La Veta, and Ludlow, culminating in the gretest and most destructive of all, the last battle of Ludlow, about the $20^{\text {th }}$ of April, 1914. Ludlow was the place near which the families of the miners lived in tents after they left the coal camps when the strike began. It is not denied that the strikers bought guns and ammunition, which were claimed to have been purchased for use in defending themselves and their homes, and, no doubt, there was an element among those men that seemed determined to win the strike by destroying property, and if necessary to take human life (17).

However, the report does not detail the casualties of the Ludlow tent colony.

16. The Bessemer Historical Society, who maintains the CF\&I archives in Pueblo, Colorado, openly acknowledges this occurrence, and a note has been included with the photocopy of the strike notebook which explains the circumstances under which the original manuscript went missing.

17. See Chapter 2 of this dissertation for a more elaborate discussion of corporal and disciplinary violence faced by waged and unwaged laborers. 
18. For more on the public speeches see Ryan Severance's article "Union Leaders Also Make Pitch to Help Present-Day Workers." 


\section{CHAPTER V}

\section{REMAPPING GLOBAL LABOR SOLIDARITY：THE TRANSNATIONAL IMAGINGATION OF VIRAMONTES, PYNCHON, AND SILKO}

$[$ F]aced with globalization and the common policies of transnational corporations, trade unions had to design and develop a comprehensive strategy, a new way to defend ourselves in a united way, without stopping at national borders. If multinational companies join forces, there is no reason for unions not to make a similar effort. This seems fundamentally obvious in an era when global trade unionism is enduring assaults and divisions by provocation across the globe.

- Napoleon Gómez, Collapse of Dignity 32.

The first time I celebrated International Women's Day, I was surrounded by nearly one thousand women from around the globe who were attending a United Steelworkers conference in Pittsburgh, Pennsylvania. As I saw this diverse gathering of women from multiple employment sectors on six continents, the idea of this chapter began to take form. The next week I marched with an international, multiethnic group of migrant farmworkers in Florida, jotting ideas and observation in a little notebook along the way. Over the next months, I worked on this chapter while waiting for a flight home from Toronto, Canada, after a United Association for Labor Education conference that 
brought international union, university, and worker-center educators together with labor organizers, artists, and activists. I wrote and reflected in airplanes going to Portland, Oregon, to present with paper and oil sector workers; Las Vegas, Nevada to teach at a Women of Steel leadership school; and Los Angeles, California, after presenting United States labor history to international guests representing dozens of countries at the USW International Convention. Eventually, I worked on revisions during bumpy car rides back and forth across the U.S./Mexico border to facilitate United Steelworkers/Los Mineros cross-border trainings on health and safety, union organizing, labor law, and other topics.

As I moved through time and space, crossing state and international boundaries, and talking with laborers of various nationalities, ethnicities, ages, genders, and employment sectors, I realized that as I composed my conclusion, I was writing my surroundings. No matter where I traveled, the inequitable influence of global capital on working peoples persisted. Yet so did their dedication, organization, and vision for creating an egalitarian future. As I spoke with laborers from Bangladeshi garment sweatshops, Korean electronics factories, Chinese shipping ports, Liberian rubber plantations, and innumerable other points of global production, I found that much more unites us than divides us. However, relationships between global labor culture, solidarity, and ideology continue to be superficially fractured by militarized borders and capitalist propaganda. Realizing this, I began to imagine...

Within the labor movement, the arts provide a flexible, seemingly limitless space for creating and manipulating different, potentially more egalitarian, organizations of power that transcend nation-state boundaries and engage current global capitalism on transnational levels. Rather than delineating what labor texts are-redefining or 
overviewing the content and representations of an exclusive genre-this dissertation has been primarily concerned with investigating the potential work that recent labor texts can $d o$ in contemporary society. This later inquiry requires theoretically sound and practically grounded readings of texts, connections to current social movements, and applications of classroom praxis (as the following chapter and appendix of this dissertation provide). Through investigating Trigg's Biomaterials Inc. in Silko's Almanac of the Dead, Chapter 2 explored how literature has the potential to inclusively expand our conceptualization of labor within contemporary biopolitical capitalism. Next, realizing that the linguistic and democratic voices of under-recognized workers are particularly marginalized within the public sphere, Chapter 3 examined how Viramontes's Under the Feet of Jesus and Forged under the Sun / Forjada bajo el sol amplify the voice of effaced workers as a method for bridging uneven power distributions and catalyzing social change. Expanding of the importance of transmitting workers' narratives, Chapter 4 considered how Pynchon's fictionalization of the Ludlow Massacre in Against the Day might inform our construction of historical memory by highlighting workers' perspectives in counternarratives of labor struggle. Finally, drawing on an inclusive definition of labor, recognizing the marginalized voices of multicultural workers, and engaging historical counter-narratives this concluding chapter will explore how Silko's Almanac of the Dead, Viramontes' Under the Feet of Jesus, and Pynchon's Against the Day communicate multiple interconnected visions of transnational solidarity that can inform a global labor movement.

This conclusion offers a rhizomal reading of Silko's, Viramontes's, and Pynchon's novels, in which, to borrow Deleuze and Guattari's metaphor, "any point of a 
rhizome can be connected to anything other, and must be" (A Thousand Plateaus 7). Each text, like nodes of a rhizome, can ceaselessly establish connections, offering "multiple entryways" for considering the following assertions: First, particular theoretical frameworks may inform our understanding of the texts' ruptures from dominant nationbased/globalization paradigms and the emergence of alternative forms of solidarity in the narratives. Second, the transnational and transtemporal nature of migrant farmworkers in Under the Feet of Jesus defies the geopolitical logic of the contemporary nation-state. The novel works against the prevailing notions of temporality and spatiality that mute migrant farmworkers' voices and obscures their existence. Third, in contrast to Under the Feet of Jesus's attentiveness to the material divisions delineated by geopolitical borders, Against the Day conspicuously situates U.S. unions within the discordant context of global capitalist development and supranational labor movements. As Webb and his sons fight labor exploitation in the Colorado minefields, in the greater terrain of the novel, these efforts link with resistance networks that battle capitalism's expansion from the frigid mines of Iceland spar to the blazing sands of Shambala. Fourth, reflecting Pynchon's complexly immense global scope and Viramontes's border zone transnationality and transtemporality, Almanac of the Dead elaborates an inclusive definition of labor that catalyzes paradigm-shifting conceptual remappings of power/knowledge networks beyond arbitrary nation-state boundaries and cultural divides. The novel literally recharts localglobal space, time, and power organization through the Five Hundred Year Map that prefaces the text. Finally, drawing on the visions expressed by each of these authors, we must consider how the immaterial labor of these texts can 
contribute both to our theoretical understanding of contemporary egalitarian social struggle and to coordinated on-the-ground efforts to alter lived power relations.

"Militancy today is a positive, constructive, and innovative activity:" Theory for Action ${ }^{1}$

Much of the theoretical framework for this chapter developed after the fact, an approach perhaps more reflective of scientific analysis than English studies scholarship. It was only after observing what was occurring on the ground in the daily lives of workers, in the structural organization of labor movements, and in the juridical rulings of federal courts (and, to a lesser extent, transnational governance) that I could critique theoretical paradigms in an informed and practical way in order to decide which frameworks best suited the conditions I witnessed and Viramontes's, Pynchon's, and Silko's texts elaborate. ${ }^{2}$ Addressing the interplay between (sometimes serial) place-bound laborers, local/global worker organizations, and federal/international law requires theoretical paradigms that address complexly intertwined place-based and global capitalist structures while simultaneously promoting liberatory resistance linked on all levels. These frameworks must not only describe conditions but also provide models for transformation. As Hardt and Negri assert, "Our deconstruction of this spectacle [the destiny of triumphant capitalism] cannot be textual alone, but must seek continually to focus its powers on the nature of events and the real determination of the imperial processes in motion today" (Empire 48).

Many of us in academia have become so accustomed to looking forward, at the newest technology, latest development, and most recent scholarship, that we risk losing touch with the lessons of our histories. However, Hardt and Negri's theoretical trilogy- 
Empire, Multitude, and Commonwealth-is grounded in archaeologies of the past that inform an understanding of the present and expectations for the future. Hardt and Negri conclude their first volume, Empire, with a forward vision that harkens back to the quintessential early twentieth century union militant:

In the postmodern era, as the figure of the people dissolves, the militant is the one who best expresses the life of the multitude: the agent of biopolitical production and resistance against Empire...A prototypical example of this revolutionary figure is the militant agitator of the Industrial Workers of the World. The Wobbly constructed associations among the working people from below, through continuous agitation, and while organizing them gave rise to utopian thought and revolutionary knowledge. The militant was the fundamental actor of the 'long march' of the emancipation of labor from the nineteenth to the twentieth centuries, the creative singularity of that gigantic collective movement that was working-class struggle...Militancy today is a positive, constructive, and innovative activity. This is the form in which we and all those who revolt against the rule of capital recognize ourselves as militants today. (411$413)^{3}$

In connecting historical militancy to contemporary social movements, Hardt and Negri take Foucault's concepts of archaeologies and biopower, Giovanni Arrighi's long $20^{\text {th }}$ century, Deleuze and Guattari's re- and de-territorialization, Agamben's state of 
exception, as well as numerous other scholarship that has influenced this dissertation and assemble them into a vast and nuanced theoretical paradigm. ${ }^{4}$

Hardt and Negri recognize contradictions in contemporary society not as singularly nullifying or destructive forces, but as productive potential. They explain, "Our basic hypothesis is that sovereignty has taken a new form, composed of a series of national and supranational organisms united under a single logic of rule. This new global form of sovereignty is what we call Empire" (Empire xii). On one hand, Empire is hegemonic and undemocratic. Empire "may have played a role in putting an end to colonialism and imperialism, [but] it nonetheless constructs its own relationships of power based on exploitation that are in many respects more brutal than those it destroyed" (Empire 43). It is responsible for famine, suffering, oppression, and death. Expanding upon Agamben's primarily national perspective of the "state of exception," Hardt and Negri globalize this concept to illustrate how populations who resist the capitalist expansion of Empire might find themselves managed to a "permanent of state emergency and exception" where national, supranational, and private capitalist forces may inflict sanctioned violence and corporal control (Empire 18).

On the other hand, Empire also holds the potential for liberation and resistance networks that work "within Empire and against Empire. New figures of struggle and new subjectivities are produced in the conjuncture of events, in the universal nomadism, in the general mixture and miscegenation of individuals and populations, and in the technological metamorphoses of the imperial biopolitical machine" (Empire 61). Hardt and Negri believe that in order for individual populations of workers to successfully change the conditions of labor they must to unite beyond employment sectors, race or 
gender, social class, national boundaries, and other divisions. Even as Empire reproduces capitalist exploitation, it provides a global infrastructure that makes such diverse transnational resistance networks possible. Hardt and Negri find inspiration in early twentieth century union movements that strove to create supranational solidarity: "International solidarity had to be recognized not as an act of charity or altruism for the good of others, a noble sacrifice for another national working class, but rather as proper to and inseparable from each national proletariat's own desire and struggle for liberation" (Empire 49-50). They further elaborate:

$[\mathrm{P}]$ roletarian internationalism was antinationalist, and hence supranational and global. Workers of the world unite!-not on the basis of national identities but directly through common needs and desires without regard to borders and boundaries. Internationalism was the will of an active mass subject that recognized that the nation-states were key agents of capitalist exploitation... (49).

Drawing on this historical occurrence, situating their arguments in the present, and looking towards the future, Hardt and Negri develop a notion of the "multitude, the living alternative that grows within Empire" (Multitude xiii).

In contrast to capitalist Empire's synthesis of different peoples into biopolitically managed populations, the multitude "is composed of a set of singularities-and by singularity here we mean a social subject whose difference cannot be reduced to sameness, a difference that remains different...The plural singularities of the multitude thus stand in contrast to the undifferentiated unity of the people" (Multitude 99). 
Reflective of Deleuze and Guattari's nonhierarchical and noncentered model of the rhizome, singularities of the multitude retain their uniqueness while recognizing their shared exploitation as "the common subject of labor, that is, the real flesh of postmodern production, and at the same time the object from which collective capital tries to make the body of its global development" (Multitude 101). Thus, the repressive biopolitical production that defines Empire actually produces the condition for liberation:

[In a prior period] it seemed as if only the labor of waged workers was productive, and therefore all the other segments of labor appeared as merely reproductive or ever unproductive. In the biopolitical context of Empire, however, the production of capital converges ever more with the production and reproduction of social life itself; it thus becomes ever more difficult to maintain distinctions among production, reproductive, and unproductive labor. Labor-material or immaterial, intellectual or corporeal-produces and reproduces social life, and in the process is exploited by capital. This wide landscape of biopolitical production allows us finally to recognize the full generality of the concept of proletariat." (Empire 402)

Under these conditions, the creation of a global multitude crucially rests on diverse singularities involved in material and immaterial production recognizing that their shared exploitation in global capitalism transcends any ethnic, gender, racial, sexual, national, or ideological divides. As Hardt and Negri elaborate in Commonwealth, the poor, under/unemployed, and those traditionally associated with Marx's lumpenproletariat are 
not excluded from a multitude united by labor. ${ }^{5}$ Rather the poor are central to its formation, as they present "an objective menace to the republic of property" which must be overthrown in order for the notions of public and private to be replaced with the shared commons (Commonwealth 45).

Hardt and Negri's Commonwealth offers a more nuanced exploration of the poor and increased elaboration of their concept of the common. However, one must be wary of how this theory translates into practice. Commonwealth develops an image of the metropolis as a common space "of people living together, sharing resources, communicating, exchanging goods and ideas" (250). This is a space of potential:

The metropolis might be considered first the skeleton and spinal cord of the multitude, that is, the built environment that supports its activity, and the social environment that constitutes a repository and skill set of affects, social relations, habits, desires, knowledge, and cultural circuits. The metropolis not only inscribes and reactivates the multitude's past-its subordinations, suffering, and struggles-but also poses the conditions, positive and negative, for its future. (Commonwealth 249)

Although the rhetoric is compelling, this model is built on underlying assumptions of privilege that do not fully account for uneven access to and agency in this space.

First, Hardt and Negri’s overtly dismiss residual and emerging differences between global rural and urban areas, declaring that " $[\mathrm{t}]$ oday, however, the circuits of communication and social cooperation are becoming generalized across the planet. Rural life is no longer characterized by isolation and incommunicability" (253). This assertion 
seems troublingly unsubstantiated considering how rural and underprivileged urban areas of the globe have been excluded from crucial technological and telecommunications developments. In the early 2000 s, the UN published findings stating, “Telecommunications companies, entrepreneurs, and policymakers have regarded rural and poor markets with some combination of too-complex-to-serve and not-interestingenough (politically or economically) to be worthy of sustained attention...more than half of the world's population that lives in largely untapped rural markets" (Best and Maclay 1). When Facebook partnered with research firm McKinsey \& Company to conduct a similar study in 2014, they found that little progress had been made in providing encompassing internet access over the prior decade; specifically, of the over 7 billion people alive today, more than half, 4.4 billion, are offline (McKinsey \& Company i). The composition of this offline population is particularly significant, as the majority of group is already marginalized by geographical location, income, age, education, or gender: "About 75 percent of the offline population is concentrated in 20 countries... and is disproportionately rural, low income, elderly, illiterate, and female" (McKinsey \& Company 2).

Second, Hardt and Negri are largely dismissive of established modes of worker empowerment and resistance, including the continued relevance of traditional labor unions. They assert, "It is not even possible for the traditional unions to represent adequately the complex multiplicity of class subjects and experiences" (Commonwealth 110). As the end of this chapter will elaborate, many unions across the globe are rapidly adapting and evolving to address the cultural, linguistic, ideological, and geographical diversity of their potential membership. Embodying their dismissal of labor unions and 
hegemonic subordinations of material labor, Hardt and Negri's metropolis is elaborated as replacing an outdated (past-tense) model of the factory as a site of agency: "In order for the metropolis to be for the multitude what the factory was for the industrial working class, it must be a site not only of encounter but also of organization and politics" (Commonwealth 254 emphasis added). Not only do the theorists overlook the factory as a continuingly relevant site of agency, they more generally dismiss the role of contemporary unions and industrial figures in progressive social change: "Today urban revolts, though still strongly defined by race, are no longer led by those industrial figures. When metropolitan production is embedded in capitalist valorization, urban uprisings present original elements that herald new forms of organization, just like the first industrial worker strikes" (256). Hardt and Negri are correct in recognizing new types of resistance in urban (and rural!) areas. However, their theoretical move to divorce this emergence from the action of labor unions and industrial figures needlessly severs a long history of workers' movements from the present, as well as overlooking contemporary mass immigration marches coordinated by the AFL-CIO, major urban port shutdowns by labor unions, workers groups' occupation of retail giants such as Wal-Mart, national fastfood organizing efforts and boycotts, and other actions that disrupt local and global capitalism. $^{6}$

Third, throughout their trilogy, Hardt and Negri call for an inclusive definition of labor; however, they not only identify a hegemonic privileging of immaterial production in contemporary biopolitical societies, they also reproduce this disparity in their own scholarship (e.g. Multitude 65, 108, 114). We must be cautious of potential first-world, ethnic, urban and class biases embedded in privileging immaterial labor in scholarship 
about a globalized economy which itself effaces modes, sites, and bodies engaged in material labor. For example, in sweeping generalizations claiming "[t]oday we increasingly think like computers, while communication technologies and their model of interaction are become more and more central to laboring activities," Hardt and Negri universalize experiences often associated with white, educated, first-world, urban, and/or male privilege (Empire 291). An undifferentiated focus on immaterial production threatens to create scholarship that mirrors our first-world effacement of material production hidden in domestic industrial zones and outsourced to third world countries. Not only might this oversight result in a void of thoughtfully theorized connections between material and immaterial production in a globalized biopolitical economy, it also demonstrates a disregard for what continues to be some of the most dangerous work on the planet in refineries, mines, construction, factories, and other industries. To combat the effacement of material labor (often associated with earlier stages of capitalism), biases towards immaterial labor are important to expose. Scholarship, such as this dissertation, can engage the continued relevance of material production, which underpins the infrastructure necessary for any type of immaterial labor.

Like Hardt and Negri, Saskia Sassen also adopts an urban model-the global cityin her exploration of contemporary globalization; however, her attention to a variety of types of material/immaterial labor, placebasedness, and uneven development provides a necessary complement to Hardt and Negri's more generalized inquiry. For Sassen, "focusing on cities allows us to specify a geography of strategic places at the global scale" (Globalization and its Discontents $\mathrm{xx}$ ). This attention to place and production "takes us to the range of activities and organizational arrangements necessary for the 
implementation and maintenance of a global network of factories, service operations, and markets; these are all processes only partially encompassed by the activities of transnational corporations and banks" (Globalization and its Discontents xxii-xxiii). As a site of place-based production and execution of transnational power, the global city exposes the "spatialization of inequality" where "we see a geography of centrality and one of marginality" (Globalization and Its Discontents 182). This inequality is not only demonstrated by, for instance, the desperate conditions between well-funded financial zones and impoverished inner-city neighborhoods, but also in the types of work that are valorized in this urban structure (Sassen, "The Global City: Strategic Site/New Frontier" 82). Sassen's empirical investigation of the global city, more so than Hardt and Negri's theorization of the metropolis, recognizes that " $[\mathrm{t}]$ here is no fully dematerialized firm or industry" and exposes the "unequal geography of access" within these sites ("The Global City: Strategic Site/New Frontier” 81; Globalization and Its Discontents 182):

Insofar as my economic analysis of the global city recovers the broad array of jobs and work cultures that are part of the global economy though typically not marked as such, it allows me to examine the possibility of a new politics of traditionally disadvantaged actors operating in this new transnational economic geography. This is a politics that lies at the intersection of economic participation in the global economy and the politics of the disadvantaged, and in that sense would add an economic dimension, specially through those who hold the other jobs in the global economy-whether factory workers in export processing zones in Asia, 
garment sweatshop workers in Los Angeles, or janitors on Wall Street.

(“The Global City: Strategic Site/New Frontier” 80)

Sassen structurally links the movement of bodies and the movement of capital, or international labor migration and global corporations. In particular, her empirical work illustrates how domestic and international migration patterns supply low-wage workers for jobs that support centers of transnational corporate and financial power: "Global capital and new immigrant workforce are two major instances of transitional actors that each have unifying properties across borders internally, and find themselves in contestation with each other inside global cities" ("The Global City: Introducing a Concept" 39). ${ }^{7}$ Sassen recognizes, "If we consider that global cities concentrate both the leading sectors of global capital and a growing share of disadvantaged populations (immigrants, many of the disadvantaged women, people of color generally, and, in the megacities of developing countries, masses of shanty dwellers) then we can see that cities have become a strategic terrain for a whole series of conflicts and contradictions" ("The Global City: Introducing a Concept" 39). These observations leads her to conclude that we cannot divide an analysis of transnational capital from localized transnational populations that are both critical to globalization and marginalized by this process.

While Sassen's global city offers a compelling model for understanding sites and inequities of globalization, it specifically focuses on the "spatial dispersal of economic activities at the metropolitan, national, and global levels" while leaving other locations outside its purview (“The Global City: Strategic Site/New Frontier” 80). My experiences and research in rural agricultural areas, small mining company-towns-turned- 
independent-municipalities, medium sized communities with steel and paper mill based economies, and other non-urban sites of production makes me attentive to the ways in which models of the metropolis and global city do not fully account for these places and peoples. Economies in these non-urban sites are intimately connected to the global markets, often producing the food and raw materials necessary for infrastructure and development. However, populations may be cut off from urban zones not only geographically, but also culturally and socially. Adopting Sassen's own placebasedness, these sites cannot be fully accounted for within an urban model. Thus, any attempt to create alternative organizations of power must be attentive to bridging spatial, cultural, and other divides, not only within and among urban areas, but also across rural, suburban, and other places.

Hardt and Negri's notion of the multitude and Sassen's investigation of global placebasedness, inequality, and immigration offer rich conceptual terrain for envisioning resistance movements; however, these theories do not fully account for persistent material labor, non-urban spaces, and established modes of resistance. To addresses what is marginalized in what Sassen terms a "new geography of centrality," we must not only be attentive to dominant global tendencies, but also to the places, process, people, and practices that are peripheral to Hardt, Negri, and Sassen's scholarship ("The Global City: Strategic Site/New Frontier” 80).

“Oil was made from their bones:" Transnational and Transtemporal Labor in Under the Feet of Jesus ${ }^{8}$

"How is the migratory subaltern subject, in a trans-American politics of location, to be conceptualized as revolutionary and antimilitaristic, Latin American and North 
American, at one and the same time?” José David Saldívar asks in Trans-Americanity (31). This question echoes in Under the Feet of Jesus's engagement with the complex transnationality and transtemporality of migrant farmworkers. As Chapter 3 of this dissertation explored, Under the Feet of Jesus resists the muting of farmworkers' voices by transmitting narratives that call for reform to labor legislation, educational systems, and other institutions that have an immediate material impact on farmworkers' lives. In addition, the novel advances a more far-reaching, revolutionary call for action. Under the Feet of Jesus demonstrates how migrant farmworkers defy the legalized geo-spatial and temporal logic of the globalized nation-state, thus bringing into question the continued efficacy and sustainability of notions such as citizenship and progress that are grounded in these paradigms.

So how does Under the Feet of Jesus address Saldívar's question concerning the trans-American migratory subaltern subject? It embraces the contradictions. On one hand, the novel portrays the devastation of what Quijano and Wallerstein term Americanity, the "gigantic ideological overlay to the modern world-system" that produced ethnic divides, merged colonial and modern powers, and institutionalized hegemonized cultures in North/South America (552). On the other hand, Under the Feet of Jesus conveys disruptions to this dominant ideology, as farmworkers in the novel are neither exclusively U.S. or Mexican but more accurately American, existing in the physical, conceptual, and material borderlands of Americanity's persistent "geo-social temporalities" (Saldívar, Trans-Americanity xii).

While Americanity's residual hegemonic racializing and nationalistic hierarchies are embedded in structures that have daily material and ideological impacts on 
farmworkers' lives, working people resist entrapment within these power paradigms. David Harvey recognizes, "Frustrated power struggles (on the part of women, workers, colonized peoples, ethnic minorities, immigrants, etc.) within a given set of rules generate much of the social energy to change those rules. Shifts in the objective qualities of space and time, in short, can be, and often are, effected through social struggle" (The Condition of Postmodernity 227 emphasis added). In Under the Feet of Jesus, such social struggle is embodied in the daily life of farmworkers whose continued economic, cultural, and physical survival depends upon destabilizing spatial borders and disrupting dominant temporal notions of progress, including conceptions of labor and citizenship that rest upon these assumptions. For the characters in Under the Feet of Jesus, life is different from the dominant narrative of "[c]yclical and repetitive motions," that Harvey contends "provide a sense of security in a world where the general thrust of progress appears to be ever onwards and upwards into the firmament of the unknown" (Condition of Postmodernity 202). For migrant farmworkers, cyclical movements over space and time are primarily a necessity for survival, and less a ritual of security. Under the Feet of Jesus opens by stating, "It was always a question of work, and work depended on the harvest, the car running, their health, the conditions of the road, how long the money held out, and the weather, which meant they could depend on nothing," and by the end of the first chapter "as they always did, sooner this time than later, they would leave" $(4,37)$.

Under the Feet of Jesus's narratives are shaped by migrant farmworkers' physical movements inside and outside of the nation, actions that destabilize the viability of static state boundaries and nationalistic workforces. Estrella remembers that after her father had "gone to Mexico," she, her mother, and siblings were left to struggle for survival in a 
state of perpetual motion, one that simultaneously recognized and resisted the delineation of nation-state boundaries (13):

[B]oxes of papers, bills, addressed correspondence, documents, loose dollars hidden for occasions like this; the late-night calls, money sent for his return, screaming arguments long distance, bad connections, trouble at the border, more money sent, a sickness somewhere in between. Each call was connected by a longer silence, each request for money more painful. She remembered every job was not enough wage, every uncertainly rested on one certainty: food. (13-14)

As the family's survival became intertwined with migrant flows and harvest schedules, departing from loved ones and meeting new friends, Estrella began "[a]lways leaving things behind that they couldn't fit, couldn't pack, couldn't take, like a trail of bread crumbs for her father" (14).

Under the Feet of Jesus's narratives of splintered families, interrupted movements, and transient survival characterize the ideological and material spaces of geopolitical boundaries as arbitrary, arguably inhumane, and ineffectual, despite the multi-billion dollar militarization of the Mexican/U.S. border zone. Since migrant farmworkers may lack permanent year-round residences, moving across state or national borders to work in seasonal crops, they defy the quantifiable spatial reasoning that legitimizes a government's disciplinary management of territories. As Reuben S. RoseRedwood explains in "Governmentality, Geography, and the Geo-Coded World," the dual forces of "geographical power-geographical knowledge" allow the state to 
conceptualize the existence of individuals and populations through the rational ordering of space (478-80). ${ }^{9}$ Because migrant farmworkers' movements resist a paradigm of static spatial ordering, the United States government and NGOs adopt a wide margin of error in their estimates that between three and five million migrant farmworkers live in the U.S. It is even more difficult to determine how many child farmworkers are in the United States:

Nobody knows how many adolescents work in agriculture in the United States. The General Accounting Office recently cited an estimate of 300,000 fifteen to seventeen-year olds working in agriculture each year, while acknowledging that 'methodological problems...likely result in an undercounting of the total number.' ... The United Farm Workers union estimates that there are 800,000 child farmworkers in the United States. (HRW "Fingers to the Bone")

Undocumented or underage workers, mobility, fear of government authorities, and other factors makes it difficult to know how many children or adults are engaged in farmwork. Migrant farmworkers' physical movements, coupled with the fear of authority present in a socially, politically, economically, linguistically, and legally marginalized population, disrupts the state's "surveillance [of] their everyday behavior, their identity, [and] their activity" that serves as "the basis of the massive increase in organizational power" in disciplinary societies (Discipline and Punish 78, Giddens 15). Driving the core of agricultural production, yet pushed to the peripheries of society, the multifaceted marginalization of migrant farmworkers and the fundamentally transient nature of their labor challenge the logic of a geo-coded disciplinary state. 
Nation-based, geo-spatial techniques of govermentality result in migrant laborers' border-crossings being conceptualized quite differently from capital's transnational movements. While the latter receives financial compensation in the form of increased profits and tax breaks for moving operations to counties where labor can be more fully exploited, the former risks fines, imprisonment, and deportation if proper documentation is not received before crossing geopolitical boundaries. In her innovative article on Under the Feet of Jesus and contemporary immigration policy, Anne Shea recognizes, "The discourse of criminality serves, in part, to figure social disorder: the changing economies, laws, and nature of the state within the restructuring by transnational capital become displaced onto the migrant worker who is seen as transgressing traditional social boundaries" (134). While borders serve as delineations that facilitate geo-coded disciplinary population management, the discourse of criminality highlights the residual corporal underpinnings of this system. Shea recognizes, “Workers' bodies are physically coerced through systems of control regulating their movement, in the fields, in the camps, and across borders. Agribusiness, processors, and the state produce discourses that reduce, instrumentalize, and, in the words of Ong, 'disassemble' workers' bodies" (73).

Within a context of mutually existing disciplinary and corporal systems, Petra voices frustration that there is "No sense telling La Migra you've lived here all your life" (62). She exposes the ineffectuality of grounding arguments in the nature of their “disassembled" bodies, quipping, "Do we carry proof around like belly buttons?" (62). Addressing the fear of her young daughter-a United States citizen terrified by the possibility that the "round, sharp white lights [that] burned her eyes" might be border patrol (59)-Petra advises Estrella: 
Don't run scared. You stay there and look them in the eye. Don't let them make you feel you did a crime for picking the vegetables they'll be eating for dinner. If they stop you, if they try to pull you into the green vans, you tell them the birth certificates are under the feel of Jesus, just tell them....Tell them que tienes una madre aquí. You are not an orphan, and she pointed a red finger to the earth, Aquí. (63)

Petra's instructions confront how migrant farmworkers' physical movements, material labors, and cultural affiliation(s) problematize the legal, moral, and material dimension of citizenship.

Currently both documented and undocumented migrant workers present challenges to nation-states' geo-spatial boundaries, disciplinary regulation of populations, and notions of citizenship. On one hand, when workers lack official documentation, such as work visas, immigration papers, or proof of citizenship, it makes it possible for employers and the nation-State to render these individuals functionally invisible in order to more fully exploit their labor. ${ }^{10}$ On the other hand, even the tenuous legal status of documented H2-A farmworkers (a classification of temporary guest workers with neither the benefits of citizenship nor the rights of immigrants) results in the lawful exploitation of these laborers. Thus, Under the Feet of Jesus reminds us that regardless of documentation status, some farmworkers' ethnicity or cultural affiliation may put them at increased risk of discrimination by immigration agents.

This realization is most poignantly conveyed through young Estrella, who feels vulnerable to possible border patrol "floodlights aimed at the phantoms in the field. Or 
were the lights directed at her?...Where was home?" (60). Although her mother assures Estrella that her birth certificate is always stored in the most secure spot in their shifting home sites, under the base of a Jesus Christ statue, Jeehyun Lim recognizes that "Petra also acknowledges the failure of the political and legal system to recognize and protect its citizenry and the people living within the bounds of the nation-state" (233). For Estrella, neither documentation provided by a birth certificate nor religious faith symbolized by Jesus Christ can combat the structural discrimination and exploitation that she experiences as a child farmworker. "As a document of Estrella's entitlement to the rights of a citizen, the birth certificate references the political and legal system," Lim asserts; yet "religious humility expressed in the image of prostrating at the feet of Jesus elevates the moral claim of Estrella's citizenship above the legal claim" (233). As Petra informs Estrella “[d]on't let them make you feel you did a crime for picking the vegetables they'll be eating" and "pointed her finger to the earth," she gestures towards the potential for citizenship to be reformed or revolutionized to give individuals rights within the territories that they labor. This connection to the soil on which migrant farmworkers' toil suggests a notion of citizenship beyond the moral claim that Lim advances; Petra's statement reflects a notion of cultural citizenship in which material acts and labor justify an individual's full legal inclusion in a nation-state.

Both progressive scholarly theory and practical labor policies seek to redefine citizenship and allow workers to move transnationally as freely as capital. While Sassen's model of the global city cannot account for the unique conditions faced by rural migrant farmworkers, her critique of contemporary immigration discourse is nonetheless relevant to this transnational population. Sassen recognizes that "there is a lack of new legal forms 
and regimes to encompass another crucial element of this transnationalization, one that some, including myself, see as the counterpart to that of capital: the transnationalization of labor. However, we are still using the language of immigration to describe the process" (Globalization and Its Discontents xxx). Shifting the emphasis from immigration to transnational labor not only has the rhetorical effect of framing this concept within the discourse of globalization, but also potentially undercuts the hegemonic privileging of global capital and subordination of global labor: "Too often immigration and ethnicity are constituted as otherness. Understanding them as a set of processes whereby global elements are localized, international labor markets are constituted, and cultures from all over the world are de- and reterritorialized, puts them right there at the center along with the internationalization of capital as a fundamental aspect of globalization" (Sassen, Globalization and Its Discontents xxxi). This is not a purely theoretical maneuver, but rather a discursive shift that may support material change as the "centrality of place in a context of global processes engenders a transnational economic and political opening in the formation of new claims and hence in the constitution of entitlements, notably rights to place, and, at the limit, in the constitution of "citizenship"” ("The Global City: Strategic Site/New Frontier” 90). Sassen's theory emphasizes crucial concepts of place, labor, and citizenship within dominant trends of capitalist globalization; however, her primarily urban focus does not elaborate how migrant farmworkers, with frequent and historically-established cycles of domestic and international migration, might be accounted for in this model.

Numerous labor groups currently support legislation that would enact a larger paradigm shift towards allowing transnational labor the same unencumbered movement 
enjoyed by global capital. With particular, but not exclusive, attentiveness to the needs of migrant farmworkers, the Farm Labor Organizing Committee (FLOC) has supported the idea of a Freedom Visa. "The Freedom Visa would guarantee the freedom to travel and to work with labor rights. It should be tied to verified employment but not to an individual employer; in other words, it would be a portable visa. It should be tied to basic freedoms like the right of association and the right to form organizations and unions to protect their labor rights,” explains FLOC founder Baldemar Velásquez. While still working for legislative change, at the grassroots level FLOC has already implemented a cross-border program where, in addition to workers' centers in the Midwest and southern United States, they have also opened facilities in Mexico. "FLOC serves as a guardian of immigrant workers, which reduces the capacity of growers to divide workers," notes Immanuel Ness in Guest Workers and Resistance to U.S. Corporate Despotism (174). "Those recruited in Mexico can rely on the union that they know to monitor wages and working conditions that were historically flouted and ignored by the growers association" (Ness, Guest Workers and Resistance 174).

While FLOC and other labor organizations have done impressive work simultaneously advocating for legislative change and addressing existing immigration and labor conditions, it is important to remember that their on-the-ground struggles face not only structural challenges but often violent opposition. The "pressure of FLOC has led both to success and continuous harassment from farm businesses and contractors. On April 9, 2007, organizer Santiago Rafael Cruz was bound and beaten to death at the organization's office in Monterrey" (Ness, Guest Workers and Resistance 175). Unfortunately such suppression of labor activists, organizations, and workers themselves 
is not unique. David Bacon reports that on May 9, 2015, in Nuevo San Juan Copala, Baja California, "cops descended in force [on striking farmworkers], allegedly because a group of strikers were blocking a gate at a local farm. A brutal branch of the Mexican police did more than lift the blockage, though. Shooting rubber bullets at people fleeing down the dirt streets, they stormed into homes and beat residents ("The Pacific Coast Farm-Worker Rebellion").

Under the Feet of Jesus considers the connections between violence towards bodies, work, geo-spatial positioning, citizenship, and human rights in a transtemporal context:

[Estrella] remembered the tar pits. Energy money, the fossilized bones of energy matter. How bones made oil and oil made gasoline. The oil was made from their bones, and it was their bones that kept the nurse's car from not halting on some highway, kept her on her way to Daisyfield to pick up her boys at six. It was their bones that kept the air conditioning in the cars humming, that kept them moving on the long dotted line on the map. Their bones. (148)

This image of migrant farmworkers challenges the dominant notion of temporality associated with progress and social-class ascension in the United States. Estrella reflects upon the persistent exploitation of her "disassembled" body-her labor power in the fields, “energy money," her "bones of energy matter"-extracted over millions of years. This vision partially reflects what Renny Christopher and Carolyn Whitson categorize as “narratives of waiting for change-because you're paralyzed or without options-[that] 
often have a style that dilates time" (74). Yet Estrella does not wait for change. Recognizing that "the nurse owed them as much as they owed her," by the end of the novel, Estrella catalyzes action (148). Moving "forward to the desk, the crowbar locked in her two fists," she demands, "Give us back our money" (149).

Farmworkers have made advancements in achieving equal rights; however, this is still a work in progress with highly racialized dimensions. As Christa Grewe-Volpp recognizes, in Under the Feet of Jesus, "Chicanos/as and the oil are mere resources for the white agribusiness, both instruments of its perpetual needs" (71). Historically, although generations of Native American, Chinese, Japanese, Pilipino, Mexican, AfricanAmerican, and other ethnic groups have toiled in the fields, the atrocities of migrant farm laborers' working and living conditions did not emerge in the public eye until the late 1930s when predominantly white "Okies" migrated to California in mass numbers. ${ }^{11}$ As Cletus E. Daniel writes in Bitter Harvest, "The entry of tens of thousands of white migrants into California's farm-labor force during the Dust Bowl years led to exposures of working and living conditions that genuinely shocked and dismayed a public that had been largely indifferent to the sufferings of brown, yellow, and black farmworkers caught in the same web of misfortune" (283). ${ }^{12}$

As a result of the Okie influx, during the 1930s over 500,000 Mexican and Mexican American farmworkers were deported to open jobs for the new "white" migrants. However, as the white workforce shifted with the onset of WWII, California found itself in need of the farm labor that it had recently deported. From the $1940 \mathrm{~s}-1960 \mathrm{~s}$ the United States government brought 4.5 million Mexicans to the United States as part of the Bracero Program, which imported Mexican workers on temporary contracts. ${ }^{13}$ 
Those workers were paid a fraction of the prevailing wage, faced substandard living conditions, suffered mistreatment from employers, and were denied the opportunity to form labor organizations. Today, "current debates about immigration policy-including discussions about a new guest worker program-have put the program back in the news... [as] top U.S. and Mexican officials re-examine the Bracero Program as a possible model" (Bracero History Archive). ${ }^{14}$ David Bacon recognizes the profound impact this could have on farmworkers and their ability to improve labor conditions: "During the bracero program, when resident workers struck, growers brought in braceros. And if braceros struck, they were deported...Today immigrant workers who already live in the U.S., like those who recently held a strike at Washington State's Sakuma Berry Farms, are being pitted against modern-day braceros brought in under the H2A program" (Bacon, “Immigration Bill's New Bracero Program Will Hurt Farmworkers"). This history demonstrates that while contemporary globalization is characterized by technological developments and progress towards instantaneous, real-time, virtual communication and transactions, migrant farmworkers still struggle against an antiquated immigration discourse, resurging agricultural guest worker policies from the WWII era, and exclusion from a century of key labor legislation.

Just as many key migrant farmworkers' issues persist transtemporally, the narratives in Under the Feet of Jesus resist easy periodization. Although Viramontes herself suggests that the novel takes place during the 1960s when "UFW information was not widely dissimilated. Whole communities of farm workers were isolated," the relatively static labor conditions for migrant farmworkers make her narrative seem troublingly contemporary (Viramontes in Dulfano 659). The experience of time in Under 
the Feet of Jesus emphasizes the fact that many migrant farmworkers are still fighting for the basic legal rights and collective representation that workers in other employment sectors have achieved through the NLRA, FLSA, and other legislation from which farmworkers are strategically omitted. Although farmworker labor groups have secured some legislative protections at the state and national level, farmworkers' continued exclusion from key labor laws suggest how and why migrant farmworkers' plight resists dominant contemporary temporalizations of progress and development. ${ }^{15}$

Attentive to this past and gesturing towards empowerment in the ever-elusive present, Under the Feet of Jesus exposes characters' feeling of entrapment while simultaneously illustrating their drive for self-advocacy and change. As Zandy explains, the "pesticide-poisoned living conditions of Mexican/American farm workers" in Viramontes' novel represent a body of working-class narratives that illustrate the “commonality of [workers'] physical labor, their limited choices (so counter to the be-allyou-can-be individualist mantra), the loss or disruption of their homes, the threats to their children, the necessity of fleeing or fighting, and to see how, like prisoners or the colonized, their sense of the present is stolen from them so that their minds must dwell in the past of in a hoped-for future (emphasis added 148).

While Perfecto's mind drifts to “another life” long ago in Mexico, Alejo’s imagination dwells in a "hoped-for future" where he dreams of his first day of high school $(79,52)$. Engaging the past and the future, in its final pages, the novel suggests that Estrella's affirmation of power at the health clinic may provide her with agency to exist in an elusive present: "No longer did she stumble blindly. She had to trust the soles of her feet, her hands, the shovel of her back, and the pounding bells of her heart...Like 
the chiming bells of the great cathedrals, she believed her heart powerful enough to summon home all those who strayed" (175-76).

“A vast unseen commonwealth:" Globalizing Struggle in Against the Day ${ }^{16}$

In Under the Feet of Jesus, migrant farmworkers' transnational and transtemporal existence is subtly omnipresent in the text, signified by cyclical tensions between physical movement and economic stagnation. In contrast, Against the Day is not implicitly transnational; it is overtly global. While Viramontes addresses the persistent material impact that nation-state borders and policies have on migrant populations, Pynchon's vision is boldly postnational, imagining and problematizing organizations of power that might replace transnational capitalist systems. As Chapter 4 of this dissertation elaborated in the context of the Ludlow Massacre, counter-narratives may be suppressed by "all the agencies of history [that] had conspired never to record it" (Pynchon 796). Yet these alternatives are never fully erased in Against the Day, they are merely obscured until the right conditions permit "a view into a Creation set just to the side of this one, so close as to overlap" (566). In particular, Against the Day illustrates how violent and oppressive international, state-based, and private capitalist structures may be subverted into a global network of placebased labor resistance. Much like Hardt and Negri, Pynchon embraces the inclusive vision of the Wobblies and explores how the global infrastructure of capitalist Empire makes a revolutionary multitude possible. Against the Day posits simultaneous realities: in one, the world as it is perceived; in another, the world slightly refracted to show what may be. While Hardt and Negri associate the multitude with relatively contemporary forms of globalization like the multi-century scope of Wallerstein's world systems theory, we can identify parallel 
historical resistance movements, such as the IWW, emerging internationally at earlier moments of capitalist globalization.

Set in the decades leading up to World War I, Against the Day illustrates the (shifting) constructed nature of nation-state boundaries and the ideological functions of these delineations. Unlike Under the Feet of Jesus, which exposes the ways in which militarized geopolitical boundaries and associated notions of citizenship have material realities for transnational migrant workers, Against the Day portrays the absurdity and ineffectuality of arbitrary, imaginary borderlines. In the novel, state borders become less physical geopolitical sites and more ideological tools that support the international capitalist system and, increasingly, private investors' relentless process of primitive accumulation. For instance, in Against the Day, the Irish insurrectionist Flaco does not differentiate between the State, capitalism, and other dominant powers, explaining, "The State is evil...I include in that obscene word the Church, the latifundos, the banks and corporations, of course" (372). Viekko, an anti-russification Finn working in the Colorado mines, conceptualizes borders as capitalist tools for dividing and containing workers' commonalities: 'He'd never seen much difference between the Tsar's regime and American capitalism. To struggle against one, he figured, was to struggle against the other. Sort of this world-wide outlook" (83). When Viekko is forcibly deported because of his militant union activities-exiled from Colorado "south on the Denver \& Rio Grande across the invisible border into New Mexico"-he experiences the illusionary and impractical nature of geopolitical borders firsthand (82): 
[A]n old geography schoolbook with a map of the state in it... showed Colorado as a rectangle, seven degrees of longitude wide by four degrees of latitude high-four straight lines on paper made up the borders Veikko had been forbidden to cross-not like there were rivers or ridgelines where the militia might lie in wait to shoot at him the minute he stepped overfrom which he reasoned that, if exile from Colorado was that abstract, then as long as he stayed off the roads, he could come back into the state anytime and just keep soldering on same as before. (83)

While the novel functionally expunges patrolled borders from its narrative-as Lieutenant Prance quips, "Oh, as if boundary-lines mattered anymore"-it does not disregard the complex ideological functions that nation-state boundaries represent (761).

In what J. Paul Narkunas terms a "dynamic dance of flexible sovereignty," the novel portrays the United States as "consolidating and edifying its geographic and political borders" even as, at the "same time, waves of immigrants to the United States needed for their cheap labor and their compression of wages offered complex problems of policing: how to regulate multilinguistic, multicultural, and multiethnic humans while leaving capital unregulated?" (239). To answer this question, capitalism evokes national identity as a racializing force to splinter collective working-class identities and interests. Workers "became increasingly ethnically and nationally marked as foreigners and 'unAmerican'-precisely when they demanded higher wages" (Narkunas 241). Narkunas insightfully recognizes, "Against the Day shows how this collapse of class into ethnicity galvanized both a theological argument and a religious war, culminating in a public- 
private partnership for putting down labor insurrections in the United States" (241). Against the Day's powerful capitalist and American demigod, Scarsdale Vibe, professes propaganda that characterizes anarchists, immigrant laborers, and trade unionists as a dangerously un-American population that puts national identity and culture as risk:

These communards speak a garble of foreign tongues, their armies are the damnable labor syndicates, their artillery is dynamite, they assassinate our great men and bomb our cities, and their aim is to despoil us of our hardwon goods, to divide and sub-divide around their hordes our lands and our houses, to pull us down, our lives, all we love, until they become as demeaned and soiled as their own. (333)

Vibe strategically conflates multi-ethnic immigrants, union sympathizers, political radicals and other subversive groups into a singular enemy that must be swiftly and permanently subjugated: “[W]hat we need to do is start killing them in significant numbers, for nothing else has worked. All this pretending-'equality,' 'negotiation'-it's been such a cruel farce, cruel to both sides. When the Lord's people are in danger, you know what he requires" (333).

The comprehensive racialization of dissident groups seeks to portray these peoples not as a social class but as a dangerous population at odds with capitalism and the nation-state. They become Esposito’s unimmunized, put at increased risk, or Agamben's homines sacri, bare life deprived of rights. ${ }^{17}$ For Vibe and other capitalists, maximum profit depends on workers being biopolitically managed through, as Mbembe asserts, a "state of exception" and "state of siege." Under a national "state of exception" the nation- 
state regulates dispossessed populations by indefinitely suspending certain rights and laws, while they are threatened with a global "permanent state of exception" under which collusive state and private forces may deploy "a powerful police function against the new barbarians and the rebellious slaves who threaten its order" (Empire 20). In addition, these "unimmunized" populations are often quarantined in "state of siege." As the Chums of Chance recognize in Against the Day, "the modern State depended for its survival on maintaining a condition of permanent siege-through the systematic encirclement of populations, the starvation of bodies and spirits, the relentless degradation of civility until citizen was turned against citizen" (19). For Esposito and Mbembe, perhaps more so than Agamben, biopolitical control over the lives of the homines sacri-through a "permanent state of exception" and what the Chums recognize as a "permanent siege"-ultimately rests on thanatopolitical or necropolitical control over their death. Anarchists in Against the Day realize, "We look at the world, at governments, across the spectrum, some with more freedom, some with less. And we observe that the more repressive the State is, the closer life under it resembles Death" (372). Not only anarchists, but also industrialists of Vibe-lineage, note that for capitalism to proliferate "sooner or later it depended on some act of murder, seldom limited to once" (170).

Against the Day illustrates the intimate corporal connections between capital, the nation-state, and death:

Central governments were never designed for peace. Their structure is the line and staff, the same as an army. The national idea depends on war. A general European war, with every striking worker a traitor, flags 
threatened, the sacred soils of homelands defiled, would be just the ticket to wipe Anarchism off the political map. The national idea would be reborn. One trembles at the pestilent forms that would rise up afterward, from the swamp of the ruined Europe. (938)

However, in this persistent march towards war-a nation-state assault to rid capitalism of its "subhuman" opponents-a productive dialectic tension arises. On one hand, Against the Day describes how capitalism conflates and subjugates "othered" populations such as "Plains Indians, strikers, Red immigrants, any who were not likely docile material for the mills of the newly empowered order" (334). The novel elaborates how working-class peoples, political dissidents, trade unionists, and other revolutionaries are racialized into an "inclusively excluded" population, to borrow Agamben's concept. For this to occur, as Balibar recognizes, "[A] racial signifier has to transcend national differences and organize 'transnational' solidarities so as to be able, in return, to ensure the effectivity of nationalism" ("Racism and Nationalism" 62). Thus, on the other hand, this transnational categorization, which indiscriminately racializes, also provides radical potential for building solidarity between seemingly disparate, but similarly subjugated, groups. As biopolitics is first individualizing then massfying, a racialized "permanent state of exception" has the potential to bind diverse transnational populations in a common mission to subvert global capitalism and destabilize violent nation-states. This crux of this campaign must be to mobilize this group; as Reef says, "[M]e and Frank will [do] what Joe Hill calls organize” (216). 
Early in the novel, Lew Bassnight, a private investigator in Colorado working as “'industrial security,' a term for breaking the heads of those either on strike or maybe just thinking about going out," recognizes how workers of different nationalities, ethnicities, backgrounds, and religions have become, unexpectedly, American (1041):

There was a kind of general assumption around the shop that laboring men and women were all more or less evil, surely misguided, and not quite American, maybe not quite human. But here was this hall full of Americans, no question, even the foreign-born, if you thought about where they had come from and what they must've been hoping to find over here and so forth, American in their prayers anyway...Yet here they were expressing the most subversive thoughts, as ordinary folks might discuss crops, or last night's ball game. (50)

The novel emphasizes that worldwide laboring populations might begin to unite through recognizing their common exploitation by global capital and their marginalization within the nation-state. From this shared experience, a campaign can be built against state and private capitalist aggression, moving towards revolutionizing the means of production and establishing more egalitarian organizations of power that recognize and protect the contributions of labor. In this way, while the dissidents in Against the Day can be understood as Agambenian homines sacri, they are not stripped of creative action and the ability to form new subjectivities. Instead, these subjugated groups, who are amalgamated by the capitalism state into a "subhuman" population, become what Hardt and Negri term a multitude: "[A] form of political organization that, on the one hand, emphasizes the 
multiplicity of the social singularities in struggle and, on the other, seeks to coordinate their common actions and maintain their equality in horizontal organizational structures" (Commonwealth 110).

Against the Day depicts workers who mirror capital's strategic disregard for nation-state boundaries in order to act as a global multitude, much like the Wobbies that Hardt and Negri invoke. The multitude in Against the Day appropriates and subverts the space and place of capitalist globalization to territorialize their own networks. In global space, which the novel identifies as the common "aether" (perhaps what we might now call virtual space), the Chums of Chance balloon beyond any borders. On land, Sassenian place-based nodes of production and resistance link in supranational networks. Forming ethereal and terrestrial connections long before contemporary twenty-first century globalization, "social singularities defined more or less by their culture or ethnicity or labor position coordinate[d] their struggles together in the multitude" (Commonwealth 111). The Chums of Chance circulate the globe unhindered by state-based geo-political borders: “'Nowadays,' Penny said, 'they'll fly wherever they're needed, far above fortress walls and national boundaries, running blockades, feeding the hungry, sheltering the sick and persecuted"' (20). Near the end of the text, in a more fully articulated image of shifting global power arrangements, the Chums recognize that "worldwide, the organization had been drifting into a loose collection of independent operators with only the 'Chums of Chance' name and insignia in common" and increasingly their "missions expanded across the borders" $(1018,1027)$. Earth-bound characters in the novel similarly create complementary complex webs of global resistance that includes Irish “insurrectionists” like Wolfe Tone O’Rooney and Flaco; militant Italian "naval 
renegades" like Rocco and Pino; "Belgian nihilists" like Eugene, Fatou, Denis, and Policarpe of the "Young Congo"; Mexican anarchists calling for "Land and Justice;" United States labor union supporters like the Traverse family and Rev. Moss Gatlin with his "Anarchist Heaven" following; possibly Russian and eastern European counterparts; and numerous other groups and individuals moving worldwide $(370,529,527,465,982)$. Within this context, particular labor struggles in the novel serve as active nodes within a global web of resistance to capitalist exploitation. Each industrial/labor conflict is not an isolated rebellion or a historical anomaly but, instead, part of an interrelated, reoccurring ideological and physical revolution that recognizes and resists the violent workings of capitalism at simultaneous global and local levels.

Solidifying around economic and social justice causes, Against the Day presents an image of a mobilized supranational laboring population that circulates in relative disregard to national boundaries in order to engage transnational capital on a comprehensive level. However, this multitude not only connects diverse sites of resistance, it also works to fundamentally deconstruct the divisive nationalistic and oppressive capitalist structures that geographically, socially, and psychologically divide workers. Resistance propagates in places where ethnically and culturally diverse workers are brought together, like the U.S. mines or the European tunnel projects, as well as in spaces that are already partially geographically and culturally deterritorialized by capitalism. For example, in the German colony around outside Tampico, Mexico, anarchists intercept "Mondragón semiautomatics from Germany, intended for the Mexican Army" (640). This region, in which “everyone speaks northamerican, it's why we call it 'Gringolandia' here," is functionally set outside of traditional geopolitical 
bounds and consolidated as a "zone running all the way [from Mexico] to the U.S. frontier, where runners of contraband operated freely" (641, 637). After Irish “insurrectionist” Wolfe Tone O’Rooney recruits funds and participants in New Orleans, he visits Mexico for "weapons for the Irish cause" and finds "himself drawn more and more, the longer he stayed in Mexico, into the gathering revolution here" (642). In this place of multinational interests, anarchists without strong national allegiances begin to introduce, in Deleuze and Guattari's terms, an overcoding of this partially deterritorialized, decoded space, as they establish their own interconnected nodes of resistance.

Reflecting the International Workers of the World's proclamation that "there can be no peace so long as hunger and want are found among millions of working people and the few who make up the capitalist class have all the good things of life," anarchists in Against the Day become active agents in creating nodes of rebellion that resist capitalist exploitation and attempt to enact more egalitarian arrangements of global power (Adamic 158). The multitude not only connects nodes of resistance into a global network, it also subverts the de- and re-territorializing tendencies of capitalism to strategically deconstruct existing power structures and introduce alternate frameworks and codes. Together, the anarchists envision themselves as a "stateless collection" that strives for the "replacement of governments by other, more practical arrangements... some in existence, others beginning to emerge, when possible working across national boundaries" and implementing “[n]o ranks, no titles, chain of command" (Pynchon 531, 933). They recognize that a world war would strengthen national allegiances, damage union striking abilities, produce new capitalist markets, and, ultimately, destroy the promise of an 
anarchist society where "only in community can social order be maintained without the state" (Taylor 95). Ratty reasons that in a global war, "Anarchists would be the biggest losers, wouldn't they. Industrial corporations, armies, navies, governments, all would go on as before, if not more powerful. But in a general war among nations, every small victory Anarchism has struggled to win so far would simply turn to dust” (938). Thus, dissidents seek a different future, situated slightly to the side of conventional global history's march to war, perhaps to step "outside of Time as it commonly passes here, above this galley-slave repetition of days, and have had a glimpse of future, past, and present" (617).

As a physical materialization of dissenting ideologies, the "Anarchist Spa" Yzles-Bains represents what Reef and Wolfe Tone O'Rooney had earlier envisioned as a mythical "place of refuge, up in the fresh air, out over the sea, someplace all the Anarchists could escape to, now with the danger so overwhelming... a place promised them, not by God, which'd be asking too much of the average Anarchist, but by certain hidden geometries of History" $(931,372)$. At Yz-les-Bains it was "not silver or gold" but a "Single Idea, whose power everything else ran off of" (931). Diverse nationalities, ethnic groups, and dissident ideologies-all those groups bemoaned as an "anti-Capitalist monster"-are drawn towards this utopian place, perhaps like Rev. Moss Gatlin's Anarchist's Heaven: "Veterans of the Cataluñan struggle, former residents of Montjuich, hasheesh devotees enroute to Tangier, refugees from as far away as the U.S. and Russia, all could find lodging at this venerable oasis without charge" (931). Similar to the IWW's ultimate goal of uniting worldwide laborers, regardless of type of work, county of origin, or gender, the community at Yz-les-Bains not only draws members from multiple nation- 
states, but also recognizes that what "[b]lighted the hopes of Anarchism for years, I can tell you-as long as women were not welcome, it never had a chance" (934). Perhaps the most revolutionary idea that solidifies in the community of Yz-les-Bains, however, is the foundational anarchist and IWW belief that because of the symbiotic relationship between the state and capitalism, revolutionary change depends on, as the 1908 IWW preamble elaborates, workers who "'take possession of the earth and the machinery of production, and abolish the wage system"” (Ademic 160).

This goal is never realized in Against the Day, yet it offers a potential geography, to borrow Stray's term, for “a vast unseen commonwealth" (976). Throughout the novel, as Professor Renfrew notices in his own work, the "railroads seem to be the key" (689). Instead of geopolitical borders, the global geography of Against the Day is delineated by webs of tracks and ties:

[T] he primary geography of the planet is the rails, obeying their own necessity, interconnections, places chosen and bypassed, centers and radiation therefrom, grades possible an impossible, how linked by canals, crossed by tunnels and bridges either in place or someday to be, capital made material-and flows of power as well, expressed, for example, in massive troop movement. (242)

On one hand, the railroad is a symbol of capitalism's rhizomatic global geopolitical growth, dually catalyzing diplomatic concessions and facilitating territorial wars. As Frank unabashedly recognizes, the railroad "broke apart cities and wild herds and watersheds, it created economic panics and armies of jobless men and women, and 
generations of hard, bleak city-dwellers with no principles who rule with unchecked power, it took away everything indiscriminately, to be sold, to be slaughtered, to be led beyond the reach of love" (930). However, on the other hand, for Yashmeen the railroad represents potential paths for freedom and choice on a global scale:

She gazed backward at iron convergences and receding signal-lamps. Outward and visible metaphor, she thought, for the complete ensemble of 'free choices' that define the course of a human life. A new switching point every few seconds, something seen, sometimes traveled over invisibly and irrevocably. From on board the train one can stand and look back, and watch it all flowing away, shining, as if always meant to be.

Much like the consequences of unfettered and unregulated capitalism, the railroad is characterized as a power not quite under the full control of its masters-potentially developing in unexpected ways, perhaps susceptible to rearticulation by alternate forces. To Lew Bassnight "the steel webwork was a living organism, growing by the hour, answering some invisible command. He found himself out lying at suburban tracksides in the deep nighttime hours, between trains, with his ear to the rails, listening for the stirrings, quickening" (177). The balloon boys perceived that from "a high enough altitude, as we have often observed, indeed that great project appears almost like a living organism, one dares to say a conscious one, with needs and plans of its own" (259). In this realization lies the potential for radically rearticulating, not just the literal system of 
railroads that crisscross the world, but also global capitalism's development of transnational networks.

Kit recognizes a "sort of railroad-metaphysics" in his travels, as he looks to each side of the train and sees "two radically different pieces of country"-a choice between two different worlds (751). These terrains can be understood as representing the parallel courses of history that Pynchon is fond of invoking in Against the Day. The challenge faced by the multitude of unionists, anarchists, and other dissident groups is not to do away with global systems proliferated under capitalism, but to alter them into "a world of common wealth, focusing on and expanding our capacities for collective production and self-government" (Hardt and Negri, Commonwealth xiii). Empire, as the "new global form of sovereignty" that "establishes no territorial center of power and does not rely on fixed boundaries or barriers," has enabled supranational forms of violent police actions and permanent states of exception, such as those depicted in Against the Day (Empire xii, xiii).${ }^{18}$ However, transnational channels established by global capitalism have the radical possibility to be rearticulated as routes for supranational dissident populations to mobilize for resistance: "The geography of these alternative powers, the new cartography, is still waiting to be written-or really, it is being written today through the resistance, struggles, and desire of the multitude" (Hardt and Negri Empire xvi). While Pynchon and Viramontes conceptualize a new geography composed by the struggles of workers in their physical, social, and ideological movements, in Almanac of the Dead, Silko literally maps this new cartography of power for a transnational and transtemporal multitude. 


\section{The Geography of Counter-Hegemonic Resistance in Almanac of the Dead}

Contrasting the capitalist geography of railroad networks and nation-state borders, Against the Day also references ancient "maps [that] were like visions of prophets, in a sort of code, outward and visible notation for what lay within" (860). In Pynchon's novel, these maps provide glimpses of the past and images of a future. Similarly, in Almanac of the Dead, Silko draws on contemporary trade routes and ancient migration paths to chart a new geography of counter-hegemonic resistance.

As Chapter 2 elaborated, Almanac enacts an inclusive definition of labor that conceptually remaps our global workforce by emphasizing the contributions of unwaged, affective, forced, bio, and other under-recognized categories of labor. Silko's Five Hundred Year Map, which prefaces the novel, provides not only a spatial and temporal reorientation of American geography, but also remaps the socio-cultural and economic terrain by illustrating the interconnected nature of laboring bodies, capitalist trade routes, resistance movement, and underground economies. For instance, Silko's map provides a

list of characters (with minimal elaborations) connected by dotted "lines of flight," of which flow to and from Tucson's proximity as the off-centered hub of the map. Rather than constructing a cartographic projection that proportionately represents physical space at a fixed moment, the Five Hundred Year Map de-settles these foundational principles of Western cartography by using a scale that communicates the cultural significance and relationship between peoples and places that stretches trans-temporally from before the European "conquest" of the Americas into the imagined future. Together the written text of the novel and the Five Hundred Year Map provide a codex-like almanac that compiles visual images, stories, history, poetry, memory, philosophy, and religion into a record of 
the past and prophesy for the future. Thus, the most important work that Silko's Five Hundred Year Map does is not in creating something revolutionarily new, but in subverting a dominant form of technology and resurrecting established flows of indigenous bodies, resources, and knowledges to provide a visual representation that illustrates Viramontes's temporal and geopolitical transgressions, Pynchon's global interconnectedness, and Silko’s own grassroots resistance.

The Five Hundred Year Map confronts cartographic principles-such as central linear perspective, rigid geopolitical borders, visual hierarchy, and uniform scale-that have standardized mapmaking from the Renaissance period forward. By disrupting these conventions, Silko highlights how maps represent and transmit dominant ideologies including particular conceptions of power, positioning, and perspective. In The Condition of Postmodernity, David Harvey explains that revolutionary Renaissance rules of perspective shaped "our ways of seeing for four centuries," establishing a fixed viewpoint which conceived of the "world from the standpoint of the 'seeing eye' of the individual" (244-45). This assumption was later reflected in the Enlightenment tradition of imagining "how the globe as a whole would look to a human eye looking at it from the outside," which served to naturalize the information that was transmitted through the map, as if it was the way in which any person might see the world from a distance (Postmodernity 246). The center of the map typically focused on a 'developed' nation quarantined from peripheral colonies by solid external borders. Geopolitical territories appeared insulated by fixed lines and curves that were nearly indistinguishable from natural phenomenon like rivers and streams. The 'seeing eye' of Western cartography transmitted the perspective of dominant society-at the center-as the natural, universal perspective. 
It was not until the period of late-modernism ${ }^{20}$ that perspectivism's foundational assumptions were broadly brought into question. As Harvey posits, "If perspectivism, for all its mathematical rigour, constructs the world from a given individual viewpoint, then from whose perspective is the physical landscape to be shaped?" (Postmodernity 253). Identifying cartographic viewpoint as a socially and politically positioned perspective allows for the recognition of alternate orientations representing the same space, yet assigned a subordinate status. In a broader sense, questioning perspective problematizes the hegemonic Enlightenment sense of the other as "necessarily having (and sometimes 'keeping to') a specific place in a spatial order"-an order in which the "other" is not privileged (Postmodernity 252). The gradual realization that power plays a key role in defining the so-called natural and universal cartographic perspective provides an intellectual space for alternate conceptions of mapping to emerge in academic conversation. $^{21}$

In "Cartography and Power in the Conquest and Creation of New Spain," Raymond B. Craib explains, “[Western] [m]apping and surveying are inherently political acts precisely because they attempt to 'fix' or capture the landscape based on a specific and ideologically saturated set of criteria. Yet the resulting product is often read as reality, with dramatic consequences for local lives and livelihoods" (30). This observation leads Craib to ask, "How did subalterns use maps to defend their territorial, political, and economic interests?" (30). Silko engages the power/knowledge relationship between maps and resistance not by asking how did subalterns use maps, limiting this to a historical occurrence, but by envisioning how might subalterns use maps. This latter articulation recognizes a sense of subaltern agency in modifying contemporary 
techniques or continuing traditional cartographic practices, such as symbolic boundaries, relational scale, and non-linear time.

Upon encountering the Five Hundred Year Map, contemporary viewers may recognize common trade routes of global capital, such as the international paths of military arms and videotapes represented on the map. However, paralleling the movement of commodities is the movement of bodies, like the "Twin Brothers [who] walk north with hundreds of thousands of people" (Almanac, Five Hundred Year Map). The movements of capitalist corruption, embodied in Trigg, the founder of Bio-Materials, Inc., and Max Blue, the mobster with political clout, are indistinguishable from the counter-hegemonic networks of the Army of the Homeless and antigovernment insurgences led by the Twin Brothers. These transnational flows, which move in relative disregard to geopolitical boundaries, expose junctures and convergences between socalled legitimate and illicit movements, as "illegal" arms, pornography, and mafia movements mirror "legal" government and industry trade routes. By illustrating appropriations and rearticulations of the transnational capitalist flows for subaltern empowerment, Silko is essentially, "subjecting global capitalist networks to its own networking logic" or "writing in reverse" the logic of global capitalism (Shackelford par. 15). Although the transnational passage of capital and labor are often treated quite differently-Against the Day illustrates the free movement associated with the former and Under the Feet of Jesus highlights the criminality associated with the latter-the Five Hundred Year Map does not represent this distinction. Instead, in Almanac, Calabasas proclaims: 
We don't believe in boundaries. Borders. Nothing like that. We are here thousands of years before the first whites. We are here before maps or quit claims. We know where we belong on this earth. We have always moved freely. North-south. East-west. We pay no attention to what isn't real. Imaginary lines. Imaginary minutes and hours. Written law. We recognize none of that. (216)

True to this assertion, several elements of the Five Hundred Year Map may seem unusual to viewers who are familiar primarily with Western cartographic projections.

First, while Silko assigns a border between Mexico and the United States, its representation as a straight line (which would possibly divide such geographical locations as Southern Texas to the Mexican side of the boundary) demonstrates the unnatural and power-latent existence of geopolitical boundaries that divide so-called core and peripheral spaces. Situated to the north of the border, Tucson-the text's narrative and map's geographical off-center hub-historically exemplifies the rigid yet impermanent nature of geopolitical divides. ${ }^{22}$ In what Almanac describes as the "U.S. or 'gringo' takeover of Mexican territory, later called Arizona and New Mexico Territory, with the Guadalupe Hidalgo Treaty," the 1848 agreement originally assigned the city of Tucson and surrounding vicinity to the Mexican side of the international border (643). Soon after the Treaty, the United States decided it had established the boundary too far to the north to include the "Americans" living in Tucson and consequently bought the region as part of the Gadsden Purchase of 1853, moving the U.S./Mexican border further south (Choate 4). Silko's map maintains, but reorients, this shifting international boundary between the 
United States and Mexico, perhaps, in part, as a physical representation of the cultural, economic, and "developmental" divide between the countries.

Second, the scale of the Five Hundred Year Map appears non-standardized, with Cherry Hill, NJ approximately the same distance from Tucson as San Diego, CA. In “Writing Deeper Maps: Mapmaking, Local Indigenous Knowledges, and Literary Nationalism in Native Women's Writing," Kelli Lyon Johnson states that "rather than representing the earth to a standard scale — the goal of nearly all European mapmaking Indigenous North American mapmakers focused on the cultural significance" (106). ${ }^{23}$ Some (but not all) Native American tribes created maps that scaled elements such as towns, borders, names, and landmarks according to their importance in the story that accompanied each map. ${ }^{24}$ As Johnson elaborates, there exists a "degree to which relationships among geographical features and locations supersede mere representations of their existence on the ground. A full understanding of Native maps relies not on a European understanding of scientific geography but of the context—and the narrativethat accompanied each Native-made map" (107). ${ }^{25}$ Thus, within a context of the Native cartography Johnson describes, the Five Hundred Year Map and the textual narrative of Almanac are interdependently necessary for interpreting each other.

Third, the Five Hundred Year map collapses various temporal chronologies into a single projection, which traces intersecting movements in both time and space. For example, Zeta, Trigg, and Leah Blue's names are listed near John Dillinger's on the path from San Diego to Tucson with no temporal markers to distinguish the chronology of these travels. ${ }^{26}$ In its depiction of ancient texts, Almanac elaborates this connection between scale and time: "An experience termed past may actually return if the influences 
have the same balances or proportions as before. Details may vary, but the essence does not change" (574). Portraying this decidedly non-Western conception of space and time, the entire scope of the Five Hundred Year Map and literary text function together like a codex, paralleling the ancient almanac that Yoeme gives her granddaughters Zeta and Lecha. In "Rereading the Maps of the Columbian Encounter," cartographic historian H. B. Harley states that Mexican and South American codices reveal intertwined textual histories and maps. Codex maps may be "defined as producing 'spatial histories' where time and space are projected on to the two dimensional plane, and in which records of geographic perceptions, ancestral migrations, and dynastic histories are combined into single documents" (525). Just as the text of Almanac spirals through more than five hundred years of post-contact history, the Five Hundred Year Map traces stories through both time and space, echoing the technologies of particular traditional Native cartographies and codices. $^{27}$

To further understand Silko's map, it is important to recognize not only how the image reflects contemporary flows of global capitalism and ancient Native cartographies, but also how the representation reconstructs the fragmented history of subaltern flows and indigenous movements. The Yaqui, central characters in Almanac, maintain a tradition of intercontinental movements depicted on the Five Hundred Year Map and paralleled by the flows of contemporary global capital. ${ }^{28}$ Although militarization of the U.S/Mexico border attempts to deter and criminalize international flows of peoples (while letting capital move under-regulated), migration has persisted along well-worn indigenous paths. For example, in his personal chronicle, A Yaqui Life, Rosalio Moisés stresses the fact that Tucson's proximity to Mexico allowed Yaqui refuges in the United 
States to move back and forth across the border and continue to support the fight for tribal homelands during the Mexican Revolution. Moisés states that on several occasions he walked from Tucson to the Sierra Yaqui region of Mexico "carrying over 50 pounds. Guns and ammunition accounted for most of the weight" (Moisés, Kelley, and Holden 40). Moisés elaborates that by around 1910 "so many people were making the trip between Sierra and Arizona that we had lots of news of what was happening in Sonora" (Moisés, Kelley, and Holden 47). As Evelyn Hu-DeHart points out, Yaquis "went to Arizona to seek work, refuge, and fresh supplies" to assist the resistance efforts in Yaqui homelands (emphasis added 168). ${ }^{29}$

Moisés's and Hu-DeHart's historical accounts parallel the contemporary resistance networks that Almanac narrates and the Five Hundred Year Map depicts. For instance, much like Yaquis who crossed the U.S./Mexico border to transport arms and supplies during the Mexican Revolution, one of Almanac's central Yaqui characters, Zeta, invests in North-South drug and gun markets to finance and arm a contemporary cross-border, counter-hegemonic revolt (701-705). Such instances suggest that Almanac's transnational flows are not just subversions global capitalist channels, nor emulations of ancient Toltec migrations, but resurrections of persistent flows of intercontinental resistance. Specifically, the Five Hundred Year Map illustrates relationships between diverse groups of people from who form a network of resistance that stretches through both time and space-"North to Alaska" and "South to Cartagena and Buenos Aires"-to unite various ethnicities, social classes, and nationalities with confluent goals of social, economic, and environmental justice. ${ }^{30}$ 
Through Silko's process of destabilizing dominant cartographic principles and resurrecting suppressed indigenous knowledge, the Five Hundred Year Map offers a visual representation of the multitude, which similarly subverts the networking structure of Empire for counter-hegemonic purposes. Silko's Map can be understood as a sort of blueprint for resistance networks that counter neoliberal biopolitical dispossession through cross-border social movements that function in a similarly transnational space. Similar to Pynchon's narration of global, interconnected revolt, the Five Hundred Year Map presents a web of on-the-ground agitation and overarching social, geo-political, and spatio-temporal reorientations. The map illustrates a version of time, as Viramontes elaborates in Under the Feet of Jesus, where progress is not a linear process but a cyclical journey-the channels of Yaquis resistance during the Mexican Revolution emerging as a contemporary counter-hegemonic movement. The Twin Brothers and their followers conceptualize themselves less as citizens of a particular nation-state and more as global citizens where, as the Barefoot Hopi claims, "everyone was born belonging to the earth" (625).

At the Holistic Healers Conference near the end of Almanac, the Barefoot Hopi asserts, "the tables had turned; now the colonizers were being colonized" (739). As Almanac critic Eva Cherniavsky points out, "Silko situates these tribal knowledges as oppositional to, but not necessarily outside of, commodity culture" (111). ${ }^{31}$ It is through this economy, that "the historical and political message infiltrates the political unconsciousness of the consumer public" (Cherniavsky 122). Viramontes's, Pynchon's, and Silko's texts may shape the wider social (un)consciousness as they envision and communicate organizations of counter-hegemonic power that transcend nation-state 
boundaries and engage current global capitalism on transnational levels. However, the challenge we must embrace is how to translate airy literary visions and theoretical realizations into on-the-ground practice for global labor empowerment.

\section{The Evolution of a Global Labor Movement}

Viramontes, Pynchon, and Silko contribute immaterial labor essential for the construction of a more democratic, egalitarian global society. Their narratives in Under the Feet of Jesus, Against the Day, and Almanac of the Dead, provide intellectual work that creates concepts, communications, and affective consequences. As is true with most forms of immaterial labor, these narratives are a type of biopolitical production, with the potential to build relationships, institutions, and, ultimately, reorder social life itself. Thus, the potential work of these texts cannot be fully understood without investigating intersections between narrative and contemporary life, in other words, without exploring the confluence of immaterial and material labor. For instance, Under the Feet of Jesus not only creates an affective experience in which readers perceive life through the eyes of young Mexican-American farmworkers. The novel also demands that society address the destruction of bodies, families, and cultures afflicted by U.S. labor and immigration policies. Because Viramontes's, Pynchon's, and Silko’s works provide immaterial labor that cannot be contained within the covers of a novel, it seems only fitting that this dissertation conclude by offering a concrete vision of change, guided by these texts and able to be enacted at place-based sites of globalization.

Mindful of implementing an inclusive concept of localized transnational labor, amplifying marginalized voices, and circulating suppressed labor counter-narratives multiple types of change must develop simultaneously: First, United States labor law 
must be revised to reflect the conditions of contemporary capitalism and the variety of material/immaterial labor and permanent/contingent/independent workers. At the same time, we must reassess immigration policy and support effective international labor law. Second, coalitions between traditional unions and community groups must strengthen in order for labor organizations to represent and convey the needs of diverse workers. Third, transnational alliances must grow around a nucleus of worker commonality in order to address the effects of transnational capitalism on simultaneous, interrelated global and local fronts.

\section{A Call for U.S. Labor Law Reform}

Labor solidarity depends on creative thinking that draws on the past to construct a new future. However, one of the largest obstacles to an inclusive workers' movement in the United States may actually be labor laws written to preserve industrial peace during widespread militant unionization efforts climaxing in the early twentieth century. As this dissertation explored, Pynchon details periods of late nineteenth and early twentieth century industrial warfare, such as the Colorado Coalfield War, in which capital and labor violently clashed over working conditions, minimum wage, child labor, company towns, the right to form unions, and other issues. Workers in Against the Day recognize that owners' unfettered accumulation of wealth is extracted from the sweat and blood of labor-"Labor produces all wealth. Wealth belongs to the producer thereof" (the IWW mantra quoted in Pynchon 93). In both Pynchon's novel and historically during the early twentieth century, labor engaged in wildcat strikes, secondary boycotts, mass protests, sabotage, and pickets; obstructed supply chains; and undertook other actions to protect workers' rights, win democratic representation in the workplace, and disrupt the 
inequitable distribution of wealth. By understanding the legal legacy of this labor history, we can contextualize unions' actions today and envision future tactics for the labor movement.

Decades of industrial/labor conflicts coupled with labor's growing unrest over post-WWI union busting (such as the 1919 Steel Strike), red scares (climaxing with the Palmer Raids), U.S. isolationism (seen in the United States's refusal to join the League of Nations and restrictive immigration legislation), and Depression Era unemployment, eventually resulted in the federal government taking a more active role in establishing and regulating domestic labor policy. The 1932 Norris-LaGuardia Act (also knows as the Anti-Injunction Bill) banned federal courts from issuing injunctions in non-violent labor disputes and recognized that employees are free to unionize without employer interference, including outlawing "yellow-dog contracts" in which workers would agree not to join unions as a condition of their employment. However, as unemployment rates reached 25\% in 1933 and labor unrest grew among both employed and unemployed workers, the U.S. passed the National Industrial Recovery Act (NIRA) in that year. The NIRA was envisioned as a comprehensive labor bill that expanded Norris-LaGuardia rights by promoting competition, encouraging fair trade, and fostering union organizing and democratic workplaces. However, the NIRA included only weak provisions for enforcing the wide-reaching regulations it enacted. Extensive backlash to the NIRA among the business community led to lawsuits in which the U.S. Supreme Court eventually found sections of the law unconstitutional.

Instead of nullifying federal labor law, rulings against the NIRA arguably led to subsequent legislation with stronger enforcement of labor protections. In reaction to the 
ineffective NIRA, stagnant economic disparity, and successful union organizing drives, mass actions ignited across the United States. In 1934, waged workers, the unemployed, families, and children took to the streets and to the picket lines in one of the most tumultuous years in U.S. labor history. In 1934, general strikes broke out in Minnesota and San Francisco, Washington State longshoreman went on strike, 400,000 textile workers walked out on the job (at the time the largest U.S. labor strike in history), and numerous other labor uprisings took place around the country. Faced with widespread labor and social unrest, in the following year, Congress enacted the National Labor Relations Act (the NLRA or "Wagner Act"). Section 1 of the NLRA clearly articulates one of the Act's primary objectives: to establish and maintain industrial/labor peace:

Experience has proved that protection by law of the right of employees to organize and bargain collectively safeguards commerce from injury, impairment, or interruption, and promotes the flow of commerce by removing certain recognized sources of industrial strife and unrest, by encouraging practices fundamental to the friendly adjustment of industrial disputes arising out of differences as to wages, hours, or other working conditions, and by restoring equality of bargaining power between employers and employees. (United States National Labor Relations Board, “National Labor Relations Act”)

Eighty years later, the NLRA continues to be the foundational statue of U.S. labor law. The Act guarantees basic private sector labor rights including the right to organize a union, engage in collective bargaining, and the right to strike. Section 7 of the NLRA 
outlines employees' rights to union activities, and while the wording is lifted almost verbatim from Section 7 of the NIRA, the NLRA sets out increased enforcement mechanisms, including the establishment of the National Labor Relations Board (NLRB), an agency with an investigative and adjudicative mandate. Additionally, three years later, Congress passed the 1938 Fair Labor Standards Act (FLSA), which increased federal labor protections by legislating a 40-hour work week, establishing a national minimum wage, codifying the right to overtime, and regulating child labor.

While the NLRA can be understood as a sort of truce between capital and laborone which was not supported by all members on either side-subsequent legislation severely limited the bill's scope and skewed U.S. labor law toward in service of capital. In 1947, the Taft-Hartley Act amended the NLRA to significantly restrict the activity and power of labor unions. The Act prohibited jurisdictional strikes (colloquially known as sympathy strikes), outlawed secondary boycotts, restricted picketing activities, outlawed closed shops (giving states the power to pass so-called right-to-work laws), required strike notification and mediation periods, contained specific anti-communist language, expanded strike injunctions, and contained other anti-union provisions. As a result of these amendments, as Michael Yates claims in Why Unions Matter, "[T]here is no doubt that our labor laws favor the employer in both union organizing campaigns and collective bargaining” (193).

Contemporary labor organizations continue to grapple with the benefits and drawbacks of federal labor law. On one hand, U.S. labor laws standardize wages, working conditions, and maximum hours, protect concerted action, and provide other safeguards for workers. On the other hand, the NLRA, particularly after the Taft-Hartley 
amendments, severely limits many effective union organizing and negotiating tactics. According to Dan Clawson in The Next Upsurge: Labor and the New Social Movements, "[T]he general principle, for the Taft-Hartley Act in particular and for labor law in general, is that any tactic that gives workers power is illegal" (34). Many examples of direct action that Against the Day details, including not only sabotage or violence, but also types of strikes and pickets (such wildcat, sitdown, or midcontract strikes; grounds for strikes; the duration, location, and even the very messages workers may print on picket signs) are limited and regulated under the NLRA.

Emmanuel Ness contends that "by embracing collective bargaining through the National Labor Relations Act (NLRA) of 1935 and the Democratic Party, organized labor deprived workers of their capacity to contest capitalist and state power.... Rather than advancing the interests of workers, the NLRA accords circumscribed workers' aspirations for democratic syndicalist and autonomist unions" (New Forms of Worker Organization 258). Ness details how WWI nativism and particular period legislation, such as the Espionage Act of 1917 and Sedition Act of 1918, set the stage for the NLRA and anti-communist witch hunt that impeded radical labor and class movements: "In retrospect there was no turning back from working-class struggle once labor law was concretized by capital, the state, and trade unions in the 1930s. The NLRA reforms constrained militancy and created a sense of hopelessness among workers who achieved a voice through direct action on the shop floor" (New Forms of Worker Organization 26566).

Understood in this way, Ness frames the NLRA is a sort of permanent suspension of activism in order to keep labor peace. Specifically, labor law restricts the multitude's 
ability to engage in direct action, general strikes, effective messaging, and other tactics agreed upon by the democratic majority in a workplace(s). If the struggle between capital and labor is a perpetual war, it is one that persists in a state of exception, where certain rights of labor are indefinitely suspended by the nation-state in order to guarantee the smooth, assured function of capital. This mechanism of control works, as Sassen recognizes, by regulating unions in placebased sites of capitalist production, as well as, in Hardt and Negri's terms, the nation-state's monopoly over legitimate violence:

[T] he state not only has an overwhelming material advantage over all other social forces in its capacity for violence, it also is the only social actor whose exercise of violence is legal and legitimate. All other social violence is illegitimate a priori, or at least highly delimited and constrained as is, for example, the kind of legitimate violence involved in a labor union's right to strike, if indeed one considers the strike an act of violence at all. (Multitude 25)

Ness counters NLRA-regulated unionism with a vision reminiscent of Pynchon's global anarchism: "While the relevancy of IWW tactics to the conditions of the early twenty-first century are indisputable-direct action, mass industrial action, general strikes, and eventual workers' control over production-radical workers ensnared in traditional unions will fail at this effort as they defy the reality of the legal institutional framework established through the NLRA" (New Forms of Worker Organization 278). Like Hardt and Negri, who contend "it is not even possible for the traditional unions to represent adequately the complex multiplicity of class subjects and experiences" (Commonwealth 
110), Ness supports a movement "of autonomous workers in solidarity, outside of the traditional trade unions" (New Forms of Worker Organization 278). Clearly, labor law that was written to keep industrial/labor peace in the beginning of the $20^{\text {th }}$ century must be scrutinized and amended to address a contemporary neoliberal global economy facing increased immaterial production, contingent labor, and transnational production.

However, while there is merit to Ness's critique of bureaucratic unionism and U.S. labor law, critics leave me unconvinced that new forms of worker solidarity require the total abandonment of traditional unions. Contemporary unions grapple with a legacy of U.S. labor law that severely limits and regulates their actions; yet, organized labor remain one of the few social, political, and economic forces fighting for worker safety, equitable distribution of wealth, and the right to a collective, democratic voice in the workplace and beyond. Therefore, rather than dismiss the contemporary relevance of unions, I believe that we can more productively create strategic coalitions that unite traditional unions with workers' centers, community groups, and other movements committed to social and economic justice. Such alliances bring together traditional unions-many of which offer established membership, political power, and relative financial stability-with alternative worker organizations that do not fall within the NLRA's regulatory purview-such as community groups, workers centers, advocacy groups, and other movements.

\section{Building a Multitude through Labor Coalitions and Strategic Alliances}

Traditional labor unions must change, not only in order to survive, but also to support an inclusive labor movement that represents diverse peoples engaged in multiple types of material and immaterial labor. Throughout David Bacon's work, including 
Illegal People: How Globalization Creates Migration and Criminalizes Immigrants; Children of NAFTA: Labor Wars on the U.S./Mexico Border; and The Right to Stay Home: How US Policy Drives Mexican Migration, he pays close attention to the interplay between traditional unions and the contemporary alternative worker organizations that develop with accelerated free trade and global migration. Bacon recognizes that we cannot dismiss the importance of labor unions or community groups; instead, we must recognize the reciprocal ways that traditional unions can support alternative worker organizations and marginalized laborers (such as those engaged in contingent labor or undocumented immigrants), as well as how traditional unions can benefit from the tactics and ideas of alternative worker organizations.

Bacon acknowledges the history that Ness details, explaining:

[From] World War II through the 1980s most U.S. unions clung to an official ideology of partnership with large corporations and the government. They supported U.S. foreign and trade policy abroad, ignoring its disastrous impact on workers in developing counties. At its worst moments, labor's cold warriors, allied with U.S. intelligence agents, helped destroy militant labor movements, often at a terrible cost in lives and living standards (Illegal People 130).

However, Bacon also recognizes that reform movements and radical factions within and outside of the established labor movement have altered this historical trajectory: “[Immigrant workers'] militant strikes often forced unions to discard old, ineffectual tactics, even to reexamine how they functioned internally" (Illegal People 132). 
Specifically, as free trade policies catalyzed privatization, destroyed traditional agricultural practices, resulted in inflation, and caused other global trends that drove people in developing countries from their homelands in order to find work, immigrants to the US “coming from Mexico, Latin America, the Philippines, and Asia often brought militant traditions and a rich repertoire of ideas for fighting employers" (Illegal People 132). Displaced by transnational free trade, global workers brought with them methods for overturning these capitalist trends: "Documented and undocumented workers participated in this labor upsurge regardless of their legal statues or lack of it. That simply reflected the situation in their families and communities, where people with and without papers all mixed together. As a result of these battles many labor organizers began to see this upsurge as a way to rebuild their unions," Bacon explains (Illegal People 134).

Established unions must visibly support-and foster-organizing drives that call for social justice and economic equality in industries whose workers may have tenuous legal status or limited economic resources. For example, the United Steelworkers have supported efforts to achieve better pay, working conditions, safety, and enforcement of other minimum employment standards in low-wage jobs which employ predominately undocumented workers, such as the car wash industry. According to Ryan Spillers, an attorney involved in the campaign to organize carwasheros in Los Angeles:

The Community-Labor-Environmental Action Network (CLEAN) Carwash campaign is a joint effort of the United Steelworkers International Union, the AFL-CIO, and a diverse coalition of community, faith, legal advocacy, environmental, and labor organizations to improve 
working conditions in the Los Angeles carwash industry through unionization and collective bargaining. The industry has long been marked by unscrupulous employers that profit by exploiting a predominantly immigrant workforce and flouting the minimums wage and hour standards, health and safety regulations, and environmental protections.

Because unionized workers represent a relatively privileged sector of the global workforce, it is vital that established unions use their resources to help more marginalized workers. In the CLEAN Carwash campaign, support not only occurs at the USW's institutional level, but also at the rank-and-file level as local members mobilize to join car wash workers' picketlines and raise community awareness about working conditions, wage theft, and other labor violations in the industry. In turn, this develops a reciprocal relationship and positive feedback loop about unions and their role in fighting for justice even in non-unionized workplaces. In 2015, when USW oil refinery workers initiated the largest oil sector strike in over thirty years, car wash workers joined rallies and walked the picket lines beside their brothers and sisters.

Additionally, Bacon explains that immigrant workers' contribution to the U.S. labor movement goes much deeper than individuals joining pickets or participating in actions. In order to support low-wage and undocumented workers, "Unions were forced to look for tactics to pressure employers to rehire fired workers, remain neutral during organizing drives, and sign union contracts without depending on the NLRB process. Today these strategies have become the bread and butter of most organizing drives" 
(Illegal People 134-4). The NLRA, FLSA, and other legislation provide legal structures for guaranteeing fundamental labor rights; however, Bacon points out limitations to the scope of these protections, which are not extended in the same measure to agricultural laborers, undocumented workers, or immigrants on certain visas. On one hand, Section(2)(5) of the NLRA, protects many workers' right to form unions and engage in collective action. On the other hand, the Act regulates and limits the actions that a labor organization can take during organizing, negotiations, and disputes. For instance, although most people might assume that the First Amendment of the U.S. Constitution protects the freedom of speech without limiting the message of handbills, picket signs, and peaceful rallies, in fact, Sections $8(b)(4)$ and $8(b)(7)$ of the NLRA limit the type, duration, and message of information disseminated during pickets, organizing, and other situations. $^{32}$

Accordingly, the NLRA is a double edge sword; it can provide protections for the workers it includes, but it allows greater freedom in organizing and messaging for those marginalized groups it excludes. Alliances between labor organizations (as defined within the scope of the Act) and those that are outside the NLRA's reach may better mobilize the advantages of both groups while diminishing the drawbacks.

David S. Birnbaum, Jennifer Hunter, Peter Sung Ohr, and Julie R, Ulmet point out that whether a "group is deemed to be a 'labor organization' is critical to determining its rights and obligations under the [NLRA]" (8). They explain, "Moreover as the definition of a 'labor organization' evolves, some worker centers and other similar groups operating outside of the context of a traditional collective bargaining relationship may adjust the scope of their activities and mission based on whether or not the organization wishes to 
be treated as a 'labor organization' for the purposes of the Act" (8). Section 2(5) of the National Labor Relations Act specifically includes within the definition of "labor organization":

[A]ny organization of any kind, or any agency or employee representation committee or plan, in which employees participate and which exists for the purpose, in whole or in part, of dealing with employers concerning grievances, labor disputes, wages, rates of pay, hours of employment, or conditions of work. (United States National Labor Relations Board)

While at first glance, this seems to be a broad, inclusive definition of what constitutes a labor organization, case law-much of which is from the last twenty years-sets a precedent for the particular qualifications that must be met to qualify as a "labor organization" under the Act. ${ }^{33}$ In greatly simplified terms, if a group serves as an advocate for workers' causes but does not engage in collective bargaining, characterize itself as the designated representative of a group of workers, or engage in a reoccurring pattern of attempting to deal with employers over time, the organization is not a "labor organization" because it does not "deal with employers" even if it engages in hand billing, picketing, mass demonstrations, and other actions. This vital distinction delineates which organizations are subject to the restrictions set out in the NLRA, and which groups are considered alternative worker organizations, which may support a social cause and even advocate for workers, but do not fall within the scope of Section 2(5) of the NLRA. Accordingly, alternative worker organizations can engage in certain types of strikes, have a much freer hand in determining what appears on hand bills, and 
have greater freedom in determining the duration of picketing, engaging in non-violent civil disobedience and participating in other mass actions that would be highly regulated or even prohibited if the organization were a traditional labor union. Mobilizing the direct action potential available to alternative worker organizations, unions often support their campaigns, and alternative worker organizations frequently show solidarity with traditional unions.

As traditional labor organizations have struggled to unionize low-wage industries, undocumented workers, and contingent laborers, alternative worker organizations such as community centers, interfaith coalitions, and social advocacy groups have had significant success. ${ }^{34}$ Bacon notes that traditional unions can learn from the tactics implemented by alternative worker organizations: "Often shared immigration culture acts as a powerful tool to help workers articulate their needs and build an organization from the grassroots. U.S. labor unions have started to pay heed, as they look for ways to unite a workforce that is more diverse and less secure than ever before" (Illegal People 129). To more fully represent diverse peoples, working together in coalitions, "growing numbers of unions, along with alternative worker organization, and allies in the faith and social justice community (examples: Jobs with Justice) have increasingly engaged in mass action tactics in labor and related disputes" (Clifton and Healey 1). For instance, United Food and Commercial Workers (UFCW) has supported the Organization United for Respect at Walmart (OUR Walmart) workers' movement. As Birnbaum, Hunter, Ohr, and Ulmet point out, "The highly publicized and ongoing dispute between Wal-Mart Stores, Inc. ('Wal-Mart') and OUR Walmart highlights the impact that a worker center can exert on an employer, even in the absence of a collective bargaining agreement" (12). This dispute 
also exposes the complications in defining a "labor organization" and forming coalitions between organized labor and alternative worker organizations. OUR Walmart has organized sit-down strikes, occupied stores, encouraged employee walk-outs, and engaged in other actions that would be illegal for a labor union to undertake under NLRA regulations. Therefore, in order for OUR Walmart to continue these actions, it was essential that the National Labor Relations Board recognize Our Walmart's status as a worker center, not a labor organization in its own right. ${ }^{35}$ Although unions and alternative worker organizations support OUR Walmart, including Jobs with Justice, Occupy chapters, Teamsters, SEIU, IATSE Locals, Interfaith Committee for Worker Justice, and others, the NLRB eventually found that OUR Walmart was not a labor organization, and, thus, not constrained by NLRA regulations.

Perhaps the group that is most marginalized by U.S. labor law are migrant farmworkers, many of whom come to this country without documentation and engage in an industry that is not regulated by the same NLRA and FLSA protections as other occupations. As Chapter 3 of this dissertation discussed, Under the Feet of Jesus illustrates the material impacts that substandard health and safety policies, permissive child labor, reduced wage regulations, ineffective educational programs, cultural prejudice, and political marginalization have on many farmworkers. Farmworkers' exclusion from basic labor protections under the FLSA and their omission from the protected concerted action provisions of the NLRA, leaves farmworkers outside the occupational and organizing safeguards that benefit other sectors. However, farmworkers have mobilized in innovative ways that are not available to NLRA-regulated labor organizations. For instance, as an alternative worker organization, Coalition of 
Immokalee Workers builds campaigns around secondary boycotts, which Taft-Hartley amendments to the NLRA prohibit for unions. In contrast to primary boycotts which boycott the supplier of a particular product, secondary boycotts call for pickets and boycotts by resellers or distributors of the product, such as grocery stores or restaurants, which may purchase or resell goods from the primary supplier. For example, in their campaigns to gain fair contracts with particular tomato growers in Florida, CIW organizes national secondary boycotts against the restaurants and grocery stores that offer the grower's produce. CIW also organizes campaigns around particular restaurants, such as Taco Bell, Wendy's, Chipotle, and McDonalds, as well as grocery stores like Trader Joes, Whole Foods, and Publix, in order to pressure them into buying from growers that have signed on to CIW's Fair Food Contact. ${ }^{36}$ In order for these national boycotts to be successful, CIW mobilizes direct action tactics unavailable to traditional unions, and depends upon a network of strategic alliances with other alternative worker organizations, faith organizations, and traditional labor unions to support the campaign. While forming coalitions with diverse religions, labor, and social groups, CIW retains its autonomy and defines itself as a democratic organization where "We Are All Leaders," in contrast to Cesar's UFW and other bureaucratic unions (CIW, “About CIW: Consciousness + Commitment $=$ Change"). In a discussion of CIW's first major victory, against fast-food giant Taco Bell, Elly Leary argued that CIW "could successful[ly] cast itself as made up of poor immigrant workers struggling for a just future, without the complicating issues of being associated with 'special interests' or 'big labor"” (20). Leary continues, "[O]nly a worker center could have pulled off this boycott and created space for organizing inside a major piece of the new capitalist economy" (20). 
This "major piece of the new capitalist economy" notably exists in the rural fields far outside of Sassan's global city or Hardt and Negri's metropolis. Organizations like CIW remind us that building connections between geographical spaces-between urban, suburban, agricultural communities, rural areas, and other places-is vital for a successful, inclusive movement. While Hardt and Negri claim that traditional unions cannot adequately represent the "multiplicity of class subjects and experiences," they pay little attention to the ways in which some unions have evolved over the last few decades, altering their structures, promoting inclusivity, and, importantly, participating in coalitions with alternative worker organizations. Although there are blind spots in Hardt and Negri's discourse and vision, the reality of an inclusive, multifaceted, autonomousand-interlinked movement, like labor union and workers' center alliances, seems to be just what the theorists are advocating: "[F]ields of struggle are, at least potentially, newly aligned, not in the sense that they are unified or that one holds hegemony over others, but in that they autonomously march forward in parallel paths" (Commonwealth 107-8). What is a coalition if not a "multiplicity of social singularities defined more or less by their culture or ethnicity or labor position [that] coordinate their struggles together in the multitude"? (Commonwealth 111).

Alliances between organized labor and alternative worker organizations, such as worker centers, religious coalitions, and social advocacy groups, illustrate the ways in which concerted action can occur outside traditional union structures. These types of alliances not only provide place-based connections but also establish a structure that can be reproduced internationally. Such transnational solidarity may form a critical mass for changing labor law, influencing the behavior of capital, and forming a democratic, 
egalitarian movement.

\section{Labor Organizing as a Global Social Movement}

Hardt and Negri explain that "traditional models of contestation and rebellion have to be changed and are being changed in the current situation-how, for example, trade unions in the context of biopolitical production have to develop new strategies to include the poor and those with precarious employment; how social movements have to construct networks across national boundaries; and so forth" (Commonwealth 235-36). Setting aside Hardt and Negri's somewhat wavering positions on unions through their theoretical trilogy (and particularly the inconsistency found in Commonwealth), they nonetheless voice critical elements to consider in constructing an effective global labor movement. Unions have adopted coalition building as one strategy for supporting precarious, low-wage, undocumented and other workers that have been historically under-represented in the labor movement; however, this cannot be a nationalistic endeavor. Recognizing “[g]lobal unions are the future," in Global Unions: Challenging Transnational Capital through Cross-Border Campaigns, Kate Bronfenbrenner asserts that "cross-border strategies can be found wherever there are workers, unions, and large foreign-owned transnational companies, which today includes nearly every country in the world" $(225,213)$.

Global capital/labor conflicts often mark the stratified sites of structural contradictions, where the farm fields from agrarian capitalism and the mines, mills, and factories that fueled industrial capitalism are reorganized by the principles of transnational neoliberalism. Parallel to the vision of amplifying global rebellion in Almanac of the Dead, we see similar trends emerging across diverse locations and varied 
industries. One million workers in South Africa went on strike in 2007, shutting down public services throughout the country. In 2008, laid-off laborers at Republic Windows and Doors in Chicago took control of their factory. In Hong Kong, five hundred dockworkers brought one of the busiest ports in the world to a halt in 2013. After widespread mine pollution displaced families in 2015, two thousand striking miners, farmers, and community members took control of the water transfer station at Grupo México’s Buenavista copper mine in Cananea, Mexico. Of particular relevance to Almanac of the Dead's tribal histories, indigenous peoples in Peru have waged an ongoing battle against Grupo México’s Tía María mining project, forcing the world's third biggest copper producer to intermittently halt the project throughout 2015. Currently, farmworker strikes led by indigenous workers along the Pacific coast stretch from Washington State to Baja California, interrupting commodity flows from the region. Recognizing that labor resistance rages at transnational nodes of neoliberal networks, the organizational challenge is to mobilize this placebased resistance into a global social movement. As Almanac's Five Hundred Year Map illustrates, this process depends upon subverting capitalist channels in cross-border labor campaigns while preserving placedbased cultural knowledge and local resistance. Additionally, educating workers about their rights and the informing the public about labor struggles supports social solidarity. As we look at these strategies, certain commonalities emerge. First, support must strengthen local labor struggles. International events are interconnected but also atomized; each labor action must be supported on its own grounds with consideration for the cultural-historical context of that particular struggle. Second, support must raise international awareness. Connecting workers through cross-border trainings, international 
meetings, and worker conferences may help illuminate common struggles and raise international awareness of shared problems. Many of the issues such as safety, accountability, wage theft, inhumane working conditions, and police retaliation are not unique to particular labor disputes, but rather conditions by which organizing along commodity chains or among sector facilities may occur. Third, while supporting local struggle, we must build international structural solutions. Strikes might respond to an array of events, but building a movement around these occurrences requires a lasting structural solution. Organizations such as IndustriALL, Workers Uniting, and strategic alliances among labor groups, workers' centers, and community-based organizations can serve to connect these events and bring people together. Recognizing and embracing the unique forms these movements can take requires insight into the historical and cultural contexts in which workers are motivated to action. Finally, we must look for ways to regulate and reform capital. While international law can help enforce international labor standards, direct and indirect consumer pressure on purchasers of these goods can help bolster labor standards. Certification programs for factories, and corresponding pressure on international companies to only purchase certified goods, could speed reform. Bottom line: Each and every global consumer has a part in this movement.

International gatherings highlight current cross-border work and provide opportunities to form new alliances. In 2014, the Institute for Transnational Social Change (ITSC) along with UCLA Labor Center and the Rosa Luxemburg Stiftung hosted the Labor Solidarity Across Borders Conference in which "representatives from progressive unions and labor groups in key sectors of the North American economy-from autoparts to energy, from green industries to mining and steel, and from agriculture to 
cross-border organizing" came together to discuss the "challenges of organizing in different sectors and regions, with the goal to draw out common lessons and plan future collaborations and solidarity actions among unions in the United States, Canada, and Mexico" (Rosa Luxemburg Stiftung). At the conference, Robert LaVenture, Manny Armenta and I joined Los Mineros leadership to discuss the newly established United Steelworkers/Los Mineros cross-border training program. Beginning in 2014, we developed a transnational education program to strengthened alliances between the organizations and help construct a comprehensive plan for combatting Grupo México’s assault on workers both sides of the border. The program focuses on taking a institutional strategic alliance between the unions and putting it into action by including rank-and-file members in the process of grassroots mobilization: "'Our unions have held an alliance on paper for quite a while,' said [USW] District 12 Director, Robert LaVenture. 'We took this opportunity to bring like-minded workers together to discuss like-minded ideas as we face a common employer, Grupo México.” (USW “Workers from Two Countries”). Through our trainings, men and women who work in the mines, smelters, and mills, are able to discuss health and safety concerns, national labor laws, organizing strategies, uneven distributions of wealth, shared labor history in the border region (much like Silko illustrates), and other topics. "“The future for this joint program continues to build not only solidarity but also potential solutions to our issues,' said District 12 Director Bob LaVenture” (USW “Cross Border Training Continues).

Paralleling LaVenture's sentiment, Bronfenbrenner recognizes that "[e]xtensive workplace education about the issues and worker-to-worker exchanges between plants and countries" can be "essential to build the links and find the common ground to 
develop the kind of solidarity" necessary for cross-border campaigns (218). However, membership education is not the only important component of this campaign. As CIW recognizes, the public, and particularly consumers, must also learn about the vital role they play in altering labor conditions:

Unfortunately, the wealth and wellbeing created by workers-from Immokalee to Bangladesh-is not shared as equitably as it might be, and workers around the globe are organizing to demand a fairer share. In good news for workers this Labor Day, consumers are beginning to step up and do their part to demand a fairer economy, and never have consumers commanded more power than they do today. (CIW "Labor Day Reflection")

For producers and consumer to form an international movement toward an equitable distribution of wealth, fair working conditions, and labor dignity, they must share in the learning process.

Literature provides one tool for transmitting labor topics to diverse audiences. As Guillermo Perez, member of the Labor Council for Latin American Advancement national executive board, explains:

If the conventional labor movement, and by this I mean those of us who work to empower workers through a legally recognized collective bargaining process-if this movement is to have a future it must embrace the struggles of marginalized workers in this global economy. To be 
effective that embrace must include reading and finding inspiration in the stories of these workers. Those stories will eventually form the larger narrative of how workers around the world came together to secure our collective voice in the social and economic decisions that govern our lives (Perez).

Together Almanac of the Dead, Under the Feet of Jesus, Against the Day, and Lucas's testimony Forged under the Sun / Forjada bajo el sol contribute to a larger narrative of worker struggle and empowerment. Along with labor unions, workers centers, and community-based organizations, professional authors and worker-writers' play a vital role in educating producers and consumers. Through texts that illustrate an inclusive labor movement, amplify workers' voices, share counter-narratives of labor empowerment, and present a vision of global worker alliances, the voices of global labor may inform the theory and practice of emerging social movements. 


\section{Chapter V Endnotes}

1. Hardt and Negri, Empire 413.

2. The latter level of inquiry, on federal juridical rulings, may seem nationalistic and incongruous with the prior sites of observation. However, I increasingly realized the impact that U.S. labor law, immigration policy, and other regulation have not only on domestic workers and organizations, but also, by extension, transnational populations and structures. While capital may function globally, labor regulations and protections are primarily nation-bound, with less enforceable international law and weak provisions included in transnational trade agreements. As K. Anthony Appiah explains, "The whole framework of international commercial law depends on the courts of national systems and on systems of arbitration, both national and international, that exist at the will of states and require national system for the execution of their decisions" (xiii). For example, addressing a particular type of worker, NAFTA's chapters on "financial services, telecommunications, and 'business persons,' contained considerable detail on the various aspects related to people operating in a country that is not their country of citizenship" (Sassen 15). However, as NATFTA catalyzed falling wages, inflation, privation, and other woes in Mexico, it served an unintentional impetus for migration to the U.S. as "over 8 million Mexicans came to the United States, and since relatively few visa were available for legal immigration over half came without them" (Bacon, The Right to Say Home 149). In this instance international trade agreements have created immigration issues that are dealt with in a primarily national legal context.

3. For more of IWW see Chapter 4 footnote 12. 
4. For more on assemblage theory see Chapter 3 footnote 4.

5. For more on the lumpenproletariat and an inclusive definition of labor see Chapter 2.

6. In addition to the biases mentioned, factors such as the language of production (for instance, English as the dominant language of the internet), access to technology (like the availability of cell, computer, and internet in rural and impoverished areas), and numerous other factors are not adequately accounted for in Hardt and Negri's utopic model of the common.

7. For more on how this pattern applies to U.S. migrant agricultural workers see Chapter 3.

8. Viramontes 148 .

9. Rose-Redwood is drawing on Foucault in this quote. Specifically, as Foucault details in Discipline and Punish, disciplinary methods of governmentality lead to the individual being constituted by "documentary techniques, [that] makes each individual a "case"” (191).

10. Referencing farmworkers in Immokalee, Florida, Giagnoni states that "it is upon places like Immokalee and the people who live and work there that the U.S. (and global) economy relies: places where human rights are routinely violated; places that remain invisible. Until we as a society realize and act upon this simple truth, there won't be real change" (3). 
11. In California and the Dust Bowl Migration, Walter J. Stein explains that the Okie migration started as a trickle in the early 1930's, then "swelled to a flood in 1935; but not until 1938 was the state seized with migrant hysteria" (x).

12. Daniel elaborates that not only did the entry of "Dust Bowl migrants into the farm-labor force not only created new racial barriers to solidarity, but also greatly aggravated the special organizational problems resulting from the surplus labor market condition" (Bitter Harvest 272).

13. The program undercut wages by paying Braceros $\$ 0.30$ when the national minimum wage was $\$ 0.45$, and the government-regulated Bracero program made in functionally impossibly to organize farmworkers.

14. For a comparison of historical conditions faced by Braceros and the U.S.'s current H2A visa program see, Farm Worker Ministries report "No Way to Treat A Guest: Why the H2A Visa Program Fails U.S. and Foreign Workers."

15. To these ends, Viramontes's and Lucas's works draw on a rich, and generally under recognized, history of migrant farmworkers in the United States. The history of migrant farm labor in the U.S. varies depending upon the geographical location, and, as a result, different organizing groups have developed to meet the specific needs of farmworkers in different locales. Viramontes's novel, set in California, alludes to the organizing done in the region by the United Farm Workers (UFW), while Lucas's text reflects on her experiences with Farm Labor Organizing Committee in the Midwest (FLOC). Today, Coalition of Immokalee Workers (CIW) also serves as an important grassroots community labor organization empowering farmworker families in Florida. 
Most histories of migrant farmworkers focus on California, and with good reason. Since the 1850 s the state has been a major producer of tender fruits and vegetables, many of which are easily damaged by farm machinery and, therefore, harvested by hand. While numerous ethnic groups have simultaneously participated in farm work, the ethnic majority employed in agricultural labor in California has shifted over time, and organizing efforts in the region reflect this change.

After its statehood in 1850, an influx of Chinese immigrant worked the California fields until the Chinese Exclusion Act of 1882. An increased number of Japanese immigrants were employed as farmworkers from 1880-1910. However, by the 1920s Mexican \& Pilipino workers outnumbered other ethnic groups, with workers of Mexican heritage accounting for nearly three-quarters of California's 200,000 farm laborers. The organizing efforts in the California agricultural sector reflect the historical diversity of the workers. For instance, an early farmworker strike in 1903 in Ventura, CA, earned limited local Japanese and Mexican workers the right to negotiate with their growers. From 1909-1915 scattered Industrial Workers of the World (IWW) unions emerged to represent farmworkers, as there was very little AFL interest in organizing the sector. In 1928, the Mexican Mutual Aid Society pushed for harvest contracts that eliminated a practice in which $25 \%$ of pay was withheld from workers as an end-of-season "bonus." However, as these select examples illustrate, "With few exceptions, the challenge that farmworkers mounted against the authority of agricultural employers before 1930 were unorganized, spontaneous reactions to abnormally poor wages or conditions by small groups of workers employed on a single 'ranch' or in a single locality," (Daniel 72). 
A revitalized farmworker movement did not take root until the 1960 s, led by Cesar Chavez and Delores Huerta, both of whom had worked as migrant farmworkers during the Great Depression. The United Farm Workers (UFW) emerged as a non-violent movement for economic and social empowerment of farm laborers. The Delano Grape Strike, which impacting over 10,000 farm workers and spanned the nation. Today, UFW has evolved pursue prominently political avenues for change.

In 1967, Baldemar Velasquez founded the Farm Labor Organizing Committee, or FLOC. FLOC was both a social movement and labor movement for farm workers. Campaigns were focused in midwestern United States. The 1978 Campbells Soup boycott lasted 8 years and gained national attention. FLOC has continued to work on-the-ground for dignity, justice, and a voice for migrant farm workers in all aspects of their lives.

The Coalition of Immokalee Workers was founded in 1993, adopting the slogan "Nothing is Impossible." A community-based farmworker organization of mostly Mexican, Mayan Indian, and Haitian workers, CIW negotiated for a minimum living wage, and adopted the Fair Food Campaign, an Anti-Slavery campaign, and efforts to improve working and living conditions. Its "One Penny More" more agreement with included restaurants such as Taco Bell, McDonalds, Burger King, Subway, and Whole Foods.

16. Pynchon, Against the Day 976.

17. It is no coincidence that in a novel preoccupied with doubles, twins, and parallels, Webb Traverse dies as a labor martyr, a homo sacer who is the mirror image of Scarsdale Vibe, an Agambenian "sovereign” ruler. 
18. While Hardt and Negri are critical of Empire, and specifically the ways in which it reproduces capitalist power structures based on exploitation, they do not see Empire's formation in purely negative terms. Instead, they insist "on asserting that the construction of Empire is a step forward" (Empire 43). They elaborate that "today we can see that Empire does away with the cruel regimes of modern power and also increases the potential for liberation" (Empire 44).

19. Deleuze and Guattari define "lines of flight" as "decoding of flows and the deterritorialization of the socius" (Anti-Oedipus 34).

20. In this context, modernism (a multi-defined concept) refers to a period of time associated at its beginning with industrial and capitalist revolutions in Europe during the 1800s and lasting through approximately the mid-1900s, ending, at the latest, during the social and technological revolutions of the 1980s.

21. Within this space, Ortega y Gasset articulated a new version of the theory of perspectivism in 1910 which "insisted that 'there were as many spaces in reality as there were perspectives on it,' and 'there are as many realities as points of view'” (Postmodernity 268).

22. Almanac critic Laura Shackelford's assumption that Silko places Tucson at the center of the Five Hundred Year Map suggest the extent to which scholars familiar with Western cartography project these expectations on to alternate forms of mapping technologies (Shackelford par. 19).

23. Almanac suggests the divergences between the Western and particular Native American conceptions of scale as "Alegría convinced Iliana that to have a house which 
was so 'out of scale' would be a crime against good taste. The discussions of 'scale' had not meant much to Menardo" (281).

24. While the scholars cited in this section generalize Native American cartography into a singular entity, it is important to point out that "Native American" is a singular phrase that denotes a multiplicity of different Native cultures within the Americas. Certainly the cartographic principles that these scholars cite were/are not present within all Native American cultures.

25. This practice is portrayed not only by Silko, but also by Pynchon on maps in Against the Day: "Instead of place-names there were hundreds of what looked like short messages. Everything reproduced in just one color, violet, but cross-hatched differently for different areas. Small pictures, almost newspaper-cartoon drawings, of intricate situations Cyprian felt it was important to understand but couldn't. There were no landmarks or roads he knew, either” (Pynchon 936). To fully read the map, it is necessary for Cyprian not only to view the projection, but more importantly to recognize the pictures, massages, and narratives it communicates.

26. Almanac suggest the very nature of that time may prove inconsistent, as Calabasas "did not think time was absolute or universal; rather each location, each place, was a living organism with time running inside it like blood, time that was unique to that place alone" (629).

27. Raymond B. Craib elaborates that "indigenous representations were humanistic, portraying the social and human composition of space and stressing the importance of social relationships and their endurance over time" (25). He continues to 
explain that some Native mapmakers fused "the temporal and spatial worlds" (Craib 25). These practices of Native mapping can be seen in Silko's projection of five hundred years of history-in which "[s]ixty million Native Americans died between 1500 and 1600. The defiance and resistance to things European continue unabated"-onto the physical space and place of the area currently identified as the US/Mexican borderland (Five Hundred Year Map). For example, as Silko illustrates, groups of Native people become bound by not only colonial territorial borders, but eventually into increasingly smaller reservation boundaries (such as the Laguna Pueblo Reservation on the Five Hundred Year Map). However, Harley asserts that "in some Indian cultures, maps were part of the intellectual apparatus by which the imposition of colonial rule was resisted" (247). Johnson maintains an "emphasis on local, Indigenous knowledges embedded in literature [exists] as a means of asserting, maintaining, and advocating political and cultural sovereignty. Native-made and Native-informed mapping practices constitute a turn toward Indigenous knowledges and practices that dominant literary theories and the mechanisms of globalization have sought to erase and dismantle" (116).

28. Historical documentation provides evidence that transnational flows of indigenous Yaqui and their Toltec ancestors, who brought with them their culture, ideas, and religions, were well-established and maintained both before and after geopolitical boundaries were institutionalized to 'divide' the US and Mexico. In her personal narrative, a Yaqui woman, Domingo Teva explains that in the early 1900s, "Yaquis in Sonora were being deported, killed, imprisoned, and persecuted" (Holden Kelley 89). The extermination and deportation policies were justified by the Mexican state as "the 
harshest punishment" to break Yaqui rebellion and guerrilla attacks which hindered 'development' of Yaqui lands (Hu-DeHart 182). Primarily between 1880s to 1910, the 'reign of terror' implemented by Mexican leaders Torres and Izabal sent some Yaquis fleeing to safety in the United States, to escape the "policy of killing some of the Yaquis and deporting others (a policy aimed at the complete destruction of Yaqui culture but did not last long enough to achieve it)" (Choate 8). Often Yaquis who attempted to escape the almost-inevitable future of deportation or murder that they faced in Yaqui Mexico, escaped to the United States by trekking through mountain and desert terrain in order to cross the border. Yet once they reached the United States, many Yaquis refused to neglect the struggles of their homeland, and often members would return to Mexico to support Yaqui resistance efforts.

Once in the United States, the disadvantaged group of Yaquis - the greatest populations of which were living in the Tucson vicinity, surviving without their traditional lands or established community structures - became difficult for the United States government to define. For Yaquis who had entered the US before 1882 (often as railroad workers), there had been no such category as "illegal immigrant" (Castile 388). Moreover, Yaquis who had entered the country beginning in the late nineteenth century were defined as 'political exiles' who were escaping deportation or death in Mexico. However, in the early 1900s, as terror in Mexico escalated and Yaqui migration increased, Mexican consulates in Arizona were "instructed to watch the border closely for Yaquis slipping surreptitiously into Arizona... [Although] Without the full cooperation of US customs and immigration officials and the merchants of Arizona, the 
Mexican consuls could do little to regulate the activities of Yaqui” (Hu-DeHart 164). It wasn't until 1924 that the U.S. Border Patrol was established and a more fully elaborated version of border militarization was implemented (Castile 387). Having maintained permanent residence in the United States and having been separated from Mexico by a militarized border, by 1936, the Yaquis were no longer viewed by United States as "refugees," and the status of the Yaqui was unclear (Castile 388).

In his personal chronicle, A Yaqui Life, Rosalio Moisés' recounts that in 1936 (the year the Yaqui were no longer recognized as "refugees"), "the immigration officials came for me... They gave me the alternative of jail or leaving the county in twenty-four hours" (Moisés, Kelley, and Holden 163). Threatened with deportation, the Yaqui population sought recognition as an indigenous, United States tribe. However, the Yaqui found it difficult to achieve federal recognition, which would allow them to stay in the United States, in part because Congress insisted that since Yaquis immigrated to the United States as refugees, they were "non-indigenous" (Castile 406; Spicer 405-7; Evers and Molina 19). However, the southern Arizona Yaqui were finally able to gain federal recognition over forty years later, in 1978 , once they pointed to the ancient Toltec as Yaqui ancestors who migrated in the United States and Mexican regions (Castile 406; Evers and Molina 19).

29. Moisés's father was one of those Yaqui fighters who lived in the United States but routinely returned "to the Sierra to fight the Mexicans, and by the time he died in 1918 I guess he had killed scores of them" (1). In fact, in 1918, assistance for Yaqui guerrilla forces caused a group of Yaquis traveling to Mexico from the United States to 
be apprehended by border patrol as they tried to smuggle arms to assist homeland Yaqui resistance efforts (Spicer 232).

30. In a counter-hegemonic interpretation of what Zygmunt Bauman notes as capitalism's global surplus "reserve army of labor," Almanac describes how routes in, out, and through the United States are subverted to unite diverse global workers into a literal, transnational "reserve army" of resistance (Bauman 54).

31. Cherniavsky asserts that the Holistic Healers Convention at the end of the novel represents an example of the resistance movements' investment in commodity culture and subversive consumption as a method for gathering funds for counterhegemonic revolt. She states, "A benumbed metropolitan elite flocks for the spiritual affect that tribal activists gladly furnish, in exchange for substantial donations" (115). The activists gather money for revolt through the very economic processes that the revolution is trying to over-turn.

32. In a presentation at the American Bar Association conference, labor attorneys David S. Birnbaum, Jennifer Hunter, Peter Sung Ohr, and Julie R, Ulmet explain, “As a practical matter, the broad definition of 'labor organization' historically assisted employee advocacy groups and aspiring unions who had not yet won representational rights over a bargaining unit" (8). They recognize:

However, given subsequent regulatory activity since the passage of the Act, there are now numerous burdens and potential liabilities associated with being deemed to be a 'labor organization' for purposes of NLRA. For example, an entity that meets the definition of a 'labor organization' is 
subject to liabilities for unfair labor practices as defined by the amendment to the NLRA set forth in the Taft-Hartley Act of 1947. (9)

33. Daniel E. Clifton and Michael J. Healey state:

[T] he organization at issues is a labor organization if (1) employees participate; and (2) the organization exists, at least in part, for the purpose of 'dealing with' employers; and (3) these dealing concerning conditions of work or concern other statutory subjects, such as grievances, labor disputes, wages, rates of pay, or hours of employment" (Polaroid Corp.). For many cases, determining whether a group is a labor organization or alternative workers group hinges on the interpretation of an established "pattern or practice of employees dealing with employers. (Clifton and Healey 6)

34. Birnbaum, Hunter, Ohr, and Ulmet emphasized, “[I]n recent years, workers' centers have emerged as a significant player in the United States labor landscape. Indeed, although only five major worker centers existed in the United States in 1992, that number grew dramatically over the next fifteen years to 160 workers centers... The number has continued to grow in recent years as a number of worker centers have emerged to advocate for, among other issues, higher wages for working class and lower-middle class" (11).

35. In a letter to the NLRB General Counsel, UFCW confirmed its solidarity with OUR Walmart, and specified that the alternative worker organization was an independent 
group, which did not seek to represent workers in negotiations and should not be regulated by the same labor law that applies to the UFCW as a labor union:

OUR Walmart is an organization of Wal-Mart workers from across the county, who, along with many supporting organizations, are calling on Wal-Mart to improve labor rights and standards for its employees. OUR Wal-Mart has no intent to have Wal-Mart recognize or bargain with it as the representative of Wal-Mart employees. Nor does the UFCW International Union (UFCW) have such an intent. (United Food and Commercial Workers, "Letter to Lafe Solomon")

The Board required that OUR Walmart and UFCW post a disclaimer, similar to the statement quoted above, which made the scope and purpose of OUR Walmart clear. While a close alliance exists between OUR Walmart and traditional unions, actions of the worker's organization are not limited by NLRB union regulations, allowing the group to occupy stores and engage in other direct action.

36. For more on CIW's Fair Food Campaign see Chapter 3. 


\section{CHAPTER VI}

\section{TEACHING ABOUT LABOR THROUGH UNION WORKER-UNIVERSITY}

\section{STUDENT DIALOGUES}

In his introduction to Organizing the Curriculum: Perspectives on Teaching the US Labor Movement, Rob Linné states, "For far too long labor has been limited to a footnote in school texts instead of being treated seriously as the most effective force for championing the rights of working people - the vast majority of the citizenry" (xi). Most university students I teach confirm Linné's assertion. Some students state that their education simply has not included labor topics. As a result, Stephanie, a freshman, explained, "I know next to nothing about unions. I've never been presented with the topic and it's something that goes unnoticed in my life." Other students state that general labor topics are sometimes discussed in history, political science, or geography courses, but these issues are often framed as secondary concerns. For instance, Jim, a sophomore, said that discussions of labor in previous classes "never went into too much depth; we mainly made note of the fact that labor issues were a cause or effect of some other major event."

In contrast to my university students who often assert they have limited exposure to labor topics, while teaching with the United Steelworkers (USW) Local 787's Institute for Career Development (ICD), I have met union members who have intimate firsthand knowledge of labor issues. These USW Local 787 members frequently voice their concern that young people have little knowledge about the labor issues that impact 
workers' everyday lives because schools may not teach the history or continuing importance of local and global labor movements. One longtime union officer, Bill, explained that after looking at his children's school curriculum, he concluded that we “don't teach labor at all in our schools. Period. The kids are taught that Carnegie and Getty and all these guys were great champions of the industrial revolution, but they don't teach at what cost." Consequently, Bill and other USW Local 787 members worry that limited or one-sided exposure to labor issues in schools may result in students' misunderstanding unions and forming negative opinions of organized labor. Specifically, another class participant and Local 787 officer, Adam, explained, “A lot of people think unions are bad, but unions don't do things that are bad; they do things for the people and the community. You see, without a union, this could be a sweatshop." While young people's perceptions of labor issues may be shaped by multiple factors, including their own experiences, family attitudes, or media representations, USW Local 787 members recognize that labor education can serve as an important tool for helping students understand the role of unions in a global economy.

By simultaneously teaching labor topics to university students at a public Midwestern university and to union workers through USW/ICD, I recognized a potential connection that could be made between several USW Local 787 members who wanted to share accounts of their labor and union experiences and university students who wanted to learn more about these topics. These groups inspired me to foster union workeruniversity student dialogues that provided students access to authentic voices of the labor movement while offering union workers the opportunity to share their labor perspectives and experiences with a student audience. ${ }^{1}$ In developing these dialogues, I drew on my 
dual roles as a university instructor and USW/ICD facilitator. However, my goal in this chapter is to present an example of pedagogical practices and classroom activities for creating union worker-university student dialogues that may be adapted to fit the learning goals of diverse educational programs including other student demographics or labor organizations.

Although numerous researchers have found that college experiences may shape students' attitudes about unions (e.g., Floyd G. Willoughby and Lizbeth F. Barclay, Floyd G. Willoughby and Thomas L. Keon), markedly little scholarship correlates this research on young peoples' perceptions of unions with specific classroom approaches for educating students about organized labor issues. Therefore, this chapter strives to bridge research on young people's perceptions of unions with scholarship on teaching about labor issues in order to suggest pedagogical approaches and classroom activities to facilitate union worker-university student dialogues that may inform participants' perspectives on organized labor. To meet these aims, I will first briefly overview the university students' initial perceptions of organized labor in order to subsequently suggest how considering the experiences, people, or topics the shape students' labor perspectives can influence teaching approaches and course material. Next, the majority of this chapter will illustrate the process of union worker-university student dialogues that we developed in our course. Finally, the conclusion will reflect on this experience and suggest the impact that these dialogues had on participants. 


\section{Considering University Students' Initial Knowledge of Labor Topics and Perceptions of Unions}

Julian Barling, E. Kevin Kelloway, and Eric H. Bremermann emphasize the significance of studying young people's perceptions of unions, asserting, "If union attitudes are indeed stable, and undergo most change during adolescence and early adulthood, an understanding of their development at that stage becomes even more important" (725). ${ }^{2}$ While quantitative studies provide statistical data concerning young people's attitudes towards unions, in my university classes, I offer students the opportunity to share narrative responses through writing activities and verbal discussions in which they can explore personal encounters, close acquaintances, educational experiences, and other factors that have helped shape their labor perspectives. Understanding what factors have significantly influenced students' perceptions of unions allows me to tailor teaching methods and classroom activities to participants' expectations, knowledge, questions, or concerns.

During two academic semesters in which I taught 100-level general education humanities courses at a public Midwestern university, a total of fifty students who were enrolled in these classes volunteered to share their attitudes about labor issues and unions in order for our class to build on their knowledge during the course and consider how dialoguing with union members impacted their perspectives. Students in these classes were between eighteen and twenty-two years old and included twenty-three freshman, eighteen sophomores, eight juniors, and one senior. These classes reflected the demographics of the university, in which 82 percent of the student population is white and 99 percent are from within the state. Need-based financial aid is received by 27 
percent of the students at the university (Barron's). However, the majority of students in my classes stated that they did not have outside employment during the school year and expressed limited prior work experience. Throughout the semester, we met three hours a week for sixteen weeks, and participants shared their evolving labor perspectives in written assignments and class discussions throughout this time.

At the beginning of the semester, only eighteen out of the fifty students expressed strong attitudes toward labor unions, with eleven students explaining that they had a positive view of labor unions and seven students stating that they had a negative perception of organized labor. The majority of students with favorable perceptions of unions, eight of the eleven respondents, acknowledged that their labor perspective was predominantly influenced by close family members' active union participation or prounion attitudes. These students explained that they typically did not pay close attention to labor issues in the news or popular culture and, instead, depended on direct conversations with family members to inform their perspective. Thus, these responses reflected the impact that close family members with strong attitudes toward unions can have on young people, as research by Barling, Kelloway, and Bremermann; E. Kevin Kelloway and Laura Watts; E. Kevin Kelloway, Julian Barling, and Sharon Agar; James G. Pesek, Rod D. Raehsler, and Robert S. Balough; and others conclude. Specifically, Janice, a freshman education major at the university, explained, "Labor unions are very near and dear to my heart. I grew up in a very pro-union household, and because of that we believe in American-made products....Although labor unions might be controversial to some, I believe they are an important and necessary part of any labor worker's job." Janice correlated her current positive attitudes toward labor unions with her personal and 
professional goals, asserting, "As a future teacher, I want to be part of a union." Similarly, Curt, a sophomore marketing major, expressed favorable views of organized labor, which he considered to be informed by a family member's active union participation and pro-union attitudes. Curt explained, "My mom is vice president of the teachers' union. The union allows the teachers to have a little bit of ground to stand on when it comes to certain discussions and disagreements with the school board....There might be some association between my mother's view and my own."

Family members' attitudes not only impacted students with positive perceptions of unions. Additionally, students with unfavorable perceptions of unions overwhelmingly cited that their perspectives at the beginning of the course were influenced by family members' negative experiences with unions. While seven students conveyed unfavorable attitudes about unions, five participants explained that their perspectives were directly influenced by close family members. ${ }^{3}$ For instance, Brianna explained that her negative perception of unions was influenced by her father, a nonunion general contractor, telling her about his experiences with a construction workers' union. Brianna stated, "Most of my attitudes and opinions about unions come from my family, in particular my dad and grandfather. They have taught me to believe that union construction workers don't work as hard as construction workers who aren't in the union. Their beliefs about union workers' work ethic has rubbed off onto me over the years of hearing them discuss it." Brianna detailed how her family found themselves in an oppositional struggle against the union; however, most students in the class who expressed negative perceptions of unions said family members' unfavorable experiences as union members had influenced their attitudes. For instance, Jesse explained that his father's experiences as a union employee 
led him to conclude that "the union can do pretty much whatever they want, once they make a decision that upsets the workforce of the union and they go on strike. All those benefits are taken away and people can no longer afford to live their life how they have been since joining the union."

Although some students expressed strong negative or positive perceptions of unions, the vast majority of participants in this study, thirty-two out of fifty students, expressed neutral attitudes toward labor unions at the beginning of the course. Therefore, most students did not express the negative perception of unions that USW Local 787 members expected or recent Pew and Gallop polls suggest. ${ }^{4}$ Rather, students generally held neutral opinions about unions, as research by Willoughby and Barclay finds. Unlike students with strong attitudes about unions who often stated a close family member who was a union worker influenced their perspectives, very few of the students with neutral opinions of labor unions, only six of the thirty-two, said a close relative was a union member. Subsequently, most students explained that they had a neutral attitude toward labor unions because they had no personal connection to organized labor and knew little about labor issues. One class participant, Ella, expressed the reason for many students' neutral perspective, as she stated, 'I don't have an opinion about unions because I don't know enough information about them to construct one." Other students acknowledge that their neutral opinions resulted from their personal detachment from organized labor, such as Mitch, who explained, "I really have few opinions on unions simply because I have no experience personally as a member of a union."

Considering students' familiarity (or unfamiliarity) with labor topics and the influences that shaped their perceptions of unions allowed me to be better informed when 
developing teaching methods and classroom activities. Specifically, my research with university students indicated that the beliefs of the few students with strong attitudes about unions were often shaped by close interactions with union members. However, the majority of students held neutral opinions about unions and typically had little or no personal contact with union workers. These findings suggested how union memberuniversity student dialogues might be adopted to inform each group's perceptions of organized labor topics. First, because students with neutral attitudes often explained that they lacked information or experiences that would allow them to assert an informed position, they frequently expressed a willingness to actively engage in union workeruniversity student dialogues that might help them learn about labor topics. For instance, Molly wanted to become more educated about labor issues before she formed her opinion, explaining, “I honestly will say I don't know much of anything about labor issues. I am very open to learning about them and becoming more informed." Second, while influences, such as the media, popular culture, personal work experience, or other factors, might have affected the perspectives of students with strong opinions about unions, these students overwhelmingly expressed that one-on-one contact with close family members was the predominant factor in shaping their perceptions of unions. Because many students with strong perspectives about unions emphasized the importance of personal interactions with union members, our class developed union workeruniversity student dialogues to offer the type of firsthand perspectives that students explained are important in shaping their perceptions of organized labor. ${ }^{5}$ 


\section{Classroom Approaches to Teaching about Labor through Union Worker-University Student Dialogues}

Informed by the insight students shared about their perceptions of organized labor and inspired by the USW Local 787 members' concern for young people's labor education, my general education humanities course was designed to foster dialogues between the students and the workers, providing each group an opportunity to discuss issues during face-to-face conversations and written correspondences. ${ }^{6}$ This process drew on Paulo Freire's assertion that "dialogue is the encounter in which the united reflection and action of the dialoguers are addressed to the world which is to be transformed and humanized" (88-89). In order to realize this lofty aim, I adopted an overall teaching method that synthesized multiple pedagogical approaches in order to engage participants through recognizing their own perceptions of unions and building on their expanding knowledge and experiences with labor. First, critical pedagogy's student-centered approach and decentered authority influenced the structure of our discussions and dialogues as well as provided a theoretical rationale for connecting our classroom activities with pertinent contemporary labor issues (e.g., Freire; Peter McLaren and Ramin Farahmandpur; Antonia Darder, Marta Baltodona, and Rodolfo D. Torres; Roland Zullo and Alice Gates). Second, cultural-historical activity theory (CHAT) offered techniques for engaging students in tool-mediated, historically and socially situated learning processes that could capitalize on our current moment of debate over organized labor (e.g., A. N. Leont'ev; Bert van Oers Wim Wardekker, Ed Elbers, and Rene can der Veer; Peter Sawchuk; Wolff-Michael Roth and Yew-Jin Lee; Helena Worthen). Finally, within a specific context of exploring labor issues, our class was guided by working-class 
approaches that recognize how labor and social class shape teaching and learning processes (e.g., Sherry Lee Linkon; John Russo and Sherry Lee Linkon) and youth labor education scholarship that addresses issues of teaching labor to a general audience of young people (e.g., Rob Linné, Adrienne Andi Sosin, and Leigh Benin.; Linda Tubach). ${ }^{7}$

Working within this pedagogical framework, my course adopted multiple interconnected classroom activities to foster union worker-university student dialogues. First, to prepare for written and verbal dialogues, students were encouraged to share their own perspectives on labor and work experiences through writing assignments and inclass discussions. Second, our course gave students the opportunity to engage with labor issues as they read USW members' stories and corresponded with the authors in written dialogues. Third, students participated in face-to-face verbal dialogues with a USW Local 787 member and connected this conversation with course topics and readings. Finally, to maintain this relationship between students and Local 787 members, students created social science-style research posters, which they presented to their class and shared with Local 787 members. As critical pedagogue Paula Allman points out, dialogue includes "at least some level of commitment, amongst participants, to develop a deeper and more critical understanding of their reality" (427). These four interconnected activities demonstrate the effort that both university students and union workers put into the dialoguing process in order to make this experience a worthwhile learning opportunity for all involved.

\section{Student Writing in Preparation for Dialogues}

Throughout the semester, our class investigated labor topics, such as international commodity chains, offshore manufacturing practices, local/global work environments, 
and transnational unionization efforts, through reading literary, cultural, and social science texts and completing multi-genre composition assignments in which we could develop and share our knowledge. Specifically, in our first writing assignment of the semester, I asked students to create a personal narrative in which they shared an experience, person, or issue that shaped their labor perspective. Informed by CHAT pedagogy, which strives to engage students in meaningful, socially situated learning processes, and critical pedagogy that builds on students' experiences and knowledge, this broad list of suggested topics was created to allow students to engage with the factors that were most important in shaping what they knew about labor topics or how they perceived unions. Additionally, by encouraging students to articulate their developing labor perspectives, this early assignment got them thinking, writing, and talking about labor topics in preparation for future union worker-university student dialogues.

This assignment appealed to the range of labor experiences and knowledge represented in the classroom. For instance, a couple of students who explained that they knew little of labor topics at the beginning of the course took this opportunity to research an issue and begin to develop an informed position. Several other students with little personal work experience reflected on a brief encounter that helped them realize the labor that goes into the products they consume. For example, Brianna wrote about how picking vegetables in her grandparents' garden helped her recognize "the hard work that goes into growing the food I eat every day, and how much I take advantage of having the privilege to eat fresh food without having to work that hard for it." For the few students who initially expressed that their perception of organized labor was significantly shaped by family members' attitudes or personal encounters, these writings gave them the 
opportunity to reflect on their perspectives or work experiences. Jim wrote about his "very tedious" summer job "on the assembly line, pulling off small packages of cinnamon apples, making sure they weighed the proper amount." Although he was "just there looking for a little extra cash," writing his labor perspective allowed him to recognize the "injustices going on at the factory" for those who were "relying on that money from the day to feed their family." He explained, "At the time, I didn't even really think about it, but looking back on it I realize how unfairly all of the other workers were treated there." As Brianna, Jim, and other students volunteered to share excerpts from their labor perspective essays in class, we were able to recognize and discuss the variety of experiences represented in the classroom as well as the numerous perspectives from which students approached labor topics.

While this assignment helped these students to begin to articulate their labor perspectives, it was particularly effective in engaging working-class students in the classroom by offering them an opportunity to share their personal connections to work and labor issues. Drawing on working-class pedagogy's goal of creating a classroom that respects working-class and labor voices, David Seitz promotes assignments that "elicit writers' multiple orientations toward cultural values of work through reflection on situated moments of their continually evolving work identity and persuasive influences on work issues in their lives" (214). However, Sherry Lee Linkon suggests that increasing numbers of students can be impacted by such assignments and pedagogies, as "even in elite schools, more students seem to be working more hours in order to be able to afford to go to college, and so-called nontraditional students are becoming more common. Such students may not be from working-class backgrounds, but they may well 
share some qualities associated with working-class students" (3). Therefore, while personal labor perspective essays may have been particularly well suited for engaging working-class students, through these narratives, all students were given the opportunity to articulate their present labor attitudes and experiences as a basis for cultivating a more knowledgeable perception of organized labor. Thus, as students began to think, write, and discuss labor topics, this early assignment laid the foundation for the union workeruniversity student dialogues our course would develop.

\section{Reading Workers' Stories and Participating in Written Dialogues}

Reflective of Linné's “call for a pedagogy that encourages the study of local histories and cultures as told through working-class voices," part of the reading that students did in the course included workers' short stories, poetry, autobiographies, and ethnographic selections (37). For instance, our investigation into how specific populations are impacted by the benefits and drawbacks of international free trade agreements, such as NAFTA, was enriched by reading accounts by U.S. and Mexican workers, including literary selections, like Jimmy Santiago Baca and Stacey James's The Heat: Steelworker Lives \& Legends, and social science ethnographies, such as Miriam Ching Yoon Louie's Sweatshop Warriors, which allowed us to see the personal impacts of political policies. Through studying these firsthand accounts, we attempted to revitalize what Adrienne Andi Sosin recognizes as the "weakened version of what was once a robust passing on of stories about labor struggles and commonly shared experiences with industrial work" (269). ${ }^{8}$ Reading workers' stories, writing to the authors, and receiving their responses enhanced our class's understanding of labor struggles and experiences as well as improved our understanding of these workers' perspectives. 
After our class read The Heat: Steelworker Lives \& Legends and discussed its important themes, such as outsourcing, workplace safety, and global social class inequities, students were invited to write to an author in the collection and share their personal responses to a story. This writing built on the critical and reflective composition processes that students practiced in their labor perspective narratives. However, this assignment offered students the opportunity to create a piece of writing that would resonate outside of the classroom and reach a "real-world" audience by initiating recursive written dialogues between students and worker-writers. This conceptualization of writing reflects what David R. Russell explains as CHAT's influence in moving "toward a theory of writing useful in analyzing how students and teachers within individual classrooms use the discursive tools of classroom genres to interact (and not interact) with social practices beyond individual classroomsthose [sic] of schools, families, peers, disciplines, professions, political movements, unions, corporations, and so on" (Russell). By engaging with particular activity systems-in this case, working with the genre of personal letters to correspond with union members about stories and labor issues pertinent to our current social moment-the assignment allowed students to reflect on what they had learned about labor topics in the course in order to compose letters that would be interpreted in rhetorical contexts beyond the classroom.

Providing a composition assignment that allowed students to engage with CHAT's concrete, real-world historical and social contexts as they wrote to authors encouraged students to reflect on how the literary selections connected to courses topics. Additionally, students had the opportunity to use their letter as a rhetorical performance in which they could voice their positive or negative impression of the author's story as 
well as address how the text influenced their evolving labor perspective. For instance, Courtney, who at the beginning of the semester attributed her neutral perception of unions to the fact that she was "confused" by the "discrepancies between pro- and antiunion arguments," wrote to one author, "When you talk about how the average individual could not survive in many ways without a steelworker employee's help, it really showed me how much we depend on steelworkers....I thought about how much steel I truly use every day....I want to tell you that your work matters and you have truly changed my perspective on the steelwork profession for the better." Other students similarly responded that the personal accounts helped them expand their labor perspective by learning about steelworkers, in particular, as well as recognizing the overarching contribution of industrial workers, more generally. Brianna, who at the beginning of the class explained that she thought some union workers do not work as hard as nonunion workers, told an author, "Your goal of opening up the minds of people to the life of a Steelworker has been accomplished....My perspective on Steelworkers has completely changed....Through your work I have gained an appreciation for not only Steelworkers, but for all laborers." These statements suggest how reading USW-authored texts and writing to authors influenced students' recognition of the labor embedded in commodities, informed their understanding of labor issues, and enriched their developing labor perspectives by offering them new viewpoints to consider.

In response to the letters, one author, Joe Gutierrez, a 70-year-old retired steelworker, replied to each student's note. In these individualized responses, he provided students with an even more personal perspective on U.S. manufacturing work, again offering an authentic working-class voice for the students to consider. Joe explained, "In 
Inland Steel, the company where I worked, more than 340 workers that we know of had died on the job and thousands more have died as the result of work-related issues....In 1983, when a steelworker retired his life expectancy was a mere six months to a year. Many retired workers in my department didn't live that long." Joe's firsthand accounts of working conditions, specifically, asbestos exposure, provided students with new information and viewpoints to inform their evolving labor perspectives and attitudes about the role of unions. Moreover, students were able to see how their letters were received and interpreted by their target audience. As we shared excerpts from Joe's replies aloud on the last day of class, tears literally came to several students' eyes as we read, "Thank you so much for your words, for your enthusiasm, for your love of humanity. Keep up the good work. I know your parents must be very proud. You are truly the light of the world." After this experience, one class participant, Molly, responded, "I literally had chills when you were reading his letters that he wrote back to us....When you said that he was touched and inspired, I found it ironic because I was the one that was very touched!" As Molly's reaction exemplifies, when students had the opportunity to discuss labor texts and topics in recursive written dialogues with workerwriters, it offered them the chance to more personally connect with the stories, people, and topics our class explored.

\section{Engaging in Face-to-Face Dialogues}

In addition to reading and responding to USW members' creative writings, another way in which we worked to create dialogues between workers and students during our course and to uphold working-class and labor voices was by inviting Adam, a USW Local 787 officer, into our classroom to speak about his work experiences and 
union activities. ${ }^{9}$ As Sosin notes, "stories about labor struggles seem more like ancient history than contemporary critical critique" (269). However, face-to-face conversations with Adam provided students with the opportunity to ask questions related to contemporary issues of unionization as well as the labor themes we explored in our multidisciplinary course texts, including Gabriel García Márquez’s One Hundred Years of Solitude, David Bacon's Children of NAFTA, Miriam Ching Yoon Louie's Sweatshop Warriors, Helen Maria Viramontes's Under the Feet of Jesus, and Jimmy Santiago Baca and Stacy James's The Heat: Steelworker Lives \& Legends.

Adam offered to come to our class because he, along with several other USW Local 787 members, believed that "young people don't understand the types of labor that go into all of these commodities" and, subsequently, that they misunderstand the role of unions in protecting workers' rights. I first met Adam when he voiced this perspective in an ICD class, "Globalization, Unionization, and Education," that I taught for USW Local 787. During this course, I was impressed by Adam's depth of knowledge on labor topics, diverse union experiences, and ability to articulate complex issues clearly and concisely. When I began thinking about facilitating union worker-university student classroom dialogues, I immediately turned to Adam to see if he would be willing to participate in this processes. As we talked before the classroom session, I encouraged Adam to share both the knowledge he had gained about issues during labor summer school courses as well as his personal experiences as a local union officer and worker in the manufacturing industry and, more globally, his travels to Mexico as part of a USW union solidarity delegation.

By inviting Adam into the classroom to chat with students, instead of only reading 
about labor unions in printed texts, our class had the opportunity to ask questions and offer face-to-face responses to Adam's statements. Through this method, we engaged in what Peter McLaren recognizes as critical pedagogy's goal of a “reciprocal exchange between teachers and students-an exchange that engages in the task of reframing, refunctioning, and reposing the question of understanding itself" (185). In our course, the exchange extended beyond the classroom walls to include students, myself, and our guests in reciprocal dialogues that could decenter classroom authority away from a teacher and focus on participant-centered inquiries and questions. As Freire describes, "Through dialogue, the teacher-of-the-students and the students-of-the-teacher cease to exist....The teacher is no longer merely the-one-who-teaches, but one who is himself taught in dialogue with the students, who in turn while being taught also teach. They become jointly responsible for a process in which all grow" (80).

When Adam visited our class, he combined a short presentation about his own work and union involvement with time for open discussion and dialoguing. He began by providing students with a glimpse of the high technology and handcraftsmanship involved in his work by showing an episode of the History Channel's Modern Marvels filmed at the Bridgestone tire factory where USW Local 787 members work. Many students were amazed that this type of manufacturing existed just a few minutes away from their school, not isolated thousands of miles away in developing nations. After the film, Adam explained multiple ways that the USW helps workers in his facility. For instance, he discussed how the union makes sure safety regulations in the factory are enforced; negotiates benefits like health care; and provides workers with educational opportunities like the USW/ICD. Additionally, Adam talked about USW's national and 
international campaigns to support struggling unions in developing nations, lobby for legislation that will benefit workers, and alert local unions to important issues through a rapid-response system. Therefore, while Adam was personally involved in the manufacturing industry, his presentation addressed some of the overarching labor issues shared by unions in multiple fields.

After Adam's presentation, students were able to chat with him about any questions, concerns, or confusion they had about unions, in general, or his work and experiences, specifically. While students learned from Adam's initial presentation, having the opportunity to discuss the information with him during face-to-face dialogues made Adam's time in our classroom even more effective. As we talked, students had a variety of insightful, respectful comments that ranged from technical inquiries, such as how the union's grievance process works, to personal questions, like why Adam became so active in union operations. Students mentioned how the safety violations Adam described paralleled the toxic chemical dangers described in Viramontes's Under the Feet of Jesus and asbestos exposure recounted in Baca and James's The Heat. Additionally, during their conversations, students asked for more information about transnational union solidarity campaigns and, specifically, Adam's involvement with USW-affiliated unions in other countries, such as Mexico's Los Mineros. When Adam described the violence perpetuated against striking Los Mineros miners, students recognized how this mirrored the anti-union aggression we read about in García Márquez’s One Hundred Years of Solitude, Neruda’s “United Fruit Co.," and other course texts.

In order to continue the dialogue with Adam after his chat with our class, students 
wrote to him sharing their reactions to his visit and asking any further questions. While reading The Heat and writing to authors enhanced students' understanding of particular labor issues and industries, Adam's dialogue with the class provided students with more specific insight into unions in general and the USW particularly. Students' subsequent feedback suggested that regardless of their initial perceptions of unions, having a firsthand dialogue with a union member was an irreplaceably important experience in shaping their attitudes about organized labor. Brianna, who voiced a negative perception of unions at the beginning of the course, wrote to Adam explaining, "Your presentation gave me great insight into what it's like to be a union member that I otherwise would not have gotten a chance to experience. I learned a lot about United Steelworkers and how the union runs....It has opened up my eyes and made me realize that sometimes the way the media depicts unions isn't necessarily true." When the course began, Brianna initially stated that her father's anti-union perspective influenced her own perception of unions. However, Adam's pro-union sentiments provided Brianna with an alternate perspective to consider. Other students echoed Brianna's experience, such as Chase, who stated, "I have to admit that I, like many others that you mentioned in your talk, had a negative view of unions. However, your personal and honest look made me reconsider my position. It never occurred to me how positive the impact of a union is on the workers." Additionally, many students who held neutral opinions of organized labor at the beginning of the course expressed that talking with Adam helped them become more informed about unions and aware of the personal struggles of laborers. For instance, Molly, who initially voiced a desire to learn more about labor issues and reacted positively and emotionally to the written author dialogues, told Adam, "I know it may be 
challenging to speak about unions and the USW, since so many people assume unions are bad. I like the way you presented your part of the story. Most people don't see the other side when they talk about all the negative things associated with unions." As this feedback demonstrates, face-to-face union worker-university student dialogues can inform students' labor perspectives by offering a working-class voice that underscores the continued imperative of labor organizations.

\section{Maintaining the Union Worker-University Student Connection}

Since union members shared their time, experiences, expertise, and stories with our class, some course assignments were designed to offer something back to the workers in return and maintain the connection that had been established between union workers and university students. Over the semester, students worked in groups to create educational, social science-style research posters that informed the audience about an important moment in labor history, ranging from past events, like Ludlow and Homestead, to contemporary efforts to unionize maquilas and Liberian rubber plantations. Groups presented these posters to their classmates during a ten-minute informational talk followed by a question-and-answer segment. In the context of our course, this assignment allowed students to look in depth at a specific labor topic, while, overall, the posters presented a historical trajectory that highlighted the continued relevance of organized labor. Courtney Snegroff and Leigh David Benin assert that perfunctory labor history curriculum that frames the rise of unions as a reaction to unique and isolated historical occurrences can leave "students with the clear impression that organized labor, like Douglas MacArthur's old generals, will just fade away" (48). However, as one student, Andrew, explained, the posters worked to "tie events in history 
to what we are currently learning about" and helped our class consider organized labor as a historically and contemporarily vital force for worker empowerment. ${ }^{10}$

This poster assignment allowed students to share their knowledge with peers while developing scholarly research and presentation skills. Additionally, as CHAT and critical pedagogy advocates, the poster assignment was designed to show students how course material relates to a wider social context and can have an impact beyond the classroom walls. Therefore, like our letters to the authors of The Heat, we shared our work with interested union members. At the end of the semester, we gave these posters to local labor unions, which displayed them in their union halls in order to provide information on labor topics to the workers. USW Local 787 members' initial concern that students do not receive an adequate labor history education motivated me to have students engage in this transtemporal inquiry into select labor issues; therefore, it seemed fitting that in response we would offer these posters to the workers. When displayed during a USW Local 787 meeting, the posters initiated discussions about the specific topics as well as labor history education more broadly. In these conversations, members reflected on their knowledge of labor events and recognized that they could benefit from continuing this area of their education. As a result, USW Local 787's ICD organized a series of labor history courses for the workers. Therefore, while university students may not have been experts on labor history, creating research posters and sharing their knowledge with the workers, in turn, catalyzed USW Local 787 members to develop their own labor history curriculum. 


\section{Reflections}

Since my pedagogical methods are student-centered, it is not enough for me to personally believe or critically and theoretically justify that a classroom approach has the potential to help develop participants' knowledge. The effectiveness ultimately depends upon participants' own reflections on how and what they learned. Therefore, by considering university students', union members', and my own assessments of the classroom dialoguing process, I have been able to recognize strengths and weakness of the approach and suggest potential changes for future classroom dialogues.

The majority of my university students initially stated that they had neutral views of unions and commonly expressed a willingness to learn more about organized labor in order to cultivate an informed position. This mirrored other researchers' findings on young people's perceptions of unions (e.g., Willoughby and Barclay) and did not reflect Local 787 members' expectation that students would hold predominately negative attitudes about organized labor. The few students who did have strong opinions about unions often stated that face-to-face interactions with a union family member was the predominant factor in shaping their perception of organized labor, as research by Barling, Kelloway, and Bremermann and others similarly conclude. Therefore, taking these findings into consideration when designing my university course, I worked to provide students with information about labor topics through classroom readings and assignments, as well as offering dialoguing opportunities in which union members and university students could share their knowledge and learn from others' perspectives.

Students' reflections on the course suggested three ways in which they found this approach successful. First, students considered written and verbal dialogues the most 
engaging and beneficial activities of our course. Second, students explained that the union and labor perspectives presented in the course helped them understand pro-labor attitudes. Third, students said that through the dialoguing process they were able to develop and more confidently voice their own personal labor perspectives.

The reading and writing we did in preparation for the dialogues was designed to help students develop their knowledge on topics and articulate their initial perspectives. However, nearly every student stated that written and face-to-face dialogues with union members were their favorite course activities and were irreplaceably influential in shaping their understanding of labor issues beyond what traditional classroom reading and writing activities typically offer. Wayne explained, "There is no supplement for having an actual person come in and be willing to have a dialogue. Having someone come in and share their experience with a group of students who for the most part have no real idea of the working world, let alone unions, is immensely helpful." Molly explained that she enjoyed "the format and the freedom" that written dialogues provided, and stated that she learned so much from Joe, who was "truly a wonderful man to share his stories with us and then to have the time to write us back is even more amazing!" Ella said that classroom verbal dialogues "gave us all a chance to understand what other people were thinking. This also made the class more interesting and gave it a little spin, so the teacher is not the only one talking while the rest of the class quietly takes notes the whole time." These statements suggest the success of written and verbal dialogues for engaging students in meaningful learning activities that can offer CHAT's culturalhistorical context in the classroom as well as uphold critical pedagogy's goals of decentered authority and student-centered learning. 
After engaging in written and face-to-face dialogues, as well as interdisciplinary readings and multigenre composition assignments, university students expressed that regardless of whether their initial perception of unions was neutral, negative, or positive, at the end of our course, they were better able to understand a pro-union perspective. For instance, Terry, who initially expressed a neutral opinion of unions, explained:

In the beginning of this year, I didn't know much about unions....The guest speaker, Adam, really was the person that I got most of my information about unions from....I believe that my previous lack of knowledge about unions really kept my mind open to what he had to say. I know that some people think that unions are corrupt and bad for the economy, but since I didn't know much about unions prior to his speech, I think Adam really molded my views in a positive way.

Terry's comments suggest that he was already aware of anti-union arguments before he entered our classroom, and union worker-university student dialogues provided him with alternate perspectives to consider as he formed his own opinion.

Similarly, Andrew stated that classroom dialogues informed his negative attitudes about unions by offering him opportunities to engage with organized labor perspectives:

Since the beginning of the semester, my perspective on labor and union has changed a lot. Coming into this class, I did not think that unions were a very important issue. I thought they were just radical people who would storm the streets with signs....After taking this class, though, my views have changed to 
side more with the unions and workers....My change of views came from readings, discussions, and our guest speaker, Adam. All three combined to change my view on unions and labor conditions and will definitely stay with me for the rest of my life.

Andrew's reflection on what he learned in the course and how dialogues with Adam contributed to his understanding of unions suggests the benefits of providing students with information, resources, and dialoguing opportunities that might aid them in forming their own opinions on issues.

Brianna, who began the course adamantly and vocally anti-union, also noted how important these resources were in helping her reflect on her initial labor perspective. She stated:

Through readings I have learned so much....My attitude has completely changed and I now support the various unions that are fighting for the rights of workers. Another aspect of the course that opened my eyes to a labor perspective of others is when Adam came to speak to the class about the USW. After hearing him speak about his personal experience, what the union is about, and who they protect, I have gained a lot of respect for union members and laborers. I am almost embarrassed about the essay I first submitted....I remember writing about how I was told that union members were lazy and didn't work as hard and how I looked at union members in a negative light. Through this course I have changed those previous opinions and attitudes and have realized what exactly a union is and 
what they stand for, and I have gained a better understanding and appreciation for all laborers.

Like Brianna, who explained that class activities provided her with new information to consider in her evolving labor perspective, students who initially expressed a positive perception of unions similarly explained that the course provided them with new information and perspectives that influenced their understanding of labor topics. For instance, Kellie noted, "Not only have I enjoyed the class assignments and readings, but I also feel a lot more educated about things in the real world....I now feel like I can talk confidently about unions."

While dialoguing with union members allowed many students to understand prounion perspectives, the overarching aim of this course was to offer readings, assignments, discussions, and dialoguing opportunities to aid students in articulating their own educated labor perspectives. The goal was to provide them with information about labor topics and unions to consider as they examined issues from multiple perspectives and formed their personal opinions. Student feedback suggests that many students found this approach particularly successful in helping them cultivate their own informed perspective on labor issues. For instance, at the end of the semester, Cale wrote, "Prior to enrolling in this course I could only view unions from the point of view the media has looked at them. Generally, I was only hearing and seeing negative connotations to these organizations. Between our reading and having Adam come in and speak with us about what they're really working for, I was finally able to form my own opinion on the matter." While not all students may have formed pro-union attitudes during the class, students 
overwhelmingly acknowledged that the course provided them with important labor perspectives to consider when developing their own positions. Specifically, Sam replied, "I came into it expecting a lack-luster 100 level general education class, but I was really able to walk away with new and powerful knowledge. This is something I will continue to carry with me and I have finally shaped my own opinion on such topics." Likewise, Ella noted, "I also did not have my own opinion about unions at the beginning of the semester because I did not know enough information to form one. However, after taking this class, I have now been able to form my own intellectual opinion about them and I am able to join in conversations that are talking about these issues." These student reflections suggest that the reciprocal process of writing and verbally articulating personal perspectives on labor issues and, in turn, listening and engaging with others' viewpoints during dialogues can aid participants in forming and voicing their own informed position on labor topics.

Because these dialogues were occurring in the university classroom instead of, for instance, a union education program, particular attention was paid to university students' learning. However, as Freire notes, dialogues should be a cooperative endeavor that contributes to the intellectual growth of all participants. Two important union member participants, Joe and Adam, both explained that during union worker- university student dialogues, they not only were able to offer their own knowledge and experiences to students but, additionally, learned from the questions, responses, and perspectives university students shared with them. Joe reflected: 
I wasn't surprised at [students'] lack of knowledge about unions. This gap is universal in our schools. But the events transpiring today across the country concerning workers losing their right to bargain are making more people aware of unions and the loss thereof. I learned that students are beginning to question, and I was excited that they were excited. Their wonderful letters intensified my belief that hope, indeed, is alive....They reinforced my belief that regardless of background people are basically good and truly concerned with justice and equality. Their words exemplified a sincere interest in something that has affected their lives and they were not even aware. That something is the Union and all the benefits enjoyed today by the blood and sweat of yesterday.

Although Joe felt disheartened by the loss of unions' and workers' rights, dialoguing with students helped restore his hope that education can provide opportunities for young people to becoming interested and excited about engaging with labor topics.

Adam's reflection iterates his similar experience. While he acknowledges that many students initially knew little about organized labor, he also recognizes the personal impact that his interactions had on their learning:

The most eye-opening thing was how little exposure to not only organized labor, but labor in general these students had. It seems that most had very little (if any) experience as a wage earner....The greatest value for me was the fact that I could give them an exposure to unions that was not filtered through one of the many conservative pundits that seem to be so prolific these days. [I came] to them on their "turf" and that makes for a less threatening atmosphere. From the letters they 
wrote, it would appear that while I may not have created future labor activists, they may be more willing to consider both sides of the issue before making up their minds about some national or local news item.

Joe and Adam's responses explain that the dialoguing processes helped them learn more about students' perceptions of unions and knowledge of labor topics. Additionally, they suggest that the dialogues allowed them an important opportunity they had not previously had to share their labor knowledge and union experiences with a student audience.

As university students' and union workers' responses demonstrate, I was fortunate to have a group of participants who were all respectful of new ideas, eager to share their thoughts, and willing to engage in dialogues. I certainly attribute the meaningful implementation of critical pedagogy's student-centered approach and decentered authority, along with CHAT's engagement with sociohistorical contexts, to participants' active involvement, which I believe is an important factor in determining the success of these methods. Moreover, the union members' participation allowed us to benefit from vibrant working-class and labor voices in the classroom, as labor education and working-class pedagogy advocates. I am heartened by the fact that students and union members voiced so many successes of the dialoguing process, from helping students articulate their own personal labor perspectives to allowing union members to share their stories and knowledge with students. It has encouraged me to hone this approach by not only considering the successes of our classroom dialogues but also addressing limitations and potential areas for future improvement. 
To improve university students' learning experience, I would like to expand the variety of perspectives students are exposed to through the dialoging process by inviting union members from other industries, as well as nonunion workers, to participate in this process. By offering students access to a larger cross-section of unions, representing a broader variety of labor perspectives and working-class voices, students may also be able to interact with union members in occupations they plan on pursuing. This would help our course not only consider manufacturing processes but also more fully address other types of labor. To make these university classroom dialogues more worthwhile for union members, additional time during the dialogues could be set aside to discuss topics that union members consider important and want to hear students' perspectives on. To foster union member learning, it might be beneficial to also arrange face-to-face dialogues in a union education setting, which would be more familiar to union members and underscore the importance of both university and union participants' learning.

Recognizing that this model of dialoguing can be improved and revised for use in the future underscores what I see as the greatest value of this approach. Namely, the dialoguing process provides a flexible model for fostering participant-based learning, which encourages all members to engage with multiple viewpoints on labor topics to inform their own individual perspectives. This process provides a model for the practical application of research on students' attitudes toward labor topics as well as emphasizes the importance of considering course participants' unique perceptions and learning goals in developing classroom approaches and activities for teaching about labor. While the example of union worker-university student dialogues elaborated in this chapter drew on my experiences as a university instructor and USW/ICD course facilitator, the flexible 
dialoguing process it presents may be personalized to meet the learning goals and educational objective of multiple educational settings. Thus, for university instructors and union education facilitators, the dialoguing process offers an interactive approach for teaching about labor topics through encouraging participants to articulate their viewpoints, engage in reciprocal written and verbal exchanges, and reflect on others' perspectives in order to enrich their own understanding of labor topics and perceptions of unions. 


\section{Chapter VI Endnotes}

1. Thanks to Sean Fagan, Jerry Evans, Joe Gutierrez, Mike Tucker, Rick Wills, and Denny Robinson for their contributions to this dialoguing process.

2. For more on children's, adolescents', and young adults' perceptions of unions, see Willoughby and Barclay; Barling, Kelloway, and Bremermann; Kelloway, Barling, and Agar; Kelloway and Watts; Fuller and Hester; Lowe and Rastin; LaHuis and Mellor; and Pesek, Raehsler, and Balough.

3. Only five out of fifty participants communicated factors other than family socialization that had shaped their strong negative or positive perceptions of unions. Both groups of individuals, those with pro- and anti-union positions, similarly attributed their strong attitudes to a mix of factors, including friends, news media, and school.

4. A 2009 Gallup poll found that public support of unions was at an all-time low, with only 48 percent of Americans approving of labor unions, representing a sharp decrease from a 59 percent approval rate the previous year (Saad). A 2011 Pew Research Center survey suggests that the public's perception of unions has continued to sour, finding that only 45 percent of people expressed a favorable impression of unions (Pew Research Center).

5. Kelloway, Barling, and Agar discuss how a young person's identification with a family member might also moderate the extent to which the member's attitude impacts the student's perspective.

6. Instructors who foster union worker-university student dialogues might encounter resistance from critics who assert that the classroom should be an ideologically 
neutral space and argue that introducing union voices might disrupt this neutrality. However, as Elaine Bernard points out, 'there is no such thing as 'neutral' education. Even public educational institutions, such as universities, are advocates whether they admit to it or not" (6). Along with Barnard, Rob Linné, Adrienne Andi Sosin, and Leigh David Benin recognize, "There is nothing neutral about what gets taught in schools....Through their influence over educational resources, corporations have been able to minimize recognition in the curriculum of labor's ongoing centrality in the struggle for social and economic justice" ("Teaching Labor's Untold Story: How to Get Labor Back into the Classroom" 86). They posit that under these conditions, providing students with an organized labor perspective introduces some balance into the already pervasive corporate advocacy implicit in students' education. Personally, my consideration of ideology in the classroom is significantly shaped by James Berlin's assertion that "a way of teaching is never innocent. Every pedagogy is imbricated in ideology, in a set of tacit assumptions about what is real, what is good, what is possible, and how power ought to be distributed" (492). What an instructor must do is realize, as Berlin states, that "ideology must continually be challenged so as to reveal its economic and political consequences for the individual" (489).

7. A significant amount of the scholarship on teaching labor studies in a university setting focuses on educating worker-students who may have full-time outside employment or students who are specifically focusing their course work in labor fields (e.g., Mantsios; Hertenstein; Bussel; Aronowitz). Some labor history pedagogy addresses teaching labor topics to a more diverse student body (e.g., Barrett and Koenker; Green). 
These fields of scholarship can be considered when developing teaching methods and curriculum for a general education course; however, perhaps scholarship on K-12 or youth labor education most directly addresses issues of teaching labor to a nonspecialized audience of young people. Although scholarship on K-12 labor studies curriculum may need modification for university classroom implementation, it suggests valuable resources to support general education instruction (e.g., Green; Glass; University of Iowa Labor Center; American Labor Studies Center).

8. Reading working-class labor literature as a method for exploring multiple perspectives on social class or different cultural orientations toward labor is also advocated by working-class scholars and labor historians. For instance, Renny Christopher offers insight into teaching working-class literature to students from multiple class backgrounds, notably stating that regardless of the student demographic or tier of the university, we can use literature to "bring discussions of social class issues, as they affect our own lives, the lives of our students and their families, and the fabric of our society, into every course in the humanities and social sciences" (221). Jim Barrett and Diane P. Koenker reiterate the value of introducing literature as a tool for fostering discussions on social issues, specifically asserting that workers' autobiographical writing and first-hand labor accounts can help instructors address the "subjective dimensions of working-class life" and shift the scope of inquiry from a general to personal context (18384).

9. Our verbal dialogue with Adam was influenced by examples of involving unions and labor activists in students' labor education, as provided by the Dolores Huerta 
Labor Institute (Delloro; Delloro and Le) and the Collective Bargaining Education Project (Tubach).

10. This method was influenced by models for labor history education, including John Delloro and Kenadi Le, Jim Barrett and Diane P. Koenker, and James Green, as well as drawing on educational resources from the AFL- CIO curriculum materials, University of Iowa Labor Center, American Labor Studies Center, and other sources. 


\section{REFERENCES}

Adamic, Louis. Dynamite: The Story of Class Violence in America. Gloucester: Peter Smith, 1963. Print.

AFL-CIO. Death on the Job: The Toll of Neglect. Washington D.C.: AFL-CIO, 2015. Print.

Agamben, Giorgio. Homo Sacer: Sovereign Power and Bare Life. Trans. Daniel HellerRoazen. Palo Alto: Stanford UP, 1998. Print.

Allman, Paula. "Paulo Freire's Contribution to Radical Adult Education." The Critical Pedagogy Reader. $2^{\text {nd }}$ ed. Ed. Antonia Darder, Marta P. Baltodano, and Rodolfo D. Torres. New York: Routledge, 2009. 417-30. Print.

American Labor Studies Center Family of Sites. American Labor Studies Center, 2014. Web. 7 Sept. 2015.

Ancel, Judy, Alex Becker, Anne Fischel, Karol Gil, Sayra Gordillo, Howard Kling, Ever Marienlarena, Ruth Needleman, Lin Nelson, and Lindsey Walker. "Crossing the Border to Cananea: High Stakes and Teachable Moments for North American Workers.” N.p.: United Association for Labor Education (UALE), 2011. Print.

Anderson, Benedict. Imagined Communities: Reflections on the Origin and Spread of Nationalism. London: Verso, 1983. Print.

Andrews, Thomas G. Killing for Coal: America's Deadliest Labor War. Cambridge, MA: Harvard UP, 2008. Print. 
---. 98th Anniversary of the Ludlow Massacre. Ludlow National Historic Landmark, Ludlow, CO. 24 June 2012. Public Speech.

Anzaldúa, Gloria. Borderlands/La Frontera: The New Mestiza. $3^{\text {rd }}$ ed. San Francisco: Aunt Lute Books, 2007. Print.

Appadurai, Arjun. Modernity at Large: Cultural Dimensions of Globalization. Minneapolis, MN: U of Minnesota P, 1996. Print.

Arceo, Ramiro, Joy Kusserow, and Al Wright. "Understanding the Challenges and Potential of Migrant Students." The Human Cost of Food. Ed. Charles D. Thompson, Jr. and Melinda F. Wiggins. Austin: U of Texas P, 2002. 222-56. Print.

Arendt, Hannah. "Selections from The Human Condition." Biopolitics: A Reader. Ed. Timothy Campbell and Adam Sitze. Durham: Duke UP, 2013. 98-133. Print. ---. "The Perplexities of the Rights of Man.” Biopolitics: A Reader. Ed. Timothy Campbell and Adam Sitze. Durham: Duke UP, 2013. 82-97. Print.

“Armed Americans At Greene's Mine.” New York Times, 3 June 1906. Web. 14 Sept. 2015.

Armenta, Manny. Personal interview. 30 Mar 2015.

Aronowitz, Stanley. False Promises: The Shaping of American Working Class Consciousness. New York: McGraw-Hill, 1973. Print.

Austin, Colin. "The Struggle for Health in Times of Plenty." The Human Cost of Food. Ed. Charles D. Thompson, Jr. and Melinda F. Wiggins. Austin: U of Texas P, 2002. 198-217. Print. 
Azcarza, William. “Col. Greene put Cananea on Mining Map.” Arizona Daily Star, 27 May 2013. Web. 15 Sept. 2015.

Baca, Jimmy Santiago, and Stacy James, eds. The Heat: Steelworkers Lives and Legends. San Diego: Cedar Hill, 2003. Print.

Bacon, David. Illegal People: How Globalization Creates Migration and Criminalizes Immigrants. Boston: Beacon, 2008. Print.

---. "Immigration Bill’s New Bracero Program Will Hurt Farmworkers.” Labor Notes, 3 Oct. 2013. Web. 27 Aug. 2015.

---. "Interview with Lucas Benitez of the Coalition of Immokalee Workers" Labor Notes, 31 May 2002. Web. 9 Sept. 2015.

---. “Miners and Farmers Challenge Mexico’s Copper Giant.” Al Jazeera America, 15 Apr. 2015. Web. 15 Sept. 2015.

---. "Tear Gas in Cananea." The Nation, 5 Jul 2010. Web. 3 Sept 2015.

---. "The Pacific Coast Farm-Worker Rebellion." The Nation, 28 Aug. 2015. Web. 1 Sept. 2015.

---. The Right to Stay Home: How US Policy Drives Mexican Migration. Boston: Beacon, 2013. Print.

---. The Children of NAFTA: Labor Wars on the U.S./Mexico Border. Los Angeles: U California P, 2004. Print.

Balibar, Etienne. "Racism and Nationalism." Race, Nation, Class: Ambiguous Identities. Ed. Etienne Balibar and Immanuel Wallerstein. Trans. Chris Turner. New York: Verso, 2011. 37-68. Print.

---. The Philosophy of Marx. New York: Verso, 1995. Print. 
Barling, Julian, E. Kevin Kelloway, and Eric H. Bremermann. "Preemployment Predictors of Union Attitudes: The Role of Family Socialization and Work Beliefs." Journal of Applied Psychology 76 (1991): 725-31. Electronic.

Barrett, Jim, and Diane P. Koenker. "The Saga of History 492: The Transformation of Working-Class History in One Classroom." Labour/Le Travail 61 (2008):181213. Electronic.

Barron's. Profiles of American Colleges 2011. Hauppauge, NY: Barron's Educational Services, 2010. Print.

Barthes, Roland. The Rustle of Language. New York: Hill and Wang, 1986. Print. Bauman, Zygmunt. Work, Consumerism and the New Poor. Philadelphia: Open UP, 1998. Print.

Beck, Scott A., and Dolores E. Rangel. "Representations of Mexican American Migrant Childhood in Rivera's ... y no se lo tragó la tierra and Viramontes' Under the Feet of Jesus.” Bilingual Review 29.1 (2008): 14-24. Electronic.

Benjamin, Walter. Illuminations. New York: Harcourt, 1968. Print.

Benton, Graham. "Daydreams and Dynamite: Anarchist Strategies of Resistance and Paths for Transformation in Against the Day." Pynchon's Against the Day: A Corrupted Pilgrim's Guide. Ed. Jeffrey Severs and Christopher Leise. Newark: U of Delaware P, 2006. 191-214. Print.

Berlin, James A. "Rhetoric and Ideology in the Writing Class." Teaching Composition. $3^{\text {rd }}$ ed. Ed. T.R. Johnson. New York: Bedford/St. Martin, 2008. 117-37. Print. Bernard, Elaine. "Popular Education: Training Rebels With a Cause." Teaching for Change: Popular Education and the Labor Movement. Ed. Linda Delp, Miranda 
Outman-Kramer, Susan J. Schurman, and Kent Wong. Los Angeles: UCLA Center for Labor Research and Education, 2002. 6-8. Print.

Bernstein, Marvin D. "Colonel William C. Greene and the Cananea Copper Bubble." Bulletin of the Business Historical Society 26.4 (1952): 179-198. Electronic. Beshoar, Barron B. Out of the Depths: The Story of John R. Lawson, a Labor Leader. Denver: Colorado Labor Historical Committee of the Denver Trades and Labor Assembly, 1957. Print.

Best, Michael L., and Colin M. Maclay. "Community Internet Access in Rural Areas: Solving the Economic Sustainability Puzzle." The Global Information Technology Report 2001-2002: Readiness for the Networked World. Ed. Geoffrey Kirkman, Peter K. Cornelius, Jeffrey D. Sachs, and Klaus Schwab. Oxford: Oxford UP, 2002: n.pag. Web. 15 July 2015.

Beverley, John. Testimonio: On the Politics of Truth. Minneapolis: U of Minnesota P, 2004. Print.

Bhabha, Homi. The Location of Culture. London: Rutledge, 2004. Print.

Birnbaum, David S., Jennifer Hunter, Peter Sung Ohr, and Julie R. Ulmet. "Employees, Employers, and Labor Organizations Redefined.” American Bar Association Section of Labor \& Employment Law. Kohala Coast, Hawaii. March 2015. Conference Presentation.

Blacker, Sarah. "Corporal Capital: Theorizing the Division of Body Parts under Global Capitalism.” Politics and Culture 7.2 (2007): n. pag. Web. 15 Sept. 2015. Boughton, Edward J., and the Colorado Adjunct General's Office. "The Military Occupation of the Coal Strike Zone of Colorado by the National Guard 1913- 
1914.” 1914. Rpt. Massacre at Ludlow: Four Reports. Ed. Leon Stein and Philip Taft. New York: Arno and the New York Times, 1971. Print.

Bourdieu, Pierre. Distinction: A Social Critique of the Judgment of Taste. Trans. Richard Nice. Cambridge: Harvard UP, 1984. Print.

---. "Structures, Habitus, Power: Basis for a Theory of Symbolic Power." Culture/Power/History: A Reader in Contemporary Social Theory. Ed. Nicholas B. Dirks, Geoff Eley, and Sherry B. Ortner. Princeton: Princeton UP, 1994. 155199. Print.

Bracero History Achieve. “About.” Bracero History Archive project of the Roy Rosenzweig Center for History and New Media, George Mason University, the Smithsonian National Museum of American History, Brown University, and The Institute of Oral History at the University of Texas at El Paso, 2015. Web. 1 Sept. 2015.

Braverman, Harry. Labor and Monopoly Capital: The Degradation of Work in the Twentieth Century. New York: Monthly Review P, 1974. Print.

Brigham, Ann. "Productions of Geographic Scale and Capitalist-Colonialist Enterprise in Leslie Marmon Silko's Almanac of the Dead." Modern Fiction Studies 50.2 (2004): 303-31. Electronic.

Bronfenbrenner, Kate. “Conclusions.” Global Unions: Challenging Transnational Capital through Cross-Border Campaigns. Ed. Kate Bronfenbrenner. Ithaca: ILR P, 2007. Print.

Bruno, Robert Anthony. Justified by Work: Identity and the Meaning of Faith in Chicago's Working-Class Churches. Columbus: Ohio State UP, 2008. Print. 
Buchanan, Joel. Personal interview. 20 Oct. 2012.

Buss, Fran Leeper, ed. Forged under the Sun / Forjada bajo el sol: The Life of Maria Elena Lucas. Ann Arbor: U of Michigan P, 1993. Print.

Bussel, Robert. "Fostering Critical Thinking about Contemporary Social and Political Issues: A Labor Education Experiment.” Labor Studies Journal 27.2 (2002): 85-9. Electronic.

Butler, Judith, and Athena Athanasiou. Dispossession: The Performative in the Political. Cambridge: Polity, 2013. Print.

Calvert Geoffrey M., Walter A. Alarcon, Ann Chelminski, Mark S. Crowley, Rosanna Barrett, Adolfo Correa, Sheila Higgins, Hugo L. Leon, Jane Correia, Alan Becker, Ruth H. Allen, and Elizabeth Evans. "Case Report: Three Farmworkers Who Gave Birth to Infants with Birth Defects Closely Grouped in Time and PlaceFlorida and North Carolina, 2004-2005.” Environmental Health Perspectives 115.5 (2007): 787-91. Electronic.

Camín, Héctor Aguilar, and Lorenzo Meyer. In the Shadow of the Mexican Revolution: Contemporary Mexican History, 1910-1989. Austin: U of Texas P, 1993. Print. Campbell, David, and Adam Sitze. "Biopolitics: An Encounter.” Biopolitics: A Reader. Ed. Timothy Campbell and Adam Sitze. Durham: Duke UP, 2013. 1-40. Print. Castile, George P. "Yaquis, Edward H Spicer, and Federal Indian Policy: From Immigrants to Native Americans." Journal of the Southwest 44 (2002): 383-436. Electronic.

Castillo, Debra A., and María Socorro Rabuenca Córdoba. Border Women: Writing from La Frontera. Minneapolis: U of Minnisota P, 2002. Print. 
Center for Disease Control and Prevention (CDC). "Farmworker Programs.” United States Center for Disease Control and Prevention, 2011. Web. 15 Aug 2015. Chase, John. "Report of the Commanding General to the Governor for the Use of the Congressional Committee to the Honorable Ellas M. Ammons, Governor of the State of Colorado." The Military Occupation of the Coal Strike Zone of Colorado, By the Colorado National Guard, 1913-1914. 1914. Rpt. London: Forgotten Books, 2013. 6-7. Electronic.

Cherniavsky, Eva. "Tribalism, Globalism, and Eskimo Television in Leslie Marmon Silko's Almanac of the Dead." Angelaki: Journal of Theoretical Humanities 6.1 (2001): 111-126. Electronic.

Cheyfitz, Eric. "The End of Academia: The Future of American Studies.” The Future of American Studies. Ed. Donald E. Pease and Robyn Wiegman. Durham: Duke UP, 2003. 510-35. Print.

Choate, Harris S. The Yaquis: A Celebration. San Francisco: Whitewing P, 1997. Print. Christopher, Renny. "Teaching Working-Class Literature to Mixed Audiences." Teaching Working Class. Ed. Sherry Lee Linkon. Boston: U of Massachusetts P, 1999. 203-22. Print.

Christopher, Renny, and Carolyn Whitson. "Toward a Theory of Working-Class Literature." Thought and Action: The NEA Higher Education Journal 15.1 (2008): 71-81. Electronic.

Clarke, Adele E., Laura Mamo, Jennifer Ruth Fosket, Jennifer R. Fishman, Janet K. Shim, eds. Biomedicalization: Technosciene, Health, and Illness in the U.S. Durham: Duke UP, 2010. Print. 
Clawson, Dan. The Next Upsurge: Labor and the New Social Movements. Ithaca: ILR P, 2003. Print.

Clifton, Daniel E., and Michael J. Healey. "Coalitions with Union Allies: Legal and Practical Considerations.” AFL-CIO Lawyers Coordinating Committee Union Lawyers Conference. Pittsburgh, PA. 3 June 2013. Conference Presentation. Coalition of Immokalee Workers (CIW). "Labor Day Reflection: Why Consumers Matter in Realizing Workers' Right.” Coalition of Immokalee Workers, 7 Sept. 2015. Web. 15 Sept. 2015.

---. "About CIW: Consciousness + Commitment $=$ Change Coalition of Immokalee Workers.” Coalition of Immokalee Workers, 2012. Web. 15 Sept. 2015.

Cockcroft, James D. Mexico's Revolution Then and Now. New York: Monthly Review P, 2010. Print.

Coles, Nicholas, and Janet Zandy, eds. American Working-Class Literature: An Anthology. Oxford: Oxford UP, 2006. Print.

Cowart, David. Thomas Pynchon: The Art of Allusion. Carbondale: Southern Illinois UP, 1980. Print.

Craib, Raymond B. "Cartography and Power in the Conquest and Creation of New Spain.” Latin American Research Review 35.1 (2000): 7-36. Electronic.

Dalpiaz, Mike. 98th Anniversary of the Ludlow Massacre. Ludlow National Historic Landmark, Ludlow, CO. 24 June 2012. Public Speech.

Daniel, Cletus E. Bitter Harvest, a History of California Farmworkers, 1870-1941. Ithaca: Cornell UP, 1981. Print. 
Darder, Antonia, Marta Baltodona, and Rodolfo D. Torres. The Critical Pedagogy Reader. New York: Routledge, 2003. Print.

de Kock, Leon. "Interview with Gayatri Chakravorty Spivak: New Nation Writers Conference in South Africa." ARIEL: A Review of International English Literature 23.3 (1992): 29-47. Electronic.

De Landa, Manuel, John Protevi, and Torkild Thanem. "Deleuzian Interrogations: A Conversation with Manuel DeLanda, John Protevi and Torkild Thanem.” Tamara: Journal of Critical Postmodern Organization Science 3.3-4 (2005): $65-$ 101. Electronic.

Deleuze, Gilles, and Felix Guattari. A Thousand Plateaus. Trans. Brian Massumi. Minneapolis: U of Minnesota P, 2005. Print.

---. Anti-Oedipus: Capitalism and Schizophrenia. Trans. Robert Hurley, Mark Seem, and Helen R. Lane. Minneapolis: U of Minnesota P, 2005. Print.

Delloro, John. “"Educate to Organize': Reflections on Building the Dolores Huerta Labor Institute.” Radical History Review 102 (2009):18-22. Electronic.

Delloro, John, and Kenadi Le. "A Primer on Teaching Labor Studies in the Los Angeles Community College District.” Los Angeles: Dolores Huerta Labor Institute Publication Los Angeles Community College District, 2008. Print.

Denning, Michael. Culture in the Age of Three Worlds. New York: Verso, 2004. Print. Dotson-Rickle, Betty. 98th Anniversary of the Ludlow Massacre. Ludlow National Historic Landmark, Ludlow, CO. 24 June 2012. Public Speech.

Drainville, André C. "Present in the World Economy: The Coalition of Immokalee Workers (1996-2007)." Cultural Politics and Resistance in the 21st Century: 
Community-Based Social Movements and Global Change in the Americas. Ed.

Kara Z. Dellacioppa and Clare Weber. New York: Palgrave, 2012.145-176. Print.

Dulfano, Isabel. "Some Thoughts Shared with Helena Maria Viramontes." Women's Studies 30 (2001): 647-662. Electronic.

Dunbar, Tony, and Linda Kravitz. Hard Traveling: Migrant Farm Workers in America. Cambridge: Ballinger, 1976. Print.

Engles, Friedrich. "The Origin of the Family, Private Property, and the State." The MarxEngles Reader. Ed. Robert C. Tucker. New York: Norton, 1978. 734-759. Print.

Escobar, Amelia. "Yaquis y Padres ABC se unen a movement contra Grupo México." El Universal, 22 Mar. 2015. Web. 15 Sept. 2015.

Esposito, Roberto. Bios: Biopolitics and Philosophy. Trans. Timothy Campbell. Minneapolis: U of Minnesota P, 2008. Print.

---. Immunitas: The Protection and Negation of Life. Malden, MA: Polity, 2011. Print.

Estabrook, Barry. Tomatoland: How Modern Industrial Agriculture Destroyed Our Most Alluring Fruit. Kansas City: Andrews McMeel, 2012. Print.

Evans, Jerry. Personal Interview. 2 May 2009.

Evers, Larry, and Felipe S. Molina. Yaqui Deer Songs/Maso Bwikam: A Native American Poetry. Tucson: U of Arizona P, 1987. Print.

Farm Worker Ministries. "Farm Workers \& Immigration.” Farm Worker Ministries, 2015. Web. 2 Sept. 2015.

Farmworker Justice. "Immigration Reform and Farmworkers." Farmworker Justice, 2015. Web. 2 Sept. 2015. 
---. Making an Impact: Connecting Advocates and Farmworkers to Create Change, 2014 Annual Report. Washington D.C.: Farmworker Justice, 2015. Print.

---. No Way to Treat A Guest: Why the H2A Visa Program Fails U.S. and Foreign Workers. Washington D.C.: Farmworker Justice, 2011. Print.

Fink, Walter H. “The Ludlow Massacre.” 1914. Rpt. Massacre at Ludlow: Four Reports. Ed. Leon Stein and Philip Taft. New York: Arno and the New York Times, 1971. Print.

Finn, Patrick J. Literacy with an Attitude: Educating Working-Class Children in Their Own Self-Interest. Albany: State U of New York P, 1999. Print.

Flys-Junquera, Carmen. "Helena María Viramontes: Social and Political Perspectives of a Chicana Writer.” Arizona Journal of Hispanic Cultural Studies 5 (2001): 223-38. Electronic.

Foucault, Michel. Archeology of Knowledge. London: Tavistock, 1972. Print.

---. Birth of the Clinic. New York: Vintage, 1994. Print.

---. Discipline and Punish. Trans. Alan Sheridan. New York: Vintage, 1995. Print.

---. History of Sexuality, Volume 1: An Introduction. New York: Vintage, 1990. Print.

---. Power/Knowledge: Selected Interviews \& Other Writings, 1972-1977. Ed. Colin

Gordon. New York: Pantheon, 1980. Print.

---. Society Must be Defended: Lectures at the Collège de France, 1975-1976. New York:

Picador, 1994. Print.

Freire, Paulo. Pedagogy of the Oppressed. New York: Continuum, 1970. Print.

Fuller, John Bryan, and Kim Hester. “Another Look at Pre-employment Predictors of 
General Union Attitudes.” Psychological Reports 81 (1997): 1327-

30. Electronic.

García Márquez, Gabriel. One Hundred Years of Solitude. New York: Harper Perennial, 2006. Print.

Giagnoni, Silvia. Fields of Resistance: The Struggle of Florida's Farmworkers for Justice. Chicago: Haymarket, 2011. Print.

Giddens, Anthony. Modernity and Self-Identity. Stanford, CA: Stanford UP, 1991. Print.

Gitelman, Howard M. Legacy of the Ludlow Massacre: A Chapter in American Industrial Relations. Philadelphia: U of Pennsylvania, 1988. Print.

Glass, Fred. 2008. "The Ongoing Need for Strong Unions: A Primer for Your Students.” American Educator 32 (2008): 35-37. Electronic.

Gómez, Napoleón Urruta. Collapse of Dignity: The Story of a Mining Tragedy and the Fight Against Greed and Corruption in Mexico. Dallas: BenBella, 2013. Print.

Green, James. "Why Teach Labor History?” American Educator 32 (2008): 30-34. Electronic.

Green, Paul E. “The Undocumented: Educating the Children of Migrant Workers in America.” Bilingual Research Journal 21.1(2003): 51-71. Electronic.

Grewe-Volpp, Christa. “'The oil was made from their bones': Environmental (In)Justice in Helena Maria Viramontes's Under the Feet of Jesus.” Interdisciplinary Studies in Literature and Environment 12.1 (2005): 61-78. Electronic.

Grmuša, Lovorka Gruić. “The Underworld and Its Forces: Croatia, the Uskoks and Their Fight for Autonomy in Against the Day." Against the Grain: Reading Pynchon's 
Counternarratives. Ed. Sascha Pöhlmann. Amsterdam: Rodopi, 2010. 263-289. Print.

Grosjean, François. Life with Two Languages: An Introduction to Bilingualism. Cambridge: Harvard UP, 1982. Print.

Gugelberger, Georg, and Michael Kearney. "Voices for the Voiceless: Testimonial Literature in Latin America.” Latin American Perspectives 18.3 (1991): 3-14. Electronic.

Hansen, Eric, and Martin Donohoe. "Health Issues of Migrant and Seasonal Farmworkers." Journal of Health Care for the Poor and Underserved 14.2 (2003): 153-64. Electonic.

Hapke, Laura. Labor's Text: The Worker in American Fiction. New Brunswick: Rutgers UP, 2000. Print.

Haraway, Donna. "The Biopolitics of Postmodern Bodies: Constitutions of Self in Immune System Discourse.” Biopolitics: A Reader. Ed. Timothy Campbell and Adam Sitze. Durham: Duke UP, 2013. 274-309. Print.

Hardt, Michael, and Antonio Negri. Commonwealth. Cambridge: Harvard UP, 2011. Print.

---. Empire. Cambridge: Harvard UP, 2000. Print.

---. Multitude. New York: Penguin, 2004. Print.

Harley, H. Brian. "Rereading the Maps of the Columbian Encounter." Annals of the Association of American Geographers 82.3 (1992): 522-42. Electronic.

Harvey, David. A Brief History of Neoliberalism. Oxford: Oxford UP, 2005. Print.

---. The Condition of Postmodernity. Cambridge, MA: Blackwell, 1992. Print. 
Hertenstein, Edward. “Distance Learning in Labor Education.” Labor Studies Journal 23 (1999): 3-16. Electronic.

Hill, Joe. "Workers of the World, Awaken!" Songs of the Workers to Fan the Flames of Discontent. $32^{\text {nd }}$ Ed. Chicago: Industrial Workers of the World, 1968. Electronic. Hoffman Plastic Compounds, Inc. v. National Labor Relations Board. 535 U.S. 137. Supreme Court of the United State. 2002.

Holt, Alejandra Okie, and Sister Evelyn Mattern. "Making Home: Culture, Ethnicity, and Religion among Farmworkers in the Southeastern United States." The Human Cost of Food: Farmworkers' Lives, Labor, and Advocacy. Ed. Charles D. Thompson and Melinda F. Wiggins. Austin: U of Texas P, 2002. 22-52. Print. Hu-DeHart, Evelyn. Yaqui Resistance and Survival: The Struggle for Land and Autonomy, 1821-1920. Madison: U Wisconsin P, 1984. Print.

Human Rights Watch. Fields of Peril: Child Labor in U.S. Agriculture. New York: Human Rights Watch, 2009. Print.

---. Fingers to the Bone. New York: Human Rights Watch, 2000. Print.

Hume, Kathryn. “The Religious and Political Vision of Against the Day.” Pynchon's Against the Day: A Corrupted Pilgrim's Guide. Ed. Jeffrey Severs and Christopher Leise. Newark: U of Delaware P, 2006. 167-90. Print.

Hunter, Robert. Violence and the Labor Movement. New York: Macmillan, 1914. Print. Hutcheon, Linda. A Poetics of Postmodernism: History, Theory, Fiction. New York: Routledge, 1998. Print. 
Ickstadt, Heinz. "Setting Sail Against the Day: The Narrative World of Thomas Pynchon.” Against the Grain: Reading Pynchon's Counternarratives. Ed. Sascha Pöhlmann. Amsterdam: Rodopi, 2010. 35-47. Print.

Irwin, Godfrey. "Eyewitness to Murder: Recounting the Ludlow Massacre.” New York World. Rpt. in Massacre at Ludlow: Four Reports. Ed. Leon Stein and Philip Taft. New York: Arno and the New York Times, 1971. 22-23. Print.

Jameson, Fredric. "Postmodernism and Consumer Society." The Anti-Aesthetic: Essays on Postmodern Culture. Ed. Hal Foster. Seattle: Bay P, 1983. 111-25. Print.

---. Postmodernism, or, The Cultural Logic of Late Capitalism. Durham: Duke UP, 1995. Print.

Jensen Richard J., and John C. Hammerback, eds. The Words of César Chávez. College Station: Texas A \& M UP, 2002. Print.

Johnson, Claudia Durst. Labor and Workplace Issues in Literature. Westport: Greenwood P, 2006. Print.

Johnson, Kelli Lyon. “Writing Deeper Maps: Mapmaking, Local Indigenous Knowledges, and Literary Nationalism in Native Women's Writing." Studies in American Indian Literatures 19.2 (2007): 103-120. Electonic.

Jordan, Miriam. "Visa Glitch Stalls Workers, Straining U.S. Farms." Wall Street Journal, 15 June 2015. Web. 6 Sept. 2015.

Kane, Dan. 98th Anniversary of the Ludlow Massacre. Ludlow National Historic Landmark, Ludlow, CO. 24 June 2012. Keynote Address. 
Kelloway, E. Kevin, Julian Barling, and Sharon Agar. "Preemployment Predictors of Children's Union Attitudes: The Moderating Role of Identification with Parents." Journal of Social Psychology 136 (1996): 413- 5. Electronic.

Kelloway, E. Kevin, and Laura Watts. "Preemployment Predictors of Union Attitudes: Replication and Extension." Journal of Applied Psychology 79 (1994): 631634. Electronic.

Kelly, Jane Holden. Yaqui Women: Contemporary Life Histories. Lincoln, NE: U of Nebraska P, 1991. Print.

Klaus, H. Gustav. The Literature of Labor: Two Hundred Years of Working-Class Writing. New York: St. Martin’s P, 1985. Print.

Klein, Naomi. The Shock Doctrine: The Rise of Disaster Capitalism. Toronto: Alfred A. Knopf Canada, 2007. Print.

Knight, Alan. The Mexican Revolution, Volume 2: Counter-Revolution and Reconstruction. Lincoln, NE: U of Nebraska P, 1990. Print.

Laclau, Ernesto, and Chantal Mouffe. "Post-Marxism Without Apologies.” New Reflections on the Revolution of Our Time. Ed. Ernesto Laclau. London: Verso, 2001. 79-133. Print.

LaHuis, David M., and Steven Mellor. “Antiunion and Prounion Attitudes as Predictors of College Students' Willingness to Join a Union.” Journal of Psychology 135.6 (2001): 661-81. Electonic. 
Lauter, Paul. "American Studies, American Politics, and the Reinvention of Class." The Future of American Studies. Ed. Donald E. Pease and Robyn Wiegman. Durham: Duke UP, 2003. 486-509. Print.

LaVenture, Robert. "Pueblo Interview.” Personal interview. 20 Oct. 2012.

Leary, Elly. “Immokalee Workers Take Down Taco Bell.” Monthly Review 57.5 (2005): n.pag. Web. 9 Sept. 2015.

Leont'ev, Aleksei. N. Activity and Consciousness. Moscow: Progress Publishers, 1972. Electronic.

Lighthall, David. “The Poor Health of Farm Workers.” Western Journal of Medicine 175.4 (2001): 223-24. Electronic.

Lim, Jeehyum. "Reimagining Citizenship through Bilingualism: The Migrant Bilingual Child in Helena María Viramontes' Under the Feet of Jesus.” Western Studies Quarterly 38.1/2 (2010): 221-42. Electronic.

Linkon, Sherry Lee. Teaching Working Class. Boston: U of Massachusetts P, 1999. Print. Linné, Rob. "Introduction." Organizing the Curriculum: Perspectives on Teaching the US Labor Movement. Ed. Rob Linné, Leigh Benin, and Adrienne Andi Sosin. New York: Sense Publishers, 2009. xi-xix. Print.

---. "Labor's Exclusion from Official Knowledge.” Organizing the Curriculum: Perspectives on Teaching, 2009. 19-40. Print.

Linné, Rob, Leigh Benin, and Adrienne Andi Sosin, eds. Organizing the Curriculum: Perspectives on Teaching the American Labor Movement. New York: Sense, 2009. Print. 
Linné, Rob, Adrienne Andi Sosin, and Leigh Benin. “Teaching Labor's Untold Story: How to Get Labor Back into the Classroom." New Labor Forum 18 (2009): 8594. Electronic.

Lipsitz, George. "'Sent for You Yesterday, Here You Come Today’: American Studies Scholarship and the New Social Movements." The Future of American Studies. Ed. Donald E. Pease and Robyn Wiegman. Durham: Duke UP, 2003. 441-60. Print.

Livingstone, David W., and Peter Sawchuk. Hidden Knowledge: Organized Labor in the Information Age. New York: Rowman and Littlefield, 2004. Print.

Louie, Miriam Ching Yoon. Sweatshop Warriors: Immigrant Women Workers Take on the Global Factory. Cambridge: South End P, 2006. Print.

Lowe, Graham S., and Sandra Rastin. "Organizing the Next Generation: Influences on Young Workers' Willingness to Join Unions in Canada.” British Journal of Industrial Relations 38 (2000): 203-22. Electronic.

Mantsios, Gregory. "Worker Education: Developing an Approach to Worker Empowerment." The Re-educadon of the American Working Class. Ed. Steven London, Elvira R. Tarr, and Joseph F. Wilson. New York: Greenwood P, 1990. 35-50. Print.

Martelle, Scott. Blood Passion: The Ludlow Massacre and Class War in the American West. New Brunswick: Rutgers UP, 2007. Print.

Martin, Randy. Financialization of Daily Life. Philadelphia: Temple UP, 2002. Print. Martínez, Deborah, Elizabeth A. Leone, and Jennifer Sternbach de Medina. "Language as a Barrier to Health Care." Spanish Language Use and Public Life in the United 
States. Ed. Lucía Elías-Olivares, Elizabeth A. Leone, René Cisneros, and John R. Gutiérrez. New York: Mouton, 1985. 151-63. Print.

Marx, Karl. Capital: Volume 1. Ed. Friedrich Engles. Trans. Samuel Moore and Edward Aveling. New York: Dover, 2011. Print.

---. Communist Manifesto. Ed. Frederic L. Bender. New York: Norton, 1988. Print.

---. Grundrisse. Trans. Martin Nicolaus. New York: Penguin, 1993. Print.

Mbembe, Achille. "Necropolitics.” Public Culture 15.1 (2003): 11-40. Electronic.

McCauley, Linda A., W. Kent Anger, Matthew Keifer, Rick Langley, Mark G. Robson, and Diane Rohlman. "Studying Health Outcomes in Farmworker Populations Exposed to Pesticides." Environmental Health Perspectives 114.6 (2006): 953-60. Electronic.

McGovern, George S., and Leonard F. Guttridge. The Great Coalfield War. Boulder: UP of Colorado, 1996. Print.

McHale, Brian. “Genre as History: Pynchon's Genre-Poaching.” Pynchon's Against the Day: A Corrupted Pilgrim's Guide. Ed. Jeffrey Severs and Christopher Leise. Newark: U of Delaware P, 2006. 1-15. Print.

McKinsey \& Company, "Offline and Falling Behind: Barriers to Internet Adoption.” San Francisco: McKinsey \& Company, 2014. Web. 4 Sept. 2015.

McLaren, Peter. Che Guevara, Paulo Freire, and the Pedagogy of Revolution. Lanham, MD: Rowman and Littlefield, 2000. Print.

McLaren, Peter, and Ramin Farahmandpur. Teaching against Global Capitalism and the New Imperialism. New York: Rowman and Littlefield, 2005. Print. 
Michael-Luna, Sara, and A. Suresh Canagarajah. "Multilingual Academic Literacies: Pedagogical Foundations for Code Meshing in Primary and Higher Education.” Journal of Applied Linguistics 4.1 (2007): 55-77. Electronic.

Moisés, Rosalio, Jane Holden Kelley, and William Curry Holden. A Yaqui Life: The Personal Chronicals of a Yaqui Indian. Lincoln, NE: U of Nebraska P, 1971. Print.

Montag, Warren. "Necro-Economics: Adam Smith and Death in the Life of the Universal." Biopolitics: A Reader. Ed. Timothy Campbell and Adam Sitze. Durham: Duke UP, 2013. 193-214. Print.

Montoya, Fawn-Amber. 98th Anniversary of the Ludlow Massacre. Ludlow National Historic Landmark, Ludlow, CO. 24 June 2012. Public Speech.

Myers-Scotton, Carol. “Codeswitching with English: Types of Switching, Types of Communities." World Englishes 8.3 (1989): 333-46. Electronic.

Narkunas, J. Paul. “Europe’s 'Eastern Question' and the United States' 'Western Quarterly': Representing Ethnic Conflict in Against the Day.” Pynchon's Against the Day: A Corrupted Pilgrim's Guide. Ed. Jeffrey Severs and Christopher Leise. Newark: U of Delaware P, 2006. 239-264. Print.

National Center for Farmworker Health. "Farmworker Fact Sheets.” National Center for Farmworker Health, 2010-2015. Web. 6 Sept. 2015.

National Migrant and Seasonal Head Start Collaboration Office. "Invisible Children of Migrant and Seasonal Farmworkers in the United States: An Examinatino of Existing Pre-K Partnerships.” Los Angeles: National MSHS Collaboration Office/AED, 2009. Print. 
Neruda, Pablo. "United Fruit Co.” Canto General. Los Angeles: U of California, 1991. 179. Print.

Ness, Immanuel. Guest Workers and Resistance to U.S. Corporate Despotism.

Champaign, IL: U of Illinois P, 2011. Print.

---. New Forms of Worker Organization: The Syndicalist and Autonomist Restoration of Class-Struggle Unionism. Oakland: PM P, 2014. Print.

O’Meara, Bridget. "The Ecological Politics of Leslie Silko's Almanac of the Dead." Wicazo Sa Review 15.2 (2000): 63-73. Electronic.

O’Neal, Mary Thomas. Those Damn Foreigners. New York: Minerva, 1971. Print. Occupational Safety \& Health Administration (OSHA). "Commonly Used Statistics." United States Department of Labor, 2015. Web. 15 Sept. 2015.

Oxfam America. Like Machines in the Fields: Workers without Rights in American Agriculture. Boston: Oxfam America, 2004. Print.

Peñalosa, Fernando. Chicano Sociolinguistics: A Brief Introduction. Rowley: Newbury House Pub, 1980. Print.

Perez, Guillermo. Personal Interview. 12 Dec. 2012.

Pesek, James G., Rod D. Raehsler, and Robert S. Balough. "Future Professionals and Managers: Their Attitudes toward Unions, Organizational Beliefs, and Work Ethic.” Journal of Applied Social Psychology 36 (2006): 1569-94. Electronic.

Pew Research Center. "Labor Unions: Good for Workers, Not for U.S. Competitiveness.” Pew Research Center, 17 Feb. 2011. Web. 11 Aug. 2015. 
Platt, Kamala. "Chicana Strategies for Success and Survival: Cultural Poetics of Environmental Justice from the Mothers of East Los Angeles." Frontiers: A Journal of Women Studies 18.2 (1997): 48-72. Electronic.

Public Broadcasting Service (PBS). "Essays by Migrant Youth.” Migrant Child Labor. Public Broadcasting Service, 28 May 2004. Web. 9 Sept. 2015.

Pynchon, Thomas. Against the Day. New York: Penguin, 2006. Print.

Quijano, Anibal, and Immanuel Wallerstein. "Americanity as a Concept, or the Americas in the Modern World-System.” International Social Science Journal 29 (1992): 549-57. Electronic.

Reilly, Terry. "Narrating Tesla in Against the Day." Pynchon's Against the Day: A Corrupted Pilgrim's Guide. Ed. Jeffrey Severs and Christopher Leise. Newark: U of Delaware P, 2006. 139-266. Print.

Rosa Luxemburg Stiftung. "Labor Solidarity Across Borders.” Rosa Luxemburg Stiftung, 6 Dec. 2014. Web. 29 Dec. 2015.

Rose-Redwood, Reuben S. "Governmentality, Geography, and the Geo-Coded World." Progress in Human Geography 30.4 (2006): 469-486. Electronic.

Roth, Wolff-Michael. "Activity Theory and Education: An Introduction.” Mind, Culture, and Activity 11.1 (2004): 1-8. Electronic.

Roth, Wolff-Michael, and Yew-Jin Lee. "Vygotsky's Neglected Legacy: CulturalHistorical Activity Theory." Review of Educational Research 77.2 (2007): 186232. Electronic.

Rothenberg, Daniel. With These Hands: The Hidden World of Migrant Farmworkers Today. New York: Harcourt, 1998. Print. 
Russell, David R. “Activity Theory and Its Implications for Writing Instruction.” Reconceiving Writing, Rethinking Writing Instruction. Ed. Joseph Petraglia. Hillsdale: Erlbaum, 1995. 51-78. Print.

---. "Rethinking Genre in School and Society: An Activity Theory Analysis." Written Communication 14.4 (1997): 504-54. Electronic.

Russo, John, and Sherry Lee Linkon, eds. New Working Class Studies. Ithica: Cornell UP, 2005. Print.

Saad, Lydia. "Labor Unions See Sharp Slide in U.S. Public Support." Gallup, 3 Sept. 2009. Web. 15 Aug 2015.

Saitta, Dean J. The Archeology of Collective Action. Tallahassee: U of Florida P, 2007. Print.

Saldívar, José David. Border Matters: Remapping American Cultural Studies. Los Angeles: U of California P, 1997. Print.

---. Trans-Americanity: Subaltern Modernities, Global Coloniality, and the Cultures of Greater Mexico. Durham: Duke UP, 2011. Print.

Sassen, Saskia. Expulsions: Brutality and Complexity in the Global Economy. Cambridge, MA: Belknap P of Harvard UP, 2014. Print.

---. Globalization and its Discontents. New York: New P, 1999. Print.

---. "The Global City: Introducing a Concept.” Brown Journal of World Affairs. 11.2 (2005): 27-43. Electronic.

---. “The Global City: Strategic Site/New Frontier.” American Studies Journal. 24.2/3 (2000): 79-95. Electronic. 
Sawchuk, Peter H. “Trade Union-Based Workplace Learning: A Case Study in Workplace Reorganization and Worker Knowledge Production.” Journal of Workplace Learning 13.7/8 (2001): 344-51. Electronic.

---. "Labor Education and Labor Art: The Hidden Potential of Knowing for the Left Hand." Labor Studies Journal 31.2 (2006): 49-68. Electronic.

Scamehorn, Lee. Mill and Mine The CFI in the Twentieth Century. Lincoln, NE: U Nebraska P, 1991. Print.

Scheper-Hughes, Nancy. "The Ends of the Body: Commodity Fetishism and the Global Traffic in Organs." SAIS Review 22.1 (2002): 61-80. Electronic.

Scully-Russ, Ellen. "Learning to Organize: US Unions, Work, and Learning." Journal of Workplace Learning 18.7/8 (2006): 522-34. Electronic.

Seitz, David. “Making Work Visible.” College English 67 (1994): 210-21. Electronic. Severance, Ryan. "Union Leaders Also Make Pitch to Help Present-Day Workers." The Pueblo Chieftain, 25 June 2012. Web. 23 Oct. 2012.

Shackelford, Laura. “Counter-Networks in a Network Society: Leslie Marmon Silko's Almanac of the Dead." Postmodern Culture 16.3 (2006): 213-28. Electronic.

Shea, Anne. “'Don't let them make you feel like you did a crime': Immigration Law, Labor Rights, and Farmworkers Testimony.” MELUS 28.1 (2003): 123-44. Electronic.

Silko, Leslie Marmon. Almanac of the Dead. New York: Penguin, 1991. Print. Sinclair, Upton. King Coal. 1917. Rpt. Mockingbird Classic Pub, 2014. Print. Smitherman, Geneva. "English Teacher, Why You Be Doing the Thangs You Don't Do?" The English Journal 61.1 (1972): 59-65. Electronic. 
Snegroff, Courtney, and Leigh David Benin. "A Letter for Family and Friends from the Labor Front." Organizing the Curriculum: Perspectives on Teaching the American Labor Movement. Ed. Rob Linné, Leigh Benin, and Adrienne Andi Sosin. New York: Sense Publishers, 2009. 41-61. Print.

Sosin, Adrienne Andi. "Where Do We Go From Here?" Organizing the Curriculum: Perspectives on Teaching the American Labor Movement. Ed. Rob Linné, Leigh Benin, and Adrienne Andi Sosin. New York: Sense, 2009. 267-73. Print. Sperling, Melanie, Deborah Appleman, Keith Gilyard, and Sarah Freedman. "Voice in the Context of Literacy Studies." Reading Research Quarterly 46.1 (2011): 70-84. Electronic.

Spicer, Edward. The Yaquis: A Cultural History Tucson: U of Arizona P, 1980. Print. Spillers, Ryan. “Organizing Workers in Los Angeles' Carwash Industry: Legal Strategies of the CLEAN Carwash Campaign.” AFL-CIO Lawyers Coordinating Committee Union Lawyers Conference. San Francisco, California. April 2014. Conference Presentation.

Spivak, Gayatri. “Can the Subaltern Speak?” Marxism and the Interpretation of Culture. Ed. Cary Nelson and Lawrence Grossberg. Champaign, IL: U of Illinois P, 1988. Print.

---. "The New Subaltern, A Silent Interview." The Cultural Studies Reader. Ed. Simon During. $3^{\text {rd }}$ ed. London: Rutledge, 2007. 229-240. Print.

Stanford, Ann Folwell. "'Human Debris': Border Politics, Body Parts, and the Reclamation of the Americas in Leslie Marmon Silko's Almanac of the Dead." Literature and Medicine 16.1 (1997): 23-42. Electronic. 
Steel, Edward M., ed. The Speeches and Writings of Mother Jones. Pittsburgh: U of Pittsburgh P, 1988. Print.

Stein, Walter J. California and the Dust Bowl Migration. Westport, CT: Greenwood, 1973. Print.

Streeby, Shelley. American Sensations: Class, Empire, and the Production of Popular Culture. Los Angeles: U of California P, 2002. Print.

Strom, Shelly. "OSM Haunted by the Past.” Portland Business Journal, 5 Nov. 2000. Web. 22 Oct. 2012 .

Stein, Leon, and Philip Taft, eds. Massacre at Ludlow: Four Reports. New York: Arno and The New York Times, 1971. Print.

Suggs, George, Jr. "Militant Western Labor Confronts the Hostile State: A Case Study." Western History Quarterly 2.4 (1971): 385-400. Electronic.

Taylor, Micheal. Community, Anarchy and Liberty. Cambridge: Cambridge UP, 1982. Print.

Thompson Jr., Charles D., and Melinda F. Wiggins, eds. The Human Cost of Food: Farmworkers' Lives, Labor, and Advocacy. Austin: U of Texas P, 2002. Print. Torres, Lourdes. "In the Contact Zone: Code-Switching Strategies by Latino/a Writers." MELUS 23.1 (2007): 75-96. Electronic.

Trevizo, Perla. "Livelihoods Washed Away by Toxic Spill in Sonora.” Arizona Daily Star, 4 Oct. 2014. Web. 15 Sept. 2015.

Trumka, Richard. "Remarks by Richard L. Trumka, President of the AFL-CIO, National Press Club, Washington, D.C.” 11 Jan. 2010. Web. 4 Sept. 2015. 
Tubach, Linda. "Labor in Schools in Teaching for Change: Popular Education and the Labor Movement." Teaching for Change: Popular Education and the Labor Movement. Ed. Linda Delp, Miranda Outman-Kramer, Susan J. Schurman, and Kent Wong. Los Angeles: UCLA Center for Labor Research and Education, 2002. 198-203. Print.

United States Committee on Mines and Mining. "Report on the Colorado Strike Investigation Made Under House Resolution $387.63^{\text {rd }}$ Congress, $3^{\text {rd }}$ Session. House of Representatives Document No. 1630.” 1915. Rpt. Massacre at Ludlow:

Four Reports. Ed. Leon Stein and Philip Taft. New York: Arno and the New York Times, 1971. Print.

United States Department of Labor (U.S. DOL). “2012 National Agricultural Workers Survey.” United States Department of Labor, 2013. Web. 4 Sept. 2015. United States Department of State Bureau of Consular Affairs. "Multi-Year Graphs/Charts, Worldwide Immigrant Visa Issuances Fiscal Years 2009-2014.” U.S. Department of State Bureau of Consular Affairs, 2015. Web. 7 Sept. 2015. United States National Labor Relations Board (NLRB). "National Labor Relations Act (NLRA).” United States National Labor Relations Board, n.d. Web. 8 Aug. 2015. United Steelworkers. “Cross Border Training Continues.” United Steelworkers, 19 Mar. 2015. Web. 15 Sept. 2015.

---. "United Steelworkers Stand with Los Mineros in the Struggle Against Grupo Mexico.” United Steelworkers, 20 Mar. 2015. Web. 15 Sept. 2015.

---. "Workers from Two Countries.” United Steelworkers, 24 July 2014. Web. 15 Sept. 2015. 
United Steelworkers Institute for Carreer Development. “The Institute for Career Development's Vision of Learning: A Position Paper Adopted in 1997.” United Steelworkers Institute for Carreer Development, 1997. Web. 1 Oct. 2015. University of Iowa Labor Center. "Child Labor Public Education Project.” University of Iowa, July 2011. Web. 6 Aug. 2015.

van Oers, Bert, Wim Wardekker, Ed Elbers, and Rene can der Veer, eds. The Transformations of Learning: Advances in Cultural-Historical Activity Theory. Cambridge: Cambridge UP, 2008. Print.

Velásquez, Baldemar. “Case for a Freedom Visa.” Campaign for Migrant Worker Justice, n.d. Web. 9 Sept. 2015.

Viramontes, Helena Maria. Under the Feet of Jesus. New York: Penguin, 1996. Print. Virno, Paulo. "Labor, Action, Intellect.” Biopolitics: A Reader. Ed. Timothy Campbell and Adam Sitze. Durham: Duke UP, 2013. 245-68. Print.

Walker, Mark. "The Ludlow Massacre: Class, Warfare, and Historical Memory in Southern Colorado.” Historical Archeology 37.3 (2003): 66-80. Electronic.

Wallerstein, Immanuel. “The Ideological Tensions of Capitalism: Universalism versus Racism and Sexism.” Race, Nation, Class: Ambiguous Identities. Ed. Etienne Balibar and Immanuel Wallerstein. Trans. Chris Turner. New York: Verso, 2005. 26-36. Print.

---. The Modern World-System, Volume 1: Capitalist Agriculture and the Origin of the European World Economy in the Sixteenth-Century. New York: Academic Press, 1974. Print. 
Weinstein, Cindy. The Literature of Labor and the Labors of Literature: Allegory in Nineteenth-Century American Fiction. Cambridge: Cambridge UP, 2009. Print.

West, Georgo P., and the United States.Commission of Industrial Relations. "Report on the Colorado Strike.” 1915 Republished in Massacre at Ludlow: Four Reports. Ed. Leon Stein and Philip Taft. New York: Arno and the New York Times, 1971. Print.

Willoughby, Floyd. G., and Lizbeth F. Barclay. "College Students' Majors and Attitudes toward Unions: Sources of Future Union Members?" Journal of Collective Negotiations 15 (1986): 223-30. Electronic.

Willoughby, Floyd G., and Thomas L. Keon. 'Changing Business Students' Attitudes toward Unions: A Significant Treatment Effect." Journal of Collective Negotiations 14 (1985): 231-8. Electronic.

Worthen, Helena. "Using Activity Theory to Understand How People Learn to Negotiate the Conditions of Work." Mind, Culture \& Activity 15 (2008): 322-38. Electronic.

Yates, Michael. Why Unions Matter. New York: Monthly Review, 2009. Print.

Yerkes, Andrew. "Against the Day and the Prospects of Historiographic Metafiction." Remaking Literary History. Ed. Helen Groth and Paul Sheehan. Cambridge: Cambridge Scholars, 2010. 223-32. Print.

Youngmark, Chris. Personal interview. 20 Oct. 2012.

Zandy, Janet. Hands: Physical Labor, Class, and Cultural Work. New Brunswick: Rutgers UP, 2004. Print.

Zimmerman, Marc. Literature and Resistance in Guatemala: Textual Modes and Cultural Politics from El Sénor Presidente to Rigoberta Menchú, Volume Two: Testimonio 
and Cultural Politics. Athens, OH: Ohio U Center for International Studies, 1995. Print.

Zinn, Howard. The Zinn Reader: Writings on Disobedience and Democracy. New York: Seven Stories, 2009. Print.

Zullo, Roland, and Alice Gates. "Labor Education in the Time of Dismay." Labor Studies Journal 33 (2008): 179-202. Electronic.

Zwieg, Michael. "Class as a Question in Economics.” New Working-Class Studies. Ed. John Russo and Sherry Lee Linkon. Ithaca: Cornell UP, 2005. 98-112. Print. 


\section{APPENDIX A \\ HISTORICAL TEXTS, CONTEMPORARY LEARNING: A CHAT APPROACH TO LABOR EDUCATION}

Cultural historical activity theories, known collectively as CHAT, offers dynamic, contextually situated approaches to my pedagogy of teaching and learning. This brief overview offers a practice-driven example of how four fundamental CHAT-inspired questions influence my course design, implementation, and assessment in the labor education classroom. My aim in sharing this experience is twofold: first, I want to offer labor educators a flexible question-based form for integrating CHAT approaches in labor classrooms; second, I want to illustrate the benefits of adopting socially and historically situated cultural texts-such as poetry, music, photography, personal letters, and workers' accounts-as a method for fostering intellectual and emotional engagement with course concepts.

\section{What is CHAT?}

CHAT asserts that learning is a collective, tool-mediated process grounded in specific cultural-historical contexts. In contrast to cognitive theories that delineate learning as an individualized mental phenomenon, CHAT conceptualizes learning as a cycle of social processes occurring during diverse daily interactions between people and their world. ${ }^{1}$ The triangle model visually illustrates the basic unit of analysis, an activity, and shows the relationships between its important components. ${ }^{2}$ 


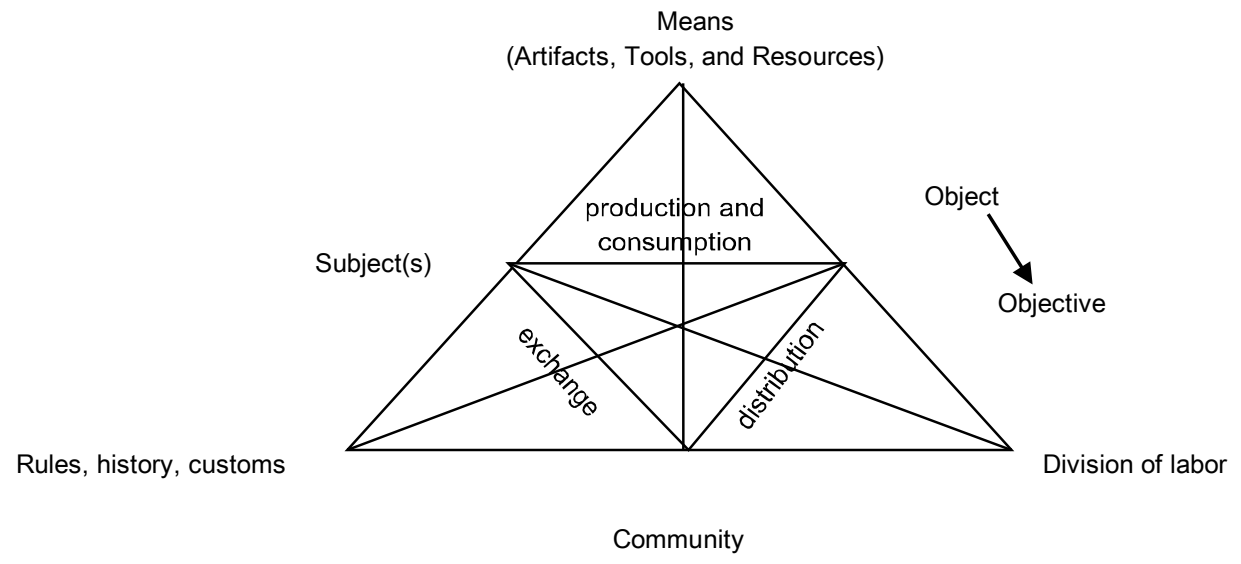

To understand how this abstract model applies to the labor classroom, one must consider the interactions between:

- The rules or customs of a labor education program

- The community in which the education program functions

- The subjects or students who participate in the course and bring multiple standpoints or perspectives to the classroom

- The object of study and objective of the class, which is influenced by the motivation of the community and subjects

- The means-or artifacts and tools-that may be used to achieve course objectives

- The division of labor that the class negotiates

- The exchange between students and their Local community

- The production/consumption of knowledge by subjects

- The distribution of knowledge or materials within the community 
I use a series of CHAT-inspired questions to help me address these interrelated factors when designing, conducting, and evaluating labor education courses. The first set of questions that I consider when adopting a CHAT approach takes into account the rules of the educational program and the different activity systems that co-exist and influence subjects' multiple standpoints.

\section{What are the purpose, structure, and goals of a particular education program? What activity systems are already present in the classroom?}

\section{I facilitate United Steelworker/Institute for Career Development (USW/ICD)}

courses for USW Local 787 members who work at the Bridgestone Off-Road Tire factory in Bloomington/Normal, IL. USW/ICD classes are guided by the philosophy that "worker growth and development are stunted when programs are mandated from above, but flourish in an atmosphere of voluntary participation in self-designed and self-directed training and education" (ICD 2012). In CHAT terms, the rules or customs of the ICD program emphasize local workers developing their "own training plan around their own interests" instead of receiving an generalized education that is "non job-specific" (Evans 2008). Local workers are subjects actively engaged in requesting and participating in courses. They choose what they want to learn about, which at USW Local 787 has ranged from building computers to scuba diving, and the local's ICD coordinator arranges the classes.

As a bottom-up design, ICD's structure may potentially resist some of the limitations of dominant, hierarchical cultural capital theories by offering an educational 
program that is responsive to multiple types of adult learning within the cultural context of working-class labor. Specifically, participants in ICD courses bring to the classroom an implicit knowledge of the multiple, often contradictory activity systems in which they participate and the kind of learning valued in each. For instance, each student is a company worker, a union member, and an ICD student. Most workers who have participated in classes with me have unhesitatingly acknowledged that they feel at the bottom of the company ladder, with their actions in the factory regulated and critiqued by management. However, the local union and ICD offer contrary activity systems through which workers see their collective voices articulated through a bottom-up structure. In other words, participants may simultaneously be workers who feel restricted by company policies and union members and students who engage in creating and mobilizing collective action and worker-based education. Negotiations between these multiple activity systems shape how students' perceive their agency as learners/teachers, union members/employees, and participants in other private and public spheres. Thus, as CHAT advocates, I believe it is essential to embrace the contradictions and conflicts between multiple activity systems in order to mobilize these productive dialectic relationships that offer workers multiple standpoints to view issues and speak with authority in the classroom.

While keeping these overarching concerns in mind, a course facilitator must additionally attend to the particular union community, their object/objective of a course, and their motivation for pursuing specific learning goals. A second set of questions address these elements, and guide my CHAT praxis. 


\section{What are the learning needs/desires of the specific community? What is the} cultural-historical context in which the course is situated?

ICD courses are intended to meet the interests and needs that local workers express, so most courses are custom-designed with the desires of the local union in mind. When USW Local 787 officers contacted me to see if I was interested in developing a new series of courses for them, their overarching goal was to offer classes that would help contemporary workers recognize and appreciate the historical struggle that earned the labor rights we now enjoy. As I met with the officers, I quickly identified that they were hoping for an interdisciplinary series of courses that would help workers hear the voices of the past and see connections to the future. Their objectives were for students to not only gain factual knowledge of historical events, but also to cultivate how these events connect to their own contemporary struggles as company employees and union members.

To meet the local's learning objectives it was important for me to understand the specific teaching objective; I also needed to consider their motivation for offering the class in order to situate the course within the pertinent cultural-historical context of the local union. ${ }^{3}$ Through conversations with officers, I learned more about their union community and their reasons for offering the class. Namely, the plant had recently made numerous new hires--young workers with no prior experience in a union. The class would benefit all workers but, particularly, help expose the new hires to union history and build solidarity with fellow local members. By understanding the course objective and the community's motivation for offering the class, it became clear that CHAT's approach to 
learning as a collective, tool-mediated process might allow us to simultaneously build our knowledge of labor history and a sense of belonging in the union through our shared exploration of labor stories, events, and voices.

The previous question sets helped me attend to USW/ICD's institutional structure or rules; the specific local community; their object/objective and motivation for the course; the context from which this need emerged; and the subjects and standpoints in the classroom. Informed by these factors, I was finally ready to consider the classroom division of labor and course content, which CHAT terms the means, artifacts, tools, or resources. I was particularly interested in providing content that would intersect with students' familiar cultural-historical context and standpoints. Because we would be drawing on familiar contexts, I recognized an opportunity to encourage participants to embrace a flexible division of classroom labor where we might listen and speak as both learners and teachers.

\section{What artifacts/tools and division of labor might aid us in achieving the course objective(s)?}

Our course embraced cultural texts and narratives in what CHAT terms tool or artifact-mediated learning. In other words, we adopted texts as tools to investigate the distinctive cultural and historical contexts under which they were produced. Thus, exploring these texts provided one method for us to learn about the past and connect this inquiry to contemporary events.

During the course, we drew on labor songs, photographs, personal accounts/letters, poems, and other texts that workers produced as a result of events such 
as the Ludlow Massacre, Triangle Fire, and Cherry Mine Disaster. We did not approach these expressions through the elitist critical tradition of high art, but rather as CHAT advocates, by situating the texts as cultural products resulting from and reflecting the particular socio-historical contexts and material conditions under which they emerged. ${ }^{4}$ Our class did appreciate aesthetic aspects as, for instance, we acted out the visual imagery of a poem. However, to achieve our specific course objectives, we were more focused on analyzing the way that a poem published in a local newspaper after a labor conflict served to popularize workers' perspectives on the events by offering a succinct, emotionally-charged account that could be more widely circulated in print.

For example, our class touched on the topic of workers' compensation. Instead of giving a timeline of the history of workers' compensation legislation, I adopted a CHAT approach that supported a different method of inquiry. Considering the objective, subjects, and their standpoints, I decided to focus on the Cherry Mine Disaster of 1909, which led to Illinois passing workers' compensation legislation. This event was particularly pertinent because it intersected with students' familiar cultural-historical context. Specifically, Cherry, Illinois, is only about an hour away from the Bridgestone plant in Bloomington/Normal. Some of the plant workers live or have family in this area. However, few students in the class had learned about the fatal mine fire of 1909 that killed 259 men and boys and left over a hundred women widowed and approximately 500 children orphaned. ${ }^{5}$

Our goal was to learn about the unenforced safety regulations and child labor that precipitated the Cherry Mine Disaster and the Illinois Workers Compensation Act that 
followed it. In addition to using historical scholarship, we listened to songs, viewed photographs, and read poetry, workers accounts, and personal letters from the Cherry Mine Disaster. Language and art became tools through which we could think, perceive, and communicate about the historical importance of this event. Additionally, these texts fostered an emotional engagement with the disaster, as we read dying miners' last letters to their families and a 1909 poem from the local newspaper that called for the nation's help to support the widowed women and orphaned children. Later in the course, as we discussed unions' ongoing fight to support the rights that past generations of workers fought and died to achieve, it was not only the facts of Cherry Mine, Ludlow, Homestead, or Haymarket that inspired students, but also the type of trans-historical emotional connection made with workers from the past. ${ }^{6}$

Perhaps this connection was influenced by the fact that these artifacts reflect working-class standpoints and voices. ${ }^{7}$ They validate the integration of these voices into the classroom and, in turn, students' own stories and experiences. Studying cultural texts produced by workers during labor conflicts sometimes provided perspectives that contradicted historical narratives that K-12 textbooks had offered the students. For example, most of the workers had heard of Rockefeller, Carnegie, and other prominent industrialists, but extremely few had learned of Ludlow or Homestead, let alone heard the voices of workers who lived through these battles.

Although students had not faced the type of large-scale disasters or corporal violence that many texts detailed, they nevertheless identified aspects of their own work experiences and perspectives in the texts we studied. Thus, my job was not to create an 
emotional response to our learning as much as it was to draw on and help students articulate the emotions that were already there. I feel fortunate that participants were willing to embrace a division of labor in which we could listen and share as both students and teachers. ${ }^{8}$ This division of labor helped foster a sense of emotional engagement and collective union belonging by connecting factual learning with personal experiences.

To explore the implications of this CHAT approach-and specifically the impact of a flexible division of labor-a final open-ended question is needed to address the exchange, production/consumption, and distribution of knowledge among subjects and the community.

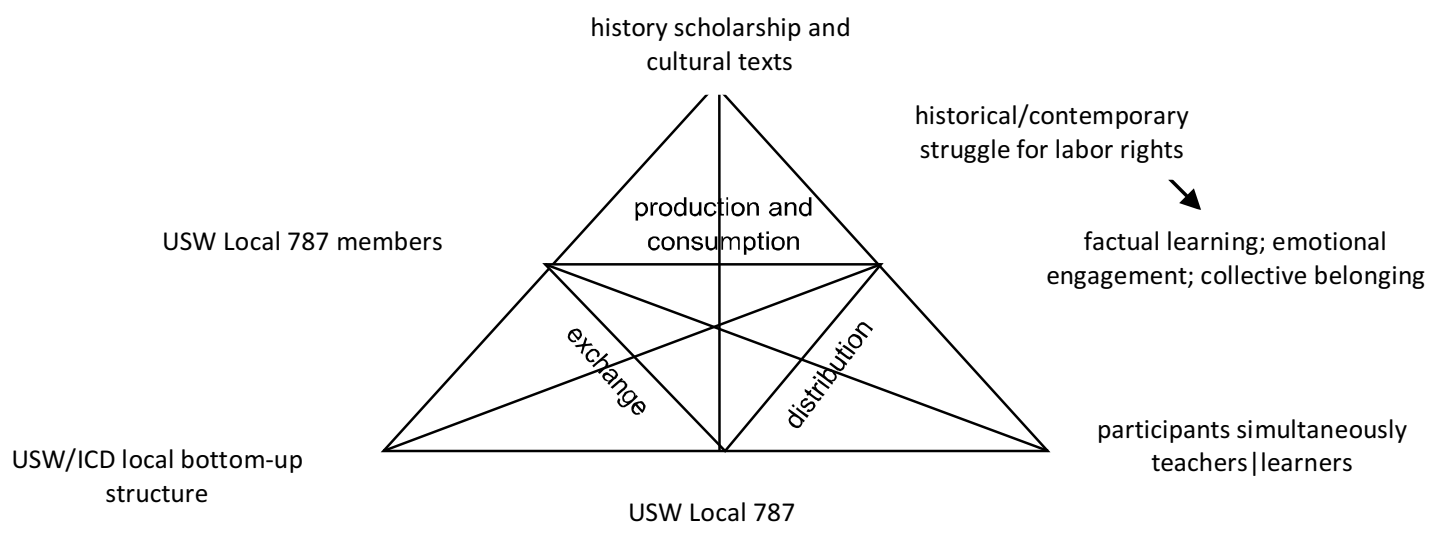

\section{What tools did the course provide for participants and the Local union?}

CHAT recognizes that the process of engaging with facts and emotions is not only how we acquire knowledge but is also how knowledge is made useful by building collectivity and connecting learning to the particular cultural-historical context of a 
specific community. Although educators typically assess the effectiveness of a course at its conclusion, it is important to remember that learning outcomes are ideally more farreaching, particularly when course objectives expand beyond factual knowledge to include emotional engagement and collective belonging.

Our ICD classroom served as a space for the community to transmit knowledge through exchanges between individual subjects and others in the union. For instance, experienced union members shared personal "battle stories" with less experienced novices. One long-time union member stated that he enjoyed being able to share his experiences about "where the union came from; where it is now; and where it is going." In response, a new hire who had worked only three weeks at the plant explained that he "learned how important it is to have unions and what we went through to get where we are now. I now know these are daily struggles that we will always have." Students gave positive feedback that indicated how the course allowed them to both consume knowledge about the history of labor rights, and produce new knowledge through the sharing of stories and experiences. ${ }^{9}$ Specifically, as class participants returned to the factory floor, they distributed knowledge gained in the class with other union co-workers who had not participated in the course. Newly interested workers that had been unable or unwilling to attend the first series of classes asked for the course to be reoffered so that they could attend, and the local ICD added three additional sessions. After one of these extra sessions, a participant explained, "The most important thing I learned was the cost in lives of the benefits we seem to take for granted...I want to see more people get involved." 
With contract negotiations looming in the near future for USW Local 787, the importance of knowing where workers' rights come from and cultivating a passion and commitment to preserving these collective rights cannot be underemphasized. Thus we see how, through adopting a CHAT approach, our classroom became a space for the community to evolve to meet contemporary demands and make learning useful for union struggles to come. 


\section{Appendix A Endnotes}

1. CHAT emerges from the work of Lev S. Vygotsky (first-generation activity theory). After his death, Vygotsky's student A. N. Leont'ev more fully articulated the concept of an activity (in coexistence with cognition) as the fundamental unit of analysis (second-generation activity theory).

2. The activity triangle is a conceptual model developed by second-generation activity theory. Third-generation activity theory tends to consider networks of multiple activity systems represented by numerous intersecting triangles. However, for the purpose of this paper, the single triangle model is useful in illustrating particular classroom considerations.

3. Helena Worthen highlights motivation as "key to understanding activity" (323), and grounds this assertion in Aleksei Leont'ev's recognition that "The main thing that distinguishes one activity from another lies in the difference between their objects...the object of activity is its motive" (6).

4. Peter Sawchuk emphasizes the fact that art can powerfully reflect cultural and historical contexts, including working-class and labor perspectives. "Good art by its very nature can represent complex and contradictory social reality in the shock of a momentwhat's called in aesthetics theory the 'unity' of expression-that often proves elusive to other forms of communication....The labor arts do this from a working-class standpoint" (54).

5. For more see Karen Tintori's Trapped: The 1909 Cherry Mine Disaster and Ronald Bluemer's Fire Below! The Cherry Mine disaster of 1909. 
6. When a course fosters students' emotional engagement with texts and topics, there are always risks involved. In describing the characteristics and risks of the liberatory classroom, James Berlin emphasizes, "the complexity of the behavior recommended in the classroom, behavior that is always open-ended, receptive to the unexpected, and subversive of the planned. Most important, success in this classroom can never by [sic] guaranteed. This is a place based on dialectical collaboration-the interaction of student, teacher, and shared experience within a social, interdisciplinary framework-and the outcome is always unpredictable" (492). Instructors must not only be prepared to address unexpected or conflicting emotional responses in the classroom; in order to truly work through the contradictions that define an individual's collective engagement, instructors must embrace diversity or dissent as an opportunity for educational dialogues. Furthermore, an instructor must consider how their own agency might influence emotional responses that students demonstrate, and he or she must work to account for these factors. "[A] way of teaching is never innocent. Every pedagogy is imbricated in ideology, in a set of tacit assumptions about what is real, what is good, what is possible, and how power ought to be distributed;" recognizing this, Berlin concludes, "A rhetoric cannot escape the ideological question, and to ignore this is to fail our responsibilities as teachers and as citizens" (492-3).

7. Numerous working-class literary scholars comment on this occurrence, such as John Russo and Sherry Lee Linkon, Janet Zandy, Renny Christopher and Carolyn Whitson. 
8. Wolff-Michael Roth and Yew-Jin Lee underscore the importance of maintaining a consideration of the division of labor in an activity system, asserting that CHAT's "desirable synthetic approach" is possible "only because activity theorists are concerned with upholding human activity-the historical results of the division of labor-as the fundamental unit of analysis" (189). Encouraging students to influence the division of labor in a course reflects the type of bottom-up democratic participation that can, potentially, [re]shape union structures and revitalize grass-roots social democracy.

9. In subsequent ICD classes that I have taught, students have both consumed cultural texts and produce their own texts as we created personal accounts and poetry. 